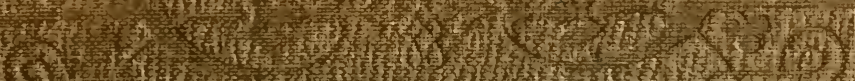

.

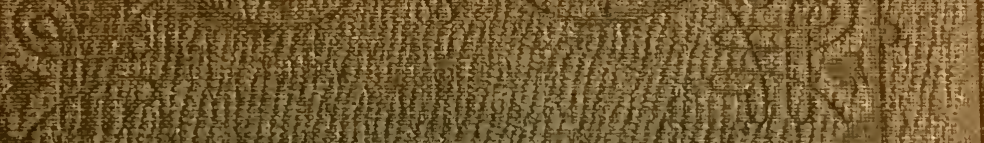

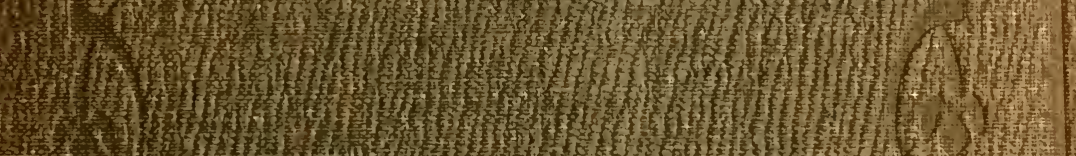

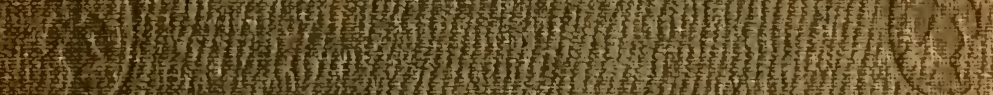

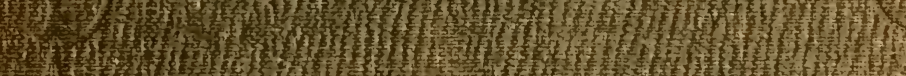

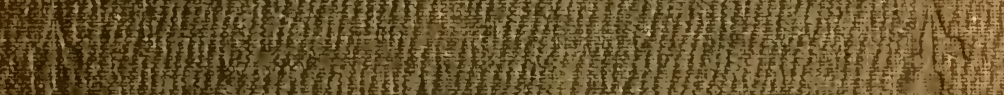

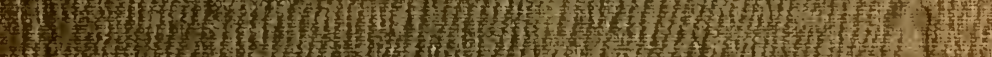

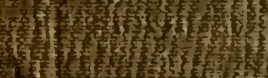

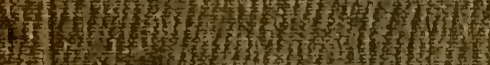

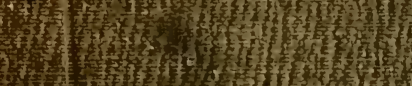

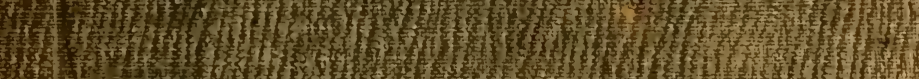

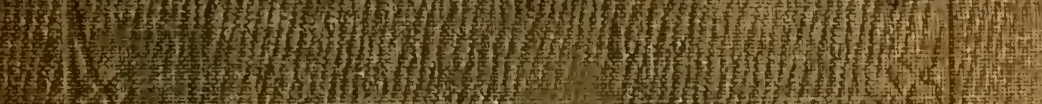

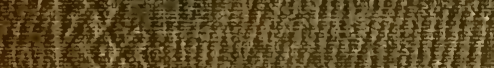

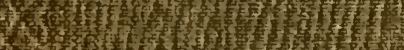

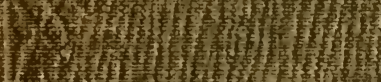

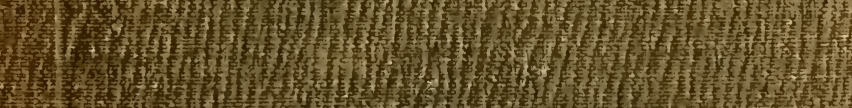

H.

1) W

L

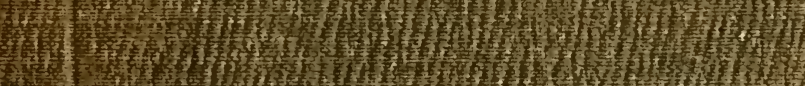

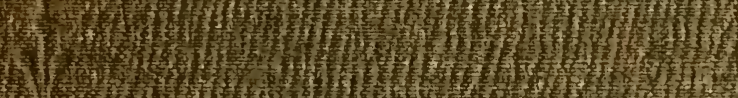

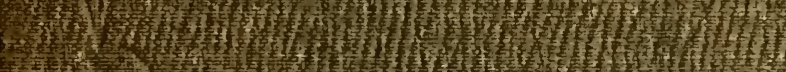

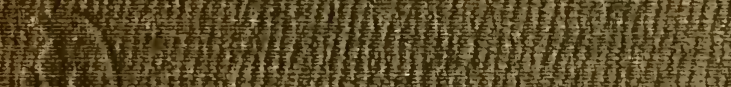

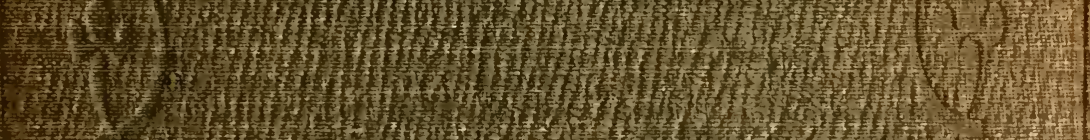

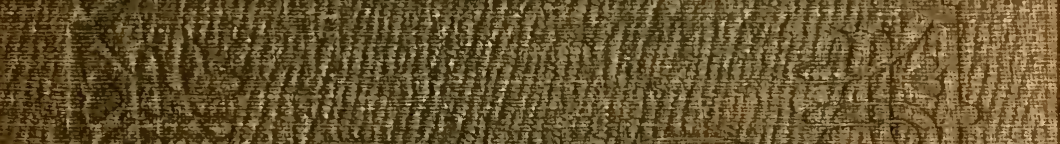

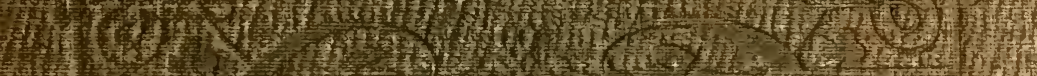

TH

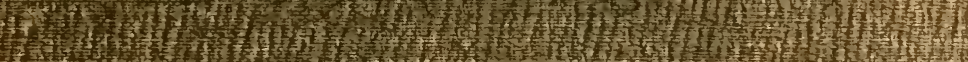








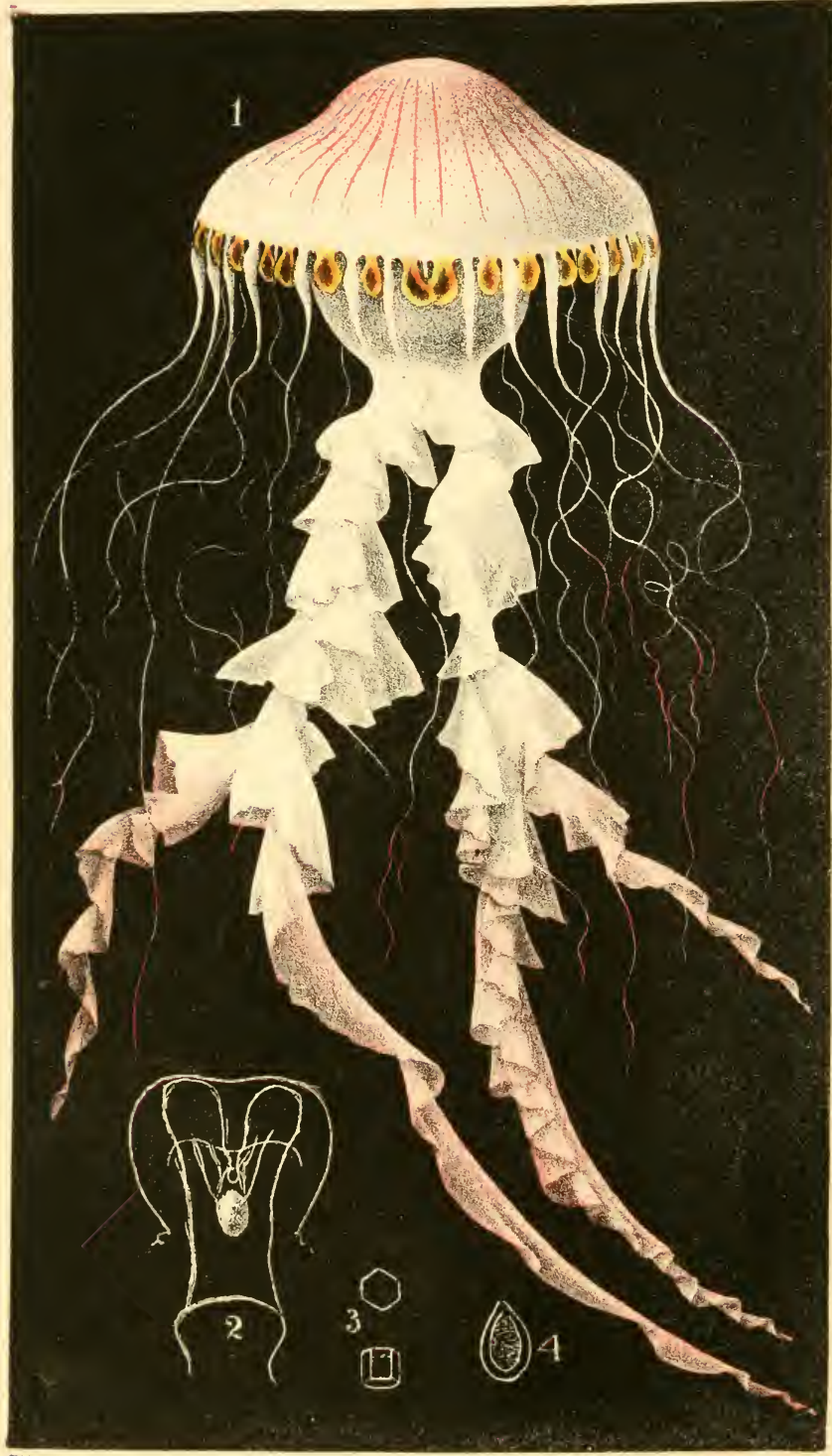




\section{NATURALIST'S RAMBLES}

ON THE

\section{DEVONSHIRE COAST.}

\section{PIIILIP HENRY GOSSE, A. L. S., \&}

AUTHOR OF' 'THE OCEAX,' 'A NATLRALIST'S SOJOURA IA' JAMAICA ;' \&C.

What prodigies can power Divine perform, More grand than it produces year by year, And all in sight of inattentive man?

CoWPER.

\section{LONDON :}

JOHN VAN YOORST, PATERNOSTER ROW.

M. DCCC, LIII. 



\section{PREF ICE.}

THE following pages I have endearoured, as far as possible, to make a mirror of the thoughts and feelings that hare occupied my own mind during a nine months' residence on the charming shores of North and South Devon. There I have been pursuing an occupation which always po:sesses for me new delight,- - the study of the curious forms. and still more curious instincts, of animated beings. So interesting, so attractive has the pursuit been, so unexpected in many instances the facts revealed by the research, that I hare thought the attempt to conrey, with pen and pencil, to others the impressions vividly receired by myself might be a welcome serrice.

Few, very few, are at all aware of the many strange. beautiful, or wondrous objects that are to be found by searching on those shores that every season are crowded by idle pleasure-seekers. Most curious and interesting animals are dwelling within a few rards of your feet, whose lovely forms and hues, exquisitely contrired structures, and amusing instincts, could not fail to attract and eharm your attention, if you were once cognizant of them. "But who will be our guide to such sources of interest?" Deign to accept these pages as your "Hand-book" to the sea-side. They contain a faithful record of what actually has fallen under an individual's observation in a single. season, and may therefore be assumed to present a fair average of what may be expected again.

But I have not made a book of systematic zoology; no: 
a book of mere zoology of any sort. I venture to ask. your companionship, courteous Reader, in my Rambles over field and down in the fresh dewy morning; I ask you to listen with me to the carol of the lark, and the hum of the wild bee; I ask you to stand with me at the edge of the precipice and mark the glories of the setting sun; to watch with me the mantling tide as it rolls inward, and roars among the hollow caves; I ask you to share with me the delightful emotions which the contemplation of unbounded beauty and beneficence ever calls up in the cultivated mind.

Hence I have not scrupled to sketch pen-pictures of the lovely and romantic scenery with which both the coasts of Devon abound; and to press into my service personal narrative, local anecdote, and traditionairy legend; and, in short, any and every thing, that, having conveyed pleasure and interest to myself, I thought might entertain and please my reader. It is not the least of the advantages of the study of natural history, that it strengthens in us "the habit of wishing to discover the good and the beautiful in all that meet and surround us."

If it should be objected that-to treat of the facts which science reveals to us, in any other manner than that technical measured style, which aims not at conveying any pleasurable emotions beyond the mere acquisition of knowledge, and is therefore satisfied with being coldly correct, -is to degrade science below its proper dignity, I would modestly reply that I think otherwise. That the increase of knowledge is in itself a pleasure to a healthy mind is surely true; but is there not in our hearts a chord that thrills in response to the beautiful, the joyous, the perfect, in Nature? I aim to conrey to my reader, to reflect, as it were, the complacency which is produced in my own mind by the contemplation of the excellence impressed on everything which God has created. 
Wordsworth has said that man and nature are essentially adapted to each other, and that the mind of man is naturally the mirror of the fairest and most interesting properties of Nature. The same mighty morer of the human heart tells us that "Poetry is the impassioned expression which is the countenance of all Science." And all that is required to make the remotest discoveries of the Man of Science proper objects of the Poet's art is familiarity with them, so that " the relations under which they are contemplated by the student be manifestly and palpably material to us, as enjoying and suffering beings."

Another eloquent writer thus speaks of the relation existing between Poetry and the Physical Sciences.

"Such studies lift the mind into the truly sublime of nature. The poet's dream is the dim reflection of a distant star: the philosopher's revelation is a strong telescopic examination of its features. One is the mere echo of the remote whisper of nature's voice in the dim twilight; the other is the swelling music of the harp of Memnon, awakened by the Sun of truth, newly risen from the night of ignorance." "*

Yet I would not have it supposed that I have ever stated the facts of Natural History in a loose, rague, imaginative way. Precision is the very soul of science,rrecision in observation, truthfulness in record: and I should deem myself unworthy of a place among naturalists, if I were not studious to exhibit the phenomena of Nature with the most scrupulous care and fidelity. Humanum est errare: I dare not suppose I have escaped error; but $I$ am sure it is not the result of wilfulness, I trust it is not that of carelessness.

Some of the investigations here touched upon are of high interest to naturalists : such as those connected with

* IIunt's 'Poetry of Science', p. 292. 
the alternation of generations, the embryology and development of the Zoophytes, and the nature and functions of their special organs. The varied forms and singular properties of the Thread-Capsules in the Polypes and the Medusæ, in particular, have excited my own admiration.

The curious observations of Sir J. G. Dalyell and other zoologists on the propagation of the Hydroid Zoophytes, might seem to render those recorded in this volume needless; but the words of the indefatigable naturalist just named warrant the multiplication of observed facts. Speaking of the mysterious appearance of certain Medusce in connexion with Tubularia, he says, "Were similar instances recorded, our embarassments might be relieved; for more frequent, easier, and stricter investigation being admitted, doubtless such a train of discovery, and thence the solution of what are to us the most abstruse problems, would follow."

The plates have been all drawn from living nature, with the greatest attention to accuracy. They are twenty eight in number, of which twelve are printed in colours: they comprise about two hundred and forty figures of animals and their component parts, in many instances drawn with the aid of the microscope.

London: March 30th, 1853. 


\section{CONTENTS.}

\section{CHAPTER I.}

A Flitting to the Coast-Rival Claims of North and South Devon-Marychurch selected-Beauty of Devonshire LanesAuthor's Outfit-First exploring Jaunt-Babbicombe Sands -Pretty Rock-pool-Petit Tor-Jackdaws-Kestrel-Pollock-fishing on the Rocks-Boulders examined-Contents of a shallow Pool-Green Sea-worm-Smooth Anemone-Turning stones at Babbicombe-Finger-cutting Serpulæ-Nakedgilled Mollusca-'Their Elegance and Beauty-Manners in Captivity-Spawn of Doris-Form and Structure of the young-Anthea-Its Form and Colours-Voracity of an Eolis - Manners of Anthea-Its Mode of marching-of swimming -Beautiful Variety-Reflections.

Page 1

\section{CHAPTER II.}

Petit Tor-Squirrel-Limestone Ledge-Stone-borers-Anemones and Sea-weeds-Clear Rock-pools-Daisy Anemone-Difficulty of procuring Specimens-Mode of Operation-A Metamorphosis-Description of the Species-TentaclesColours-Varieties-Habits-Structure of the TentaclesThread-shooting Capsules-Petit Tor Pools-Thick horned Anemone-Description of the Species-Suggestions of Identity with $A$. coriacea-Its Habits-Beautiful VarietiesChanges of Figure-Deep Tide-pool-Prawn-Its Beauty of Colour-Changes produced by Exposure to Light.

\section{CHAPTER III.}

A Visit to Brixham-The Road-Character of the Coast-Berry Castle-Legends-Brixham-Coast Scenery-Animals of the 
Shore-The Painted Scallop-Its Beauty-Mantle-Tentacles -Gem-like Eyes-Climbing Powers-Leaps-Mode of performing these misunderstood-Explanation-Functions and Structure of the Eyes-Structure of the Gills-Ciliary Action -Beauty of the Phenomenon-Oddicombe Rock-pool-Its Form-Contents-The Feather-star-Its Habits in CaptivityReproduction of its Limbs-Watcombe-Romantic Scenery Sandstrne Cliffs-The Sea Lemon-The Purple Dye---MIode of applying it-Changes of Colour-Tor Abbey Sands-Shore Animals-The Pholas-Its Siphons-Their Use, Structure and Currents-Curious Contrivance-Anstey's Cove-View from Babbicombe Downs-Skylark's Song-Precipice of Limestone-Abundance of Animals-Pleurobranchus.

\section{CHAPTER IV.}

The Dead Man's Fingers-Appearance when contracted-when expanded-Beauty of the flower-like Polypes-StructureSpiculæ-The Polypidom-Zoophytes and Crustacea upon Tangle-Small Nudibranchs and their Spawn-The Angled Laomedea-Its medusiform Young-Appearance, Manners and Structure of the Embryo-Escape of one from the Vesicle -Regular Arrangement of the Zoophytes-The Rosy Anemone-Its Locality-Description-Habits-Structure-The Snowy-disked Anemone-Peculiarities of its Locality-Description-The Snake-locked Anemone-Description-Farewell to South Devon.

\section{CHAPTER V.}

1lfracombe-Beautiful Scenery-Walk to Watermouth-HeleHockey Lane-Fine Sea-view-Daws-Doves-Charms of Spring-Watermouth-Curious mode of Fishing-Grove of Flowers-Rabbits-Sharp Rocks-Gemmaceous AnemoneLiving Madrepores-Their Localities-Appearance-Mode of detaching them-Their Structure-The Plates-Beauty of the Animal-Protrusion of the soft Parts-Their Translucency-Analogy with the Anemone-Brilliancy of ColoursTentacles-Cilia on their Surface-The globose Heads-The Tentacles are tubular-Imprisoned Animalcule-Sensibility 
of the Madrepore to Light-Experiments in feeding themSense of Taste-Feproduction of Parts-The Frilled Bands - Their Use-Their Structure-Thread-Capsules-Singular Forms of these Organs-The Madrepore easily preserved alive.

\section{CHAPTER VI.}

A Walk to Hele-Bird's-eye View of the Harbour-Quay Fields -Lion Rock-Hele Strand-A threatened Shipwreck-Eucratea--Description-Mode of Growth-Form of the CellStructure of the Polype-Tentacles-Digestive System-Muscular Bands-Evanescence of the radiate Character-RootThread-Snake-head Coralline-Frill-Vermicular OrgansDoor and Hinge-Ciliated Cellularia-Cells-Spines-Birds' Heads-Their Motions-Slimy Laomedea-Structure of a Sertularian Zoophyte-Its Contraction-Marginal Folds of the Cell-Researches in Gastronomy-Anemones cookedEaten-Commended-Best mode of preparing them-Anthea tried.

\section{CHAPTER VII.}

Charm of the Sea-side-Watching the receding Tide-The Lion Rock-Approach of Erening-Its Accompaniments-The Warty Cycloum-Harvey's Syrinx-Capstone Hill-Its Promenade-Precipitous Walks-Noble Prospects-SunsetBird's-eye View-The Welsh Coast-Flowers-The Summit -Inland View-Seaward Rocks-Wildersmouth-A fatal Accident-The Gemmed Anemone-Description-HabitsProduction of the Young-Sea-Spider-Black Sand-wormA second Visit to Watermouth-Flowers-A Crab at Home -A walk to Lee-Beautiful Valley-Character of the Cove -Stone-turning-The Worm Pipe-fish-Its Form and Colours-Manners in Captivity-Intelligence-Appearance of Disease-Surgical Aid-Difficulties of Microscopical Sketching.

154

\section{CHAPTER VIII.}

Rock-pools-Their Abundance--Southey's Description-Its truth to Nature-Their Loveliness-Chondrus-Its brilliant Reflec- 
tions-The Branching Coryne-A Parasite-A Beautiful Sea-weed-Structure of the Zoophyte-Origin of its NameTentacles-Their Structure-Egg Capsules-Escape of the Eggs-The Bird's-head Coralline-Elegant Shape of the Polypidom-Advantage of studying living Animals-The Cell -The Polype-Its Organization-Muscles-Economy in God's Works-A Populous Stone-Enumeration of its Tenants-Reflections-God's Purpose in Creation-The hopeful Future-The Sessile Coryne-The Belgian Pedicellina- Its Form and Structure-Production of its Young-Its Habits -Its Affinities-The Slender Pedicellina-Its singular Bulb.

\section{CHAPTER IX.}

Metamorphosis of Lepralia-Appearance of the GemmuleBudding of the Cell-spines-Development of the PolypeGrowth-The Three-headed Coryne-Singular Use of its Disk-Beania-Coralline Light-Lime Light-TubuliporaMarine Vivaria-The Principle explained-Elegance of Seaplants-Facilities for Study-Details of ExperimentsMode of procuring the Sea-weeds-Success-Anticpations -A curious Coincidence-Sponge-Crystals-Their elegant Form-Immense Numbers-Mutual Entanglement-Ciliated Sponge-Its crystal Coronet-Powers of Restoration. 218

\section{CHAPTER X.}

Respiration and Circulation-A Transparent Ascidia-Organs of Sight-Play of the Gills-Ciliary Waves-The Heart-Coursing of the Blood-globules-Reversal of the Current- "Nature," what is it ?-The Praise of God-Luminosity of the Sea-A Charming Spectacle-Light-producing ZoophytesLuminosity a Vital Function-Noctiluca, a Luminous Animalcule-Its Structure-Production of its Embryo-The Slender Coryne-Description-Parasites.

\section{CHAPTER XI.}

Hillsborough-Meaning of its Name-Its Grandeur-Its Flowers -Commanding Prospects-View Westward-Inland-Eastward-Seaward-Formation of a Beach-A Rock-slip-An- 
thea--Its Tentacles retractile-Their Structure--ThreadCapsules-A Summer Morning Walk-Autumnal FlowersLangley Open-The Hangman-Curious Legend-Coast Scenery-Lee-A Ship's Travels-Solitude-Caves-Sponges -The Hispid Flustra-Its Appearance and StructureExpansion of its Bells-Ciliary Action-A miniature Whirlpool-Visit to Braunton-Carn Top-Tragical LegendScore Valley-Squirrels-Trentistowe-White BindweedOak Hedges-Reaping-Braunton-Curious monumental Inscription-Braunton Burrows-Sea-side Rocks-Marine Animals-Rare Plants on the Cliffs-Snails-Botany of the Burrows-Insects-Shells-The Feather Plumularia-Its Egg-Vesicles-Young Polypes-Their Development from Planules-Structure of the Polype.

261

\section{CHAPTER XII.}

A Visit to Smallmouth Caves-Chasm formed by a Rock-slip-View of Samson's Bay-Samson's Cave-SmallmouthNatural Tunnel-View of Combmartin Bay-Brier CaveAbundance of Animals-The Twining Campanularia-Form of its Cells-The Polypes-The Egg-Vesicles-Birth of a Medusoid-Its Form and Structure-Tentacles-Eyes-Circulating Canals-Alternation of Generations-Ride towards Barricane-A Showery Journey-Lee-Damage Farm-A romantic Dell-Devonshire Wells-Rockham Bay-White Pebbles-Morte Stone-Shipwreck-Gallant Exploit-Morte - Tomb of De Tracy-Approach of a Storm-KestrelsParasites on a Crab-The Bristle Plumularia-Birth of its Young-Dissolution-The Lobster's Horn Coralline-Secondary Cells-Suggestion of their Purpose-Egg-VesiclesBirth of the Planule--Its Development into the Polype-form -Death.

292

\section{CHAPTER XIII.}

Capstone Spout-Holes-Purple Hue of low Rocks-Tadpole of a Mollusk-Its Habits-Visit to Barricane-A Beach of ShellsRock-pools-Their Contents-Antiopa-Its Spawn-Hatching of the Embryos-Immense Number in one Brood-The Torrs-Bloody Field-Flowers-View from the Cliff-Torr 
xir.

Point-Rocky Staircase-White Pebble Bay-Tide-poolsMaiden-hair Fern-The Precipice-A curious MedusoidMedusoid Fishing-Mode of Operation-Difficulties-Thaumantias pilosella-Its Luminosity-Description of its Structure-The Umbrella-The Sub-Umbrella-The PeduncleThe Radiating Vessels-The Ovaries-The Tentacles-Pigment-cells-Eỹes.

320

\section{CHAPTER XIV.}

Rapparee Core-Strange Grarel-Its singular Origin-The Glassy Equorea-Its Form and Structure-The Forbesian Equorea-The Bathing-Pool-Medusæ therein-Description of a new Species-Its Habits-Luminousness-Distinctive Characters-The Ruby Medusa-Its first Occurrence-Wigmouth-Production of the Gemmules-Their AppearanceMotion of the Turris-Metamorphosis of the GemmulesTheir Polype-form-Goodness of God in the Beautiful-A Christian's Interest in Nature-The Redeemed InheritanceThe Crystalline Johnstonella-Its Beauty-Its Doubtful Affinities-The Starry Willsia-Parasitic Leech-Thread-Capsules-Nature of these Organs.

\section{CHAPTER XV.}

This Coast farourable for Oceanic Productions-The Red-lined Medusa-Its Form and Structure-The Eyes-The Furbelows-A parasitic Shrimp-Its supposed Young-Beauty of the Medusa-Its Prehensile Powers-Capture of PreyCurious Mode of eating-Experiments-New Use of the Furbelows-Development of the Eggs-Their StructureThread-Capsules-Synonymy-The White Pelagia-The Mantis Shrimp-Its spectral Figure and strange ActionsIts Weapons-The Cadis Shrimp-The Tiny OceaniaBusk's Thaumantias-The Fairy's Cap.

\section{CHAPTER XTI.}

The Maritime Bristle-tail-Its Nocturnal Habits-Discorery of its Retreats-Its Companions-The Scarce Polynoe-Its Armoury of Weapons-A rocky Bay-Romantic Incident- 
Chivalrous Self-sacrifice-The Tunnels-Crewkhorne Carem -The Torr Cliffs_Precipitous Path-Torr Point_SolitudeThe Scarlet and Gold Madrepore-Scene of its DiscoveryDescription of the Species-Its Microscopical Structure-The Stony Skeleton-Thread-Capsules of Actinia-The Clubbearing Medusa-Entanglement of Air-Structure of the - Tentacles-The Eyes. 359

\section{CHAPTER IVII.}

Various Effects of Light on Scenery-Ode to Light--The Sabella -Its Tube-Its Crown of Plumes-Fatal Attack-Discovery of more Specimens-Laborious Mode of Procuring themThe Young-Reproduction of the Crown-The CorynactisA low Spring-tide-The Tunnel Rocks-Discovery of the Species-Its Form, Structure, and Colours-Manner of taking Food-Thread-Capsules-Their elaborate Structure-Propulsion of the Thread-Identification of the Species-The Purple-spotted Anemone-Its Locality and Manners-Its Form and Colours-Thread-Capsules-Nature of these OrgansSystematic List of Zoophytes-Conclusion.

\section{APPENDIX.}

Marine Vivaria-Facts Established-Ozone-Its Mode 'of Action -Application of Principles-Aquaria in the Zcological Gardens-Parlour Aquarium. 


\section{LIST OF PLATES.}

\begin{tabular}{|c|c|c|c|c|c|c|}
\hline \multicolumn{3}{|c|}{ Plate } & & \multicolumn{3}{|c|}{ To face page } \\
\hline 1 & Actinia bellis, \&c. & - & - & - & , & 28 \\
\hline 2 & Pleurobranchus, \&c. & - & - & - & , & 66 \\
\hline 3 & Alcyonium, \&c. - & - & - & - & , & 78 \\
\hline 4 & Laomedea geniculata & - & - & - & , & 84 \\
\hline 5 & Caryophyllia Smithii & - & - & - & , & 112 \\
\hline 6 & Eucratea chelata, \&c. & - & - & - & ,. & 134 \\
\hline 7 & Cellularia ciliata, \&c. & - & - & - & , & 142 \\
\hline 8 & Actinia gemmacea, \&c. & - & - & - & , & 168 \\
\hline 9 & Coryne ramosa - & - & - & - & , & 190 \\
\hline 10 & Cellularia avicularia & - & - & - & , & 196 \\
\hline 11 & Antennularia antennina & - & - & - &, & 314 \\
\hline 12 & Pedicellinæ & - & - & - & , & 210 \\
\hline 13 & Lepralia, \&c. & - & - & - & , & 218 \\
\hline 14 & Corynes - & - & - & - & , & 222 \\
\hline 15 & Clavellina, \&c. - & - & - & - & , & 236 \\
\hline 16 & Coryne stauridia, \&c. & - & - & - & , & 254 \\
\hline 17 & Plumularia pinnata & - & - & - & , & 288 \\
\hline 18 & Campanularia & - & - & - & , & 296 \\
\hline 19 & Medusoid of Campanularia & & - & - &, & 300 \\
\hline 20 & Willsia, \&c. $\quad$ - & - & - & - & , & 360 \\
\hline 21 & Thaumantias Corynetes & - & - & - &, & 408 \\
\hline 22 & Medusoid of Coryne, \&c. & - & - & - &, & 332 \\
\hline 23 & Equorea vitrina - & - & - & - & , & 342 \\
\hline 24 & Fquorea Forbesiana & - & - & - & , & 346 \\
\hline 25 & Johnstonella Catharina & - & - & - & , & 356 \\
\hline 26 & Balanophyllia, \&c. - & - & - & - & ,. & 400 \\
\hline 27 & Chrysaora. - & - & - & (Fron & e) & \\
\hline 28 & Thread-capsules & - & - & - & , & $12 S$ \\
\hline
\end{tabular}




\section{A NatURalist's RaMBLES.}

\section{CHAPTER I.}

A Flitting to the Coast-Rival Claims of North and South Deron-Narychurch selected-Beauty of Deronshire LanesAuthor's outfit-First exploring jaunt-Babbicombe sands -Pretty Rock-pool-Petit Tor-Jackdaws-Kestrel-Pollock-fishing on the Rocks-Boulders examined-Contents of a shallow Pool-Green Sea-worm-Smooth Anemone-Turning stones at Babbicombe-Finger-cutting Serpulæ-Naked-gilled Mollusca-Their elegance and beauty-Manners in Captivity-Spawn of Doris-Form and Structure of the young-Anthea-Its Form and Colours-Voracity of an Eolis -Manners of Anthea-Its Mode of marching-of swimming -Beautiful Variety-Reflections.

"You are seriously ill, Henry," said my wife; "you hre been in the study a great deal too much lately; you must throw it all up, and take a trip into the country."

"O no," said I, "not bad enough for that, I hope; a few days' inaction, with God's blessing, will set me right. I do not want to leave London."

But I got worse; sitting by the parlour fire, doing nothing, was dreary work; and it was not much mended by traversing the gravel walks of the garden 
in my great coat: there was nothing particularly refreshing in the sight of frost-bitten creepers and chrysanthemums in January. To walk about the streets in the suburbs, or eren in the city, was dreary too, when there was no object in view, nothing to do in fact but to spend the time. But, after all, the dreariness was in myself; I was thoroughly unwell, overworked, and everybody said there must be a rustication. The Doctor added the casting vote: - "Bad case of nervous dyspepsia; you must give up study, and go out of town." I succumbed.

"Now where shall it be? Leamington-Tonbridge Wells-Clifton?" No, none of these; since I must go, it shall be to the sea-shore; I shall take my microscope with me, and get among the shells and nudibranchs, the sea-anemones and the corallines. What part so promising as the lovely garden of England, fair Devonshire?"

Devonshire then was decided on. But North or South Deron? The Bristol or the British Channel? Ilfracombe or Torquay? Each had its claims for preference, each was unknown, each was said to be "comely in its kind;" South Devon I knew (by report) to be rich in its marine zoology; North Deron was described as magnificent in scenery. Each too had its objections. The South was too relaxing for a nervous complaint; the North was out of the world, and difficult of access in winter. So nearly were the pros and cons balanced, that the very evening before the time determined on for starting left the point sub judice, when a friend calling, a Torquay man, settled it.

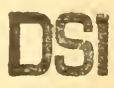


"Why not try Marychurch? It is very high, and the air is bracing. Moreover you will be within an easy walk of the shore at several points; the coast round is indented with coves and inlets; most of it is very rocky, and will give you plenty of hollows and dark pools, full of sea-weeds and zoophytes, interchanged now and then with sandy and shingly beaches. Try the South first; you will then be as well situated as now for reaching the North coast, should the air not suit you."

The counsel seemed sound and seasonable. The next day the luggage was sent off to the 'Torquay station, and we all, (wife, self, and little naturalist in petticoats) followed by easy stages.

And very pleasant it was to us to find ourselves at the end of January in the midst of the "Devonshire Lanes." No frosts had as yet sullied the verdure of the herlge banks, or nipped the shrubs in the sweet cottage gardens. Indeed frost seems here almost unknown, if we may judge by the myrtles dressed in their glossy foliage of deepest green, reaching up to the eaves of the houses, and the fuchsias, not always of the most common varieties, whose thick roughened trunks have evidently braved the open air through many winters. As we trudged, despite the tenacious red mud that lay ankle-deep, along the narrow lanes around Marychurch and West-hill, lanes that were even now dark with the tall hedges, and the roadside trees that met over our heads, we felt that we had left the reign of winter far behind us. The high sloping banks were fringed every where with the long pendent fronds of the hart's tongue fern; the broad arrowy 
leaves of the wake-robin, glossy and black-spotted, and great tufts of the fetid iris, a rare plant elsewhere, were springing up from all the ditches. Strange warm damp lanes, so suited for lovers' evening walks, (not exactly at this season to be sure) winding and turning about, ever opening into some other lane, that again presently into another, and all leading apparently nowhere,-with the little birds hopping fearlessly about the hedge-tops and the trees overhead, the robin sweetly singing, the tiny gold-crest peeping into the crevices of the ivy, the yellow hammer and the chaffinch in their gay plumage twittering almost within reach of your hand! And ever and anon we pass some thatched cottage in the sheltered bottom, its little garden in front trimly kept, and still bright with the blossoms of the chrysanthemums, the trailing roses over the porch displaying a lingering flower or two, and the indispensable myrtle peeping in at the chamber lattice; while at one of the lower windows sits the venerable dame in a snowy eap of ancient fashion, with horn spectacles on her wrinkled but gentle face, reading her large Bible. Early violets were beginning to peep from their lowly retreats, and very soon we found them in plenty, and the delicate pale yellow primroses quickly bespangled every bank.

It was in the midst of such rural scenes, and yet within a quarter of an hour's walk of the boundless sea, that I set myself down for a temporary sojourn. I had brought with me a plain but good working compound microscope, a small simple one, and a few books essential to the littoral naturalist. Among them were Cuvier's and Jones's Animal Kingdom, 
Forbes' Star-fishes and Naked-Eyed Medusæ, John ston's Zoophytes, Sponges, and Introduction to Conchology, Yarrell's Birds, and Fishes, Alder and Hancock's Nudibranch Mollusca, Swainson's Malacology, Grant's Outline of, and Owen's Lectures on, Comparative Anatomy, Audouin and M. Edwards' Littoral de la France, Harvey's Marine Algæ, and his beautiful little Sea-side Book, and a few minor works on the same or kindred subjects. I was not long in discovering that with such aids to inquiry, an ample field was before me, and that I should not lack abundant materials of entertainment and instruction for myself, and, as I hope, for others also.

It was on the very first afternoon, that is to say, on the 30th of January, 1852, that I set forth to see what promise the shore might afford. A zigzåg road, such as a carriage can traverse, leads down the steep from Babbicombe to the beach below. The beantiful coast stretches away before us; first appear the bluff red headlands from Petit Tor northward, in distinct prominence, but each becoming more dim than its predecessor: the white houses of Exmouth shining in the full afternoon sun on the blue hazy shore; thence the blue becomes fainter, more hazy and watery, and the band of coast itself slenderer, till at length it can only be discerned by the eye carefully tracing it from the visible part onward. In front expanded

The peaceful main,

One molten mirror, one illumin'd plane

Clear as the blue, sublime, o'erarching sky.

Montgomert.

The rocks to the right presented little to reward 
the toil of scrambling over their projecting masses, but I observed strong iron bars driven perpendicularly into the crevices here and there, to which, in one case, a line was affixed that ran out into the sea: this I was told was attached to a herring-net, set across the tide; though few herrings are yet come in. On the sand and shingle were several young dog-fish; probably hauled in the seine, and thrown out to putrefy as useless. Towards Oddicombe on the left, in climbing and crawling around the face of the rough cliff, I found a pretty tide-pool, a delightful little reservoir, nearly circular, a basin about three feet wide and the same deep, full of pure sea-mater, quite still, and as clear as crystal. From the rocky margin and sides, the puckered fronds of the Sweet Oar-weed, (Laminaria saccharina) sprang out, and gently drooping, like ferns from a wall, nearly met in the centre; while other more delicate sea-weeds grew beneath their shadow. Several sea-anemones of a lind very difierent from the common species, more flat and blossom-like, with slenderer tentacles set round like a fringe, were scattered about the sides: when touched they contracted, more and more forcibly, into a whitish grey tubercle.

PETIT TOR.

Feb. 3rd.-When the tide was nearly at ebb, I walked down to the cove at Petit Tor. The red earth, so abundant hereabout as to tinge the clothes of the peasants, the coats of the numerous donkeys, and the wool of the sheep, of a rufous tint, was saturated by the recent rains, and formed a tenacious mud, 
rery unpleasant to walk in, of which the little lane leading from Marychurch has quite enough. This passed, however, a gate leads out on the down at the summit of the cliffs, whence, as the day was most cloudlessly brilliant, the prospect out upon the sea was magnificent. There was scarcely any wind, the atmosphere was very clear, and the transparent blue of the water sparkling in the sun was particularly summery. The mossy turf of the down was scarcely firm enough to sustain the tread on the slope, but continually slid away beneath the feet from the ruddy mud, affording a treacherous footing in the descent, which as the pathmays over the cliffs frequently pass close to the edge of tremendous precipices, is not without danger. A zigzag road, however, leads down to the beach through the gully, or chine, ( as it mould be called in the Isle of Wight) which bears the name of Petit Tor, though this name belongs of right to the bluff promontory on the south of it. The object of the road appear's to have been the transport of the beautiful rariegated marbles, huge blocks of which, some of them sawn and marked with numbers, were lying beside the way at different points, ready for removal. By running, jumping and sliding I arrived at the bottom, and paused awhile to look around. The ruined walls of what was once probably a fisherman's cottage, built in the curious manner peculiar to the neighbourhood, of rough fragments of friable limestone, set in a strong red mortar, stand on the declivity; and in the midst of the beach, starts up from the very shingle a pointed columnar mass of rough conglomerate rock about 60 feet high, reminding one of our common idea of the pillar of salt. The 
back of the cove is like the receding slope of an amphitheatre, on the grassy sides of which, half-covered with furze-bushes, and tufts of the stinking Iris, and brakes of fern, a few sheep were grazing. On the northern side the cliffs of red conglomerate rise to a great height; and on looking up to the summit my eye was caught by the Jackdaws, which were playing there, and I sat down on a mass of rock partly hidden by fern and brambles to watch their movements. A flock of fifty or sixty, sometimes more, sometimes fewer, were flying about a chasm near the lofty inaccessible summit, now and then alighting in the fissures, then shooting down into the air to join their comrades' play. They uttered a short querulous call, more sharp and impatient than the caw of the rook, and occasionally two would engage in a sort of conversation, a rapid reiteration of the note. Now they disappeared one by one, and presently they would come trooping round the seaward face of the headland in little companies, as if assembling by agreement, their glossy backs and wings gleaming in the bright sun, play awhile in the air about the chasm, then go again. The rough face of the rock was partially concealed by large patches, green and yellow, of ivy, reaching, irregularly and interruptedly, from the very base to the top; in the upper parts of this, the daws would frequently rest awhile, but not long. A Hawk, which from its size, and the dark margin of its tail I took to be the Kestrel, was hovering among the troop; its superior ease and grace of flight were very observable, though the daws are birds of powerful wing. The latter were apparently unfavourable to the intrusion of the suspicious stranger; 
for they set upon him in a troop and chased him away, though not far. Presently a Gull came by and sailed away straight out to sea for a long distance, then turned, as if to challenge the terricolous daws to try an ocean-flight with him.

The beach ends northward in a wilderness of boulders, enormous masses of red conglomerate detached from the precipice above, and piled in confusion upon each other,-Pelion upon Ossa, and Ossa upon Olympus. This sort of composite rock readily vields to the action of the weather, and hence the fallen masses take rounded forms. On one of the most prominent stond a gentleman, angling; I scrambled over to him, and learned that he was fishing for pollock; they come in shoals and bite readily; but it was rather too early in the season now.

Great boulders like these do not generally afford, a very favourable field to the naturalist; where, however, one is resting partially on others, so as to allow an examination of its under side, this is sometimes productive, provided it be not far from low-water mark. In a dark cavernous recess here $I$ found attached to the overhanging surface of a huge mass, a specimen, as big as a dinner-plate, of that curious dense sponge discovered by my esteemed friend Mr. Bowerbank, and named by him Pachymatisma Johnstonia. In another similarly situated, was a numerous colony of the common smooth Sea-anemone (Actinia mesembryanthemum), composed, in about equal numbers, of two pretty varieties, the one a fine dark red, the other a clear grass-green.

I went back to the limestone ridge at the southern 
extremity of the cove and amused myself with examin. ing the little shallow tide-pools, one or two inches deep, regularly paved with small muscles, and fringed with dwarf fuci, ulve, Rhodymenia palmata, and coralline,-representatives of the olive, green, red, and stony sea-weeds, all gathered together, but all stunted and poor, being so high above low-water line. Several of a long slender many-footed sea-worm (Phyllodoce lamelligera), looking like a centipede, but of a bright green colour, were lithely crawling and turning among the sea-weeds and muscles, and were difficult to get hold of, from their length and slipperiness.

These shallow pools, the sides of the rocks, the boulders, and the small stones left dry by the tide, are all studded with the common Smooth Anemone (Act. mesembryanthemum) in great abundance. The most frequent variety is of a rich deep red, sometimes brightening into blood-red, but more ordinarily deepening into a full brownish purple or liver-colour. Less common is the olive variety, likewise varying in tint according as the green or the brown element preponderates. And not rarely we see specimens, usually of large size and of oval outline, with the ground-colour dark-red, marked with uumerous and close-set green dots. This species is the most careless of exposure to the air of all our native zoophytes; we see them adhering to the rocks almost up to high-water mark, so that the periods during which these are left dry are considerably longer than their immersions. Yet it is only while covered with water, that they expand their beautiful flower-like disks and petaloid tentacles, and consequently obtain nutriment. And even when we 
look at such as are immersed, we quite as frequently see them closed as open.

Southey has poetically described the influence of the returning tide upon these charming creatures.

\author{
Meantime with fuller reach and stronger strell, \\ Wave after wave adranced ; \\ Each following billow lifted the last foam \\ That trembled on the sand with rainbow-hues: \\ The living flower that, rooted to the rock, \\ Late from the thinner element \\ Shrank down within its purple stem to sleep,- \\ Nor feels the water, and again \\ Awakening, blossoms out \\ All its green anther-necks.
}

Thalaba, xii. 3.

\title{
NAKED-GILLED MOLLUSCA.
}

Feb. 18th.-The beach at Babbicombe, which, when the tide is in, is composed entirely of pebbles, changes lower down to larger stones, and at extreme low water presents only rounded and flattened blocks from six inches to a yard in width. They are invested with a clothing of green weeds, and are hence slippery to walk on, and when their drapery is flagged and half withered by the sun, are unpleasing to the eye. It struck me that I might find something under them, however, and I spent an hour or two turning them over, not without some loss of blood, for their edges and under sides were crowded with the shells of Serpula, the little projecting points of which over the mouth were as sharp as needles, and cut and tore my fingers continually. But I was rewarded by a good many of those elegant creatures, the naked 
gilled Mollusca, which were adhering to the surface of the loose stones, awaiting the return of tide. The large grey Eolis papillosa, the little Doris bilamellata, and a more minute buff-coloured species of Doris, I took here; and the pretty green Polycera ocellata was numerous; but the most abundant, and at the same time the most lovely species was the exquisite Eolis coronata, with tentacles surrounded by membranous coronets, and with crowded clusters of papillæ, of crimson and blue that reflect the most gem-like radiance.

I brought home my captives and placed them in a vase of sea-water to observe their manners. When out of water they exhibit nothing of their peculiar beauty, and if the searcher has not a sharp eye, he may readily overlook them; they look like little shapeless lumps of fibrous jelly, But on being dropped into water, no sooner do they feel the bottom and begin to crawl, than all the clustering branchiæ are separated and waved, the long oral tentacles are thrown from side to side, and the pellucid animal glides quickly along with a graceful even motion. Both the species of Eolis bristle up their branchiæ and throw them forward when irritated. One or two of my specimens had lost some of their tufts of these organs, which were evidently sprouting again. I think that they lost some while in captivity.

$E$. coronata was very active, continually gliding with a uniform motion around the sides of the vessel, or climbing about the numerous branching sea-weeds, that were growing in it. They frequently crawled close to the edge of the water, but never came actually 
out, though they occasionally flonted at the surface by means of the expanded foot, back-downward.

Polycera ocellata on the other hand is fond of coming out of the water, and of remaining at the edge of the vessel, when it looks like a little ball of olive-coloured jelly. It frequently floats by the foot, and is capable of a slow progression in this manner. If pushed under water, it retracts its branchire and tentacles, incurves the edges of the foot, and sinks rapidly to the bottom; but soon recovers its equanimity, and crawls up to the summit of the nearest sea-weed, or up the sides of the reservoir to the surface again.

Doris tuberculata slowly glides round and round the ressel just beneath the surface, now and then lifting and puckering up the edge of the cloak, and allowing the air to bathe the boly.

Doris bilamellata, of which there were three in the vessel, was very social in confinement, continually finding ont one another, and crowding close up together. They crawl round the pan, generally resting close to the surface, often with the mantle a little raised, so that the air may reach the body.

Feb. 22nd.-The Doris bilamellata laid a ribbon of spawn attached to the side of the pan almost at the surface of the water. It adhered by one edge and formed an imperfect spire or cup, the ribbon being bent upon itself; the upper edge or brim leaning a little outward, and being puckered. The general substance is white and opaque, owing to a vast number of minute eggs, enveloped in a clear jelly. The colour therefore appears uniform except 
that a clear line runs round just within the edge, caused by a narrow space free from eggs The ova, though numerous and close-set, occupy only the central portions of the band (seen in section), there being a considerable space of transparent jelly without them, on each surface. The Doris was disturbed, and seems to have finished prematurely, the latter part of the ribbon being distorted.

Within a day or two after this, the other two of the same species laid their spawn; it had much the same appearance as the first, that of a long ribbon irregularly bent or folded on itself; that of the largest is above $\frac{3}{8}$ ths of an inch high, and 1 inch long.

Early in March I observed, similarly attached to the overhanging surface of a rock between tidemarks, a ribbon of like appearance, but much larger; about $\frac{3}{4}$ ths of an inch high. Doubtless this was the spawn of D. tuberculata: it hung down in a wet flaccid manner, being left uncovered by the recess of the tide.

On the 19th of March I cut off a small piece of the first ribbon of spawn (laid Feb. 22) and examined it beneath the microscope. I found that the young were fully formed, each enclosed in a globular egg, perfectly transparent and colourless. The young Doris, unlike the adult, which is a naked slug, inhabits a transparent shell, formed like that of the nautilus, from the mouth of which project two large fleshy circular disks set round with long cilia. These latter organs were in constant and vigorons vibration, by the motion of which each little animal revolved freely in its egg-shell, incessantly turning upon its centre 
in every direction. Sometimes one would suddenly suspend the motion of its cilia, as if tired; then after having rested a few moments, put forth one cilium in a cautious manner, then another, and in a moment the whole were again in vibration, and the little embryos was grrating in its giddy dance.

The embryos remained active in the piece of the ribbon under the microscope, for several days, but did not appear to increase in development, nor were any hatched. They then became motionless, and were doubtless dead.

\section{ANTHEA CEREUS.}

Feb. 23rd. Under a stone at low water mark I found a fine specimen of Anthea cercus, attached to the under surface. I kept it some days in the vivarium, where its appearance was very beautiful. The body is about $1 \frac{1}{2}$ inch thick, and the same in height, of a purplish-brown hue marked with numerous longitudinal narrow bands of dull lilac, each band margined with darker colour. The tentacles when fully expanded are $1 \frac{1}{2}$ inch long, and about a line in thickness at the base, tapering gradually; of a brilliant satiny light-green, with the tips purplish-red. The tentacles were contractile but not retractile, and were never regularly radiating, but mingled irregularly in a tortuous manner in all directions. They were adhesive to any foreign substance on all parts of their surface The body was frequently distended by the imbibition of water; when it became more pellucid.

In the same pan I had three individuals of Eolis 
yapillosa. One of these was rather large, the others scarcely half grown. One day I found the largest eating the tentacles of the Anthea, and when I attempted to pull it away, it held so firmly that the mouth was almost everted. Soon afterwards I again found it at the same work of destruction, and one of the smaller specimens was attacking the unfortunate Anthea also. They were eager and fierce, stretching forwark to their prey from their points of attachment, to which they adhered only by the extremity of the foot, and frequently erecting and reversing their crowded branchize. On being again removed they again returned, though from a considerable distance; so that whenever I looked at the pan, I almost always found one or all of the Eolides devouring their victim, so much larger, thongh more sluggish, than themselves. The tentacles when gnawed and torn, became shrivelled; some of them were torn away by the Eolides, and a large quantity of viscid albuminous matter was discharged in the form of irregular threads or webs, attached to the surrounding objects. The process went on from day to day. On one occasion, one of the Eolides attacked a magnificent Actinia crussicormis in the same ressel, and had eaten a hole in its side as large as a pea before I discovered it.

Anthea cereus is abundant around Tor Abbey Headland, inhabiting in great numbers the shallow pools in the red sandstone and conglomerate, which occur on the broad surfaco left exposed at low water. They are principally of the variety with plain grey tentacles, but specimens of the more beautiful variety described above, having those organs of a satiny 
green with rosy tips, are sufficiently numerous. They are content to be corered with a few inches of water, their bases resting on the rough bottom, in which they seem to be imbedded to a slight depth; but this is probably the effect of the animals' choosing a hollow of suitable dimensions; for I do not believe that their muscular base has any faculty of eroding the rock. When half-a-dozen or more are seen inhabiting a small pool, their appearance is curious, and not a little beautiful. The great mass of long and slender tentacles are not arranged, like those of other Actinice, in circles of divergent rays, but contorted and intertwined in all directions, like the dishevelled snakelocks of Medusa's head. In the beautiful lines already cited from Southey, I think he had this species in view when he speaks of the "green anther" necks"; but the "purple stem" of the sleeping one was most likely the common Smooth Anemone. Perhaps he thought that they were the same species in different conditions.

In a large vase of sea-water Anthea's actions are as peculiar as its appearance. It is fond of climbing up the sides of the glass, a feat which it accomplishes with a considerable measure of (comparative) activity. It glides up by the broad fleshy base, pretty much in the same manner as a gasteropod does by its expand. ed foot; and yet the process is not exactly the same. The power which Anthea has of inflating portions of its body, swelling them out in large tumid lobes separated by deep sulci from the rest of the circumference, assists it in crawling. We will suppose the Anthea resting on the bottom of the vessel, when it 
feels a desire to mount the sides of the glass. Pushing out a great inflated lobe towards that side, the sole of which is free from the surface, it takes hold of the glass with the edge of the lobe, and when the contact is firm, relaxing its former hold, it slowly drags forward the body, until the lobe is again lost in the general circumference, or even till the body projects in two smaller lobes, one on each side of the principal one. The base being now made firmly to adhere, again the lobe is freed, and again protruded, and the same process is repeated until the animal is satisfied with the position that it has gained. Sometimes this is at mid-height, the intertwined tentacles streaming loosely down by their own weight. At other times it rises to the very water's edge, and even thrusts out its base in an inverted position upon the surface of the water, as if it would float by the mere contact of the dry base with the air, just as the Linnee and many other Mollusca do. It does not, however, so far as I can judge, appear capable of quite accomplishing this; but it can remain so suspended, if the slightest possible portion of the margin remain in adhesive contact with the side of the glass.* A little shaking of the vessel, however, causes the water to overflow the surface of the base, which had been hitherto dry, when the animal instantly falls prone to the bottom.

April 23rd.-I found a curious and beautiful variety of Anthea cereus in a pool at Tor Abbey Headland. Its body and oral disk are very light

\footnotetext{
* I have since seen one, howerer, floating quite freely on the surface of the vessel, base uppermost.
} 
pellucid olive, but the tentacles are spotless snowy white, as if carved out of ivory, or rather as if modelled in the purest white wax. Its appearance, as it hangs on the side of a glass vessel, with the long and slender tentacles arching and drooping downward in the most graceful curves, is exquisitely attractive.

These objects are, it is true, among the humblest of creatures that are endowed with organic life. They stand at the very confines, so to speak, of the vital world, at the lowest step of the animate ladder that reaches up to Man; aye, and beyond him. Creatures linked in the closest alliance with these were long reckoned among the sea-weeds and mosses, eren by the most eminent philosophers; and to this day the collectors who make sea-weeds into pretty baskets, arrange the hydroid polypidoms among them without a misgiving of their identity. Nay, the madrepores and corals, nearer kindred still to the Actinia, were supposed even by the immortal Ray, to be inanimate stones, with "a kind of regetation and resemblance to plants."

The lamp of vitality, then, is just going out in these forms; or, if you please, here we catch the first kindling of that spark, which glows into so noble a flame in the Aristotles, the Newtons, and the Miltons of our heaven-gazing race. What then? shall we despise these glimmering rays? Shall we say they are mean creatures, beneath our regard? Surely no: God does not despise them. The forecasting of their being 
occupied his eternal Mind "before the mountains were brought forth;" the contrivances of their organization are the fruit of his infinite Wisdom, and elicit adoring wonder and praise from the hierarchies of angels; and the exquisite tints with which they are adorned are the pencillings of his almighty Hand. Yes, O Lord! the lowly tribes that tenant these dark pools are, like the heavens themselves, "the work of thy fingers," and do as truly as those glowing orbs above us "declare thy glory," and "show thy handy work." If then they were worthy to be created and sustained by Thee, they are not unworthy to be examined by us with reverential regard. 


\section{CHAPTER II.}

Petit Tor-Squirrel-Limestone Iedge-Stone-borers-Anemones and Sea-weeds-Clear Rock-pools-Daisy Anemone-Difficulty of procuring Specimens-Mode of Operation-A Metamorphosis-Description of the Species-TentaclesColours-Varieties-Habits-Structure of the TentaclesThread-shooting Capsules-Petit Tor Pools-Thick-horned Anemone-Description of the Species-Suggestions of Identity with $A$. coriacea-Its Habits-Beautiful VarietiesChanges of Figure-Deep Tide-pool-Prawn-Its beauty of Colour-Changes produced by Exposure to Light.

THe beach of white shingle at Oddicombe, whither ladies so often repair to search for pebbles containing fossil madrepores, washed up by the tide, is bounded on the north by the promontory known as Petit Tor. This is a bold bluff headland, almost entirely composed of compact limestone, which, on the side that fronts the sea, has been extensively cut away by the quarrymen, for building and ornamental purposes. Its rounded summit is clothed with a turf of that beautifully smooth and close texture, peculiar to downs, which many a nobleman's lawn might envy; sheep love to graze on it, and may be seen perched about the giddy heights, and upon the narrow winding footpaths that their own steps have worn, nipping the short fine grass in perfect security, where a false step must send them down upon the stony beach below. The always verdant and almost always blossoming 
furze covers large spaces with its profuse clumps, interspersed with beds of the stinking Iris, a plant which has little to recommend it, but which is very common on these seaward slopes. Down the perpendicular steeps hangs and creeps the ivy, concealing the rugged rock with its evergreen beauty; and on the slopes that are less precipitous, matted thickets of the brake-fern and bramble inclose and protect little sheltered spots, where, all through the spring, primroses grow by handfuls, and stud the hill-side with thick spots of their delicate yellow, as thick as star's and constellations in the sky of a winter's night. In these thickets I was rather surprised and pleased to find the Squirrel residing; one morning in March as I was quietly sitting on a stone, looking down from the brow of the promontory on the sea that was beating in over the rocks below, out pops Squggy, and with a grunt and a flourish of his feathery tail over his back in he dashes again, then out to peep, and away to go again; I all the while holding my breath, in hopes to confirm his confidence. But no; he would not adventure again.

The limestone at the base of the promontory, on that side I mean which faces the south, and bounds Oddicombe beach, is very precipitous; but it has been fretted by the incessant breaking of the waves into caverns and groins, buttresses, basins, shelves and ridges of all sorts of fantastic shapes. In some places there are spout-holes, the sea running up into a funnel-shaped cave, with a peculiarly hollow sound when you hear it beneath your feet, and breaking out at an opening some way within, with a gust of wind 
and spray, and a loud roar. The surface of the rock itself, from some distance above high-water mark downward, is corroded into a thousand little cavities, all honey-combed, as it were, in the most irregular manner, a circumstance which greatly facilitates the action of the sea in wearing down the masses. These cavities hare been produced by a stoneboring shelled Mollusk, Saxicava rugosa, which, as I believe, attacks only limestone, but this, hard as it is, it burrows through and through. It can live only where it is covered during a part of every tide; and therefore as part of this honey-combed structure is now above the reach of the tide, it must be inferred that this limestone has been elevated, since the existence of these stoneborers. It would be worth while to inquire how far the honey-combed limestones of other regions, of the South side of Jamaica for example, may have had a similar origin, though this is explained by Sir $\mathrm{H}$. de la Beche in a very different manner.

One can scramble out upon the side of these rocks at low water, and find between tide-marks a sort of ledge sufficiently level to permit examination; though the rough surface, and especially the sharp points that project between the honey-combed carities, render the footing precarious and uncomfurtable. The surface is leprous with myriads of acorn-shells, each tenanted by its living inhabitant, and every one putting forth, as soon as corered by the tide, its delicate little grasping hand of feathery fingers, or, if you please, its casting net, with which it is perpetually making its little throws for passing prey. Limpets, periwinkles, and murices also stud the rock, and in 
the lower parts, where the limits of the tide's recess are approached, are Actinice of a deep red hue, the common, unattractive species, the only one known however to thousands of sea-side visitors who talk enthusiastically of sea-anemones,- $d$. mesembryanthemum. The whole of the space between the tide lines is covered more or less thickly with matted masses of olive sea-weeds, short and stunted on the higher sites, and becoming more and more luxuriant as they approach low-water mark, where they wave in tangled tresses at every incoming sea, or hang in streaming shaggy locks as it recedes. The irregularities of the surface necessarily produce many hollows of various sizes, which, being covered at high water, remain full as the tide recedes, and, except in very rough weather, when the sea is much loaded with earthy particles, hold their contents in the most beautifully transparent condition: and the contracted dimensions allowing no room for the action of the wind, no ruffling of the surface is there to mar the glass-like clearness of the water, or to prevent the eye from peering down into every corner and crevice. The constant presence of water in these basins allows many delicate species of sea-weeds to grow freely in them, at a height above low-water mark, where otherwise they would never be found: and hence sheltered tide-pools constantly present specimens of the smaller and more lovely Alge in great perfection. In some of these grow along the sides, just beneath the surface, single fronds of the pretty little Rhodymenia palmetta, and waving tufts of the finer sorts of Ceramium, with the moss-like Plocamium coccineum, and whole 
masses of Chylocladia articulata, that look like the thickets of prickly pear which we see in the tropics, only viewed through a diminishing glass, and turned purplish-red. Laurencia pinnatifida clothes the lower rocks abundantly, where the sea washes up; and along the margins of some of the ledges, and around the rims of some of the lowest pools, that curious plant Rhodymenia ciliata throws out dense pendent tufts of its deep red fronds, all bristled over with little leaflets in the most singular fashion.

\section{THE DAISY ANEMONE.}

All along this line of limestone rock, in almost every tide-pool and hollow that retains the sea-water, from the size of one's hand upwards, we may at any time find colonies of the lovely Daisy Anemone, Actinia bellis. In the sunshine of a fair day they expand beautifully, and you may see them studding the face of the rock just beneath the surface, from the size of a shilling to that of a crown piece. Nothing seems easier than to secure them, but no sooner do the fingers touch one, than its beautifully circular disk begins to curl and pucker its margin, and to incurve it in the form of a cup; if further annoyed, the rim of this cup contracts more and more, until it closes, and the animal becomes globose and much diminished, receding all the time from the assault, and retiring into the rock. Presently you discover that you can no longer touch it at all: it is shrunk to the bottom of its hole; the sharp irregular edges of which project and furnish a stony defence 
to the inhabitant. Nothing will do but the chisel, and this is by no means easy of appliance. It is rare that the position of the hole is such as to allow of both arms working with any ease; the rock is under water, and often, if your chisel is short, it is wholly immersed during the work, when every blow which the hammer strikes upon its head has to fall upon a stratum of water, which splashes forcibly into your eyes and over your clothes; the rock is very hard, and the chisel makes little impression; and what is frequently the greatest disappointment of all, the powdery debris produced by the bruising of the stone mingles with the water and presently makes it perfectly opaque, as if a quantity of powdered chalk had been mixed with it, so that you cannot see how to direct the blows, you cannot discern whether you have uncovered the Actinia or not, and frequently are obliged to give up the attempt when nearly accomplished, simply because you can neither see hole nor Actinia, and as to feeling in the pap-like mud that your implement has been making, it is out of the question. Supposing however, that you have got on pretty well, that by making a current in the pool with your hand you have washed away the clouded water sufficiently to see the whereabouts, and that you perceive that another well-directed blow or two will split off the side of the cavity, - you have now to take care so to proportion the force that at last you may neither crush the animal with the chisel on the one hand, nor on the other drive it off so suddenly that it shall fall with the fragment to the bottom of the pool out of reach.

However, we will suppose you have happily 
detached and secured your Actinia without injury. But how unlike its former self, when you were desirous of making its closer acquaintance, is it now! A little liard globose knob of flesh, not so big as a schoolboy's marble, is the creature that just now expanded to the sun's rays a lovely disk of variegated hues, with a diameter greater than that of a Spanish dollar. It is moreover covered with tenacious white slime, which exudes from it faster than you can clear it away; and altogether its appearance is any thing but inviting. You throw it into a jar of water, which of course you have with you when collecting living zoophytes; and thus bring it home, when you transfer it to a tumbler or other suitable ressel of clear sea-water freshly drawn. And here let us wateh its changes;-which, however, will not be effected immediately; for it will not expand itself in all its original beauty until it has taken a fresh attachment for its base, which will not in all probability be for a day or two at least.

The body or stem of Actinia bellis is more or less cylindrical generally; though subject to some change in this respect, for it is occasionally a little enlarged, as it approaches the disk; the sucking base is slightly larger than the diameter of the body, which in specimens of an inch-and-a-half expanse, may be about half an inch. The length of the body varies much, according to the depth of the carity in which the animal lives, for it must expand its disk at the surface. In the open water in a vase, when it appears at home, it may commonly be about an inch from the base to the expansion of the disk, but I have a beantiful specimen before my eye at this moment, which has stretched 
itself to a height of three inches, expanding at the extremity as usual: the thickness of the stem is in this case somewhat diminished.

From the upper part of the cylindrical stem or body, the disk abruptly spreads around to the width above indicated. In this respect the $A$. bellis differs so greatly from other littoral species of sea-anemones, that it can never be mistaken by those who have once seen it. In these the disk is merely the termination of a short thick column, occasionally a little expanded over the edge; in bellis, however, the diameter of the disk is generally four times that of the body, at the point from which it expands. Its form, viewed externally, is that of a shallow cup, but its surface is in general almost flat, or a very little depressed to the centre. The whole bears a likeness closer than usual to a flower, with a footstalk. The disk is so thin and membranous, that it is continually changing its form; the margin is frequently bent over outwardly or inwardly in places; as it lies on the uneven rock, it accommodates itself to the roughnesses, and is hence often irregularly undulated; it very commonly bends inward the edge in several places, so as to make puckers or frilled scollopings around the margin. And this surely must be meant by what writers describe and draw as "lobes" to the disk: for of lobes proper it has none; not the slightest trace; the outline of the disk is most perfectly and beautifully circular; and I find it often expanded in this state, without any puckering or festooning. (See Plate I, fig. 1.)

The tentacles are small but numerous: they are 
Fil $a+1$

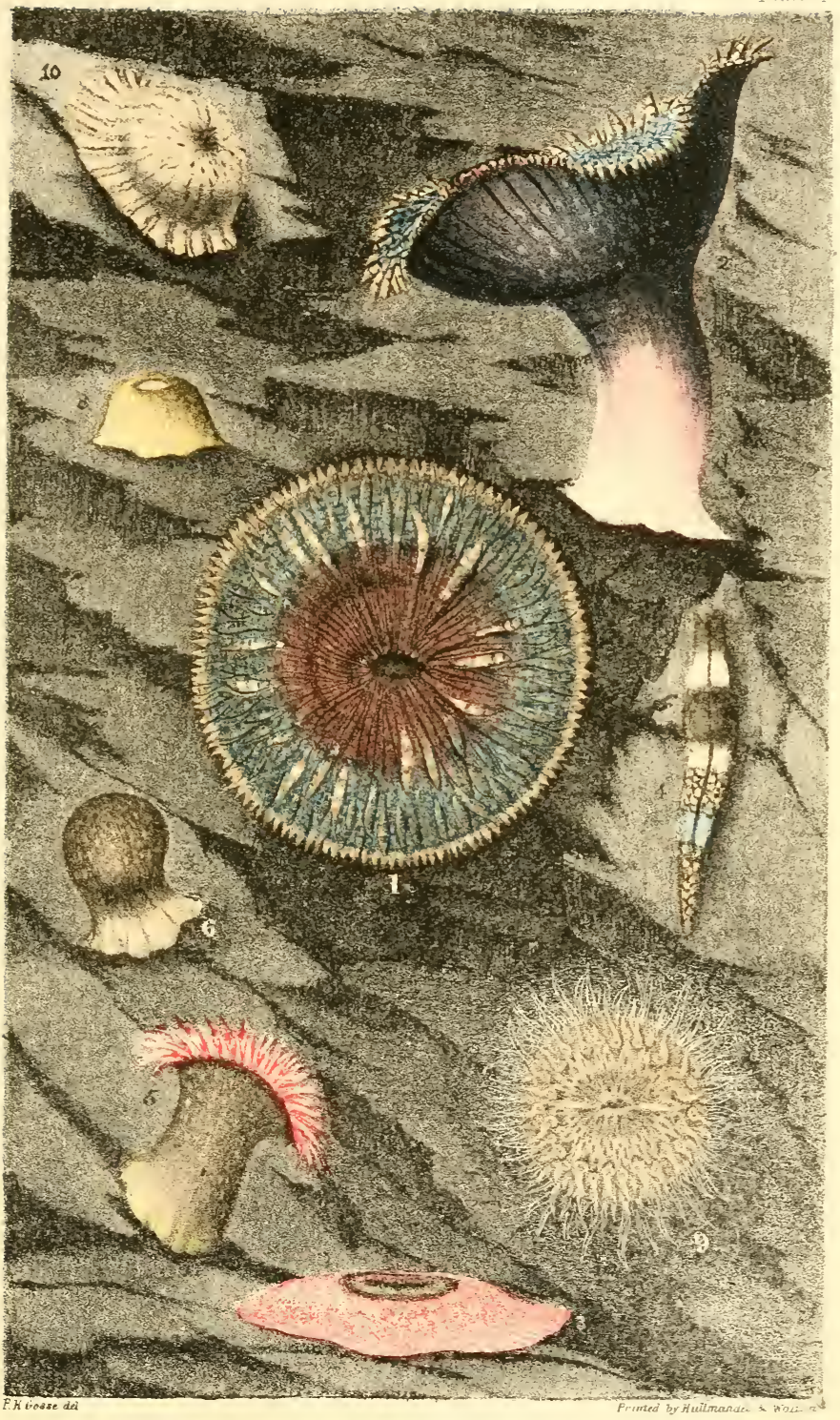

-4 ACTINIA BELIIS 8, ACE. NIVEA

56 ACT. ROSEA 910 ACI. ANTICU:- 

arranged in about six rows; the innermost series contains about twelre tentacles; the next about the same number; the third about twice as many; the fourth is again doubled; the fifth increases in the same proportion, and the sixth contains about thrice as many as the fifth. This ratio, if accurately carried out, would give a total of seven hundred and sixty eight tentacles to one Actinia, a number which is not far from the mark, though as in other species, the rows are not quite regular. The inmost series of tentacles is usually erect, or even inclines inwards, the other's decline more and more towards the circumference, until the outmost two or three rows lie quite flat upon the disk, to which the exterior one of all forms an exquisite fringe; all the rows are small, but they diminish outwardly in size, and more rapidly the nearer they approach the edge; those of the outmost row are very minute, the longest (for they are not equal) not exceeding the sixteenth of an inch in length, and some being only tiny tubercles: they are slender, and set so close together, that I counted sixty in an inch.

The mouth is oblong, sometimes contracted to a slit, at others showing a sub-oval, or lozenge-shaped opening, with the lips within finely crenated. Delicate depressed lines diverge from the mouth to the circumference of the disk, by tracing which we shall find that the convex space included between two lines leads to and terminates in a tentacle; the disk may in fact be described as formed of the roots of the tentacles soldered together. Tiewed from outside, with a strong light behind, the substance of the disk is 
exquisitely beantiful; the diverging but almost parallel fibres, resembling the grain of a beautiful piece of wainscot, and each ending abruptly with a rounded point, where the tentacle springs up from the surface on the opposite side.

The colours of this very lovely Actinia I have not found to vary much. The base is white, which as it ascends becomes flesh-coloured, then lilac, passing (at about the point where the disk expands) into a dull greyish purple, more or less tinged with brown. The upper part of the stem, and the whole of the outer surface of the disk, are studded with pale spots, which are the extremities of tubular glands, one use of which is to attach by a kind of suction, minute bits of shell, gravel, \&c., to the surface, for concealment as is supposed. I have not seen this habit commonly resorted to by this species, but I have witnessed it. (See fig. 2.)

The upper surface of the disk is of a rich deep umber-brown, often mottled with grey at the first row of tentacles, and merging into grey, lavender-colour or white, towards the third or fourth row. The tentacles are tapered to a point; they are grooved longitudinally on the upper side; they are commonly dark brown at the base, and yellowish-brown through the rest of their length, blotched and speckled with white. Those of the inmost row, and frequently some of the others, have one or two broad rings of pure conspicuous white near the basal part, and a broad spot of white divided by a brown line lengthwise, on the disk just at their foot. There is some diversity in the proportions of brown and grey, in different individuals, 
but the yellowish brown tentacle studded with whitish specks is, I think, characteristic.

There is, however, a very marked variety; for though I at first was disposed to consider it distinct, it must, I feel sure, be referred to this species. In a specimen before me from Capstone Hill, Ilfracombe, the disk and tentacles are unrelieved by any trace of white or grey, being of an uniform dark brown, except that the tentacular ridges that cross the disk are bounded on each side by a fine line of scarlet, scarcely visible except with a lens: its effect is however to give a tint of chocolate to the surface. The outside of this specimen differs not materially from the common state; it is, however, of a particularly bright crimson, instead of purplish. (See fig. 3.)

That this is a variety of $A$. bellis is manifest, because I have another on the table from the same locality, which beautifully connects the two states. This is a very handsome specimen; the disk is deep brown, almost black, with the fine lines of scarlet diverging from the centre as in that just described. The tentacles are some of them brown with one or two specks only of white near the base, and others, mottled in the ordinary manner with dark brown, light brown, grey and white; what is strange is that these varieties of colour are disposed in groups, a cluster of tentacles of the former hues, and then $a$ batch of the latter. The scarlet ruus up around the base of each tentacle, flushing its lower parts in a very elegant style; and the oral aperture is marked around the very edge with conspicuous white toothlike lines. This specimen was remarkable for the 
extent to which it was clothed with coarse gravel, and for the tenacity with which it held fast its strange stony garment, not dropping a fragment eren after sereral dars' captivity. In general Actinice drop their gravel coats soon after they are put into a ressel of clear water.

It is for the most part a stationary species, and that not only in its own selected hole in the rock-pool, but even in captivity. It seldom leares the spot in the glass ressel to which it has once attached itself. I have had a specimen, howerer, take it into his head to be a traveller, after sereral weeks' residence in oné spot: he walked off in a straight line to a distance of four inches, performing the feat, at a pretty uniform rate, in about eight hours, or half-an-inch per hour.

In order to examine the structure of the tentacles I ant off with a fine pair of scissors the tips of one or two, and submitted them to the microscope upon the compressorium. As soon as the pressure began to flatten them, it became apparent that the tentacle was composed of rather thick gelatinous walls surrounding a tubular centre. The latter was filled with a rast multitude of very minute granules of a rich sienna-brown hue, and almost quite globular in form; all being quite alike in shape, colour, and dimensions. These escaped by thousands, on the increase of the pressure, from the tip of the tentacle, where there was evidently a natural orifice forced open by the pressure, but ordinarily, as I suppose, kept firmly closed by muscular action. The gelatinous walls of the tentacle contained, imbedded in their substance, a goodly number, (not so immense as in some other species) of those 
highly eurious organs known as the filiferous capsules. They are in this case very minute, being about one twelve hundredth part of an inch in length, almost linear, and slightly eurved. The pressure being continued, each of these little organs suddenly shoots forth from one end to a great length, a slender, highly elastic thread, which had hitherto been coiled up spirally within its cavity. The expulsion of this thread is effected by a proper organism, excited by the pressure on the tissues of the tentacle, but not forced out by the compression of the capsule itself, for this is much too minute to be compressed by the glass plates, under any power that can be brought to bear upon them. It is supposed that the adhesire touch of the tentacles resides in these little organs, and that a poisonous fluid accompanies the emission of the thread; since the mere contact of a tentacle with any small animal appears at once to paralyse it, however lively it may have been but a moment before. If this be so, what a highly curious example is here of the wondrously effective provision which the infinite resources of the Divine Wisdom have made for the wants of every creature! We shall have further occasion to speak of these curious organs, and to exhibit them under forms even much more complicated and wonderful than they appear here.

PETIT TOR POOLS.

The north side of the limestone promontory of Petit 'Tor,- that side that bounds the little cove where Woodley cuts the great blocks of variegated marble 
which he makes into his well-known tables and chimney-pieces,-is not less rugged and worn into caverns and holes than that side which I have just been describing. It is, however, very different in its character and its productions. The erosions have a greater tendency to form deep basins in which the water always lies; and the lofty rock overhangs much more. Add to this that, the aspect being north, the sun's rays never penetrate to the cavities. For all these reasons they are particularly dark, and therefore favourable for the development of the deeper-growing Alga, and many of the zoophytes which are impatient of much light.

To get at them you walk along a tolerably level platform of rock beneath the cliff, for some distance, towards the point of the promontory, till you are arrested by a cleft, a little too wide to be leaped, that runs right up to the perpendicular face of the cliff. By means of one or two slight projections you can scramble across here, and then from the opposite side descend into the chasm, where you will find one or two beautiful little deep basins, almost as regular and smooth, especially near the bottom, as if they liad been chiselled out of the marble by a sculptor.

\section{ACTINIA CRASSICORNIS.}

In the few holes and angles that are found around the sides of these rock-pools dwell some fine specimens of the noblest species of Sea-anemone that I am acquainted with, Actinia crassicornis. They are rather difficult to procure, because of the firmness 
with which they adhere to the rock, and the protection which their base receires from the edges of the hollows in which they live. One large fellow that I attempted, just below the surface of the pool, contracted so forcibly on being touched, that little streams of water as thick as a pin shot out perpendicularly from many of the tentacles to the distance of a foot. The species became a farcurite with me, for its magnificent beauty; and I kept in captivity many specimens.

A fine variety not uncommon has the body of a dull dark red, with numerous, rather large, grey warts; the tentacles dark purplish red, with pale, almost white, tips. When fully expanded, and quite at home, it imbibes water to such an extent as to become subdiaphanous. Under these circumstances it is exquisitely beautiful. A specimen now before me is about two inches in the diameter of the body, which is not inflated to nearly its full capacity. The groundcolour of the body is pale olive, tinged rather irregularly with red, becoming darker towards the oral margin. The warts are pale lilac, evidently arranged in perpendicular rows of about fifteen in each row; the tentacles are large, tumid, and elegantly diaphanous; their general colour is pale purple or lake-red, the tint disappearing towards the tip, which is whitish brown; a rather broad ring of white goes round near the middle of each tentacle, which ring is, however, broken on the outer side. Besides this, each tentacle is marked on one side with a large patch of opaque white extending from the base through about half its length. This patch frequently sends 
off a half-ring of white, on the interior side, near its middle. The patch itself is irregular in form and extent, generally losing itself gradually at its upper extremity; it is not always on the same side; frequently two contiguous tentacles have the patch on their two opposing faces. The oral disk is dark vinous red, crossed by some streaks of white, each of which is double, separating to enclose the base of an inner tentacle, and re-uniting. These stripes have a very pleasing effect.

I doubt much the specific distinction of $A$. crass cornis and A. coriacea. Dr. Johnston describes the former as best distinguished by the readiness with which the rim of the disk is twisted, by the facility with which it becomes tumid, and by the vesicular furrowed lobes, which are frequently protruded from the mouth. All these characters my specimens have with distinctness; the last named I shall presently allude to. For one of the others the following instance may suffice. I brought home a fine specimen of the crimson variety, which I put into a pan of water just sufficient to cover it. In an hour or two it protruded the lips and inflated them so immensely that at first sight I thought the animal had turned bottom upwards, and that I was looking at the broad base. The surface was nearly smooth, flat and circular, about two and a half inches in diameter, occupying the whole breadth, so that the tentacles were partly overlaid by it, and appeared only as a thick fringe peeping out from under its edge in a horizontal plane. There was a curious, sharp-edged, narrow groove across the centre of the surface, rather deep, 
extending from one margin to the opposite, and meeting in the central orifice, looking as if it had been cut with a knife. The animal remained in this state all through the evening and night, and in the morning slowly retracted its pouting lips, and resumed its ordinary appearance.

On the other hand the same excellent authority affirms that $A$. crassicornis never endues itself with an extraneous covering, a habit which he notices as distinctive of A.coriacea. Now I generally find $\mathrm{my}$ specimens, which are abundant on this coast, covered with a coating of gravel, adhering to the warts, which however is soon thrown off in captivity. Mr. Couch's description too of $A$. cor. agrees closely with mine. I particularly notice, in the variety $I$ am about to describe, the thickened rim of the body outside the tentacles, which comes to a distinct edge all round, crenated with close-set, yet isolated, small white glandular knobs.

I have no doubt that the species is the $A$. coriacea of Rapp, and the A. gemmacea of Dalyell; but throughout this volume I have taken as my standard of nomenclature the Brit. Zooph. of Dr. Johnston, the second Edition.

A more common and still more beautiful variety has the body of a clear green, more or less inclined to olive, and profusely marked with crimson, arranged in longitudinal stripes of irregular form and size, varying from fine undulating lines to very broad bands; the whole presenting an appearance, especially when the tentacles are withdrawn, like that of some apples that are streaked with red. The warts are, as 
in the former case, clear bluish grey. The tentacles agree with those of the former variety, except that the redness has none of the purple element in it; it is moreover very faint, and is confined to an annular band, extending from the white ring about half-way to the tip.

The peristomatous disk is of the same rich red as the body; but the part from which the tentacles spring is pale pellucid glaucous, streaked with red. The streaks are convergent towards the centre, and for the most part embrace a tentacle, uniting both. behind and before its base; which produces a beantiful effect.

The changes of figure in this species when kept in captivity, are remarkably great and rapid. They are evidently effected by the admission of water into any part or the whole at will, and its ejection, or transmission from one part to another. Sometimes it appears vaselike with a small foot, above which there is a strong constriction, the whole of the body above being greatly tumid and diaphanous; then the animal will transmit the contained fluid into the foot, and the constriction is made to pass in quick succession all up the body, until it disappears at the margin of the oral disk, imparting the most curious gradations of form. At others it is greatly lengthened perpendicularly, being thick withal, cylindrical with an expanded top, or else with the top rounded, and perhaps the tentacles crowded, and just peeping forth.

Such then is one of the finest native examples of

The zoophyte,

That link which hinds Prometheus to his rock, The living fibre to insensate matter.

MONTGOMERY. 
THE PRAWN.

Beyond the chasm just described, we scramble into another, and come to a far larger and lower tide-pool, so low as to be separated from the sea only at spring-tides. It is about twenty-five feet long, and eight or ten wide, and is quite overshadowed by the dark rock, in a sort of cavern of which it lies. The great oar-weeds and tangles (Laminaria saccharina and digitata) have here room to attain their full size; and their rich brown fronds wave to and fro, or lie motionless in the clear water, often supporting whole forests of tiny zoophytes, such as Laomedea geniculata. All round the edges of the pool, from the water-line downwards, grow in luxuriance the large oval dark red fronds of the dulse (Iridcea edulis) and the more brilliant and more elegant Delesseria sanguinea, of which an American Poet has said,-

"The crimson-leaf of the dulse is seen

To blush like a banner bathed in slaughter ;"

and other minor sea-weeds, mostly of the red elass, are found in fine condition, some in and some out of the water.

Large Prawns swim at freedom through this large pool; and a very pleasing sight it is to watch them as they glide gracefully and equally along. The tailfans are widely dilated, rendering conspicuous the contrasted colours with which they are painted; the jaws are expanded, the feet hanging loosely beneath. Now one rises to the surface almost perpendicularly; 
then glides down towards the bottom, sweeping up again in a graceful curve. Now he examines the weeds, then shoots under the dark angles of the rock. As he comes up towards me, I stretch out my hand over the water; in an instant he shoots backwards a foot or so; then catching hold of a weed with his feet, and straddling its vertical edge, he remains motionless, gazing up at me with his large prominent eyes, as if in the utmost astonishment.

This Prawn, that comes to our tables decked out and penetrated, as it were, with a delicate, pellucid, rosecolour, beautiful as he is then, is far more beautiful when just netted from the bottom, or from the overhanging weed-grown side, of some dark pool. If you happen never to have seen him in this state, let me introduce him to you. Form and dimensions of course you are acquainted with; these do not change, but I will just observe that it is a "sizeable" fellow that is now before me, whose portrait I am going to take. Stand still, you beauty! and don't shoot round and round the jar in that retrograde fashion, when I want to jot down your elegant lineaments! There, now he is quiet! quiet but watchful! maintaining a sort of armed neutrality, with extended eyes, antennæ stretching perpendicularly upwards, claws held out divergently with open pincers ready to seize, as if those slender things could do me any harm, and feet and expanded tail prepared in a twinkling to dart backward on the least alarm.

Look then at his cephalo-thorax, or what you would perhaps call the head, the cylindrical shield that you would pick off as the first essay towards eating 
him. Its ground colour is a greenish grey, but so translucent that we can hardly assign any hue-proper to it. This is marked with several stripes of rich deep brown, running longitudinally, each stripe being edged with buff. Then the body, or more correctly the abdomen, is marked with about a dozen stripes of similar colour, but set transversely, girding the segments round with a series of dark lines; and the last segment before the setting on of the tail-fins has three lines running lengthwise again.

Now we come to the tail. But here the pen fails: only the pencil could convey an adequate idea of this exquisitely painted organ. The four oval plates, that play over each other, and that form a broad and powerful fin when expanded, are bordered with a pale red band: the outer pair have in the centre a red spot, the inner pair a streak of the same hue; each plate has near its extremity a spot of cream-white (much larger on the outer pair) made more conspicuous by being broadly margined by reddish brown. Finally the plates are studded all over with red specks, which when magnified are seen to be stars. Besides these colours, there are scattered over the body in symmetrical order, several spots of opaque cream white, and some of pale chesnut or fawn-brown. And to close this enumeration of colours, the claws and feet are light blue, encircled at regular distances by bands, of which half is deep purple and the other half pale orange. I have not spoken of the fringes of the jaw-plates, nor of those that terminate the tail-fin, but the structure of these is exquisitely fine, especially when examined with a lens. 
To add to these beauties there is seen in certain lights a rich flush of iridescent purple reflected from the whole surface of the animal.

A few hours' captivity changes all this, and the Priwn, though it does not appear to have suffered in health or vigour, has put on a most quakerly sobriety of colour, all the fine bands and stripes and spots having become so pale as to be scarcely distinguishable from the general pellucid olive hue of the body.

I cannot tell how this loss of colour is effected; but I have reason to think that light, the great agent in producing colour in most cases, is the cause. I took two specimens just dipped from a deep pool, and equal in the richness of their contrasted colours; one of these I placed in a large glass rase of sea-water that stood on my study-table; the other in a similar vase shut up in a dark closet. In twenty-four hours the one that had been exposed to the light had taken on the pale appearance just alluded to ; the one that had been in darkness had scarcely lost any of the richness of its bands and stripes, though the general olive hue of the body had become darker, and of a browner tint. This individual, however, assumed the appearance of the former, before it had been an hour emancipated from its dark closet. Without attempting to account for the phenomenon, I would just advert to the parallel exhibited by the sea-weeds. The brilliant colours displayed by many of these exist, as is well known, in the greatest perfection, when the plants grow at considerable depths, or in the caves and holes of the rocks, where light can but very dimly penetrate. Some of these will not grow 
at all in shallow water or in a full light; and those that can bear such circumstances are commonly affected by them in a very marked degree,-marked by the degeneracy of their forms, and by the loss of their brilliancy of colour. The Prawn, as I have already hinted, delights in the obscurity of deep holes and rocky pools; it is here alone that his fine zebra-like colours are developed. When taken in shallow pools, he is of the plain pale-olive tint of the specimen that had spent four-and-twenty hours on my table. 


\section{CHAPTER III.}

A Visit to Brixham-The Road-Character of the Coast-Berry Castle-Legends-Brixham-Coast Scenery-Animals of the Shore-The Painted Scallop-Its Beauty-Mantle--Tentacles -Gem-like Eyes-Climbing Powers-Leaps-Mode of performing these misunderstood-Explanation-Functions and Structure of the Eyes-Structure of the Gills-Ciliary Action -Beauty of the Phenomenon-Oddicombe Rock-pool-Its Form-Contents-The Feather-star-Its Habits in CaptivityReproduction of its Limbs-Watcombe-Romantic Scenery Sandstone Cliffs-The Sea Lemon-The Purple Dye-Mode of applying it-Changes of Colour-Tor Abbey Sands-Shore Animals-The Pholas-Its Siphons-Their Use, Structure and Currents-Curious Contrivance-Anstey's Cove-View from Babbicombe Downs-Skylark's Song-Precipice of Limestone-A bundance of Animals-Pleurobranchus.

On a fine morning near the middle of March I walked to Torquay Station, and took my seat on the box of the omnibus for Brixham. I wanted to see what advantages the place might present for a temporary settlement, what rents were, what sort of a coast it was zoologically, and so forth. The road was pleasant, or rather would have been, if it had not been so bitterly cold; but the wind had been for many weeks, was then, and was destined to continue, most pertinaciously at East, and it blew right upon the shore, along which the way lay for a great part of the distance.

Long beaches of sand and shingle, the Tor Abbey, the Livermead, and the Paignton Sands, divided by 
low but perpendicular cliffs of red conglomerate, often underworn and sometimes insular, jutting out in bold headlands,-are characteristic of the shore hereabout, till we arrive at Paignton; a variety of coast which cannot but be productive to the littoral naturalist, especially as the receding tide lays bare an ample area of low sandstone, hollowed into thousands of tidepools.

My fellow passenger was a legal gentleman from town, revisiting Brixham after an absence of twenty years, intelligent and facetious; Coachey was communicative and confidential; and by and by, as the sun came out, and we turned off into the sheltered road from Paignton onward, under the lee of high hedges, we began to find it not so dreary after all.

The songs of birds came from the groves, mellow and cheery, though spring had not yet thought of beginning to deck with leaves their naked bowers. How delightful is the voice of a singing bird! how it soothes the mind, and fills it with pleasant emotions!

'Tis sweet in solitude to hear' The earliest music of the year,

The Blackbird's loud wild note;

Or, from the wintry thicket drear,

The Thrush's stamm'ring throat.

In rustic solitude 'tis sweet

The earliest flowers of spring to greet,-

The violet from its tomb,

The strawberry, creeping at our feet,

The sorrel's simple bloom.

Montgonery.

The ruined castle of Berry, standing about three 
miles on the right hand of the road gave occasion to discuss the legendary history of the Pomeroy family to whom it belonged. In particular, the story of that redoubtable Baron who slew the King's herald sent to arrest him for high treason; who then gained possession of the Monastery on St. Michael's Mount by assuming the disguise of a monk, and who caused himself to be bled to death when unable longer to maintain it against the royal forces. And the romance of his two sons, who rather than yield their castle to be dismantled, leaped on horse-back from the precipice on which it was built.

The little town of Brixham, pretty as it appears when viewed from Torquay, is but a sordid affair when you see it at hand. The lower town particularly is close, mean, and dirty ; indeed, truth to tell, I saw refinements in filth here, which I had never the fortune to see parallelled in all my wanderings. The place looked, with some exceptions, pretty much as one may suppose it to have looked in the days of the Plantagenets or the Stuarts, stationary, when all around is advancing. "Fast place this!" said my fellow traveller of the morning, with an arch leer, as he saw me resume my place on the box to return, after the day's exploration.

The scenery on either hand, when once clear of the harbour, is bold and magnificent. The coast is rocky and precipitous, (the town itself appears strangely stuck upon precipices, reaching from top to bottom) and is indented with little coves, the most picturesque imaginable. Berry Head, a noble promontory of compact limestone, rears its lofty head 
abruptly out of the sea not far from the town, and forms a commanding boundary of the prospect, conspicuous all around.

I did not obtain much in the way of naturit history on the shore, except what I was already familiar with at Petit Tor. Under the large stones at low water Trochus ziziphimus was numerous, " handsome shell, very regularly conical, and marken. with triangular spots of purple on a grey ground The animal also is handsomely coloured, the foot being pale orange, somewhat like the flesh of a melon, spotted and freckled above with dark brown. Hundreds of tiny crimson warts were projecting from the face of the slimy overarching rock, each of which when touched disappeared, and left to mark the spot only the orifice of a minute hole. This was the siphon of Saxicava rugosa, a little bivalve shell, the animal of which is endowed with the power of boring holes in the hardest limestone. And under the flat stones I obtained two or three small specimens of that beautiful scallop, Pecten opercularis, which is taken in great abundance with the dredge oft this harbour. I came home with little desire to see Brixham again.

\section{THE PAINTED SCALLOP.}

I have before me a small specimen of Pecten opercularis, which I have kept for some dars in a glass phial of sea-water. The transparency of the ressel enables me to observe it and to watch its motions with advantage. An object of unwonted beauty indeed it is. Its ordinary condition is to lie with its valves 
separated to the distance of about one-sixth of an inch. In this state I will describe it. The open space is occupied by what seems a fleshy cushion, extending from one valve to the other all round, but just within their edge. It is of a delicate flesh-colour, with mottlings of dark brown, making a kind of irregular pattern with transverse bands; a close examination, however, shews that this substance is divided into two parts; for when the animal is quite at ease, it is seen to gape, with a fissure parallel to the valves, widely enough to give us a peep into the internal structure. This is, in fact, the mantle, of which these two parts are the thick and glandular edges. Around its circumference, on each portion, just where it is in contact with the valve, there are set a great number of tentacles,-delicate thread-like organs, tapering to a fine point, and of a pellucid white appearance; they are capable of being protruded and retracted at the will of the animal; I have occasionally seen some of them extended to a length equal to the diameter of the shell. They are more commonly contracted to about one-fourth of that length, or even much less, with the points curled up; but frequently the animal protrudes them to their utmost extent, bending them back above the edges of the shell, and waving them slowly in every direction. Sometimes one or two only are protruded, and the others kept short. Along the very edge of each division of the mantle, bordering the fissure, is another row of similar tentacles, smaller in their dimensions. But the most beautiful feature of this animal is yet to be described. In the line of the 
larger tentacles, and alternating with them, is seen a row of minute circular points, of high refractive power, possessing all the brilliancy of precious stones. They look indeed like diamonds of the first water, each set in a ring or socket of black substance, which greatly enhances their beauty. They are about half as numerous again as the radiating grooves of the shell; but are not set with perfect regularity. They are still less uniform in size, some having a diameter twice as great as others. These are believed to be eyes, and certainly they are well placed for enabling the animal to watch the world around it. It is very sensitive, withdrawing its tentacles and mantle, and bringing the valres of its shell together, on any shock being given to the ressel in which it is kept. I observe, however, that it will not actually close the valves, unless it be repeatedly disturbed, or unless the shock be violent; contenting itself with narrowing the opening to the smallest space appreciable; yet even then the two rows of gem-like eyes are distinctly visible, peering out from the almost closed shell; the two appearing like one undulating row from the closeness of their contiguity. Those who are familiar with the pincushions, so frequently made between the valves of these very Scallop shells, can hardly fail to be struck with the resemblance borne by the living animal to its homely but useful substitute; and the beautiful eyes themselves might be readily mistaken for two rows of diamond-headed pins, carefully and regularly stuck along the two edges of the pincushion. A friend, to whom I showed it when nearly closed, compared. 
it not unaptly to a lady's ring set with small brilliants.

My attention was attracted to the Pecten by this curious circumstance; that it was adhering by one valve (the flat one) to the side of the glass phial, at some distance from the bottom. On close examination with a lens, I discovered that it was attached by a very delicate byssus. Curious to ascertain how it contrived to mount from the bottom to this position, I tonched it slightly, and caused it to loose its hold. In the course of half an hour I found that it had resumed the same position again. I again disturbed it, and began to watch its motions. It was lying with the convex valve downwards on the bottom of the phial. The first thing I observed was the thrusting forth of the delicate little foot, an organ which seemed to me appropriately named, when I marked its close resemblance in form to a human foot and leg, enveloped in a white stocking. What I may call the sole of this tiny foot was pressed against the side of the glass, feeling abont from place to place; while with the lens I could distinctly see, in the part corresponding to the toe, the opening of the fleshy lips, or sides of the grooves, in which the threads of byssus are said to be formed. While it was thus engaged my surprise was excited by seeing it suddenly throw itself with a jerk into an upright position; but the action was too startling to enable me to see how it was performed. I again laid it prone, and though for a moment it closed the valves, it presently opened them again, and performed a similar feat. This was followed by several leaps in different directions, in quick succession; 
but I was still at a loss to know the modus operandi. It appeared to me certain, that the ordinary supposition, viz., that the action is performed by the vigorous opening and shutting of the valves, was not the correct one. At length a farourable observation gave me a suspicion of the truth. I perceived the lips of the mantle, (which were held in contact, though the valves were considerably separated,) suddenly open to a partial extent, as if by a blowing from within. At this instain there was a leap in the opposite direction, attended with a considerable agitation in the water. With this che, I observed more definitely. Having rendered the water a little turbid, in order the more distinctly to see any motion of the particles suspended in it, several leaps confirmed the notion that had suggested itself to me. The mode of proceeding is as follows: when the Pecten is about to leap, it draws in as much water as it can contain within the mantle, while the lips are held firmly in contact. At this instant the united edges of the lips are slightly drawn inward, and this action gives sure warning of the coming leap. The moment after this is observed, the animal, doubtless by muscular contraction, exerts a strong force upon the contained water, while it relaxes the forced contact of the lips at any point of the circumference, according to its pleasure. The result is, the forcible ejection of a jet of water, from that point; which, by the resilience of its impact upon the surrounding fluid, throws the animal in the opposite direction, with a force proportioned to that of the jet d'eau. The action may be well imitated by the human mouth blowing a stream of air from any determined 
point, while the lips are held firmly together at all other points. The resemblance, indeed, of the mantle to the human lips performing such an action, (a resemblance perhaps more close than flattering) struck me as ludicrously faithful. Nor was the appearance less suggestive of a pair of bellows withont a nose, of which the valves were the covers, and the mantle the leathers, discharging their contents from any part of their sides.

That the Pecten widely opens and forcibly closes its valves, if left uncovered by the water, is doubtless correct; I have seen my specimen perform such an action, and perhaps it might by such means jerk itself from place to place with considerable agility. But I do not think so rude a mode of progression could enable it to select the direction of its leaps, which under water appears to me to be determined with accurate precision.

I observed also a fact which appeared confirmatory of the supposition that the brilliant points among the tentacles are organs of vision; viz., that in the ordinary state of expansion, and when about to make these quick movements, the gem-like points are so situated as just to project beyond the margin of the shell. So that when the latter is viewed perpendicularly, the eye of the beholder looking down upon its convexity, the minute points are seen, all round its circumference, just, and but just, peeping from under its edge. It is clear that if they are eyes, this secures to them the widest range of vision with the least possible exposure.

The death of my little Pecten gave me the opportunity of submitting some of the gemmeous specks to 
the microscope. With a power of 220 diameters, I distinctly perceived a large lens, a glassy coat investing this, which itself was buried for more than half its rolume in an investiture apparently granular of a yellowish brown colour, having an ill-defined circle near its anterior side, of a blackish hue. Uniter pressure with the compressorium, the lens was manifestly circular; the coloured socket discharged dark granules, and from the darkest part a deep crimson pigment, which did not appear to be granular (See Plate III. fig. 5.)

I submitted portions of the gills also to the same magnifying power. Each of the four laminæ consists of a rast number of straight slender transparent filaments, evidently tubular, and about $\frac{1}{1500}$ th of an inch in diameter, arranged side by side; or rather of one filument, excessively long, reverted upon itself again and again, at both the free and the attached end of the laminæ, throughout its whole extent. This repeated filament is armed on each of two opposite sides with a line of ribrating cilia, the two lines moving in contrary directions; by the action of which a current of water is made continually to flow up and down each of these delicate filaments; so that the blood which cireulates in their interior (for they are doubtless blood-vessels) is continually exposed throughout this its long and tortuous course to the action of oxygen.

Like all organic functions, the action of these cilia is not under the will of the animal. It is said that if during life a small portion of the gills be cut off, the motion of the cilia will convey the fragment swiftly away, 
with a smooth easy motion, through the surrounding fluid, in a definite direction. It does not cease even with the life of the animal. The specimen which I examined had been dead at least fifteen hours, yet when I placed the torn fragments of the branchiæ, one after another, beneath the microscope, the energy of the ciliary action, as the wave flowed with uniform regularity up one side and down the other of every filament, filled me with astonishment. Even the next morning, twenty-six hours after death, when the tissues of the filaments were partially dissolved, the ciliary motion was still going on, on portions that preserved their integrity.

Surely, when a Christian naturalist examines the more recondite anatomy, not of the human body merely, but of any, even the lowest, forms of animal being, he is constrained to say with the Psalmist, "I will praise Thee; for [all is] fearfully and wonderfully made: marvellous are thy works, and that my soul knoweth right well!"

ODDICOMBE ROCK-POOL.

I took another look at my pretty little rock-basin at Oddicombe. It is a deep, oval, cup-like cavity, about a yard wide in the longest diameter, and of the same depth, hewn out, as it were, from the solid limestone, with as clean a surface, as if a stone-mason had been at work there. It is always, of course, full of water, and, except when a heavy sea is rolling in, of brilliant clearness. All round the margin are growing tufts of the common Coralline, forming a whitish 
bushy fringe, reaching from the edge to about six inches down: a few plants of the Bladter Fucus are scattered around and above the brim; and the arching fronds of the Sweet Laminaria, that I before spoke of, hang down nearly to the bottom, closely resembling, except in their deep-brown hue, the hart's tongue fern that so profusely adorns the sides of our green lanes. Below the Coralline level are a few small red sea-weeds, as Rhodymenia palmata; and the dark purple Chondrus crispus growing in fine tufts reflecting a rich steel-blue iridescence. But all the lower parts of the sides and the bottom are almost quite free from sea-weeds, with the exception of a small Ulia or two, and a few incrusting patehes of the Coralline-base, not yet shot up into branches, but resembling smooth pink lichens. The smooth surface of the roek in these lower parts is quite clean, so that there is nothing to intercept the sight of the Actinice, that project from the hollows, and spread out their broad circular disks like flat blossoms adhering to the face of the interior. There are many of these, all of the species $A$. bellis, and all of the dark chocolate variety, streaked with scarlet; and they are fine in the ratio of the depth at which they live; one at the very bottom is fully three inches in diameter.

There is something exceedingly charming in such a natural virarium as this. When I go down on $\mathrm{my}$ knees upon the rocky margin, and bring my face nearly close to the water, the whole interior is distinctly visible. The various forms and beautiful tints of the sea-rreeds, especially the purple flush of the Chondrus, are well worthy of admiration; and I can 
see the little shrimps and other Crustacea busily swimming from weed to weed, or pursuing their instinctive occupations among the fronds and branches, - an ample forest to them. Tiny fishes of the Blenny genus are also hiding under the shadow of the tufts, and occasionally darting out with quivering tail; and one or two Brittlestars are deliberately crawling about, by means of their five long and flexible arms, in a manner that seems a ludicrous caricature of a man climbing up by his hands and feet,-only you must suppose an additional arm growing from the top of his head. The variety of their colours, and the singular but always elegant patterns in which they are arranged, render these little star-fishes attractive.

Such a calm clear little well as this, among the rugged rocks, stored with animal and vegetable life, is an object well calculated to attract a poet's fancy. The following description must have been drawn from just such a rock-pool, and most true to nature it is.

In hollows of the tide-worn reef, Left at low water glistening in the sun, Pellucid pools, and rocks in miniature, With their small fry of fishes, crusted shells, Rich mosses, tree-like sea-weed, sparkling pebbles, Enchant the eye, and tempt the eager hand, To violate the fairy paradise,

Moxtgonery.

THE FEATHER-STAR.

At Petit Tor in March I found, adhering to the under side of a rough stone, a fine specimen of the Rosy Feather-star. It was of the size of Prof. Forbes' 
figure, but was much more beautiful than I had supposed, eren from that representation. It was marked all over with alternate bands or patches of erimson and yellow, not very regularly; the latter colour studded with red dots. The larger dorsal filaments were thirty, the smaller, I think only two or three. The pinnæ were forty (not 34 ) on ench side of each arm. I saw the hooked claws of the larger filaments, but could not make out the points of the pinnæ.

In eaptivity the Feather-star sits upon the firond of a Sea-weed, or on a projecting angle of rock, which it grasps very firmly with its clawed filaments; so firmly that it is difficult to tear it from its hold. When violence is used, it catches hold of its support or any other object within reach, with the tips of its arms, which it hooks down for the purpose, and with its pinnæ, so that it seems furnished with so many claws, the hard stony nature of which is revealed by the creaking, scratching noise they make as they are forced from any hold, as if they were made of glass. I was surprised to observe that sereral of the arms were unsymmetrically short; and examining these with a lens, saw distinctly that each had been broken off and was renewed; the new part agreeing in structure and colour with the rest, but the joints were much less in diameter; and this difference was strongly marked at the point of union, the first of the new joints being not more than one-third as wide as its predecessor. The appearance much reminded me of a Lizard renewing its tail.

In sitting, the Feather-star bends its arms with a 
sigmoid curve, the tips bending upward. It waves them now and then, but not much; and remains long without moving from its hold. Though I repeatedly took it ont of water, removing it forcibly, it manifested no tendency to voluntary dislocation.

\section{WATCOMBE.}

One of the most wildly romantic scenes in this neighbourhood is Watcombe, about a mile from Marychurch, on the Teignmonth road. A narrow lane, muddy from a little streamlet that oozes down it, but fringed with primroses and violets, leads off from the highway on the right, and presently opens a magnificent prospect of the sea, with a handsome villa just in front in the midst of ornamental grounds. A step or two farther, and we are on a large area of broken ground, most irregular and uneven, but covered with the fine close turf, peculiar to downs, on which the sheep are tranquilly grazing. On the left, rise abruptly from the turf, perpendicular cliffs of red sand-stone of stupendous height, their summits clothed with turf and thickets of furze; so angular and uniform are they that they look like the ruined walls of some Cyclopean castle. The place is formed by what geologists call a fault, the ground having at some period fallen in from the higher to the lower level, a catastrophe which explains the uneven character of the down, the hills and vales, the chasms and pits, that are so remarkable here.

The fault,-which is certainly one that we cannot very harshly blame, since its effect is so beautiful,- 
is still at a great elevation abore the sea-level; and when we have made our way to its sea-ward margin, and look down upon the pebbly beach, we find that we can reach it only by a narrow zigzag path, or almost a succession of narrow steps, so steep and hazardous that the utmost circumspection is necessary to descend it with safety.

Once down, we can walk along the rough platforms and ledges of sandstone that extend along at the foot of the lofty cliffs towards the north from the cove. The strata form narrow shelves with sharp edges, sufficiently level to be traversed without difficulty, but gradually rising from the horizontal, so that we cannot pursue any given stratum beyond a short distance, as we find it carrying us too far above the sea, but must successively descend to lower ones.

In the crevices and shallow pools of the ledges between tide-marks I observed numerous colonies of Actinia bellis, a variety more than usually pied with white on a dark ground: and the fine A. crassicornis was common in the darker fissures. It was here that I saw for the first time the largest of our naked-gilled Mollusca, the Sea Lemon, Doris tuberculata. It was lying in a narrow horizontal shelf under the shadow of a rock, whence it had doubtless fallen after it had been forsaken by the tide. My first momentary impression was that a large limpet had been extracted from its shell and thrown there to die, but an instant's examination told me what it was. I carried it to a shallow pool and threw it in; and presently it turned itself on its foot, and protruding its two curiously-ribbed tentacles from their holes, began to glide along 
the bottom, expanding, as it proceeded, its beautiful starry flower of branchix in the centre of its back. When this and the horns are concealed, the animal bears a curious resemblance in size, form, colour and warty surface to the half of a lemon, divided longitudidinally.

THE PURPLE DYE.

These two days past I have been experimenting on the dye of Purpura lapillus. Hundreds of this shell may be seen adhering to the rocks between tide-marks, some quite white, or discoloured only with age, while others, (frequently all found in one particular locality) are rather prettily marked with three broad bands of yellow or brown, running spirally round the whorls. The latter variety is much more furrowed than the white variety, and the bands of colour are often divided into several narrow lines separated by the ridges. The inner part of the mouth, especially in old specimens, is often tinged with purple, which may help an uninitiated observer to identify the species. They congregate together, and you may easily collect, at low-water, as many as you please. The best way to kill them that I know is to break the shell to pieces with a hammer, moderating the blow eautiously, so as not to erush the soft animal, and then, having shaken off the fragments, throw it into a basin of cold fresh-water, in which the creature presently dies. With the shell unbroken, I find it has the power of resisting the action of fresh-water for a time far longer than would be fatal to many marine Gasteropoda; for some that 
I placed in a basin of fresh-water, proved to be quite uninjured when I broke the shells eighteen hours afterwards, as was seen by their forcible contraction when divested of their shelly covering. Doubtless this power of resisting the action of fresh-water consists in the close-fitting opereulum, which is forcibly drawn in under the stimulus, so as to keep the water perfectly out.

When the animals appear dead, examine them for a ressel of yellow or cream-coloured matter, that runs diagonally across the body, behind that projecting veil under which the tentacles retire when contracted. It is sufficiently conspicuous, flat, somewhat wrinkled, as if not quite full, with one margin blackish. Insert into the membrane, which is very tender, the point of a sharp pair of scissors, or a needle, and open the vein, which you will find filled with a substance exactly resembling in colour and consistence the pus or matter formed in a boil. You will not find much; that of a large Purpura I managed to spread over a space of calico as large as a shilling. From its viscid consistence it is difficult to use with a pen, and I do not know how it may be uniformly diluted; but with a small camel's-hair pencil I have used it with much more facility.

As soon as the matter is applied to the linen, its hue is a rich "King's yellow," but becomes in a few minutes a delicate pea-green. In about an hour, if the weather be cloudy, it has become a yellow grass-green, firom which it slowly and imperceptibly turns to a blue green, thence to indigo, and thence to blue. A red tinge now becomes apparent, generally in parts, caus- 
ing the hue to become first violet, then a purple more and more tinged with red, till at length, after five or six hours (in a room without direct sun-light) it assumes its final tint, a rather dull purplish crimson, or lake. The direct beams of the sun, however, greatly expedite the process, and at any stage will carry the remaining stages through to completion in a few minutes.

TOR ABBEY SANDS.

Off the Tor Abbey sands and headland, the receding tide leaves bare a large surface of rock, chiefly sandstone and conglomerate. Little shallow pools occur abundantly, filled with Alga of various species, among which colonies of Anthea cereus, of both the grey and the green varieties, are common. The soft sandstone is inhabited by Pholas dactylus, and Ph. parva; the orifices of whose burrows reveal their secret; the first stroke of the hammer on the stone causes the animal to contract in alarm, and the result is an instant ejection of a slender jet of clear water from the hole, to the distance of several inches.

Under loose stones I found Doris bilamellata numerous, four, five and six under one stone, mostly spawning; one specimen of the blackish-grey variety of D. pilosa occurred among them. The soft spongy texture of the cloak in this species gives it a character very different from that of the former. In the same situations also I found several of the pretty little Gibbous Starlet (Asterina gibliosa;) also the young of Truchus ziziphinus, and a lump of rock covered with 
living Serpule, the expansions of whose fans in captivity, and the use of the stoppers,-were highly amusing.

\section{PHOLAS DACTYLUS.}

The respiration of many of the bivalve mollusea is effected by means of a siphon, the two extremities of which are situated close together, and are often united so as at first to appear but one tube. A glance at the very tip, however, even in this case, shews that there are two openings, one of which is a little smaller than the other, and commonly this subordinate orifice diverges at a slight angle from the principal one. The latter is the entrance, the former the exit for the water, a perpetual change of which is absolutely indispensable to the life of the animal. The interior of these tubes is said to be lined wirh innu merable delicate cilia; by the action of which the surrounding water is drawn towards the entering orifice, and conveyed in a strong current through the tube over the surface of the gills. Then, having been deprived of its oxygen, it is ponred through the other tube and expelled in a jet at its extremity, by a similar machinery.

This apparatus of double siphonal tubes is principally developed in those species which burrow, whether in sand, mud, wood or stone. As the burrowing bivalve usually, if not always, dwells in the interior of the passage it has excarated, it is needful that there should be a communication with the external water, and hence a hole is always found extending to the surface of the material bored. The entering 
and departing currents keep this passage clear, a process which in mud or sand might seem at first not very easy of accomplishment. It is facilitated, however, by the faculty which the boring bivalves have of lengthening the siphonal tubes at will; and the degree to which this may be accomplished depends on the depth of the cavity which the species is accustomed to make.

If we take one of the stone-boring Mollusca, a Pholas or a Saxicava for example, from its excavation, without injuring the animal, and place it in a glass ressel of sea-water, it will not be difficult to detect the currents in question, even with the naked eye; though a lens of moderate power will render them more distinctly appreciable. The ressel should be so placed as that the light may be nearly, but not exactly, opposite to the eye. By this arrangement the minute atoms of floating matter are illuminated while the back-ground is dark, and these by their motion clearly reveal the currents of the fluid in which they are suspended. A few moments' practice will enable even an unaccustomed eye to perceive the atoms converging from all points around, with an even but increasing velocity, towards the principal tube, down which they disappear like the streams of passengers and traffic in the neighbourhood of a great city, converging towards it as to a common centre of attraction by a hundred different routes. The current of the expelling tube is even still more marked in its character; a forcible jet of water is continuously ejected from this orifice, which draws the surrounding particles into its vortex, and shoots them forward to a 
distance of many inches. It is by the expulsive force of this anal current, chiefly, that the passage is kept free from the deposit of mud and other substances, which would otherwise soon choke it up.

A fresh supply of water for respiration, and its dismissal when no longer fit for use, are efficiently provided for by this contrivance, But since many particles of matter float in the water, which from their form or other qualities, might be hurtful to the delicate tissues of the viscera to be traversed, how is the entrance of these to be guarded against in an indiscriminating current? A beautiful contrivance is provided for this necessity. The margin of the entering siphon, and sometimes, though more rarely, of the ejecting one, is set round with a number of short tentacular processes, varying indeed in their length, but the longest scarcely more than equalling half the diameter of the month of the tube. In Saxicara rugosa, which bores through and through, with small holes, the hardest limestone of our coast, these tentacular appendages are found fringing both the tubes. The tentacles in this species are simple, and appear as if cut off transversely; and some are not more than half as long as the others, with which they irregularly alternate. The object of this diversity in length, will be manifested presently. In Pholas parva, the processes are few and short, and are confined to the receiving tube, from the interior margin of which they project, towards the centre. But it is in Pholas dactylus, a noble species of large size that excavates the softer rocks on our shores, that this apparatus is developed with peculiar beauty, and its 
use is made most clearly manifest. The tentacular filaments are in this case also confined to the oral tube. They are numerous, each forming a little tree, with pinnate branches, bearing no small resemblance to the flower of feathery branchiæ, that expands around the mouth of a Holothuria. These branched tentacula are ordinarily bent down across the mouth of the tube, the longest of them just meeting in the centre; alternating with these are placed others of similar structure, but inferior size; and the interspaces are occupied by others smaller still, and simply pinnate; so that when the whole occupy their ordinary transverse position, the small ones fill up the angles of the larger, and the branches of all form a net-work of exquisite tracery, spread across the orifice, through the interstices or meshes of which the current of entering water freely percolates, while they exclude all except the most minute floating atoms of extraneous matter. The accompanying figure, which I have drawn from a fine specimen of Pholas dactylus just obtained from the submerged sandstone at Tor Abbey, and at this moment receiving and ejecting its currents in my glass jar, as placidly as if it were still ensconced in its own quiet hole, will give some idea of the form of this tentacular net, a portion only of which is here given, that the ramification may be seen with greater clearness. (See Plate II. fig. 7.)

(P. S.) After a while, these beautiful organs lost their elegance, and shrank up into thick wart-like bodies, merely digitated at their tips, in which, if I had not personally, so to speak, known the individual 


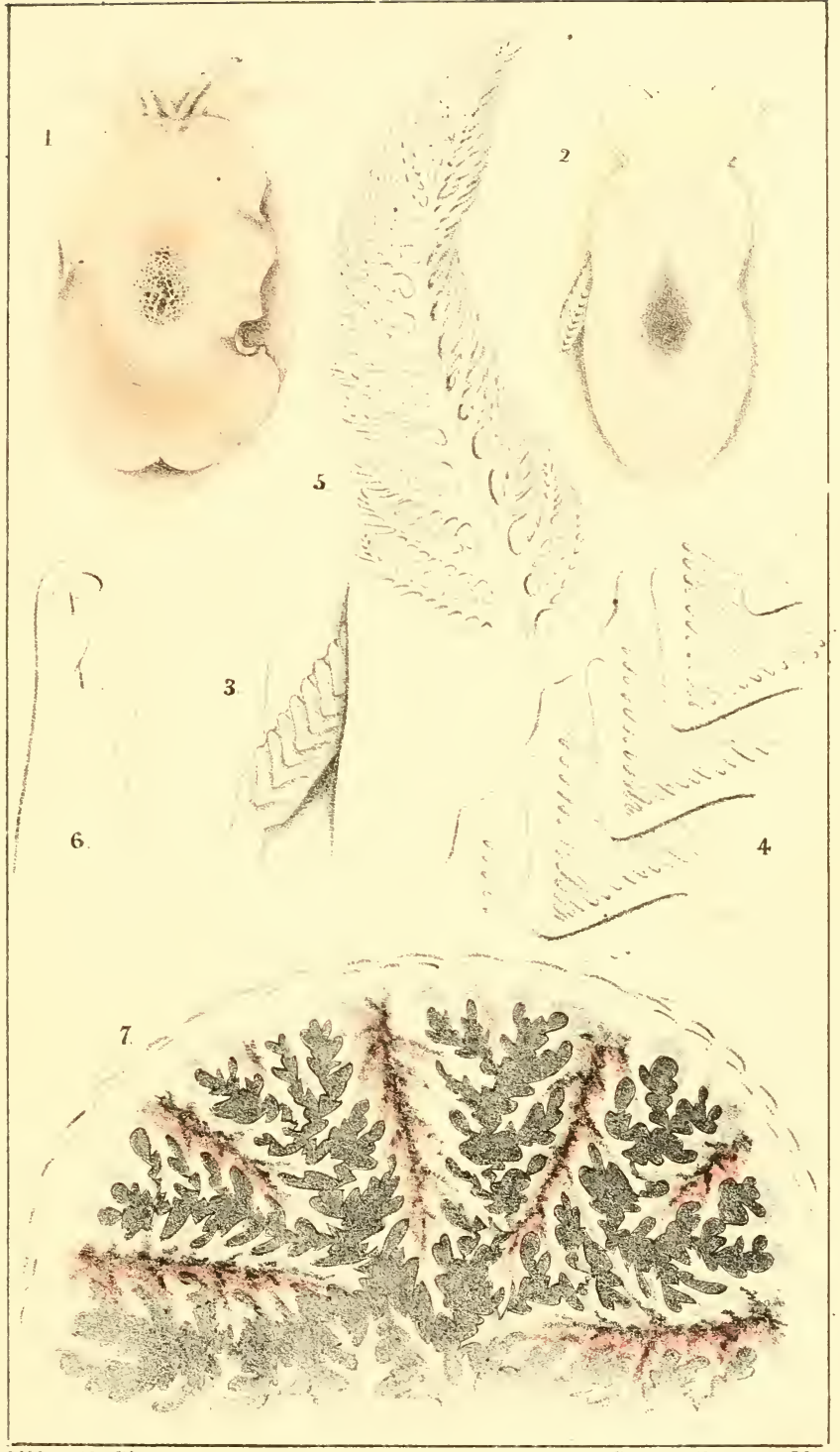

H Gosise de? et in $\mathrm{H}_{2}$

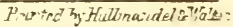

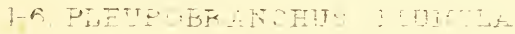

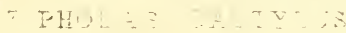



animal, I should not have been able to trace any resemblance to the ramified trees that had at first guarded the orifice. It would appear therefore that they are to be seen in perfection only when the Pholas is in high health, and newly taken from its rock.

This contrivance, or rather this series of contrivances, for the health and comfort of a poor shell-fish that spends its whole life buried in a sepulchre of stone, may seem to some but an insignificant matter. But it strikes my mind with power as an example of the beneficent care of God over all his creatures, and of the infinite resources of Divine wisdom in which creation has been planned and executed. And so far from the meanness of the object on which such care is bestowed rendering it less worthy of remark, that very circumstance ought to enhance our admiration. It seems less difficult to conceive of the tender beneficence of God exercised towards an angel, or towards man who was made in his own image; but that the Mind of the High and Lofty One that inhabiteth eternity should occupy itself about the feelings of such a worm as this, is marvellous indeed! It is one of those innumerable examples that occur to the Christian philosopher, in which " the invisible things of Him from the creation of the world are clearly seen, being understood by the things that are made, even his eternal power and Godhead."

ANSTEY'S COVE.

April 6th. A lovely spring morning; one of those that make one say with the Royal Poet of Israel, "Lo, 
the winter is past, the rain is over and gone; the flowers appear on the earth ; the time of the singing of birds is come; and the voice of the turtle is lieard in our land." I took my basket of collecting jar's, my hammer and chisel, in $\mathrm{my}$ hand, and determined to explore some of the rocky coves that I had not yet visited, for it was spring-tide. It is a favourable circumstance for the littoral naturalist on the Devonshire coast, that lowest water on the days of spring-tide is near the middle of the day. This is a point that should be attended to in selecting a site for such researches, as in some places the lowest water might occur at a much less convenient hour of the day. At Margate, at Portsmouth, and at Whitehaven for example, it is about six o'clock in the morning and evening on the days of new and full moon.

It was exhilarating to walk over the lofty Babbicombe Downs, and gaze out upon the wide expanse of sea, its sparkling azure speckled over with ships and boats whose white sails gleamed brilliantly beneath the rays of the mounting sun.

There lie the ships,

Their sails all loose, their streamers rolling out With sinuous flow and swell, like water-snakes, Curling aloft ; the waves are gay with boats, Pinnace and barge and eoracle ; - the sea Swarms like the shore with life. O what a sight Of beauty !

Southex.

There was breeze enough to raise up a curling ripple fringed here and there with a foaming mantle, and to mark with a long line of white the foot of the red cliffs 
that receded away to the northward. Beautiful these looked in their bold fantastic forms, as they receded, headland after headland, from the palpable grandeur of those close at hand to the hazy indistinctness of those a dozen miles off; the ruddy hue gradually and insensibly changing into the clear decided blue of the distant line of coast. The handsome white villas above Petit Tor and Watcombe reflected the sun, as did presently the houses of Teignmonth, and its conspicuous church-tower, just opening behind a projecting cliff; and on the blue shore across the broadlyincurved bay, the terraces of Exmonth were singularly distinct. The little hamlet of Babbicombe was behind, and below my feet were the gardens and shrubberies of several villas, the trees and bushes in which were just beginuing to burst their leaf-buds. I did not hear the voice of the turtle, it is true,-it had hardly as yet arrired - but the carol of the lark was blithely pouring forth, "at Hearen's gate," as Shakspeare says, far above even these elevated cliffs. Far up, far up, higher and higher into the radiant dazzling sky he soars, and still he struggles up and up, till the watering eye can with difficulty find the tiny speck,yet his beart all the while is down in some humble tussock of grass.

" Wild is thy lay, and loud,

Far in the downy cloud,

Love gives it energy, love gave it birth :

Where on thy dewy wing,

Where art thou journeying?

Thy lay is in heaven, thy love is on earth."

HoGG.

The very loftiest part of the down terminates in an 
abrupt precipice of compact limestone, which has been quarried away for some distance inland, leaving only the flat base like a stone-cutter's yard a little above the water's edge, to mark where the cliff formerly reached. Alongside of this base, as at a natural pier, craft of considerable size lie, and receive their cargoes of the quarried marble, and one or more may commonly be seen here. I inquired of a quarryman if there were any practicable access to this platform, but found there was none but a narrow and precarious path from the summit, available only to the practised feet of the stone-workers. Nor can they always tread it with impunity; he mentioned a quarryman who was lately dashed to pieces by falling from near the summit although he had been nearly fifty years in the occupation.

This abrupt head forms one boundary of Anstey's Cove, a favourite resort of Torquay visitors, and a very picturesque scene. A beach of pebbles of snowy whiteness, among which the fossil madrepores for which the vicinity is famed, are often found, is divided by a projecting pile of rocks into two coves, the one of which is overlooked by the stupendous limestone precipice, and the other merges into a shore strewn with boulders, beneath a lower cliff of slate and shale.

I found the base of the precipitous rocks to the south of this latter cove very productive. Beneath the shadow of the cliffs, animals are much more numerous under the limestone boulders, than they are under similar stones where the sun shines, though only just left uncovered by the tide. Very fine tufts 
of Iridea edulis and of Delesseria sanyuinea grow in the shallow but shaded pools near low water mark. Among the creatures I brought home were several of the Common Squat Lobster (Galathea rugosa) and a fine specimen of the much more beantiful Gal. strigosa, with its livery of scarlet and azure. Trochus ziziphimus was common; Cyprea Europrea, common; Pecten distortus, several; Pecten opercularis, small; Anomice and Serpula, common on stones; two or three Botrylli; two of a beantiful Pleurobranchus; Doris tuberculata, D. Johnstomi (?), and another Doris; Ophiocoma rosula, abundant, and in much variety; one had the body relvet-black;-Polynoe cirrata; Actinia alba, and one or two other small species; Echinus esculentus?; a rough Sponge; a small Crab; and a mass of eggs, probably of a crab.

THE PLEUROBRANCHUS.

The most interesting of these captures was the pair of Pleurobranchi. The species proved to be P.plumu$l a$, an animal very rarely seen by naturalists, and a variety more than usually rich in colouring. It therefore appeared to me worth while to make careful drawings and notes from these individuals, which lived for some time with me. (See Plate II.)

Length when crawling $1 \frac{2}{3}$ in. breadth $\frac{3}{4}$ in. The form oval, convex; the cloak ample, smooth; the oral veil, undulate at front margin, the tentacular sides produced into blunt angles, and the centre notched. Dorsal tentacles blunt, curved outwards, projecting a little beyond the veil. Eyes small, black 
round points, beneath the skin, at the outer and upper part of the base of dorsal tentacles.

General colour golden or orange chrome; the veil and foot rather paler; under side of the foot (fig. 2.) approaching to flesh-colour; showing a large black cloud in the centre. The same spot seen dorsally (fig. 1.) makes a cloud of brown, slightly tinged with red in front. In this part, over the internal dark body, are many dots which appear pellucid, and two or three larger than the rest, through which the dark body appears; the yellow mantle between the dots assumes a reticular appearance. The tentacles, especially the dorsal pair, have a central line of dark brown; all are tubular, by the bending together of their sides, but open in front and beneath, where the edges do not quite meet. The branchial plume projects from between the mantle and foot in crawling; it is transparent, and appears when viewed from above, to be composed of many triangular laminæ set imbricate, and pointing backwards. Each lamina shows transverse wrinkles. (See fig. 3.) Viewed laterally it is seen to consist of a central stem, with about 18 pinnæ on each side, each pinna being again pinnated on each side (fig. 5.) The stem, pinnæ and pinnulæ are all dilated, inwardly, so that the stem, which is narrow and slender at (5), is wide at (3), and the pinnre are the triangular laminæ, whose wrinkles are in fact the pinnulæ. The organ is connected with the bottom of the lateral sulcus for about two-thirds of its length by a sort of membrane. The plume can scarcely be recognized in its two aspects, even though examined again and again in quick succession. It appears very sensitive 
and changes much in appearance by its various degrees of contraction and expansion. Fig. 4 is a portion of fig. 3 more carefully drawn, and more enlarged.

Of the two specimens found, one was rather paler. In captivity they were sluggish, fond of hiding among the fronds and leaves of Delesseria and Iridcea; but at times gliding freely like a Doris. They swam on the surface by the foot reversed, and then left behind a great wake of clear viscid jelly. They were beautiful animals. After keeping them in health about a fortnight, I put one into fresh water to kill it, for preservation. This, however, was not so readily fatal to it as I had supposed, for at the end of half an hour I found by its contraction when touched, that it was still alive. Probably the mode in which it had contracted on being put in, the foot being narrowed, and the edges of the mantle being incurved on all sides around the foot, may have in some measure prevented the access of the water to the vital parts. At the end of that time I replaced it in sea-water, when it soon partially recovered its activity, relaxing its mantle, and contracting it dorsally so as to expose the sulcus between it and the foot greatly, protruding the tentacles and veil, and the branchial plume. Thus I was enabled to get a much better sight of these parts.

As soon as it was replaced in the sea-water, a quantity of white mucus was dissharged from the whole surface, most copiously from the foot, which as it lay on its back, was uppermost. This mucus, gradually, by the contractions of the animal, was accumulated in a knob at the posterior end of the foot, and then thrown off. The reticulate structure 
of the mantle-integument was much more distinct than in health; it was seen to form a delicate lacework of yellow fibres all over the surface, covering and inclosing a pellucid parenchyma.

The animal evidently had been injured by its bath of fresh water; for it lay on its back, expanding and contracting its various parts, without the power of turning over to crawl, or even of adhering by the foot when turned, but rolling helplessly back. The form and appearance too were very different from those of health, the sulcus being widely exposed by the contraction of the mantle, much like the figure in Prof. Jones' 'Animal Kingdom,' which I should think was taken from a specimen in spirit; it does not much resemble mine in health.

Running along near the edge of the foot, parallel with it, on the upper surface, is a narrow projecting lip or ledge, more opaque than the surrounding parts, and capable of .being slightly raised. Between this and the oral veil is the mouth, from which in my sick specimen was projected a large pear-shaped or vase-shaped body, of which the narrow part, which was outward, was wrinkled up, and showed at times a small central orifice, triangular in form. The body was pellucid with an opaque central nucleus.

The oral veil is thick, and is deeply grooved along each outer edge: the margins of these grooves, being infolded, make the oral tentacles. Fig. 6 represents the outer side of the left dorsal tentacle ; showing a sinuosity in the edge of the cleft; probably accidental, since I did not observe it in the other tentacle. After death the form of the shell could very dis- 
tinctly be traced in the centre of the back. On making an incision I found it superficially placed within the substance of the mantle, whence it was very readily extracted, having apparently no organic adhesion to the flesh. A careful examination shews a very close agreement with that of $\mathrm{Pl}$. plumula, which I have no doubt it is. Its length was exactly $\frac{1}{2}$ inch, its breadth a little more than $\frac{1}{4}$ inch. It lay over the dark brown liver: its own colour was darkish horn, tinged with reddish: as it dried, a silvery nacre covered it in parts, which gradually extended to the whole. There were two radiating depressions on the surface. 


\section{CHAPTER IV.}

The Dead Man's Fingers-Appearance when contracted-when expanded-Beauty of the flower-like Polypes-StructureSpiculæ-The Polypidom-Zoophytes and Crustacea upon Tangle-Small Nudibranchs and their Spawn-The Angled Laomedea-Its medusiform Young-Appearance, Manners and Structure of the Embryo-Escape of one from the Vesicle -Regular Arrangement of the Zoophytes-The Rosy Anemone-Its Locality-Description-Habits-Structure-The Snowy-disked Anemone-Peculiarities of its locality-Description-The Snake-locked Anemone-Description-Farewell to South Devon.

\section{ALCYONIUM DIGITATUM.}

At low water, after an unsuccessful hour spent in turning stones, I went to the end of the rocks at Petit Tor, and by leaping over an inlet through which the tide was pouring in and out, reached a mass of rock covered with Fuci and Laminarice. Here, growing on the side of a deep hole under water, illuminated by light proceeding from the far end of the cavernous passage, I had for the first time the pleasure of seeing Alcyonium digitatum. It was composed of two cylindrical lobes rounded at the ends, their form suggesting both of the names vulgarly applied to this Zoophyte, of Dead-man's-fingers and Cows' paps, or the more elegant appellation, assigned to it by Sir John Dalyell, of Mermaid's Glove. By lying down and creeping beneath a ledge of rock, and thrusting my 
arm down the hole, I succeeded in laying hold of it, and easily detached it from its base without laceration. My basket of bottles being at a distance, I gently put my prize into my coat-pocket, until I could again immerse it in clear sea-water. The lobes were now contracted, about as large as a man's forefinger, of a cream-white hue, of a smooth surface, except that it was covered with slight depressions of a long-oval form, divided by narrow angular lines. In this state I brought it home, and placed it in a glass vase of clear sea-water.

After a few hours how different was its aspect! I will endeavour to describe it as it lies now before my eye; and the more willingly because neither any description that I have met with, nor any figures, give an adequate idea of either its form or its surpassing beauty.

I do not mean that its general form and structure are not correctly stated, but that the details of the beautiful flower-like polypes themselves are not given with accuracy. The fingers or lobes are now greatly swollen both in length and thickness, the colour is of a much purer white, and the substance is almost pellucid, especially in those oval, or rather polygonal depressions, which I have mentioned above, and which are the terminating cells of the aqueducts that run through the whole system. They are now, however, depressions no longer; for from each has protruded a polype, which resembles a flower of exquisite beauty and perfect symmetry. But how shall I describe one of these? From each of the cells springs a clear white tube, translucent, but not perfectly transparent, 
and yet sufficiently so to reveal with perfect distinctness the few and simple organs contained in the interior. Its base is commensurate with the margin of the cell from which it springs; but it tapers upward to the length of nearly half-an-inch, where it dilates into a flower of eight slender and pointed petals, which diverge in a trumpet-form. Each slightly bulges outward at its junction with the tube, so as to give a slightly campanulate outline to the flower; indeed the resemblance to the blossom of a Campanula is sufficiently striking. Examined with a lens each petal is perceived to be furnished, on each of its two lateral margins, with a row of delicately slender pinnæ or filaments, which are short at each extremity, but increase in length, in regular gradation, towards the middle of the petal. These pinnæ do not proceed in the same plane, but arch outwards, so as greatly to increase the elegance of the flower. Submitted to a higher power, the pinnæ are seen to be roughened, throughout their whole length, with numerous prickly rings, somewhat like the horns of an antelope. The whole appearance is very different from the broad petals, notched along each edge, which are commonly represented.* (See Plate III. fig. 1.)

* Ellis observed long ago that "each tentaculum or claw had on both sides rows of minute short fibres, like the down on some pappous seeds of vegetables." (Corall. p. 84.) And this appearance he has expressed in the plates of his "Corallines" and of his "Zoophytes." But these figures, notwithstanding Dr. Fleming's verdict on their accuracy, do not represent very precisely what presents itself to my eyes. Sir John Dalyell says, " Each side of the tentaculum is bordered by cylindrical fleshy prongs, whence the pectinate aspect." (Rare Anim. of Sc. ii. 178.) 


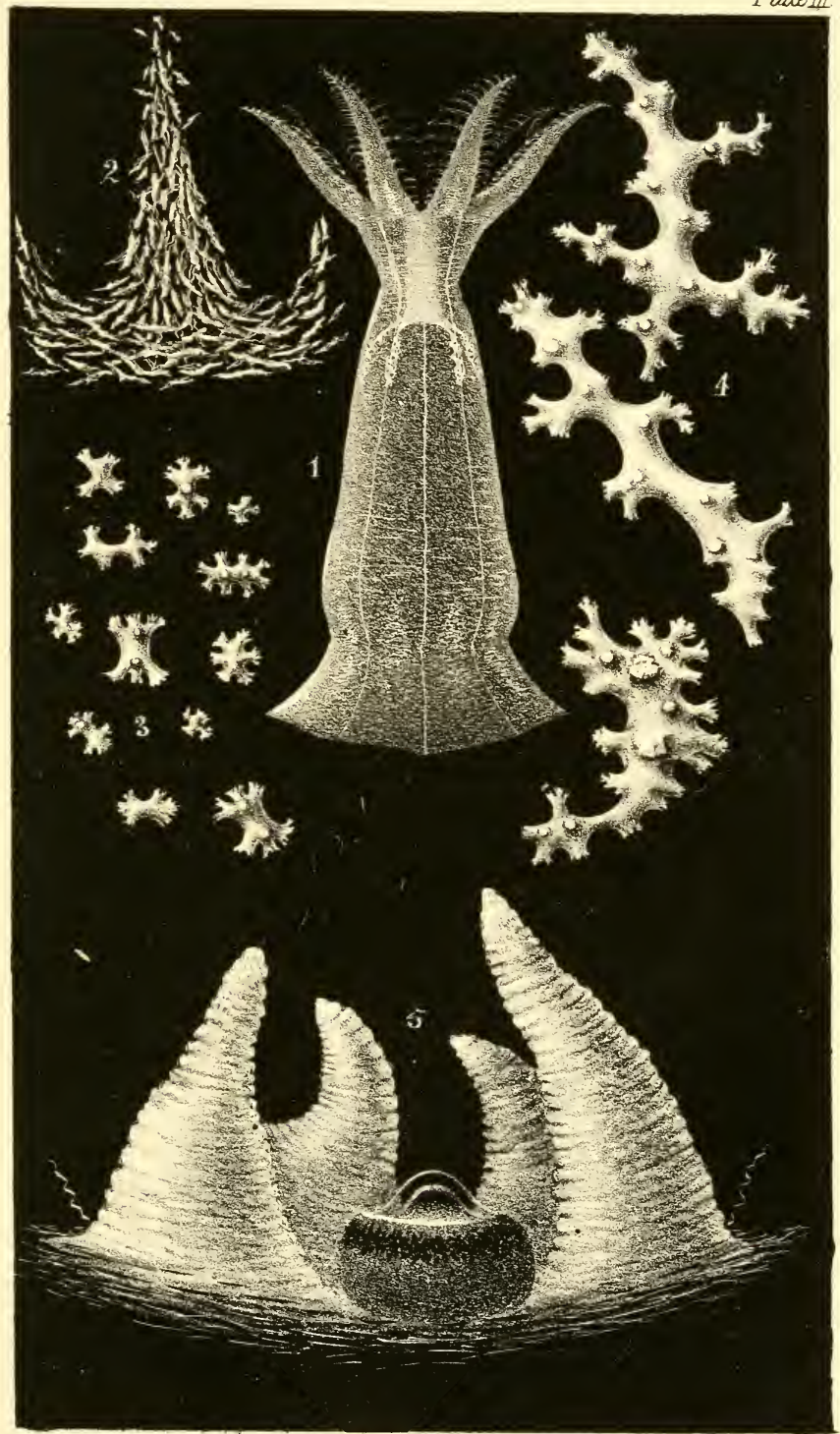



The pinnæ are capable of independent motion; one being frequently jerked inwards towards the centre of the disk, while its fellows on each side remain motionless. I cannot detect any appearance of cilia on them, nor do I think there are any, for I have seen minute suspended particles slowly sink, till they rested on the pinnæ, without the least indication of a vortex or current in the water.

The beautiful form of the petals above described is quite lost after the animal has been about a day in captivity. In both of my specimens, though the water has been several times renewed, the petals after the first day shrank up into short, thick, unshapely masses, rudely notched at their edges, and never afterwards expanded more than this, though apparently healthy in other respects, and sufficiently sensitive to handling. Probably the defect in extant representations arises from the figures having been copied from specimens in this condition.

In the centre of the floral expansion a narrow slit opens into the stomach, a cul-de-sac of the same narrow form, viz. that of a sack when empty, or of a pillow-case as it comes from the laundress, flat, thin as viewed in one aspect, and wide in another at right angles to it. At the bottom it is truncate; and from hence spring off, arching downwards, three threads on each side, which are thickened and much contorted in their course. These threads appear to form the edges of so many delicate membranes, which run up as septa connecting the stomach with the exterior parietes of the body, and dividing the whole of the space surrounding this viscus into chambers, perfectly isolated. 
With a strong light behind the animal I distinctly perceived a ciliary vibration down the interior of the stomach, at least at the two sides when viewed transversely.

The septa are eight in number, but two in every polype are destitute of the contorted threads; which, I am inclined to think, where present, run between the sides of each septum, this consisting of two membranes; but of this I am not quite certain.

The base of each polype does not rest like an independent body on the surface of its cell, but springs from the circumference of the cell, each polype-base being actually contiguous to, and in fact continuous with its surrounding neighbours. The polype-skin is really a prolongation of the common integument of the mass.

Under a power of 220 diam. a living polype showed a current along the pellucid skin; minute globules being earried both upwards and downwards with a motion much like the circulation in Chara, \&c. I saw it most distinctly near the basal part of the animal, but whether it was within the substance of the skin, or along the interior surface, I could not be absolutely certain. It was a very different motion from the close and rapid ciliary waves of the stomach, which were plainly visible in the same animal. The currents must, however, be in the cavity; for I observed the globules follow the outline of one of the tortuous threads, and also that of the angle of the stomach, whence I must conclude that the whole of the interior surface, as well as the various organs, is covered with vibratile cilia of excessive tenvity. 
Around the neck of the expanded Polype, that is, just below the base of the petals, there are seen by means of a lens, a number of short lines placed transversely. With a higher power, on the animal being subjected to pressure, these are found to be calcareous spiculæe, arranged in a singular manner, as seen at fig. 2. They are fusiform, and slightly knotted. The basal part of the animal is also studded with minute points; these likewise prove to be spiculæ, but of different form and appearance, (fig. 3.) each consisting of a star of six points, all truncate and digitate. These are scattered all orer the base, for about one-fourth of the height of the Polype, but there are rounded accumulations or constellations of these stars among the rest, where they are densely crowded together. These clusters seem to be arranged one in each interspace of the septa ; the former kind runs up in points into the base of each petal.

When the polypidom is carefully cut open lengthwise, it is seen to be permeated by canals running throughout from the base to all parts of the surface, where they dilate a little and form the cells, which contain the several polypes. Under a microscope, the substance which separates the cells, is seen to be spongiose, containing a great number of spiculæ of much larger size than those of the polype-skin. They vary in form, but follow one model, and much resemble very gnarled branches of oak, with the branchlets broken off, leaving ragged ends. I have figured some of them at fig. 4.

EOLIS DESPECTA, ETC.

In the large tide-pool at Petit Tor, I pulled up by 
the base a frond of the Digitate Oar-weed, the footstalk of which was densely crowded with a parasitical forest of the angular stems of Laumedea geniculata as thick as they could bristle. A considerable number of stems of that lovely feather-like zoophyte, the Crested Plumularia, were also springing from the root of the Oar-weed, most of which were studded with curiously folded ovarian vesicles in various degrees of maturity. A small Mantis-shrimp, (Caprella) of curious form and the most delicate transparency, which I have found to make its favourite home upon this zoophyte, was upon the plumes in some numbers, and a few were also upon the Laomedea. Its habit is to take a firm hold of the zoophyte with its hindermost feet, and to rear its long spectre-like form in the free water, through which it sways backward and forward, catching with its singularly constructed fore feet for any straggling prey that may be passing, exactly in the manner of that curious predaceous insect, which in habit, as well as in structure, it so closely resembles.

Many of the stems of the Laomedea were studded with little oval masses of white spawn, each enclosed in a ball of transparent jelly, the largest not so big as a small pin's head, These were doubtless the spawnmasses of the minute Eolides of the section Tergipes, so readily distinguished by having the branchiæ disposed in large but few club-shaped excrescences, growing along each side of the back.

I put the whole stock into a glass of water; and the next morning on searching over it with a lens I discovered adhering to the side of the vase a specimen of the pretty Eolis despecta, which I had no sooner 
extracted with a tube than I observed sprawling on the bottom, the tiny E. exigua. A careful examination of the zoophyte revealed three or four more of $E$. despecta, adhering by the slender foot to the zigzag stems, so firmly that I could scarcely dislodge them. Near the base of the frond-stalk I detected a specimen of the beautiful Doto coronata, a curious creature, with the dorsal tentacles springing from the midst of trumpet-like sheaths, like a stout pistil out of the midst of a flower, and with large branchire all budding out with prominent knobs. It is indeed a pretty little creature, studded all over with purple specks upon a pale buff, pellucid ground. I observe that both this species and Eolis despecta have the power of elongating and contracting the branchial processes at will; so that these are sometimes fully twice as long as they were the moment before, and as they appear perhaps the moment after. This is a peculiarity that I have not seen noticed. One of the E. despecta deposited from its side, while in the trough under examination, a minute globule of jelly containing a small quantity of spawn; and as there were visible in the pellucid body several more detached white masses of similar appearance, I conclude that this Mollusk de posits its ova not all at once but in successive portions as matured; each mass, however, being always enclosed in its own envelope of jelly. Perhaps, indeed, this is the habit of all the nudibranchs; for the specimens of Doris bilamellata that I have kept have commenced to deposit a second ribbon of spawn a day or so after completing the first.

Doto coronata, like the Dorides, occasionally 
crawls completely out of the water, a habit which I have not observed in the Eolides.

\section{THE ANGLED LAOMEDEA.}

The elegant zoophyte itself, on which the Mollusca just described were living, was eminently worthy of admiration. I mean the Laomedea geniculata. I have called it $a$ forest, for the slender zigzag stems shoot up in crowded rows like trees in a wood, from a creeping root that meanders over the sea-weed, every angle of the stem bearing a glassy cell inhabited by a many-tentacled polype.

The frond had not been in my possession many hours before I observed, on holding up to the light the phial in which I had placed it, one of those delicate little medusa-like objects that Mr. Peach and others have described, dancing through the water. Presently another appeared, and then another, and in the course of an hour or two, there must have been scores of them, playing about in the most entertaining manner. The naked eye readily detects them, and can even distinguish their form, which is that of a circular disk, or rather a shallow vase with a foot, and fringed all round the edge with slender threads about as long as the diameter of the disk. (Plate IV. fig. 4.) The little creatures are very active and sprightly, making their way rapidly through the water, by a sort of flapping motion of all the marginal threads together; an action which, when viewed in profile, could not fail to remind the observer of the flight of a flagging-winged bird; but so exquisitely delicate is the tiny creature, 
Plate IV

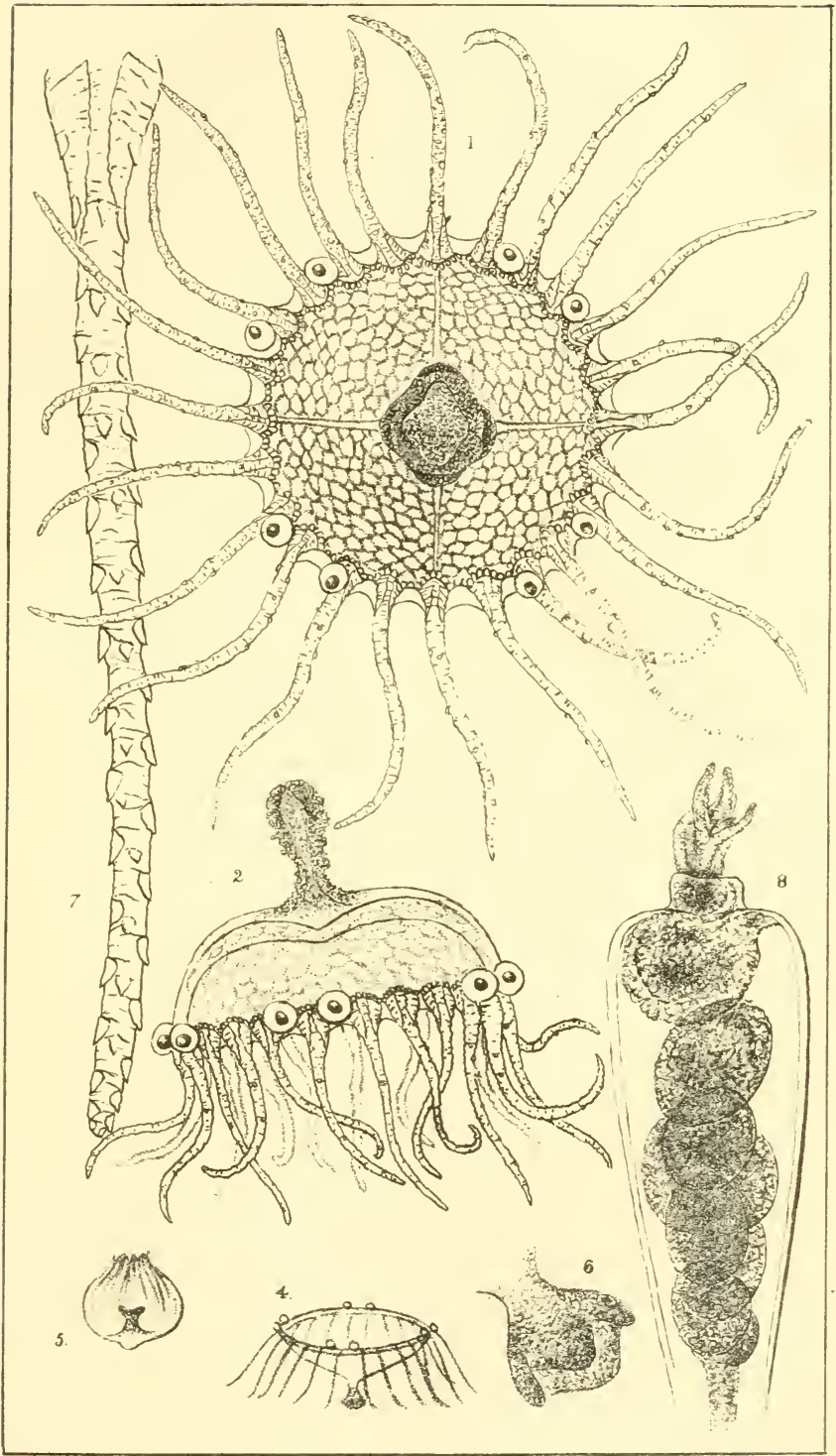

L.OMEDEA GENICULATA. 

so transparent, so shadowy, that a friend to whom I shewed it aptly called it the soul of the zoophyte. There is something in it also that reminds me of the pappus of a dandelion floating on the breeze.

Immense numbers of these tiny sylph-like creatures were successively produced from the Laomedea in the glass jar, so that the water at length seemed quite alive with them; but I could not find that a single individual either became stationary, or changed its form, or grew. In the course of a day or two they all died.

I will now describe one of them more in detail. Under the microscope it is seen to be a pellucid colourless disk or umbrella of considerable thickness, about $\frac{1}{60}$ th of an inch in diameter in its average state of expansion. Its substance has a reticular appearance, probably indicating its cellular texture. Intermally, the disk rises to a blunt point in the centre, whence four vessels diverge to opposite points of the margin. These form elevated ribs, the surface being gradually depressed from each to the centre of the interspace. (See fig. 1.) Externally* the centre of the disk is produced into a fleshy foot, having a narrow neck, and then expanding into a sort of secondary disk, of a square form with the angles rounded. (See figs. 1 and 6.) This organ appears to be muscular, or at least it is capable of varied precise and energetic motions. The angles, which correspond in their direction to the four internal ridges, are very

*I use the terms "internally" and "externally" only with reference to the appearance of the embryo: this process is the representative of the peduncle of a Medusa, which is within the concavity of the umbrella. 
protrusile, and when the little animal is active are continually being thrust out in rarious directions, sometimes everted, but more commonly made to approach each other in different degrees; sometimes one being hent in towards the centre, sometimes all closing up around a hollow interior. These four lobes, thus perpetually in motion, and changing, within certain limits, their form and their relation to each other, remind one of the lips or the tongues of more highly organised animals. The substance of this foot appears to be delicately granular; but there is a very manifest tendency to a fibrous character in its texture, the fibres being directed from the exterior towards the interior, supposing the lobes to have their points in contact.

Let us now look at the margin of the disk. Here are attached twenty-four slender tentacles, six in each quadrant formed by the divergent ribs; but in some specimens I could not count more than twenty-three. Each tentacle springs from a thickened bulb, which is imbedded in the margin of the disk: it is evidently tubular, but the tube is not wider in the bulb than in the filament. The general surface is rough with projecting points, which in some assume a very regular muricate appearance (as shown at 7 ), and the tentacle terminates in a blunt point. The diseal part of the bulb is fringed with a row of minute bead-like glands. Around the edge of the circumference of the disk, on the exterior, are arranged eight beautiful organs, which are doubtless the seats of a special sense. They are placed in pairs, each pair being approximate, and appropriated to each of the quadratures of the 
circle: they do not appear to be organically connected with the tentacles. Each of these organs consists of a transparent globe, not enveloped in the substance of the disk, but so free, as to appear barely in contact with it (see fig. 2): it contains a smaller globule or lens, of high refractive power, placed excentrically towards the outer side. The inexperienced naturalist on first seeing these organs would unhesitatingly pronounce them eyes. They are, however, considered as rudimentary organs of hearing; the crystalline globule or otolithe being capable of vibration within its vesicle. Their exact counterparts are found in most of the small Medusæ, a tribe of animals, which this tiny zoophytic embryo represents in its whole form and structure.

The disk is endowed with an energetic power of contraction, by which the margin is diminished, exactly like that of a Medusa in swimming; and the tentacles have also the power of individual motion, though in general this is languid, their rapid flapping being the effect of the contraction and expansion of the disk just mentioned, producing a quick involution and evolution of the margin, and carrying the tentacles with it. Occasionally, howerer, all the tentacles are strongly brought together at their tips, as at fig. .5 , with a twitching grasping action, like that of fingers, which is certainly independent of the disk, and may be connected with the capture of prey.

Several months afterwards, having obtained some populous colonies of this species attached to alyce, I selected some, to examine afresh their embryology. Some of the stalks were crowded with resicles, which 
projected in regular succession in one plane, forming a right angle to the distichous arrangement of the cells. The vesicle contains as many as ten or more developing medusoid embryos, (or rather chorions, each containing several embryos) included within the nutrient membranous tube, which they swell out into ovate sacs. The basal part of this tube, containing no embryos, is recognisable, but so tensely does it envelope the medusoids in the greatest part of its length, that one would be ready to conclude these were free in the cavity of the vesicle. The nutrient granules are seen to circulate through the base of the tube, in some specimens their course being from the medullary core of the stalk into the vesicle, in others vice versa.

I was so fortunate as to see the escape of one of the medusoid embryos. The terminal swelling was larger than the others, and seeing what I fancied to be the tentacles of the medusoid projecting from the mouth of the vesicle, I watched it. (See fig. 8.) These were, however, extraneous particles of matter, but it so happened that presently the real tentacles began to protrude, all in a loose bundle, bent and irregularly contracted, just as the polype protrudes from the cell. It emerged rather leisurely, and when at length it was free, I was surprised to see that the globose sac, which I had supposed to be the escaping medusoid, was scarcely diminished, that in fact it contained others, two more I should think at least, from a comparison of its bulk with that of the liberated embryo,-and that, therefore, to judge from analogy, each of the swollen sacs in the ovigerous tube of the vesicle contains not one, but several developing 
medusoids. And this explains the very great abundunce of the little airy creatures that presently swarm in the ressel in which we have put only a limited colony of the zoophytes.

As the embryo was slowly emerging from the narrow neck of the resicle, I could see the fluids m into those parts of the tentacles that were extruded, carrying minute clear granules into them.

The medusoid when liberated seemed feeble, its tentacles corrugated and shortened; it slowly fell through the water, making now and then a weak contraction, but it gathered strength in a few seconds, the tentacles lengthened, and the motions acquired the vigom and sprightliness that characterize this interesting form.

Again I have been ntterly unable to preserve the fragile medusoids for more than a few hours, though with every precaution to maintain the oxygenation of the water by living alge. They soon sink to the bottom, when the tentacles become indistinct, the whole outline becomes obsolescent, and shortly a mere mass of gramules is all that remains. Has it ever been proved that these continue the race? Are they male polypes?

The Laomedea geniculata does not always grow in the close forest-like masses above described. I found in Nay a frond of Laminaria digitata, just ready to throw off the old lamina of last season. On the smooth olive expansion of this old frond the gemmule of a Laomedea had rested after its brief gyrations; from it a glassy thread of extreme tenuity had crept along for a length of about seven inches, adhering so firmly to its support as not to be removed without 
tearing. The filament had proceeded for about three inches in a line but slightly curved, it had then made a right angle for about an inch, then another, and another, so as to inclose a square area, across which a branch joining the two sides had been sent forth, dividing the area equally. From this creeping thread, as a root or base, there had shot perpendicularly upward into the free water, the zigzag stalks which bore the cells with their indwelling polypes, arranged very evenly at intervals of about one-sixth of an inch, and standing about half-an-inch high. There were about forty stalks in all, each carrying from fourteen to twenty polype-cells, so that this colony may have included 7 or 800 individuals. The appearance of the regular stalks, growing along the line, as the frond gently waved beneath the transparent water, was very pretty and attractive.

\section{THE ROSY ANEMONE.}

The very beautiful species of Actinia, which believing it new, I describe below,*-has the habit of $A$. bellis, protruding its beautiful rosy disk from holes in the sides of shallow pools. I find it rather numerous in the hollows of the worm-eaten limestone rock, that bounds Babbicombe to the north, the south face of the promontory known as Petit Tor, where also

* Actinia rosea. мıнг. Body elongate, cylindrical, tentacula about 120 , arranged in four series, the innermost and next row containing ten each, the third about 20 , and the fourth about 80 . Oral disk ribbed divergently; mouth 4-lobed, crenated. Tentacles rose-red; disk olive. Body rich umber-brown, marked with numerous white sucking glands, not always visible. Inhabits holes in rocks. 
A. bellis is abundant. The position of these pools is several feet above low-water, but many species of interesting Algce grow in them. The Actinice in question strike the eye at once by their brilliant contrast with the rock, though they are not large; none that $I$ have seen exceeding an inch in diameter in widest expansion. Like $A$. bellis, they can be obtained only by means of the hammer and chisel; for they retire into their holes on being annoyed, so that they cannot then be removed, nor even their bases be touched. By chiselling away the rock, however, an operation of considerable difficulty under water, I detached several, which I brought home for examination. The long white seminal filaments were discharged copiously by the larger ones, both from the detached base and from the mouth; and these, as usual, were endowed with independent motion when liberated, by means of the delicate cilia with which they are covered. Some of the tentacles when distended, as will presently be described, showed, in their pellucid interior, beantiful coils of these filaments.

The body (Plate I. fig. 6.) when contracted is globose, slightly wrinkled both transversely and longitudinally, and studded with white glands, not warty, to which minute gravel, \&c. adheres. The ground colour is umber-brown, sometimes verging to reddishbrown. The disk, in the ordinary state of expansion, undistended, presents an exquisite marginal fringe of tentacles, (fig. 5.) of uniform rosy-red, the colour very pure and brilliant, the outmost rows perhaps showing a slight tendency to lilac. When these are just protruding from the opening animal, like a budding 
daisy, the appearance is also very attractive. The tentacles are all of the same size, about one fourth of the diameter of the fully expanded disk in length: they are arranged in four or five rows, not with perfect regularity; the innermost series when distended are apt to stand upright, while the others lie down, or hang over the edge. Although a considerable space exists between the inmost series and the mouth, each tentacle may be traced by an arched ridge running from its base to the mouth; the mouth is formed of four rounded lobes so as to make a cross, and the edge of each lobe is notehed with many distinct and very regular white crenations, the terminations of the tentacular ridges. The disk thus formed is pale olive, somewhat silvered; deeper brown around the bases of the tentacles, where this colour forms sinuous encircling lines. The ridges are marked throughout with close-set transverse wrinkles of extreme delicacy.

The animal, like $A$. crassicornis, protrudes the peristoma in large corrugated pellucid lobes. It also distends the tentacles to a translucent condition; in which state they are seen to be ammulated with a broad blackish band at their base, and with two remote pale narrow ones, at one and two thirds of their length. This appearance of the tentacles again reminds us of crassicornis.

May 12th. In one that has been in my possession about three weeks, I see several of the tentacles contain the white seminal filaments coiled up throughont their length, beantifully distinct through their pellucid substance.

The tentacles on being cut off and flattened by the 
compressorium are seen to be covered with very minute but close-set and numerous hairs. The movement of extraneous particles indicates the presence of vibratile cilia also upon the surface. The cavity of the tentacle is large, the walls being proportionally thin. They contain, imbedded in their substance, but in no great numbers, the usual filiferous capsules, which are of the ordinary appearance in the Actinice, linear, slightly curved and minute, averaging about $\frac{1}{1300}$ th inch in length. The projected thread too is short, being generally about six times as long as the capsule.

\section{THE SNOWY-DISKED ANEMONE}

I found this species, ${ }^{*}$ April 20 th, the same day as A. rosca, and in situations not very dissimilar. It was on the north side of the limestone promontory of Petit Tor, where the rock forms those large somewhat cavernous pools already described, isolated only at very low tides, and dark with the shadow of the slimy sponge-covered precipitous rocks that overhang them; and where Laminaria digitata grows and waves abundantly, and affords many a nidus for profuse forests of parasitical Corallines of the genera Sertu. laria, Plumularia and Laomedea. The little shining red orifices of thousands of Saxicava rugosa hang

*Actinia nivea, мrнr. Body elongate, cylindrical, studded with sucking warts : tentacula about 120 , in four series, sub-equal in size and length. Oral disk ribbed divergently; mouth conical, a slit with slightly tumid lips. Body yellowish brown, becoming pale and nearly white towards the base; disk and tentacles snowy white. Inhabits tubular holes in rocks beneath low-water mark. 
down from the holes which they have excavated in the solid limestone, each terminated by a shining diamond-drop of water, awaiting the moment when the returning tide shall cover their abodes, and restore to them activity and enjoyment. It is their season of periodical idleness and repose. Among the roughnesses of the rock, and the conical papillary pores of the sponges, which, olive, yellow and scarlet, stud the surface,- -green Nereidous worms glide along in and out, by means of the curious packets of slender bristles, alternately projecting from every segment and withdrawn, that serve them instead of feet. Below the water line, that is to say, the level of the lowest part of the margin of the pool, which of course never varies, such animals and plants as require to be perpetually covered with water enjoy cireumstances suited to their wants. In the deepest shadow fine specimens of the fleshy Dulse (Irideca edulis) and the lovely leaf-like Delesseria sanguinea display their crimson fronds in copious tufts, plants that cannot bear the absence of water, their delicate leaves becoming orange-coloured in large patches, which soon die and 'slongh away,-if left unbathed even for a single tide. The curious white Cows' paps, all studded with their clear glassy polypes, project from the rock, and here I saw several white Actinia, which at once attracted my notice, though beyond my reach, on the opposite side of the pool. At length, however, by searching in another smaller pool, to which I could gain access, I found, beneath the drooping Oarweeds, one of the white Actinice within reach. It was three or four inches beneath the surface, so that to 
procure it, it was needful to bale out the water to that depth, which I effected by the aid of one of my collecting jars, and then to cut out the animal's cell with the steel chisel. I was however sufficiently repaid for the labour by the beanty of this snow-white Anemone.

It does not appear to exceed $\frac{3}{4}$ inch in diameter when expanded; when contracted it is about the same in height, and about $\frac{1}{4}$ inch in thickness; though by more forcible contraction it becomes more globose. In this state it is wrinkled both transversely and longitudinally; its colour is yellowish-brown, gradually merging into white on the basal half; the porous suckers are also white, and are rather large, and papillary. (See Plate I. fig. 8.) The number, arrangement, and character, of the tentacles closely agree with those of $A$. rosea, and, as in that and other species, they are continued across the disk in lines converging to the mouth. They do not appear however to be capable of disteision, so as to become diaphanous. The mouth forms a sort of conical tubercle in the centre of the disk, the lips of which are only slightly tumid, not protruded in lobes. The lips do not appear to be crenated. The tentacles and disk are opaque white, beautifully distinct, without any markings, except that, when fully expanded, a grey tinge spreads in a circle around the disk, at the bases of the tentacles; produced by the degree of pellucidity of which the integment is capable, when filled with water.

When much alarmed, as when we attempt to remove it from its place of attachment, it discharges the contorted seminal filaments in unusual copiousness from 
the pores on the outside of the body, as well as from the mouth. These are slender, and of the purest white. The animal sometimes shows slight traces of longitudinal bands of pellucid white, alternating with the opaque.

(P.S.) I have since taken it in May at extreme low water, on the rocks at Wildersmouth, Ilfracombe; attached to a frond of Delesseria.

\section{THE SNAKE-LOCKED ANEMONE.}

In the coves around Marychurch I have found attached to stones, generally on the under side, near very low water mark, a smallish Actinia, which I take to be the A. anguicoma of Mr. Price. It is by no means common, however. The largest specimen I have seen was obtained at Anstey's Cove in April, beneath the shadow of the high rocks that form its southern boundary, below the slab of slate that some one has laid as a seat for those who will venture along the narrow giddy ledge on the precipitous face of the rock. This individual, in contraction (See Plate I, fig. 10), has a base of about an inch in diameter, and forms a hemispherical wart of $\frac{1}{2}$ inch in height, much narrower than its base. When expanded its height and thickness are subject to great variation. Mr. Price speaks of its stretching itself to a length of $5 \frac{1}{2}$ inches; I have never seen my specimens attain nearly that height, but do not in the least doubt the fact, from the tendency which I perceive the animal has to elongate itself in the dark, at the expense of its thickness, to become, as a gardener would say of a flower 
if in like manner deprived of light, drawn. I think two inches may be the limit of length to which I have seen mine extend.

The body is of a delicate buff hue, elegantly pencilled with fine irregular lines of dark brown, running in longitudinal bands, which diverge from the disk. As these bands approach the base they become more defined, and the contrast between the dark rich brown and the buff is beautifully distinct, especially as the alternating light and dark bands are about equal in diameter, and pretty regular. A few blackish-brown. specks are scattered around the body near the edge of the disk.

The oral disk is rather wide, and prettily mottled and speckled with pale and dark brown, and white (fig. 2). On examination this effect is seen to be produced by the converging ribs which reach from the individual tentacles to the mouth, and which are common to the genus. These run in sub-parallel, but irregularly undulating lines; they are raised in the middle, with a depression between them, and are delicately striated transversely. Each rib has a dark brown spot on each side, at the very base of the tentacle, it is then pale brown for about half-way to the mouth, when it becomes blackish, then white, then blackish again, and finally pale as it is lost in the oral aperture. The narrow lines that separate the ribs are whitish, and the different distances from the centre at which the black and white spots occur in the alternate tentacle-ribs, (those of the inner rows crushing out, as it were, the others) give the pretty speckled appearance, which is I think characteristic. From 
the two ends of the mouth, which is an oblong aperture, contracting to a slit, there are two more conspicuous white dashes each extending towards the nearest tentacle.

The tentacles are very long, slender, taper and flexible. They form about five alternating rows, of which the outmost are shorter and more numerous. They appear to me to be numbered as follows:-12. 12. 24. 48. $96=192$ : of course approximately. They are of the most delicate pellucid white, marked with two or three annular bands of positive white, but very evanescently; these are, however, more perceptible in young than in adult specimens. Each tentacle is striated with a narrow line of dark brown, which runs along each side throughout its length. This line is readily identified, and appears quite characteristic of the species.

When looked at through a glass, to the side of which the base is adherent, the transparency of the substance permits with peculiar facility the internal structure to be seen. The converging laminæ are very distinct, arranged in pairs, about twelve of which extend from the circumference to the centre, about as many intermediate pairs are lost before they reach the centre, and other pairs respectively occupying the interspaces, can be traced only a short distance from the circumference. The appearance is well suited to give a vivid impression of the analogy in structure between an Actinia and a Madrepore. Let these membranous plates only have a deposit of lime upon them, and they become the skeleton of a coral. Within the spaces inclosed by the laminæ, I could 
see the seminal filaments copiously lying, coiled up in contorted masses.

The species is well-named; for its long intertwining slender tentacles give the animal somewhat of a snaky-haired aspect, a sort of Medusa's head appearance; - at least as far as such a symbol can agree with beanty, for delicately beautiful our Actinia certainly is. It seems to expand more readily than many species, almost always being in full blossom when covered with water, and if alarmed to closing, soon recovering its placid confidence, and opening again. The transparency of its tentacles can scarcely be represented by painting, at least not without greatly enlarging the scale.

I took a specimen at Watermouth, near Ilfracombe, in Nay; in similar circumstances to the former ones.

Young specimens have the colours much paler and more pellucid; the delicate buff of the longitudinal bands being almost white.

Filiferous capsules are abundant in the walls of the tentacles: they are linear, slightly curved, and minute, being about $\frac{1}{1800}$ th inch in length. I could not see the discharged thread with a power of 300 diameters. 
HERE end my littoral researches in South Devon. My residence there was not attended with that improrement in health, that had been looked for, and I determined to try the more bracing climate of the northern coast. At the end of April, before yet the pertinacious easterly winds that characterised the spring of 18.52 had ceased, when all nature seemed scarcely more adranced than I had seen it three months before, I bade adieu to Marychurch. I left behind unexplored much well worth risiting; many of the beautiful cores and rocks in the vicinity I had not eren seen; my infirm health, and the frequent prevalence of a heary surf upon the shore, caused by the underiating wind setting full on the coast, prevented my making so full use of a three months' littoral residence as I could hare wished. 


\section{CHAPTER V.}

Ilfracombe-Beautiful Scenery-Walk to Watermouth-HeleHockey Lane-Fine Sea-riew-Daws-Dores-Charms of Spring-Watermouth-Curious mode of Fishing-Grove of Flowers-Rabbits-Sharp Rocks-Gemmaceous AnemoneLiving Madrepores-Their Localities-Appearance-Mode of detaching them-Their Structure-The Plates-Beauty of the Animal-Protrusion of the soft Parts-Their Translucency-Analogy with the Anemone-Brilliancy of ColoursTentacles-Cilia on their Surface-The globose Heads-The Tentacles are tubular-Imprisoned Animalcule-Sensibility of the Madrepore to Light-Experiments in feeding themSense of Taste-Reproduction of Parts-The Frilled Bands - Their Use-Their Structure-Thread-Capsules-Singular Forms of these Organs-The Madrepore easily preserred alive.

\section{ILFRACOMBE.}

May lst. We are come to sojourn in this charming place, the scenery of which is most beautiful. My study looks out upon the Public Baths, and one or two pretty rillas, with the fields of the Rumnacleaves behind them most richly green, sloping upwards to the edge of the cliffs that border the sea. The sheep, peacefully lying or grazing, speckle with white these verdant slopes: and young ladies come 
out there in the afternoon from one of the houses, with their targets and bows, to practise archery. Capstone Hill with its flag-crowned summit and its bold precipitous face, round which a scarped promenade winds, rears itself on the right, between which and the slopes is a pretty little peep of the Channel, and in clear weather of the Welsh Coast beyond; the blue water lying as it were in a cup, and momentarily relieved by the ships and small craft that pass to and fro, whose white sails are seen for a brief space as they emerge from behind the Capstone and glide across the opening.

Behind the house we step out from our sittingroom window upon a little garden of grass, bounded not by hedge nor walls, but by steep even banks, so that the little inclosure is a sort of grassy basin. The turf was at first gay with daisies and dandelions, and the ripe seeds of the latter presented a temptation to Goldfinches, which came in little flocks, with Chaffinches and Yellow Ammers, to twitter and feed in unsuspecting confidence immediately before the window. But the mower has just been here, who has no mercy on dandelions or daisies; and now there is only the smooth-shaven turf and the flower-beds that are cut out of it. It looks cleaner and brighter for the change to be sure, but the Goldfinches will come no more to it. Other gardens lie beyond ours, and then the upper part of the town, with the fine old church, and the whole view bounded by an ample amphitheatre of sloping fields and high downs crowned with golden-blossomed furze. It is indeed a lovely view, especially in the morning sun; and to 
us just come to it, it seems as if we could not be profuse enough in admiration.**

THE MADREPORE.

Mr. Ralfs, who has furnished some valuable zoological and botanical lists to the North Devon Guide, gives Watermouth and Smallmouth as localities for Caryophyllia Smithii. To seareh forth is interesting coral then was the object of my first excursion. Circumstances were favourable: it was spring-tide, and the time of low-water was about eleven in the forenoon: there was no sea running, for the winds had lately been light; it was delightful weather, and as I passed along the edge of the cliffs that border the sea beyond Hillsborough, the long line of coast to the north of the Channel, and Lundy Island in the offing, that have been for several days barely visible, stood out in bold distinctness, darkly blue. The lofty eminence of these cliffs allowed me to see even the low line of land that stretches away beyond the promontory known as Worms Head, and that forms the back of Caermarthen Bay on towards Tenby.

The opening of Spring is always pleasant, but to a naturalist it is like the opening of the gates of Eden: and now its charm was enhanced by delay

*I hope I shall be excused for giving a grateful testimony to the way in which our comfort was studied while in the lodging house of Mrs. Williams of Northfield, Ilfiacombe. We remained here the whole time of our residence in the place, six months; and during this period the unvarying cheerfulness and kindliness, the utter disregard of self, and the entire devotedness to our wishes, manifested by the inmates, were such as one rarely finds, except from the warmest friends. 
through the long continuance of dreary east winds. Every thing was lovely, the young fresh verdure of the hedges, the leafing trees, the sun, the sea, the birds, the butterflies, the flowers, - all contributed to make this morning more than usually delightful.

Leaving behind me the pretty little village of Hele, with its neat houses and cottages, its trim gardens sloping up the steep side of old Hillsborough, and its hedges covered with white garments put out by the laundresses for the benefit of this brilliant sun,-I pass over a brook by a rustic one-arched bridge, and wind up Hockey Lane to the lofty downs. The lane, barely wide enough for a wheelbarrow, has been scarped out of the soft slaty rock; but the ruggedness of its sides is concealed by a profusion of verdure. On the left or seaward bank, all starred with primroses, dogviolets, and daisies, is a hedge of thorn, just now out in its primal greenness. The right side is more perpendicular, and is for the greater part of its length densely tapestried with ivy, and crowned with bramble and elder bushes. On both sides the cheerful pilewort is abundant, and the spotted arum, now in flower; and ferns are abundant too, the common Pteris or brake, and the Hart's tongue, especially the latter, whose young yellow-green fronds stand up thickly with their curlerd points, among the torn and black-stained fronds of last year.

On the edge of the down at the top of this lane is a limekiln for the burning of the blue limestone which is so rare on this side of the county, but a little vein of which occurs just here in the almost universal grauwacke. Here I stood awhile to look out upon 
the beautiful Bristol Channel, with its white-sailed craft beating up against the faint easterly breeze, and to gaze down on the romantic coves and rocks about Rillage point; the ridges of slaty rock running out edgewise into the sea, the oarweeds and fuci laid bare about their bases by the recess of the tide, and the beaches between of smooth grey sand, still wet with the recent water. Jackdaws, recognized by their grey polls, were shooting out from the clefts of the precipices, and hovering round with shrill cawings, presently returning to the crevices which doubtless contained the callow objects of their parental solicitude.

Fair is the dark [blue] deep ; by night and day Unvex'd with storms, the peaceful billows play;

The firmament above is bright and clear;

The sea-fowl, lords of water, air, and land, Joyous alike upon the wing appear,

Or when they ride the waves, or walk the sand;

Beauty and light and joy are everywhere.

KEHAMA, xv. 13.

Farther on, a pair of Rock Doves, alarmed probably at the sound of my footsteps, darted forth from the ivy-mantled cliff, just beneath me, and flew away on rapid wing side by side. They too probably had the "home where'er the heart is", in some rugged nook in these inaccessible heights. I was now above Watermouth, the outlet of a little stream, which at low water (as now) winds along a channel through a muddy creek to the sea; but which at high tide is lost at the head of the inlet, which is then filled by the sea. It is a very romantic creek, being walled in as it were by 
high precipitous rocks, especially at the very mouth, one side of which is formed by a conical hill, gay with blooming furze, which is known as Saxon's burrow. Across the inlet, at some distance within its mouth I observed a row of stout poles erected, about twentyfive feet high, from each of which a rope extended to the head-line of a net that lay along at the foot, and a chain-hawser was affixed to a stouter post at some distance up the creek. A number of men were busy about the net, and some of them were dragging a light cart towards the shore, with a net formed like a shrimper's net, but much larger. A hind who was passing on the road told me that the net is set at high water by men who go thither in a boat, raised doubtless by the lines which I saw at the top of the poles. It remains during the spring tides, but at neap tides it is taken in. Grey Mullet are the chief fish taken, which are found in the pools of the mud after the recess of the tide; two hundred-weight, he assured me, were taken at one tide, about six months ago, when the net was first set. The fishery belongs to Arthur Bassett, Esq., the proprietor of the estate, whose mansion, a castellated structure of grey stone, overlooks the inlet, and has a rather imposing appearance.

The foot-path above the inlet passes through a small grove, the more pleasing as timber is not a common feature in the landscape hereabouts. The russet hue of the budding oaks contrasted with the different shades of green displayed by the expanded foliage of the sycamores and thorns; and the sloping turf beneath was covered with clumps of primroses 
and spotted with glossy pileworts, those ubiquitous flowers, mingled with frequent spikes of the graceful wild hyacinths, and now and then one of the more beautiful purple orchis. The pilewort, or celandine, as some call it, is one of iny favourites ; for I must certainly beg to be admitted among the "three or four" whom Wordsworth covets to praise his little flower of the "glittering countenance." Blackbirds were pouring forth their rich mellow notes from some of the trees: and from the summit of a furze-crowned hill opposite came the welcome call of the Cuckoo, the more welcome because it was the first time I had heard it for the season; and Cuckoos' notes had been of late years somewhat of a rarity to me.

Below the house, I crossed a small bridge over the brook, and climbed the steep face of the down,-where wheatears were flitting to and fro, and goldfinches were rifling the seed-heads of the dandelions, and humble-bees were probing the dead-nettles, - to the edge. This is margined with furze, a cover for numerous rabbits, whose infant progeny ran out and in before me in surprise and affright at the intrusion. Here I saw before me the sea-washed rocks again, and though the little cove at my feet was neither Watermouth nor Smallmouth, I resolved to try it, as I presumed that a zoophyte common to those localities might be found at an intermediate station.

On scrambling down to the water's edge, an operation much more difficult and dangerous than on the South Devon Coast, owing to the rock here universally being grauwacke, a grey, friable slate, which stands up in sharp, almost perpendicular, ridges,-the first 
thing that caught my attention was an Actinia, which I at once saw was new to me. It was projecting expanded from a crevice in the rock, just below the surface, in a little pool. A few minutes' labour enabled me to open a passage for the draining of the water, so far as to expose my Anemone, which I then soon dug out of his retreat by means of the chisel and hammer. On examination at home it proved to be Act. gemmacea, a fine species apparently rare, since Dr. Johnston seems not to be personally acquainted with it. He gives only Gaertner's specific character and locality, and old Ellis's description, and for his figures he is indebted to Mr. Cocks. Mr. Ralfs, however, had given in the Guide to North Devon this very locality for the species, and I afterwards found it not uncommon on this coast.

I searched some time without success for the Coral, and had begun to despair of finding it, for the tide was almost at its lowest; when sudddenly I caught sight of one projecting from the under surface of one of the slanting ridges of rock. The water would not allow me to reach it with any hope of detaching it uninjured, but presently I peeped into a small cavern formed by large masses of the rock piled one against another, in which there were nearly a score of them. By a little manœuvring I managed to squeeze my body between the stones, so as to work with the chisel, disregardful of the water that covered my feet below, and of the coating of mud, the slimy zoophytes, and sponges, that adhered to the overhanging rock above me. The Corals varied in size, from that of a pea to $\frac{3}{4}$ of an inch in height and diameter. They were not 
at all clustered, but scattered at irregular distances. I observed them to be affixed to perpendicular and overhanging surfaces, but in no case on a diagonal or a horizontal one with an upward aspect, not even in the remotest part of the cavern. All that I saw were left exposed by the receding tide, though in any but a spring-tide they would all have been constantly covered. I afterwards found a few more on the sides of pools in the rocky ridges, several feet above low-water mark.

In general the terminal half shewed only the white radiating plates of stone, within which the animal was so completely drawn that the eye could not detect the delicate membrane which enveloped them. From some of the largest, however, particularly those which were affixed to overhanging surfaces, there depended a shapeless mass of transparent jelly, extending in some cases to $1 \frac{1}{4}$ inch. This, however, was speedily retracted when the Coral was rudely touched. I procured a dozen specimens, for the friable slate was easy to dislodge; but in many cases the Coral itself was detached from its base during the process; and of some I found that I could detach them, and even break to pieces the texture of stony plates, with my fingers. I brought home and put in sea-water all that I obtained but those only which remained attached to a piece of rock expanded their tentacles Those which had been broken from their bases contented themselves with protruding the tips of these organs around the oral disk.

But after some weeks those whose bases had been detachea opened as freely as those which had the 
pieces of rock, and all displayed their beautiful structure without any reserve.

Just eight weeks have now elapsed since I took the specimens above-mentioned; and I have added two more which I found at Hele, adhering to the perpendicular side of a narrow, but deep rock-basin. They ure all alive and in excellent condition, with the exception of one or two that I selected to experiment on. I shall proceed to describe these interesting and beantiful pets.

Doubtless you are familiar with the stony skeleton of our Madrepore, as it appears in museums. It consists of a number of thin calcareous plates standing up edgewise, and arranged in a radiating manner around a hollow centre. The upper edges of these plates are rounded in their outline, and are free, that is, not in contact with each other; but a little below the outer margin, their individuality is lost by the deposition of rough calcareous matter, mingled and overlaid with dirty floccose extraneous substances; so that only the general form is discernible on the outside, except at the very summit. This general form is more or less cylindrical, commonly however a little, and sometimes considerably wider at the top than just above the bottom. The base itself is a flat expansion, or rather a low cone, of which the breadth varies greatly in different specimens.

The plates are not all of the same size. There are commonly about fifteen principal ones, which are higher than the rest, and project more into the central cavity. Between each of these and the next, are 
normally three small plates, of which the middle one is a little larger than the others. This regularity, however, of arrangment is not always perfectly maintained. All the plates, though very thin and delicate, are roughened on both surfaces with minute tuberculous knobs, set in rows in quincuncial order (See Plate V., fig. 5), which near the edges run into nne another, and make small ridges. In looking at this structure I was reminded of the spiculie of Alcyonium, \&c., which are roughened with similar knobs; and though the latter are only minute atoms imbedded in the flesh, they are doubtless the rudimentary representatives of these stony plates.

The interior edges of the plates form a deep cup, at the bottom of which they meet. 'The central one of the three intermediate pliates, or what has been called the second cycle, sends oft another plate into the hollow of the cup, which is similar in form to those of the circumference, but much smaller, the top not rising to nearly their level. The centre of the cup is occupied by a series of slender frilled and irregularly twisted plates, forming a spongy mass, the top of which is still lower than the level of the subordinate circle of plates.

This is but the skeleton; and though it is a very pretty object, those who are acquainted with it alone, can form from it a very poor idea of the beauty of the living animal. When we take it from its attachment and remove it from its native element, the violence causes it to contract so forcibly, that you would see nothing but what I have described, and would scarcely perceive any difference between it and 
the dry skeleton. Nor would any alteration be presently manifest on again putting it into sea-water. But let it recover its confidence, its equanimity; then you will see a pellucid gelatinous flesh emerging from between the plates, little exqusitely formed and coloured tentacles fringing the sides of the cupshaped cavity, across which stretches the oral disk marked with a star of some rich and brilliant colour, surrounding the central mouth, a slit with white crenated lips, like the orifice of one of those elegant cowry shells that we put upon our mantelpieces.

The animated part of the zoophyte will sometimes rise to the height of an inch above the level of the plates, exclusive of the tentacles, which can be extended to almost half an inch more. Its resemblance to an Actiria is then seen to be as great in appearance as in structure, though the diversity, independent of the stony base, is sufficient to prevent your confounding one with the other. Like the Sea Anemone, our Madrepore has the power of filling its body and tentacles with water from without, a process which when carried to an extreme, as it often is, especially when the animal is expecting food, or after it has received it, imparts to the tissues a charming translucency, a sort of filmy cloudiness to the eye, as if we were looking on the ghost of a zoophyte, instead of real solid substance. (See fig. 1.)

How far down on the outside the gelatinous envelope extends, whether indeed it surrounds the whole stony deposition, even passing between the base and the rock, close as the contact seems, I can- 


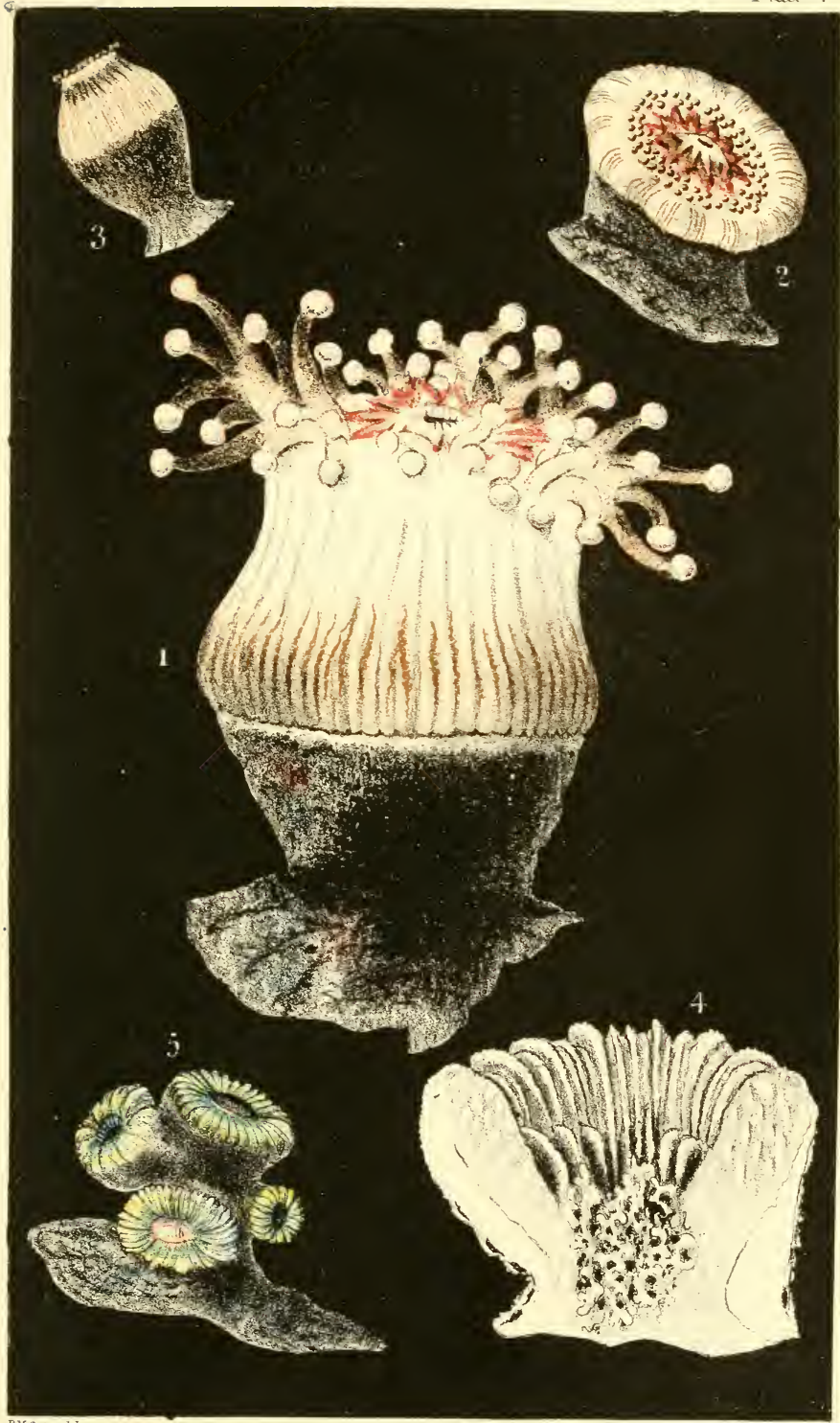



not certainly say. It is not visible, at any time, much below the level at which the individuality of the plates is lost in the rough surface. You would suppose that it is pushed out from between the plates, but in reality, the plates are clothed with it, as the bones of a vertebrate animal are with muscles and skin. When the soft parts are withdrawn, the film of flesh that invests the plates is indeed extremely thin, so attenuated that it is not appreciable by the senses; but, it is there, as you will perceive if you exactly watch the process of protrusion. I think I have before mentioned that the interior of an Actinia consists of a number of perpendicular veils of membrane, stretched from the skin to the centre, where they all meet; and if you imagine that every one of these membranes is turned to stone, or, which is more correct, that stony particles are deposited in the interspaces of such veils, - you will understand the formation of the Madrepore's skeleton, and its relation. to the soft inresting flesh: a knowledge of the more importance, since the structure of all the rast variety of corals that swarm in the tropical seas will be understood at the same time.

The colours of our native Madrepore vary considerably; but they are always beautiful. The mouth is a transverse slit, the edges or lips of which are white, and minutely notched. The mouth is always more or less prominent, and it can be protruded and expanded to an astonishing extent. A space surrounding the lips is commonly fawn-colour or rich chestnut-brown; then there is a star or vandyked circle of vivid colour, on which the beauty of the 
animal mainly depends. (See figs. 1 and 3.) Sometimes it is a deeper chestnut, sometimes a fine rich red; sometimes pale vermillion; and not seldom the most brilliant emerald green, as brilliant as the gorget of a Humming-bird. The hue, whatever it be, is usually continued in a fainter tint around and among the bases of the tentacles, until it is lost in the fawncolour or pale bay of the outer margin.* The tentacles are conical in shape, tapering from a broadish base almost to a point, but terminating in a little globular head. The head is generally white, rarely tipped with pink, nearly opaque; but the body of the tentacle is transparent, and almost colourless, but studded all over with very minute opaque warts, close-set, and frequently arranged in irregular lines; these are of a rich siemna-brown, varying in intensity, and give a very peculiar character to the aspect of the animal. Indeed it is impossible to look at it through a lens, and that whether as a transparent object up against the light, or as an opaque one, with a dark background, without being charmed by the elegant form and pleasing effect of these little knobbed organs, curling and waving here and there at the wayward will of the creature. (See Plate XXVI. fig. 4).

It is not uncommon, however, to find specimens in which the colours are so very evanescent, that the

*A singularly good representation of a highly-coloured specimen of our Madrepore may be obtained by cutting across a ripe strawberry of moderate size. The mouth with its painted margin, the vandyke circle of flesh-colour, and even the radiating white plates are all there with felicitous vraisemblance. 
whole animal appears white, a translucent white. This is a very lovely variety. Still, even in these, the hues I have mentioned above may in general be faintly traced.

I am not aware that any naturalist has recorded an interesting peculiarity, that I have observed in the tentacles. It is that their surface is delicately ciliated. I was examining one with a rather low power, when I thought I saw something like a eurrent in the water over the tentacles. I immediately put on a power of 140 diameters, which was but just sufficient to show it distinctly; I was precluded from the use of a higher power by the nature of the ressel in which the specimens were kept. However I unmistakeably saw minute atoms slowly moving in the water come into proximity to a tentacle, then immediately whirled along with rapidity in the direction of the point; the same thing was seen on both sides of the tentacle, and in fact all over its surface, the direction being in all cases the same, from the base towards the point. I tried many tentacles, and two specimens of the Madrepore, with precisely the same result. I saw a very minute atom, hurled along close to the surface, rise over the warts and descend into the hollows between them, so as to show that the cilia clothe both the warts and the plain surface of the tentasle. The globular tip, however, I think is destitute of them, for though the atoms were often hurled partly round this, I believe it was only by the impetus already acquired, for I could never see any motion either originated or undeniably continued there. The cilia themselves I could not detect by the most delicate manipulation, 
nor the marginal haze that generally indicates their presence; still I am as certain of their existence by the results, as if I had seen them. They must evidently be very minute; none but the smallest atoms obeyed the current ; larger ones continued their course or remained motionless.

Under this power the globular head of the tentacle is seen to be clothed with a dense coat of very short hairs: the warts also of the body are rough, though not so definitely. The tubular nature of the tentacles was singularly illustrated in one instance. Within one of the tentacles was a small living animal, formed like an Annelide, but the imperfect transparency would not permit me to make out its characters with precision: it swam vigorously, with a serpentine wriggling, and was foreibly driven, over and over, towards the narrow extremity of the eavity. I am almost sure, however, that more than its own spontaneous motion was in exercise: it seemed to be driven forward against its strenuous efforts, sometimes making a little way, then hurled along backward. If this was so, the inference is unavoidable, that there is a current over the interior surface of the tentacle as well as over the exterior, and in the same direction. I did not see, however, any evidence of a stream passing through the tip of the tentacle, and hence suppose that the internal waves spend themselves at the extremity of the cavity. A curious inquiry remains,How did the little animal find its way into its living prison?

The tentacles are adhesive, but in a slighter degree than those of an Actinia of the same size: I did not 
find the least heat or stinging follow the contact, even with tender parts of the skin, as the backs of the fingers.

Like the Actiniæ the Caryophyllice appear to have a sense of the stimulus of light. They expand most during the night, or in the darkness of a closet; and I have several times observed that one fully dilated in a dark cupboard would suddenly, on the door being opened, draw in some of the tentacles and perceptibly contract itself, though it might expand again a moment afterwards; and this in a deep glass vessel, covered with six or eight inches of water, so that no vibration of the air could have been appreciable. I have not however been able to detect any coloured tubercle at the angles of the mouth, nor any other organs which might be supposed to be analogous to eyes.

The feeding of the Madrepores affords much amusement; they are very greedy, and the presence of food stimulates them to more active efforts, and the display of greater intelligence, than we should give them credit for.

I put a minute spider, as large as a pin's head, into the water, pushing it down with a bit of grass to a Coral, which was lying with partially exposed tentacles. The instant the insect touched the tip of a tentacle it adhered, and was drawn in with the surrounding tentacles between the plates, near their inward margin. Watching the animal now with a lens, I saw the small mouth slowly open, and move over to that side, the lips gaping unsymmetrically; while at the same time by a movement as impercepti- 
ble as that of the hour-hand of a watch, the tiny prey was carried along between the plates towards the corner of the mouth. The latter, however, moved most ; and at length reached the edges of the plates, and gradually took in and closed upon the insect: after which it slowly returned to its usual place in the centre of the disk.

After some quarter of an hour, observing that the tentacles were more fully expanded than before, and inferring that so tiny a morsel had only whetted the Coral's appetite, I caught a house fly in the window pane, and taking hold of its wings with a pair of pliers, plunged it under water. The tentacles held it at the first contact as before, and drew it down upon the mouth, which instantly began to gape in expectation. But the struggles of the fly's legs perhaps tickled the Coral's tentacles in an unwonted manner, for they shrank away, and presently released the intended victim, which rose to the surface like a cork; only however to become the breakfast of an expectant Actinia bellis, which was much too wise to reject or to let slip so dainty a prey. The poor Coral evidently regretted the untoward necessity of letting it go, for his mouth,-I will not say watered, for being under water the expression might be open to criticism, but-yaped, for some time after the escape.

I more commonly, however, fed them with shell fish, such as limpets, perriwinkles, \&c., cutting these into pieces proportionate to the size of the Madrepore. In taking a large morsel, the mouth is produced out, and stretched over it, the unyielding stony margin of 
the stomachal cavity preventing it from being drawn in, as it would be in the case of an Actinia; and hence when the food has disappeared, the lips having first embraced it on every side and then covered it, meeting in a little puckered knot in the centre, the whole oral disk projects perpendicularly, from amidst the tentacles like a thick pillar, through whose pellucid sides the contained food is seen as a dark nucleus. Maceration, however, soon softens the morsel, and it is not long before all the parts resume their ordinary proportions and relations; the tentacles and the outer margin becoming distended with water, and rising to the level of the mouth, if the size of the food still prevents the latter from sinking to theirs. After a period, varying from five or six to twenty-four hours, the morsel is evacuated rather suddenly, very little changed, if it be solid, in form or appearance, and not invested with that glairy mucus, which covers the rejected remains of an Actinia's food.

There appears to be the sense of taste, or some perception analogous to it, in these creatures, at least so far as to enable them to discriminate in their reception of food. I cut a large specimen of one of our most common rock shell-fish, Trochus cinerarius, into many pieces, distributing most of them among my dozen pet Madrepores. They began to take in their morsels with as prompt a voracity as usual, but every one, without an exception, rejected the food before it was half swallowed. The same pieces were taken and swallowed by Actinice bellis, gemmacea, and anguicoma, and by Anthea cereus, though not apparently with much gusto. The lean of cooked meat, 
and portions of earth worms were unobjectionable to all.

Dicquemare has recorded an experiment in which an Actmia, being cut across transversely, instead of healing up into a new basis, produced another mouth and tentacula, so that an animal was formed which caught its prey and fed at both ends at the same time. The same power of reproduction belongs to the Madrepore. One of the specimens which have been in my vases for the last five months has just exhibited to me a phenomenon exactly parallel. When it was dislodged from its original rock, the fragment of stone broke in such a manner, that only the very edge of the base of the Coral remained in junction, all the rest of the base (perhaps four-fifths) being exposed. The stone, however, that adhered thus slenderly was sufficient to keep the base of the Coral from contact with the bottom of the ressel in which it has been since kept; and I have just discovered (Sept. 27th), in casually taking it up, that a new disk, with mouth, tentacles, and a new array of radiating plates, has formed on what was originally the base. The proper disk has retained full vigour and beauty, so that here is a Madrepore with a head at each extremity. The new disk is smaller in all its parts than the whole one, but is perfect in its symmetry, and its colours agree in their hues and distribution with those of the their extremity; as indeed was to be expected, since it is not a new animal, but only a new growth of the old; just as any accidental variation of tint in a flower, though liable to be lost when the race is 
reproduced by seed, will be retained in new shoots and cuttings, which are integral parts of the individual plant. While I write these lines, the new mouth is swallowing a morsel of raw beef, stretching its expansile lips with the same deliberate skill as it it had had many years' practice, instead of this being the first occasion of its so hanselling its new powers.

I have another specimen in which about half the disk of calcareous plates had been broken away in the act of dislodging it. New plates were very soon formed to replace the lost ones, which, however, have not attained the height of the former, so that though, when looked at vertically, the radiating disk of plates appears perfect, when viewed side-wise, a deep step or shoulder is seen across the disk, the new half presenting a considerably lower level than the old. Yet when the soft parts are protruded, the distortion is not conspicuous, the disk only seeming somewhat oblique instead of horizontal.

On breaking a living Coral in pieces we find among the plates a multitude of narrow membranous bands with thickened edges, frilled and puckered and convoluted to a great degree, and of a pale salmon-red tint. These answer to the similar bands that I have before mentioned in the Actinia, and are considered to be the ovaries. If we watch them closely we shall see that they have a spontaneous motion, slowly twisting and twining over each other like so many worms; and if we submit a small portion to microscopical examination we shall find it fringed with minute vibratile cilia. 
But are these frilled bands ovaries? A specimen that was broken longitudinally into two nearly equal portions, I was keeping in a glass cell for examination, hoping to see the commencement of the process of reproduction of the parts. Both the portions of the fractured animal appeared to be in good health, notwithstanding the accident, and were so placed in the glass (which had parallel sides) as to be highly convenient for observation. I wished to see the process of feeding, now that only half a mouth was possessed by each; and therefore presented to each a minute morsel of raw beef. The interior of the animal was opposite my eye, as I watched it with a lens. The lips slowly expanded and embraced the morsel exactly as usual, to the degree that their imperfect condition permitted, and when this was effected, I saw with surprise, that the salmon-coloured frills from the interior slowly reared themselves up one by one, and appressed their surfaces and extremities (which appeared somewhat dilated), to the sides of the morsel, embracing it closely on that side which (on account of the fracture) was open, but not confining themselves to that side. These phenomena were the same in the other specimen, and were repeated in each, on subsequent occasions, whenever fed.

My first inference was that these organs were performing a part analogous to the chyliferous system of higher animals, absorbing those juices from the food, which were destined to nourish the vitality of the Coral. But having detached a minute portion of one of the bands, I submitted it to an uniformly graduated pressure on the stage of the microscope, when I found 
that in its substance were imbedded a great number of filiferous capsules, exactly resembling in essential points, those of certain Medusæ.

The capsules are transparent and colourless, in shape a long oval from $\frac{1}{650}$ to $\frac{1}{800}$ inch in length, and are seen to contain a thread closely coiled. When the pressure reaches a certain point, the capsule shoots forth from one end the elastic thread, which in a moment starts out like a spring to a length thirty times as great as that of the capsule: sometimes in a straight line, sometimes in a serpentine or (as 1 rather believe) a spiral form. The capsules do not burst, yet at the instant of the propulsion of their filament there is a distinct crack heard.

I now cut off carefully, with fine-pointed scissors, two or three tentacles from one fully expanded, and submitted them to the same scrutiny. The rounded head of the tentacle appeared rather rough or hairy at first, but as pressure began to flatten it, filiferous capsules were seen to be protruding from the outline, which increased in number as the pressure proceeded, until an amazing multitude appeared, and the whole substance of the tentacle-head was seen to be literally composed of these capsules, as thick as spiculæ in any sponge, with only a slight quantity of gelatinous matter to hold them together. To see these thousands of little vesicles discharging their missiles in rapid succession, like the flights of arrows in ancient battles, was an astonishing sight. When the propulsion could be distinctly followed by the eye there was always seen a little zigzag line on each side of the thread reaching to a considerable distance from the base, 
which I at first thought indicated a delicate membrane pushed out from the orifice of the capsule by the projected thread, until it at length burst, and shrank back in folds around the base. The form of the capsules differed from that of those described above, in that they were proportionally longer and more slender, being in fact almost linear. I could not discover any capsules in the body of the tentacle; but only in the head.

If, indeed, these projected bristles are so many darts injected into the bodies of those minute animals which are the prey of the Madrepore, accompanied, as we must suppose each puncture to be, to insure its effect, with a fatal poison,-does not their presence in the convoluted bands of the interior militate against the supposition that these bands are ovaries, especially as I have seen the curious manner in which these are appressed to the swallowed morsel? Is it unreasonable to conjecture that their office may be accessory to that of the tentacles, destroying what may remain of life in the victim, after it has been inclosed by the lips, and is consequently out of the reach of the tentacles?

This inference was confirmed by the results of further investigation; for, examining in the same manner other minute portions of the frilled bands, as I could detach them with the point of a pin, I at length found a piece in which the capsules were much more numerous, and vastly larger than any that $I$ had yet seen, whether in the bands or the tentacle-heads. They were fully $\frac{1}{300}$ th inch in length, long-oval, but somewhat curved. Their size enabled me with a 
power of 300 diameters to see their structure much more distinctly.

At the larger end is situated a lozenge-shaped body reaching to the middle; from the inner end of this, partly coiled round it, but extending through the remainder of the capsule is the thread, lying in an irregular, rather loose spiral, the appearance of which differs considerably in different capsules. (See Plate XXVIII. fig. 14). When it is projected, the whole contents of the capsule disappear from the interior, in a manner which induces me to believe, strange as it seems, that the lozenge-shaped body at least, if not the whole thread, is turned completely inside-out: for the extended thread is attached, not to the smaller. but to the larger end, without the least appearance of rupture. (Fig. 15).

Now for the structure of the thread, or wire, for it is as elastic as steel. This is marvellously elaborate, especially when we consider its excessive tenuity, the threads of the largest capsules being less than $\frac{1}{7000}$ th of an inch in diameter, and those of the smallest perhaps $\frac{1}{20,000}$ th of an inch. The basal part of the thread, to a length about half-as-great-again as that of the capsule, is clothed with alternate series of triangular plates, laid one over the other, or imbricated, like the scales of an artichoke. About half of this portion is furnished with an armature of hairs rather closely set, standing out at right angles, like a bottle-brush ; they are twice or thrice as long as the diameter of the thread, in the middle of the brush, but diminish to each end; the individual hairs taper to a point. (Fig. 16). 
I have offered a conjecture that the projection of the thread is an evolution of its interior, and I believe that it is a complete one through its whole length. I have, even since I wrote that conjecture, seen an example of the process, which I can scarcely describe intelligibly by words, but the witnessing of which left on my own mind scarcely a doubt of the fact. It was effected not with the flash-like rapidity common to the propulsion, but sufficiently slowly to be watched, and by fits or jerks, as if hindered by the tip of the lengthening thread being in contact with the glass. In consequence, probably, of this impediment, it took a serpentine, not a straight form, and each bend of the course was made and stereotyped (so to speak) in succession, while the tip went on lenythening; and the appearance of this lengthening tip was exactly like that of a glove-finger turning itself inside out.

The brush of hairs, I think, is originally inclosed in the lozenge at the large end of the capsule. Both the lozenge and the brush are wanting in the small filiferous capsules; when I observed them in the large ones, the suggestion occurred that I might have overlooked them in the smaller, on which I examined some afresh with the utmost care, but in each case, the thread, which at first occupied the whole cavity of the capsule without any lozenge, was simple when evolved.

The capsules appear confined to the thickened edge of the frilled band, in which they are set side by side, pointing outwards.

At the great recess of the tides in October I observed that the rocks and caves all about Ilfracombe 
were studded at low-water mark with this Madrepore, - a curious and interesting spectacle. I obtained at this time a considerable number of individuals, many of which were of large size and of great beauty. Double specimens were numerous, triple ones not uncommon, and I possess a four-fold one, the bodies being all agglomerated into one, and the plated disks with the fleshy parts alone being separated; these diverge in the form of a cross. (Plate V. fig. 5). I presume that these forms are to be accounted for by supposing that two, three, or four gemmules happened to affix themselves near together, and that in process of growth, the stony particles depositer became soldered together. The appearance however of the specimens is that of a branching Coral.

The Madrepore is as easily kept in captivity as an Actinia, and from its beauty is particularly suited to an inmate of such a marine aquarium for the parlour as I have been endeavouring to form, and shall presently describe. At the time of these pages going to press I have specimens which have been in my possession more than eight months.

Plate V, fig. 2, represents Caryophyllia Smithii, of the natural size, a fine specimen, much distended, but little expanded. Fig. 3 is a smaller one, in a different condition. Fig. 1. One fully expanded, about $2 \frac{1}{2}$ times as large as life (linear measure). Fig. 5. The quadruple specimen above-mentioned. Fig. 4. The calcareous skeleton split open, to show the internal structure:--magnified $2 \frac{1}{2}$ times. 


\section{CHAP'TER VI.}

A Walk to Hele-Bird's-eye View of the Harbour-Quay Fields -Lion Rock-Hele Strand-A threatened Shipwreck--Eucratea-Description-Mode of Growth-Form of the CellStructure of the Polype-Tentacles-Digestive System-Muscular Bands-Evanescence of the radiate Character-RootThread-Snake-head Coralline-Frill-Vermicular OrgansDoor and Hinge-Ciliated Cellularia-Cells-Spines-Birds' Heads-Their Motions-Slimy Laomedea--Structure of a Sertularian Zoophyte-Its Contraction-Marginal Folds of the Cell-Researches in Gastronomy-Anemones cookedEaten-Commended-Best mode of preparing them-Anthea tried.

A pleasant walk of about a mile leads to Hele, a picturesque village, inhabited chiefly by gardeners, laundresses, donkey-keepers and other persons, whose subsistence is largely dependent on summer visitors to Ilfracombe. There is a foot-path through the fields to it, which is pleasanter than the carriage-road, and is a favourite walk with me. I like to stand in the quiet lane above the shipbuilder's yard, and look down upon the harbour, as I lean over the iron rail that guards the steep bushy cliff. The fishing-boats are perhaps just come in from trawling on the opposite side of the Channel, and the idlers are crowding down to the quay-steps to see the fish as it is landed. Pleasure skiffs full of laughing ladies and attentive 
beaux are leaving the stairs for a few hours' sail along the coast. The Bristol Steamer at the pier-head is impatiently blowing off her waste-steam, as some tardy passenger is seen bustling along with babies and luggage, almost too late. The coasting schooners are taking in or discharging cargo; below my feet is a busy scene, where the brawny shipwrights are wielding the hammer and adze with continuous din around the growing skeleton of a fine ship. All this is pleasant to contemplate on a sunny day from the elevated nook I speak of, its bowery quietness forming an agreeable contrast with the bustle below.

Duwn the slope of the Quay fields, over the rustic bridge that strides the deep road leading to Larkstone Cove, between hedges full of blossom, on which the gay tortoise-shell butterfly is fluttering, and scores of banded and yellow snails are crawling, and along the foot-path through the corn across Brimlin's fields to the high road. In the midst of these fields, if we pause and turn, we shall get a fine and commanding view of the town. The slopes above the terraces on the left, and the majestic Hillsborough on the right, form a sort of ample basin, in which a wide expanse of sea lies, half filling the concave. In the centre rises Capstone Hill, a conical mass verdant to the summit, and crowned with its signal-staff; and below the base of this is seen the harbour and the lower part of the town. Between Capstone and the Runnacleaves, the green slopes to the left, is the favourite bathing cove of Wildersmouth, through which we have a fine view of the sea; and here, if the tide be in, the stranger's eye can hardly fail to be attracted 
by an insular rock at some distance from the shore, that bears a very faithful resemblance to a couching lion. It is visible of course at all times, except at very high spring-tides, when the sea reaches the level of the colossal statue's back, but it is only the apex of the rock that forms the likeness, and this is of course less conspicnous when the shapeless lower part is also exposed.

I said that Hele is a picturesque village. The houses are partly placed around the base of Hillsborough, up whose steep side the gardens extend, and partly up a lovely valley. A brawling brook comes down through this wooded glen, turns the village mill-wheel, and runs off to the sea between two walls, one of which forms a causeway about a yard in width, between the cottage-doors and the water-course.

This leads us to the cove,--Hele Strand as it is called,- - an admixture, like all the coves hereabout, of pebbly beach and ledges of rough rock, with many sharp ragged points and eminences rising on every hand. The bounding promontories that form the inlet are of the same rough character, wildly picturesque to look at, but scarcely less unapproachable than chevaux de frize.

Almost every little cove with which this iron-bound coast is indented has its legendary story of shipwreck, or marvellous escape from shipwreck. Our landlady's daughter is eloquent in her description of an incident of the latter character that occured in this little cove. I will give it you as nearly as possible in her own words.

"There was a little vessel called the 'Maid of 
Alicant', a fruiterer. I don't exactly know whether she was a brig or a schooner, but she had two masts, and I remember she had what I call D-sails.* She was a beautiful little thing, just like a gentleman's yacht. Well, sir, it was on the 6th of December, about four or five winters ago, that there was a report in Ilfracombe, about a ressel going on the rocks at Hele. Almost the whole town went out to see, and I went among the rest. $\mathrm{O}$, it was such a dreadful sight! It was blowing a perfect storm, and the sea upon the rocks was rolling mountains high! The little ressel had dropied her anchor just within the cove; every body was expecting that every wave would loose her hold, and then there would have been no help, but she must have been immediately dashed to pieces on the rocks. We could see the crew standing up, and could hear their cries and screams for help. One gentleman wanted to strip and swim off to her, but the people held him back, because you know, sir, though he was a very good swimmer, he could not have given them any assistance. The hobblers, (that is what we call the men that own little boats, and get their living partly by fishing, partly by piloting, and partly by letting out their boats for hire) wanted to try to go round to her from Ilfracombe, to bring the crew ashore, for there are no boats at Hele; but the hobbler's' wives hung round them, and some even went down on their knees, beseeching

* This odd expression she explained. It was an original and ingenious mode of indicating what are technically called "square-sails," looked at edge-wise, when bellying out before the wind; the mast being the upright part of the $\mathrm{D}$. 
them not to risk their lives; for it was blowing a most dreadful gale. So nobody went off, but the little anchor held on beautifully, and the vessel rode out the storm till the next day. Then the wind abated, so that she was able to come round to Ilfracombe harbour; and it was a very wonderful deliverance. She was repaired here, and I have often seen her in the harbour since."

\footnotetext{
'Tis pleasant by the cheerful hearth, to hear Of tempests, and the dangers of the deep, And pause at times, and feel that we are safe ; Then listen to the perilous tale again, And with an eager and suspended soul Woo terror to delight us.
}

Madoc. Iv.

\section{EUCRATEA CHELATA.}

In a round and deep little pool in a rock at Hele, overshadowed by its side, and almost as regular in its form as if it had been chiselled by human art, I found two specimens of Caryophyllia; and close to it, in another open pool, grew Dasya arbuscula, on the old decaying frond-stalks of which that rather rare and very pretty zoophyte, Eucratea chelata, was numerous. The inhabiting polypes were in high health and activity, and afforded me an opportunity of making myself acquainted with their structure.

The Polypidom is irregularly branched, but the whole is composed of cells in single series, and springs from a single cell at the base. The normal shape of the cell has been compared to a bull's horn, (perhaps a powder-hom would be a better compari- 
son,) the outline being nearly half a crescent. The increase of the branch is effected by a cell growing out of the upper and outer rim, the aperture being obliquely truncate; from the outer rim of this another grows; and so on in succession for an indefinite number. But when a new branch is to be formed, the first cell of which it is to be composed shoots from the inner and lower rim, and the cells then face the opposite way to those of the original shoot. The basal part of the cells is slender for some distance before the expansion commences; and the germination of a new cell is a slender tubular process; and this, in the case of the commencement of a branch, is the explanation of "the spinous process beneath the rim," which is mentioned in the specific character by Ellis as if it were an essential part of the cell, which it is not. The name chelata (clawed), if derived, as I presume, from this supposed spine, is therefore a misnomer.

The cells are pellucid white, but when viewed by transmitted light are tinged of a yellowish horn colour. They are, however, perfectly transparent, especially the upper ones, for those nearest the base are more horny, and are liable to become studded with parasitic Diatomacere.

The aperture of the cell is large, oval, oblique, and surrounded by a rather high rim. This is covered with an elastic membrane, which when the polype is withdrawn into its cell, projects considerably beyond the rim (as seen in Fig. 3, Plate VI.), but, when the animal is projected to its utmost (as in Fig. 4), shrinks within the horny rim and becomes concave. 
The actual orifice for the emission of the animal is at the upper and outer part of this membrane, where the integuments are protruded by gradual evolution, according to the universal rule in this Class of Zoophytes, in three successive stages, which resemble, when fully protruded, the slides of a telescope. The first of these is horny, and has a sort of spine on the inner margin; the second, of about the same length, is of the most delicate filmy transparency, and has its margin surrounded by a sort of scolloped frill, composed of short ribs united by a waved membrane,* and diverging at right angles to the tube. From this projects the third, which generally bulges more or less at the back or outer side, where the orifice of the rectum is situate. A bell of twelve ciliated tentacles, nearly as long as the interior of a cell, crowns this last evolution; and the whole when extended to the utmost, is more than commonly prominent.

Let us now examine the anatomical structure of this beautiful animal. The tentacles are slender filaments, set with cilia, which are seen to be hairs of extreme tenuity, and at least five or six times as long as the diameter of the tentacle. This, however, can be detected only by using a high power (say 200 linear) with delicate manipulation, when the ciliary action is suspended; as when the tentacles are in the act of emerging. The waves of the ciliary motion run (as usual in Polyzoan zoophytes) up one side of

* This marginal frill is, I presume, analogous to those fine setr, connected by a membrane, which Dr. Farre has described as surrounding the sheathing tube of the polype, in Bowerbankia densa. (Phil. Trans. 1837. 


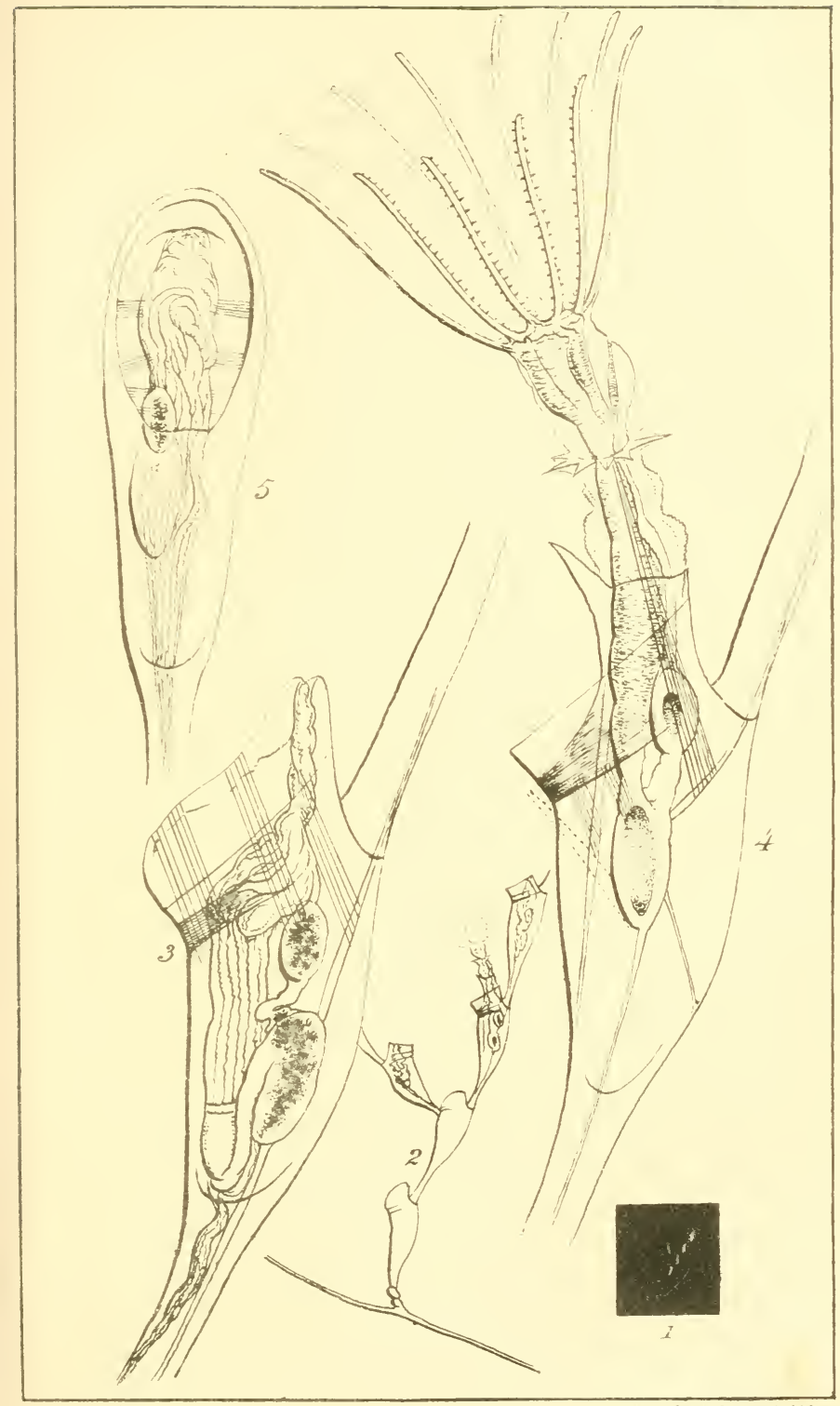

PH irasse del et bith

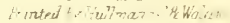

EUIRAIE: CHE 

the tentacle and down the other. A slender thread is seen to pass through the centre of each tentacle, connected with a thickened ring which surrounds the base of the circle; possibly this is nervous in its character.

The tentacles are set around a circular mouth, which leads into a funnel-shaped gullet, the walls of which are thick, granular, expansile and contractile, and highly sensitive. From the outer (or upper) side of its margin, there is given off a singular thick band apparently identical in texture with the walls of the gullet, which passing down by the side of this carity unites with it at a short distance, being free in the greater part of its course, but connected with the gullet at each extremity. The use of this curious band I cannot, after many and careful examinations, discover. It appears equally sensitive with the gullet; a vertical aspect shows that it is not, as I was disposed to imagine, tubular; and I do not think it is a muscle. It must not be confounded with the rectum, which is quite distinct, though on the same side.

The gullet passes into a lengthened tube, which after a narrowing, becomes slightly swollen, and presents the same granular texture with minute transverse corrugations, as the funnel of the gullet. After another constriction it opens into a long-oval stomach, which occupies nearly the centre of the cell, and for a reason which I shall presently mention, is capable of but little change of position.

Close to the entrance of the first stomach is the exit, the intestine being inserted in the upper end of this viscus, just behind the extremity of the gullet. 
It is a short thick tube, and presently leads into an oval second stomach, closely resembling the former, but a little smaller. Both have thick walls, and their internal surface is lined with cilia, by whose action the contents are formed into lengthened pellets, and continually made to revolve on their long axes. From the upper extremity of the second stomach proceeds a slender but expansile tube of great length, which may be called the rectum, and which proceeds upwards parallel with and behind the gullet, to its terminal aperture, on the posterior side of the head, a littlo below the tentacular ring.

The first and second stomachs, and the intestines connected with them, retain their position permanently; at least so far as any change might be produced by retractation; for the lower extremity of the first stomach is bound to a slender thread, which passes up from the preceding polype, through a foramen in the bottom of the cell. This thread appears to merge into the integument of the stomach; and at its upper extremity, it collects again into a thread, which goes up through the back of the cell into the tubular foot of the next, aud through the foramen at its bottom to be tied to the extremity of the stomach of the succeeding polype, in like manner. This thread is the link of vital connection, and, as far as I can see, the only one, between the individual polypes, uniting them in a corporate life. When a new branch is to be formed, another thread goes off from the lower extremity of the stomach, to the front margin of the cell, where as I have described above, the new branch pullulates, and enters the tube, as in the other 
case. The course of this thread is indicated by the dotted line in fig. $t$.

These threads tie the stomach to one position in the cell; but besides these there is another thread, which is fastened to the hinder part of this riscus, and passes down diagonally to the hinder part of the cell, where it is inserted in the walls. Thus the only motion permitted to the stomach is, that it may swing a little backward by the elasticity of the connecting threads, and this is allowed, to make room for the anterior parts to retire within the cell. These, forcibly retracted by muscles presently to be described, push the first stomach, and in a less degree, the second also, out of the centre, towards or eren into contact with, the hinder wall of the cell : as it is seen in Fig. 3.

Many bands of muscular fibre appear with beautiful distinctness in this zoophyte. The great retractor muscle runs along the whole length of the animal on the rentral or front surface. It is inserted into the front side of the tubular foot of the cell, a good way below the bottom of the cavity, through which it must, pass, and which therefore must be perforated near its front margin as well as in the centre. The muscle is a ribbon of fibres, which widen and diverge as they proceed, so as to be narrowly fan-shaped; the broad end is fastened into the body of the animal, probably at one or other of the points where the integument sheaths, but I have not been able to trace it much beyond the margin of the cell in the extruded animal. It is certainly free for the greater part of its length, for I have seen it, in partial retractation, thrown into sinu- 
ous curves, when its flat ribbon-like form was also distinctly shown. It is evident, from the necessity of the case, that this or any other retractor muscle must perforate the integument and be inserted in the inner surface, in order to sheath it in the manner in which this operation is known to take place: but at what point this perforation occurs, the transparency of the parts forbids my detecting.

'There is a second muscle, (or rather perhaps a symmetrical pair,) inserted in the hinder wall of the cell just below the point whence the new cell grows. Its insertion here is broad, and it narrows upward ; I can trace this to the bottom of the funnel of the gullet: and its contraction is probably the first step in the process of retractation. Beyond this point, the funnel and the tentacles are not inverted, but descend directly by the introversion of the integuments below them; the tentacles merely closing together in a fascia, as they descend.

Besides these, there are inserted within the horny margin of the cell, some eight or ten bands, or perhaps more, composed of parallel fibres. The course, and use of these are very difficult to make out intelligibly, from their apparently contradictory appearances in different aspects and circumstances. I incline to think however that they pass from the corneous rim, to various parts of the lining membrane, and in particular to that portion of it which covers-in the broad aperture of the cell,- that which I have described as prominently convex and protuberant during the retractation of the animal, and concave during its extrusion. I venture to presume that it is 
by the means of these muscles that the extrusion of the polype takes place: these muscle-bands, drawing in the membrane to a concave form, diminish the contained space, which is already full, either with water, or as I rather suppose with the rital juices; the only yielding part is the long body of the polype, which accordingly is forced out through the proper aperture.

It is manifest that the radiate structure is becoming a subordinate character in these zoophytes; at least so far as that character implies a perfect circular symmetry. This Eucratea for example has certainly a dorsal aspect and a rentral one: the direction of the intestinal canal, and the position of the excretory orifice making sufficiently plain which is the former. For from this arrangement, which is almost exactly repeated in some of the tubicolous Rotifera, as Ecistes for example, the oval orifice is gradually brought lower down the back by successive stages in Melicerta, Limnias, and Stephanoceros; until in Monocerca, Furcularia, and Notommata among the illoricate Rotifera, it attains the normal situation which it holds in the higher animals. Hence I have not scrupled to call this the dorscal side of the zoophyte, in the preceding description. While on thes subject I may mention that Eucrutea frequently inflates the membranous integument just below the anus, in a manner common to many of the Rotifera.

The ciliary action is doubtless in some measure involuntary; but the tentacles have the power of separate and voluntary movement. I observed an 
animal, apparantly annoyed by the introduction into the tentacular vortex of a mass of focal matter recently discharged, drive it out again forcibly, by altering the current in some way: it was presently drawn in again, and again driven forth; again and again it returned. At length, as if convinced that other means must be resorted to to get rid of the intrusion, the animal suddenly bent inwards one of the tentacles, and by a beautifully precise and momentary action, pushed out the substance sidevays, or lifted it out as it were, and it returned no more.

Though very sensitive,--often, when in the midst of full play, suddenly withdrawing in an instant within the protection of the cell, and remaining there, perhaps for hours, before it ventures to peep forth again, and that without any cause of alarm appreciable by us,the animal is not easily induced to retract by any tap or jar given to the table, or even to the ressel in which it is held. Nor does the admixture of indigo with the water cause it to suspend its motion, as is frequently the case when we wish to administer pigment to zoophytes. The colour is readily imbibed, and affords, by its conspicuous risibility, an excellent demonstration of the course of the digestive system.

The form of the cells is liable to considerable variation from that which is normal; but not so great as to make it all difficult to be recognized. The degree to which the animal can protrude itself differs greatly in different specimens, perhaps also with the will of the animal. I have drawn one in extreme extension, in which the distance from the base of the tentacles to the margin of the cell was about 
equal to the depth of the cell measured to the rounded bottom. The tentacles themselves were nearly as much more. The average length of a wellgrown cell is about $\frac{1}{40}$ th of an inch, measured from its origin to its dorsal margin; of this the cavity, and the foot or tube, make nearly an equal division.

Another specimen shows me more distinctly the manner of growth. Along the delicate frond of a Rhodymenia, runs a shelly pellucid thread of excessive tenacity, from which, at intervals of about a line, spring up the rows of single cells. The whole appearance reminds me of a Laomedea. The foot of the first cell, at its emergence from the root thread, is constricted at short intervals, so as to resemble joints, or nodes. In another case the thread wanders over the rock, or rather over the thin stratum of incipient Coralline, which covers it. (Fig. 2.)

No ray of phosphoric light was elicited on plunging specimens into fresh water in the dark, though the experiment was repeatedly tried.

Fig. 1 represents the zouphyte of the natural size. Fig. 2, the same enlarged. Fig. 3, A single polype, viewed sidewise, retracted, much magnified. Fig. 4, the same extruded. Fig. 5, the same, retracted, viewed in front.

\section{THE SNAKE-HEAD CORALLINE.}

The crevices between the slanting ridges of the slaty rocks at Hele form little angular pools, densely fringed with various species of red sea-reeds, many of which are of exceeding delicacy and beauty, and 
grow under the shadow of the overhanging ridges with profuse luxuriance. Among these I found that elegant species, Delesseria hypoglossum. Around its base and twining up the lower part of its frond were two interesting little zoophytes which had entwined their slender trailing stems with each other, in irregular tortuous windings, forming a sort of mat. One of these was Anguinaria spatulata. It consists of a long creeping stem, which embraces the sea-weed, just as a creeping plant does a tree, throwing out, at irregular intervals, the cells, which form the habitations of the polypes. 'These cells are unlike those of any other zoophyte ; each consist of a bent cylindrical neck of considerable length, swollen at the end into an oblong head, which is open on one side somewhat like a spoon, (Plate VII, fig. 15); whence the specific name: the resemblance however of the cell to the head of a snake is much more obvious, and has given rise to the generic appellation, and this likeness is increased by numerous rings that surround the neck throughout its length, somewhat like the cartlages of the windpipe. The swollen head is marked with minute punctured dots, arranged in lines parallel to the rings of the neck, of which they are a continuation; though the distinction between them is abrupt and well marked. A polype of twelve slender tentacles protrudes in a funnel-like form from the end of the cell (Fig. 8), or contracts itself into the neck, along which the tentacles then lie close-pressed, as a bundlo of parallel fibres.

June 24th. I saw an Anguinaria with the membranous sheath of the polype partly extruded, the 


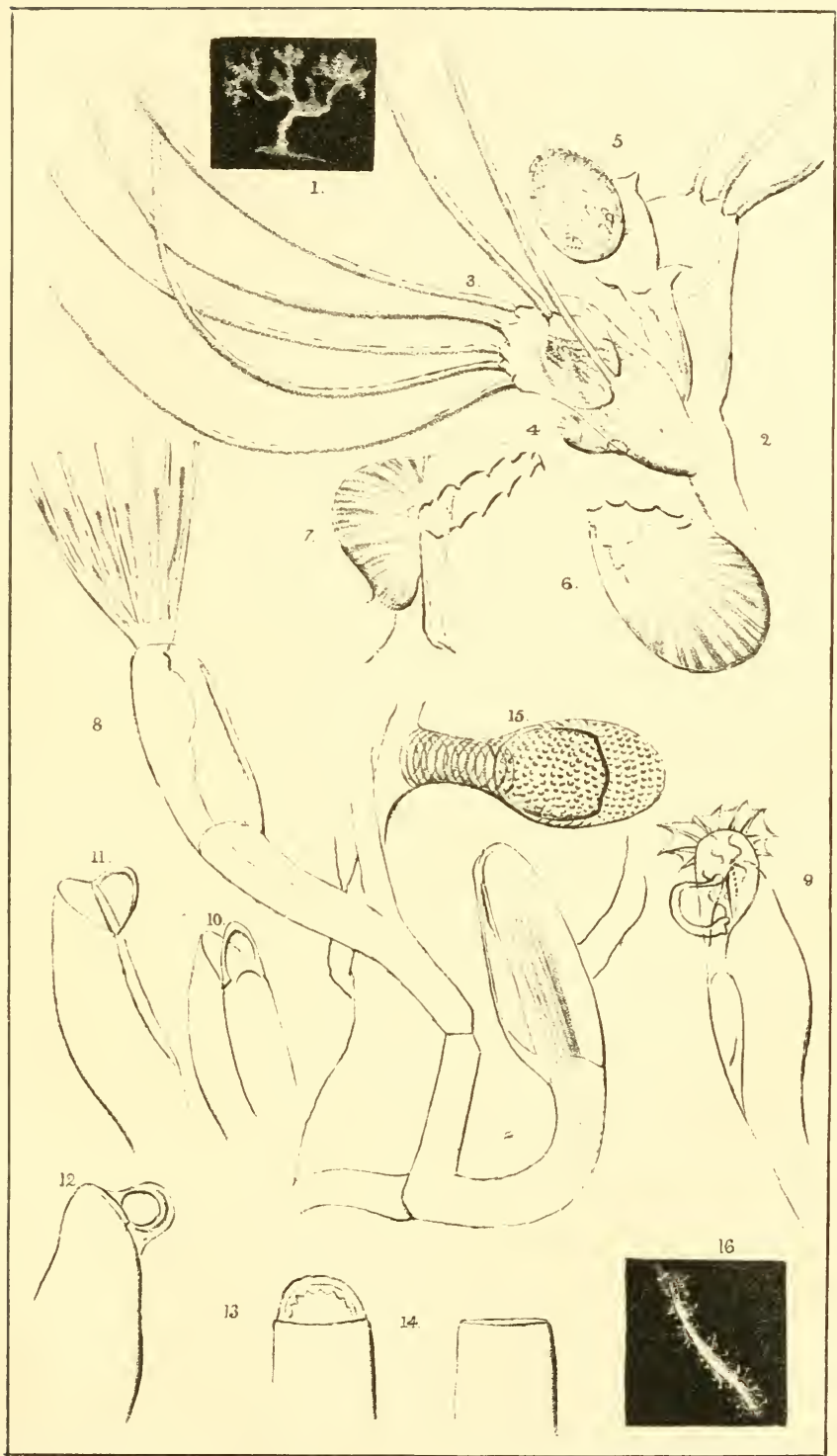

PHGosse del et lith

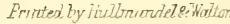

1.7 CELLULARIA CILTATA

8_16. ANGUINARIA SPATULATA 

extremity of which was surrounded by an extremely delicate fringe or frill of filmy rays united by a dentated or randyked membrane, closely resembling that of Eucratea. The appearance of the protruded membrane and the cell, I have very carefully copied at Fig. 9 ; but the relation of the parts to each other is very difficult to understand. The interior of the sheath contains many very slender threads constantly waring with a rermicular motion; indeed they might be mistaken for minute intestinal worms. They are probably long ciliary hairs.

Aug. 14th. A stem of Plumularia cristata, itself parasitic on the shell of a Crab, was covered for its basal half with a numerous colony of Anguinaria spictulata, and for its terminal half with one equally crowded of Plum. setacea. An examination of the former enables me to add a little to my knowledge of this curious zoophyte. I perceive that the terminal extremity of the head is furnished with a sort of door, that works on hinges. When the polype is throughly retracted, this is closed, and held firmly down by means of a ligamentous muscle fastened to its interior, and connected with the animal. When the latter relaxes, the door begins to open, I presume by the elasticity of the hinge acting as a spring; and as the polype protrudes, the door in proportion falls back, until it makes more than a right angle with its closed position. It appears to consist of a half-ring of horny substance, across which is stretched a delicate membrane, continuous with that which covers the large ventral aperture. I have seen it in many individuals, in various aspects and positions, and have witnessed 
the opening and closing of it repeatedly. It is a beautiful piece of mechanism, contrived for the protection of the delicate little inhabitant, permitting him to inhale the surrounding fluid without exposing himself, and enabling him in a moment to shut and bar his gate on the approach of danger. For I see that it is not necessary that the polype should protrude in order that the door should open widely; this seems to be dependent on the relaxation of the muscular ligament ; it is often wide open while the animal is far within, then in a moment it is pulled to, with a simultaneous shrinking on the part of the inhabitant, though without any appreciable withdrawing further.

Figs. 10 to 12; lateral views, the door open in different degrees. 13, 14; back views, door open, and shut.

Anguinaria spatulata, though described as rare, is by no means uncommon in this neighbourhood. It is very frequently found densely investing the stems and fronds of the smaller sea-weeds that grow at low water.

THE CILIATED CELLULARIA.

Still more abundant is another species, like the former frequently parasitic on sea-weeds, but less exclusively so, Cellularia ciliata.

To the naked eye it appears like a minute shrub composed of numerous branches rising to about half an inch in height. With the microscope the branches are seen to be set with a number of transparent cells, somewhat like a wine glass in form with the rim oblique. They are set alternately on opposite sides 
of the branch. From the higher and outer side of the rim spring five long and slender spines gracefully curved, which are each affixed by a joint to a tubercle on the rim. A sixth spine exactly similar springs from a little below the margin on the outer side,* and a serenth from the middle of the inner rim. In $\mathrm{my}$ specimens these spines are of great length; on some of the older cells I have seen them four and even five times as long as the cells. The spines grow after the cells are formed; for on the same branch may be seen oval cells not yet opened, yet containing the polype, without the least appearance of spines; others on which they are just budding; others on which they are short but distinct; and so on in all intermediate stages of growth, through those in which they are perfect in length and number, to those near the base of the branch, from which the polypes have died out, and from whose margin the spines have been either partially or wholly broken off. The polypes that inhabit these cells have about twelve tentacles, but I have not been able to see one in a state of expansion, beneath the microscope. They remain contracted within their cells, their tentacles wrinkled up and pressed together, and showing no roluntary motion, except now and then a spasmodic contraction, on a slight shifting of some of their parts. Their

* Dr. Johnston (Br. Zooph. i. 335̃,) says, "on the inner side," but I am sure this is a mistake. The perfect transparency of these creatures often renders it difficult to determine on which side of the glassy surface any given point is. By delicate focusing, however, I have distinctly proved this spine to originate on the outside, as indeed was, a priori, more likely. 
transparency however permits the intestines to be perfectly visible, and the contents of these, of a yell lowish colour, are often seen whirled round and round with a rapid movement, doubtless by the action of internal cilia.

But the most singular chapter in the history of this polype is the presence of some curious appendages which it has in common with a few more species of the same family. On the outside of some (not all) of the cells, in this species, there is a little tubercle near the bottom, to which is articulated by a slender joint an organ which has been aptly compared to the naked head of a vulture. It has a beak with two mandibles, of which the lower alone is moveable, opening and shutting like that of a bird, but with a far greater width of gape; for the lower mandible can be opened till it extends in the same line with the upper. The upper mandible is furnished with five strongly projecting teeth on each edge; the lower has a single tooth at its point, which fits into the notch between the terminal pair of the upper. The whole of the back of the head is wrinkled transversely.

The motions of this strange appendage are in keeping with its curious structure. The whole head ordinarily sways to and fro upon the slender joint at the poll, at intervals of a few seconds; but besides this motion, which is even, though rather quick, the lower mandible, which commonly gapes to its ntmost extent, now and then at irregular intervals closes with a strong sudden snap, much like the snapping of a turtle's jaws, and presently again opens, and leisurely resumes its former expansion. The muscles 
which move the lower mandible are distinctly seen, occupying the position of the palate, and extending back to the inner surface of the skull, if we may use such terms for an organization so remote. These motions are highly singular to witness, and one can scarcely look upon them without ascribing them to an active volition in the animal.

But curious questions arise in connection with these birds' heads. Are they a part of the organization of the polype? If so, why are they found attached to some cells, and not to others? why to some specimens and not to others? and why are some species of a genus furnished with them, while others, essentially the same in every other respect, are destitute of any such appendage?

Anatomical examination does not throw any light on these questions. The animal within the cell appears to be organically independent of the bird's head, for as Dr. Reid affirms, and as I have myself witnessed in another species, the latter continues its morements for a considerable time after the polype has been dead. Dr. Johnston suggests that the use of the organ is to grasp and kill passing animalcules, which then may be drawn into the cell by means of the ciliary currents of the tentacles; and this seems to me not improbable, and receives confirmation from the toothed structure of the beak, which, though strongly marked, I have not seen noticed. Plate VII. Fig. 1. Cellularia ciliata, nat. size. 2. a portion of a branch, (magnified 200 diameters.) 3. a cell containing the contracted polype. 4. the bird's head appended to it. 5. an immature cell. 6. the bird's head more 
enlarged, seen from beneath. \% the same viewed sidewise.

I have not at all entered into the structure of the polype itself in the preceding description; for the specimens that I have as yet observed were not in sufficient vigour to allow me to have a sight of one at work. It is only under very favourable cireumstances that these sensitive creatures will display their beautifully delicate organization; in nine cases out of ten, or even more, you will find the polypes forcibly contracted within their cells, and pertinaciously refusing to protrude themselves until they die.

\section{THE SLIMY LAOMEDEA.}

May 16th. A very clean and beautiful specimen of Laomedea yelatinosa affords me an excellent example of the structure of a Sertularian polype ; the more so besause the stem carries but a single cell, the inhabitant of which expands with the utmost confidence. From a fibrous thread that creeps along the lilac crust of a Coralline, springs up a slender transparent tube standing erect to a great height as compared with its thickness, sending off at remote intervals branches on either side. These branches are marked just above their commencement and just before their termination with a number of constrictions, causing the substance between to assume the form of so many rounded joints, or appearing as if tied tightly round. The end of each branch bears an elegant vase-like cell, in form like a deep ale-glass, of 
the most hyaline transparency. Such is the polypidom, which appears to me to be perfectly homogeneous, though some observers profess to have seen a delicate net-work of vessels ramifying through its walls. This horny tube, however, is permeated by a central core of living flesh, of a thin gelatinous texture, which runs through the whole stalk and through each branch, without any apparent rariation until it reaches the cells. A grood microscope shows that the flesh of the polypidom is tubular; its walls are composed of a clear jelly inclosing a loose texture of equally colourless granules. The tubular interior appears to be filled with a subtle fluid, in which minute colourless granules may be seen here and there to move with an irregular quirering dancing motion, to and fro or round and round, but not with any definite order or progression. The motion does not appear to be ciliary, but more like that of the granules in the cells of plants, except that it is more minute, and follows no settled order. Intervals occur in which no such motion can be traced; the dancing globules are very minute and ferr, but obrious enough, if carefully looked for.

A little above the bottom of the cell there is a partition or false bottom running across, perforated in the centre, because the core of flesh passes through it. From this point may be considered to commence each polype: the body is homogeneous with the fleshy core, which it a little exceeds in thickness, being dilated however into a sort of cushion at the bottom, which rests on the partition. At its upper part it spreads into a star of many rays, very elegantly expanding over and 
around the edge of the vase-like cell. The rays or tentacles are slender and long, of equal thickness throughout, and marked with numerous whorls of rough projecting points, which appear to me to terminate in very fine but short bristles, not however of a ciliary nature. I eannot discern any vortex produced by the tentacles at all. When alarmed, or when the water becomes deoxygenated, the polype contracts its whole body (uniformly by a real contraction of its substance, not by an involution of the parts,) and draws the tentacles within the cell in a parallel bundle. If further annoyed, it contracts still more, both the body and the tentacles themselres, which cau be reduced in length, until they look like so many teats or fingers.

When thus contracted the margin of the cell can be examined. In this specimen there is no extraneous matter adhering, which is a great advantage : the edge however is so subtle that it is only at the sides that it can be distinctly seen. I perceive that it is transverse; I think perfectly so, but the sides themselves form angular longitudinal folds near and at the edge, which may perhaps account for the conflicting description of this species, as having an eren or a serrulate rim.

GASTRONOMY.

And now for a paragraph of cookery. Dicquemare's testimony to the excellence of Actinia crassicornis for the table tempted me to taste. it, and I determined to take an early opportunity of cooking a 
few. In a few minutes I collected some half a dozen of different sizes at low water near Wildersmouth, and having rubbed them with my fingers in a tide-pool till the coating of gravel was pretty well got rid of, brought them home. I put them into a pan of sea water for the night to cleanse them, and most beautiful and gorgeous was the appearance they presented when expanded; no two alike in colours, and yet all so lovely that it was difficult to say which excelled. Perhaps one with the tentacles partly cream-colour and partly white was as beautiful as any.

'The next morning, however, I began operations. As it was an experiment, I did not choose to commit my pet morsels to the servants, but took the saucepan into my own hand. As I had no information as to how long they required boiling, I had to find it out for myself. Some I put into the water' (sea-water) cold, and allowed to boil gradually. As soon as the water boiled, I tried one: it was tough, and eridently undone. The next I took out after three minutes' boiling: this was better; and one at fire minutes' was better still; but not so good as one which had boiled ten. I then put the remaining ones into the bniling water, and let them remain over the fire boiling fast for ten minutes, and these were the best of all, being more tender, as well as of a more inviting appearance.

I must confess that the first bit I essayed caused a sort of lumpy feeling in my throat, as if a sentinel there guarded the way, and said "It shan't come here." This sensation, however, I felt to be unworthy of a philosopher, for there was nothing really repugnant 
in the taste. As soon as I had got one that seemed well cooked, I invited Mrs. G. to share the feast; she courageously attacked the morsel, but I am compelled to confess it could not pass the vestibule; the sentinel was too many for her. My little boy, however, roted that "timny was good," and that "he liked 'tinny;" and loudly demanded more, like another Oliver Twist. As for me, I proved the truth of the adage, Ce n'est que le premier pas qui coute; for my sentinel was cowed after the first defeat. I left little in the dish.

In truth the flavour and taste are agreeable, somewhat like those of the soft parts of crab; I ate them hot, with the usual crab-condiments of salt, pepper, mustard, and vinegar, mixed into a sauce. The internal parts, including the ovaries and the tentacles, though from their mottled appearance rather repelling to the eye, were the most agreeable in taste; the integuments somewhat reminded me of the jelly-like skin of a calf's head. I wonder they are not commonly brought to table, for they are easily procured, and are certainly far superior to cockles, periwinkles, and mussels. After a very little use, I am persuaded any one would get very fond of boiled Actinias.

Some I had left with a little of the gravel still adhering, in order to see whether this would be thrown off, when life departed; but it was not so. They should be cleansed before cooking, which can be easily and quickly done with the fingers under water; the base also should be scraped, so as to remove any bits of slate or rock or dirt, that adhere to it. Attention to these particulars greatly improres the appearance 
when cooked. They are of a pellucid rosy hue, of a firm consistence; at least sufficiently firm to be readily cut with a knife.

The next that I tried mere prepared in a different manner, and truth to say, the experiment was far more successful this time. I cleansed them more perfectly, carefully scraping the bases, until ther were freed from every particle of extraneous matter and from slime. These I had fried in egg and bread. crumbs, and ther were rery far superior to eren the best on the former occasion. All prejudice rielded to their inviting odour and appearance, and the whole table joined in the repast with indubitable gusto. I know not if my readers are familiar with a dish which in Newfoundland during the codfishing season we used to consider worthy of an epicure,- - the tongues of the cod taken out as soon as the fish are brought on shore, and fried immediately. The Actiniæ fried as abore described I should scarcely be able to distinguish, either by the ere or by the taste, from fresh cods' tongues, except that perhaps my proteges are slightly firmer in consistence.

Anthea cereus I subsequently tried, prepared in the manner last mentioned. Ther too were sarourt, but the sliminess of the tentacles was somewhat disagreeable. They are far less substantial, in proportion to their apparent size, than the Actiniæ, little, indeed, remaining, but a mass of tentacles. When Dr. Johnston speaks of "the hot and peppery Anthea," I presume he glances at its urticating properties, for there is no pungency in its taste. 


\section{CHAPTER VIT.}

Charm of the Sea-side-Watching the receding Tide-the Lion Rock-Approach of Erening-Its Accompaniments-The Warty Cycloum-Harrey's Syrinx-Capstone Hill-Its Promenade-Precipitous Walks-Noble Prospects-SunsetBird's-eye View-The Welsh Coast-Flowers-The Summit -Inland View-Seaward Rocks-Wildersmouth-A fatal Accident-The Gemmed Anemone-Description-HabitsProduction of the Young-Sea Spider-Black Sand-wormA second Visit to Watermouth-Flowers-A Crab at Home -A walk to Lee-Beautiful Valley-Character of the Cove -Stone-turning-The Worm Pipe-fish-Its Form and Colours-Manners in Captivity-Intelligence-Appearance of Disease-Surgical Aid-Difficulties of Microscopical Sketching.

The sea-side is never dull: other places soon tire us; we cannot always be admiring scenery, though ever so beautiful, and no body stands gazing into a field, or on a hedgerow bank, though studded with the most lovely flowers, by the half-hour together. But we can and do stand watching the sea, and feel reluctant to leave it: the changes of the tide, and the ever rolling, breaking, and retiring waves, are so much like the phenomena of life, that we look on with an interest and expectation akin to that with which we watch the proceedings of living beings. Last night we sat long to gaze on the receding tide from the promenade that looks out upon the little 
cove called Wildersmouth. It was spring-tide, and the water had just begun to ebb ; presently the sharp ledges of rock here and there began to peep above the surface, making black oblique lines upon the face of the water only just ruffled by the evening air, and reflecting all the ruddy glow of the north-west sky opposite. We thought of the Poet's words :-

Bright with dilated glory shone the west;

But brighter lay the ocean-flood below, The burnish'd [golden] sea, that hear'd and flash'd Its restless rays, intolerably bright.

Madoc, ii.

The most distant insular peak of rock needed not a warm fancy to form into a couching lion; the resemblance was very exact, and soon became even more perfect, by the sinking of the water revealng what seemed his outstretched fore paws. His face, his mane, the undulation of his back, and the rounded haunches were all represented in verisimilitude.

How rapidly the sea leares the beach; yonder is an area distinguished from the rest by its unruffled smoothness on the recess of the ware; presently a black speck appears on it; now two or three more; we fix our eyes on it, and presently the specks thicken, they have become a patch, a patch of gravel; the waves hide it as they come up, but in an instant or two we predict that it will be covered no more. Neanwhile the dark patch grows on every side ; it is now connected with the beach above, first by a little isthmus at one end, inclosing a pool of clear perfectly smooth water, a miniature lagoon in which the young crescent 
moon is sharply reflected with inverted homs: the isthmus widens as we watch it; we can see it grow, and now the water is running out of the lakelet in a rapid; the ridges of black rock shoot across it, they unite; - the pool is gone, and the water's edge, that was just now washing the foot of this causeway on which we are sitting, is now stretched from yonder points, with a great breadth of shingle-beach between it and us. And now the ruddy sea is bristling with points and ledges of rock, that are almost filling the foreground of what was just now a smooth expanse; and what were little scattered islets, now look like the mountain-peaks and ridges of a continent. The glow of the sky is fading to a ruddy chestnut-hue; the moon and Venus are glittering brightly; the little bats are out, and are flitting, on giddy wing, to and fro along the edge of the causeway, ever and anon wheeling around close to our feet. The dorrs too, with humdrum flight, come one after another, and passing before our faces, are visible for a moment against the sky, as they shoot out to sea-ward. The moths are playing round the tops of the budding trees; the screaming swifts begin to disappear; the stars are coming out all over the sky, and the moon that a short time before looked like a thread of silver, now resembles a bright and golden bow; and night shuts up for the present the book of nature.

'Tis spent,-this burning day of June !

Soft darkness o'er its latest gleams is stealing :

The buzzing dor-hawk round and round is wheeling :-

That solitary bird

Is all that can be heard

In silence deeper far than that of deepest noon !

WORDSWORTH. 
THE WARTY CYCLOUM.

I found at low water near the Tunnel what seems a curious variety of Cycloum papillosum. It embraces the slender stem of a red sea-weed, encrusting it all round, so as to form a cylindrical or sub-spindleshaped mass, not at all lobed, an inch in length, and $\frac{1}{8}$ inch in diameter. A portion of the membranous frond accidently hanging down, has been attached by the surface of the polypidom, and adheres firmly. The substance is fleshy, closely covered with conical papillæ, which appear imperforate (under 200 lin.), and certainly do not contain the polypes; they are more or less filled with green granules and vermicular threads, which give a colour to the whole mass, of olive brown. The polypes protrude seventeen long tentacles (I counted four or five specimens over and over, and invariably found this the number) set with cilia, and expanding in the form of a bell.

\section{H.ARVEY'S SYRINX.}

On turning over a flat stone at the water's edge at Wildersmouth I picked up a curious creature, not very attractive indeed to look at, but which I found, on examining Prof. Forbes' Brit. Starfishes at home, to be a rare species, Syrinx Harveii. His figure is admirably exact, and agrees with mine in size and contour. My specimen is lively for so dull a creature, inverting and unfolding its proboscis with great rapidity, and to a length fully equal to that of its whole body besides. The very extremity is encircled 
with several rows of short bristles, as if it had omitted to shave its beard since the day before, and when these are all everted, out pops a dense tuft of white tentacula, like those of a half-expanded Actinia. These are no sooner exposed then they are infolded again, and the process of inversion runs rapidly down to the base of the proboscis, like the drawing of a stocking or a glove-finger within itself; the tentacles, however, during the brief moment they remain out, are kept in quick motion, wriggling and twisting about among themselves. The whole proboscis is of a dull dirty brown, as is the abruptly-pointed tail; they are both reticulated, being marked with coarse annular and longitudinal wrinkles: this texture, as well as the colour, is separated abruptly frum that of the body. The latter is pure white, of a satiny lustre, smooth to the eye, but examined with a lens seen to be marked with innumerable fine punctures, oblong in form and connected with each other by very delicate transverse lines. The posterior half of the brown tail of this Syrinx was studded with little projections which I at first thought were the viscera forced through pores in the skin, but which I presently discovered, to my surprise, to be a colony of Pedicellina, (of the species Belgica, I believe) which had chosen this strange locality to spread their mat upon, surely without asking leave of the tail's owner. The gemmule having once fixed itself, was a tenant for life, and the various wanderings of the Syrinx could not displace its parasitic friend, but only carry it about, while it proceeded to rear its family. 
CAPSTONE HILL.

The favorite promenade of visitors to Ilfracombe is on the side of Capstone Hill. The little town is built in a valley, that runs for awhile parallel to the sea, a range of hills rising like a wall between it and the rocky coast, and thus sheltering it from the fierce cold breezes from the north and north-west, that prevail so greatly here, especially in winter. The newer parts of the town are arranged on the landward slope of the valley, forming handsome terraces on its steep side, and commanding those fine views of the sea that are so much admired over the seaward range of hills.

In this range there is but one interruption, but one natural way of access to the shore. For the hills, though they present inviting verdant slopes on the valley side, are externally the most abrupt and rugged precipices, being eut down, as it were, perpendicularly from their very summits to the wash of the tide. At one point, however, there is an exception to the continuity, where a little brook, finding its way to the sea, forms a narrow cove.

The bounding hill-range, which on the left of the cove attains no great elevation, rises on the right into a large, somewhat conical hill, known as the Capstone. It is an enormous mass of shale, in some parts very friable and rotten; in others more compact, with occasional narrow veins of white quartz running through it. The upper and inner portions are covered with turf, and afford pasturage for a few sure-footed sheep that hang and climb with uncon- 
scious security in places where a false step would plunge them heallong. But in other parts, and especially on the side that overlooks the little cove of Wildersmouth, the sides are awfully perpendicular and even projecting, and the broad faces of the grey rock are here particularly majestic and picturesque. With considerable labour, availing itself skilfully of the natural facilities of the rock, a broad road has been scarped round the seaward-side of the hill, extending from the back of Wildersmouth round to the eastern extremity, and sending off branch roads in zigzag directions, by which the lofty summit may be gained. To a new-comer these tracks seem not a little dangerous, for though they are guarded by low parapets here and there, they are everywhere so steep, often so slippery, and in some points approach so close to the yawning edge of the perpendicular precipice, that the blood beats with a quickened energy as we ascend, especially if we are accompanied by children. But a few weeks residence rubs off the edge of this sensitiveness, and we wonder after a little while that we could have associated danger with what appears so commonplace a matter.

But no frequency of repetition avails to prevent our appreciation of the beauty and interest of this charming promenade. The crowds of persons who frequent it sufficiently proclaim its power to please. On a beantiful summer evening we may see the visitors not only thronging the walks, and filling the comfortable seats that have been let in so numerously into the solid rock, but studding the steep sides from the summit to the water's edge, on ledges, and points, and 
slippery projections, wherever there is standing room. And truly this bold headland commands some noble views. To see the sun set on such a calm evening as I have mentioned is very fine: the clouds piled, like mountain upon mountain, about the horizon, all brilliant as he sinks among them, like an oriental monarch into his bed of gold and gems; and then, having hidden his person from our view, prochaiming who is behind by the gilded edges, almost too bright to gaze on, that fringe them; the broad expanse of blue water just broken into a ripple by the breath of the western breeze, awakened as the sun goes down, and reflecting the glowing radinnce of the sky, like a great causeway of light reaching across its bosom from the spectator to the horizon:- -this surely is a magnificent sight, behold it where and when we may : and it is seen to unusual advantage from the elevated promenade of Capstone Hill. The spectator's linger on the sight, every face turned towards the west; though the glittering splendour has changed to rich hues of crimson and orange, and these in their turn have faded to a ruddy brown hue, that is already leaving the western quarter and creeping round towards the north, and will not quite leave the horizon all through the night, until it brightens in the eastern sky with the rays of morning.

On a clear sunny day it is very pleasant to wind along the rocky path, resting at intervals on the convenient seats, or pausing to enjoy the beauties presented by different points of view. As we ascend the western side, we may stand at the parapet and look over the precipice on the beach of Wildersmouth 
below. Perhaps the tide is out, and the long ledges of rock are exposed, alternating with little spots of shingle. The bathing machines are drawn down to the water's edge, and the singularly-attired priestesses of the bath are carrying out little girls in flannel gowns, and ducking them in the ware. Ladies are speckling the grey rocks with their gay dresses and parasols as they sit in the sun, and merry children are sailing their tiny boats in the pools, or digging up the pebbles with their toy-spades.

We proceed, and gradually open the dark, ironbound coast of North Devon, as far at least as the Bull point, a bluff promontory, black and frowning, that projects far into the sea. Far out upon the horizon appears Lundy Island, like a band of blue ribbon, dark and palpable. As we wend farther round, we descry Worms Head, a distant mountain, the terminating point of a long line of coast, stretching away upon the northern horizon. This is the opposite side of the Bristol Channel, and those hills that we can just discern, rising range beyond range, are the mountains of South Wales.

But if we turn our eyes to the scene round about, we shall find much to admire. The varying effects of light and shadow on these great breadths of angular rock; the inclination of their strata, at an angle of $45^{\circ}$ to the horizon; the fissures that run directly across these, some filled with the quartz deposits, others gaping; the greasy gleam of the shale in some places, the singular light-bay tint in others that makes one think the sun's rays are falling on the spot and are clouded elsewhere,-may all claim a 
passing notice. Or we may find objects of interest in the plants, that leave not even our rocky cliffs quite barren. In spring, and lingering on even into early summer, sweet and delicate tufts of primroses grow in profusion on the sloping turf, and in the hollows and clefts. The fleshy, glossy leaves of the scurvy-grass, hot and pungent, are seen in many spots, and the tufts of thrift are gay everywhere. The kidney-vetch, varying from light-yellow to creamwhite, the bird's-foot lotus, and the bladder-campion, are very abundant; samphire adorns the precipitons sides with bunches of dark-green succulent leaves, flowering late in the season; curionsly-cut leaves of the buckliorn plantain form radiating crowns of foliage over the minor elefts; and ivy all the year round spreads an ample drapery of graceful foliage over the otherwise bare rock, especially in those aspects where the rays of the sun can seldom reach, and where flowers scarcely love to grow.

If we trace our way up one of the winding paths to the very summit, we shall be rewarded by the wide grandeur of the view. At one point a corner of the track comes to the very verge of the cliff, and here a short iron rail is placed as a guard. Few would pass this without a moment's gaze of admiration at the precipice, a hundred and fifty feet in height, and perfectly perpendicular, that is just over against us, or a glance at Wildersmouth far beneath. The wheat-ear twits and flies over the edges of the cliff as we disturb him, and the rock-pipit may be seen perched on some projecting rock; while at the top numerous agile wagtails are running over the breezy 
down among the sheep that are grazing and bleating there.

And here we are at the summit, nearly three hundred feet above the level of the sea. A flag-staff has been rigged on this point, and around the knot of rock on which it stands there are seats facing various directions. Seaward the view embraces the coasts already mentioned, but the horizon is of course more distant, and the range of sight more ample. The numbers of craft of all sorts, continually coming and going, add much to the interest of this scene. If we tnru and look inland, a prospect equally beautiful, but of very different character demands admiration. From the west round by the south to the east a verdant amphitheatre extends, bounded by hills of various form and elevation, and diversified with woods and cultivated fields. The peaks called the Torrs, the rounded elevated down of Langley Cleve, and a curious, somewhat isolated conical peak known as Carn Top, that always reminds me of Mount Tabor, are the leading eminences to the west and sonth-west. Then gentle slopes sweep away along the south line, with the town, spread out as in a map, occupying the bottom. To the eastward the noble mountain-mass of Hillsborough, presenting a bluff headland to the sea, nearly five hundred feet in height, and Rillage Point, running out in a long sharp spit behind it, terminate the view; but between us and the former is the harbour of Ilfracombe, with its shipping and fishing craft, and perhaps a steamer lying at the pier; and Lantern Hill, another almost isolated peak of inferior elevation, crowned by its ancient lighthouse, 
and facing its opposite neighbour the giant Hillsborough, the joint guardians of the harbour mouth. And thus we have gazed over a semicircle, and are brought round to the channel again.

If now we descend to the principal promenade, and stand on that side which faces the Welsh coast, there stretches down from our feet to the water's eage a rough, irregular slope of rock about fifty feet in perpendicular height, broken into broad shelres and wall-like descents, and cleft with deep narrow chasms, up which the sea shoots and boils with a tremendous uproar. Steps rudely cut in the rock give easy access to the ledges at different elevations, and on fine sunny days these are farourite spots with the ladies, who scramble down and seat themselves with their books or their netting on the little rocky perches by the hour together. When there is a heavy swell in from the north or west, these stations are in more than wonted demand; for the incoming sea rushing upon the stony barrier, dashing up to a great height in impotent fury, and breaking into a cloud of spray and foam that sprinkles the beholders even far up on the heights, is a sight well worth seeing.

WILDERSMOUTH.

The little bay that lies between Capstone and the Runnacleaves is scarcely less attractive as a place of resort than the promenade of the former hill by which it is overlooked. A tiny brook, dignified however 
with a proper name, the Wilder, discharges itself here after a long brawling course through the upper part of the town, and imparts to the cove itself an appellation, familiar to the ear of every one who has visited Ilfracombe,-Wildersmouth. Before the Tunnels were pierced through the Rumnacleaves, now affording access to the bathing pools at Crewkhorne, this cove was the only bathing place available,-indeed the only access to the shore. And still it is a favourite lounge, especially when the tide is out. There are great masses of rock, sloping upward from the land-side, but projecting in a sharp angle over the sea, scattered everywhere about the cove, and up these inclined planes visitors climb, ladies as well as gentlemen, and sit or lie at length by the hour together, in the pleasant sun, tempered by the breeze of summer. Some may be seen collecting from the rocks the adhering limpets, or the tiny periwinkles of various hues,-white, green, orange,-that lie by scores in the fissures, or gazing with curious eyes on the glossy purple Anemones, that crowd the rocks between tide-marks. And later in the season, the heaps of sea-weeds washed ashore by autumual gales afford an endless subject of interest to collectors.

The sunny cove seems the very abode of mirth and recreation; and yet it has been the scene of dire disaster and heart-breaking sorrow.

Some years ago a party of nine ladies went down to the rocks at Wildersmouth, at the part below the Capstone, which is rather secluded by means of the more than usually large masses of rock that rise there. One of the ladies was the aunt of another, the 
latter a little girl, whose parents were in India. The child was to be bathed, but the sea was high, and she did not like it. When she had been dipped twice, she begged that it might suffice, but all protested that she must have her full allowance of three dips. The aunt accordingly plunged her a third time, but at that instant a heavy wave coming in took the child out of the grasp of her relative, and bore her back beyond reach. The tide was setting down, and the party had the agony of seeing their little companion carried rapidly away across the mouth of the cove towards the Tunnel rocks.

A young man, a relative, I believe, of one of the ladies, instantly stripped and swam after the child, who still floated. He succeeded in catching her, but so fast had the tide swept her down, that he had to land on the Tunnel side of the cove, and then to climb the precipitous cliffs with his helpless burden in one arm. She was found, however, to be quite dead, and no appliances could restore her.

The aunt was like a maniac; crying and tearing her hair in distraction. They put her into one of the bathing machines until the first paroxysm of her grief had exhausted itself; but she never recovered the shock. She used long afterwards to come down to the fatal spot, and gaze out upon the sea in hopeless and speechless melancholy, a melancholy that never left her.

To complete the sad story, the parents of the child, who had not heard of the event, were returning from India shortly after, when the ship was wrecked, and they too were both drowned. 
THE GEMMACEOUS ANEMONE.

The most obvious character of this fine species lies in its large and numerous warts. These are not contractile, or otherwise changeable in appearance, and therefore are always appreciable. They are welldefined, protuberant, round or oval, of considerable size on the upper part, but diminish regularly towards the base: they are arranged in about 30 longitudinal series, which of course diverge from the centre when the animal is contracted; between some of the principal series there are other smaller rows, not included in the above number. Each principal series contains about twenty-two warts. Six of the rows are white, and these are disposed symmetrically, so as to form a white star on the summit. Between every two white rows, are from three to five rows of an ashy grey, with dark grey centres. The ground colour is delicate rose-pink or carnation at the base, gradually merging into a reddish-grey between the thickly-set warts. The resemblance which the Actinia, in this eondition, with its radiating lines of warts, bears to the common Sea Urchin denuded of its spines, is singularly close and striking. (Plate VIII. fig. 1.)

The tentacles are about fifty in number, arranged in three or four imperfect cireles. They increase in size from without, the innermost range being largest: they are conical, obtusely pointed, and more or less bent in a sigmoid curve, like the branches of a candelabrum. Their colour is a pellucid olive on the exterior side, unspotted, but marked across the inner side with about eight transverse oval bands of white, 


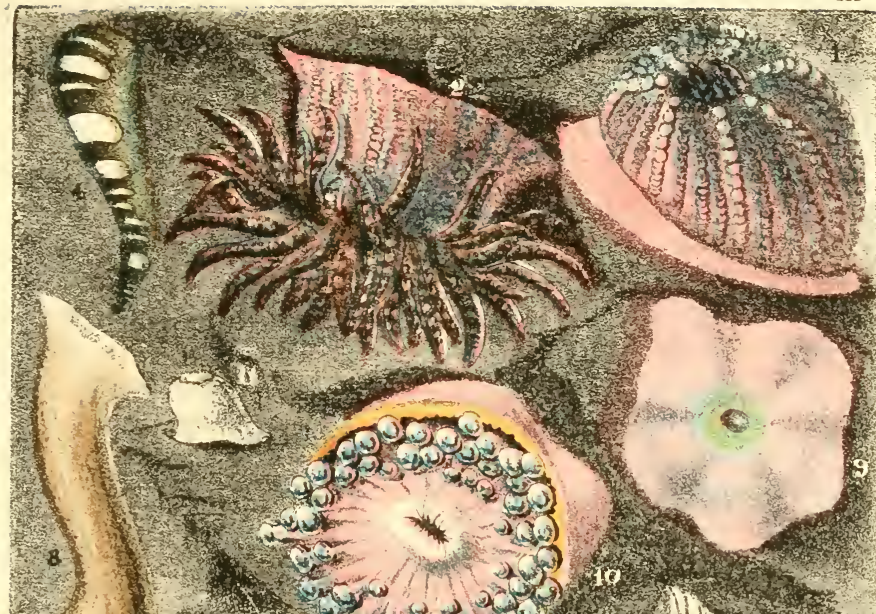

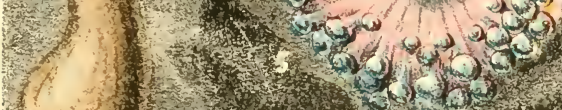

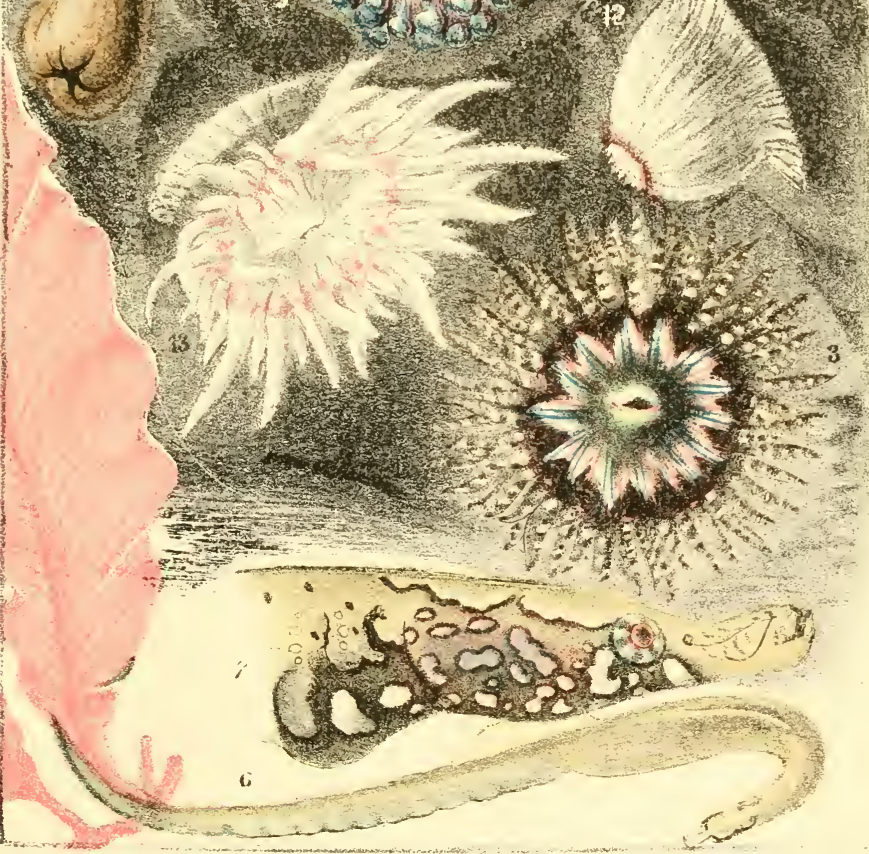



reaching about half-round. (Fig. 4.) These bands are very characteristic; they are perfectly well-defined and contrast strongly with the olive ground, which approaches to black on this side: some of the bands are occasionally divided into two narrower ones by a crossing dark line: they are not set at quite regular intervals, nor are they of equal breadth. The innermost two rows of tentacles, without losing the olive and white hues which distinguish the others, are suffused with a rich purple glow, which greatly adds to the beauty of the animal.

The oral disk is sometimes of a fine sienna-brown, marked with bands of blueish gray, proceeding from the base of the inmost tentacles, and tapering to a point at the mouth, towards which they converge. The brown hue of the disk becomes yellow-olive, or a fine green, immediately around the mouth, which is prominent. The lips are wrinkled, whitish, marked at the two opposite points of the long diameter with a tubercle, the summit of which is rose-red; this is constant; the tubercle is the termination of a ridge proceeding from the corresponding tentacle on each side. The disk is more generally variegated in a pretty manner with black, scarlet, fawn-colour, green and white, the hues arranged in divergent stripes, and running out between the bases of the inmost tentacles in a starry pattern. (Figs. 2 and 3.)

My largest specimen was ordinarily, when contracted, a hemisphere of $1 \frac{1}{4}$ inch in diameter, but when much annoyed it would shrink to the dimensions of a cherry. When expanded it was about two inches in diameter, and about one inch high. In the darkness, 
whether of night or of a closet, it would presently elongate itself to about two inches in height, the thickness being consequently diminished to abont half an inch. Whether the tentacles were expanded or concealed, this curious habit of elongation was almost invariably practised in the dark. Some other Actiniæ have the same habit.

I find several, mostly of small size, in the crevices of the rocks near low water around the bathing pools. They are generally enveloped in small grarel, from which, if closed, their six-fold star appears prettily conspicuous. One that I brought home prodnced a single young in the night, which I found in the morning adhering to the bottom of the ressel beside its parent. It is comparatively large, being about one fourth of the diameter of the mother; - there are only twelve tentacles in a single row, but with a tendency to serial arrangement, for the alternate ones are much smaller than the rest. It is interesting to see the characteristic colouring distinctly shown in this newborn young: the tentacles in particular have the bands across the upper surface as numerous, as vivid, and as well-defined, as in any adult. Probably twelve tentacles is the normal number of the infant Actinia in all species, constituting the inner row. In a week or two other tentacles begin to appear, not in a regular series, but here and there from between the bases of those already formed.

There seems a greater readiness in this species to produce young in captivity than in any other that I have kept. Most of the specimens in my ressels have 
produced; some of them twice. One young at a time seems the rule, though I should not have expected so limited a birth: it is extruded from the mouth of the parent (as I conjecture, for I have not witnessed the parturition) and dropping on the bottom, attaches itself close by her side, or not far off, and maintains its position pretty pertinaciously, expanding its star-like disk for prey, and greedily seizing and derouring it when offered; even though it should be so large as to swell the body up to twice its former dimensions.

The tentacles on being subjected to pressure display a great number of filiferous capsules (Fig. 5) which are thrown off in multitudes with the mucus pressed off: They are very minute, almost linear. about $\frac{1}{1200}$ th inch in length. The extruded thread reaches to about $\frac{1}{70}$ th inch: no barbs were discernible on it.

SEA-SPIDER.

A singular marine spider (Phoxichilus) looking like a skeleton, throws about its long legs, and crawls slowly over the parasitic Crisice \&c. from the roots of Laminarice. A small one found to day carried under it four globose masses of eggs, altogether much wider than its body. They were difficult to detach, being firmly held by the first pair of feet, which are slenderer than the rest and bent under: the egg masses were of a flesh-colonr, and under the microscope were full of minute perfectly globular opaque ova.

BLACK SAND-WORM.

May 22nd.-I again visited Watermouth and 
Smallmouth. The Primrose still lingers in the lane leading up from Hele, but is almost replaced by the greater Stitchwort, and the red Campion; the pretty Milkwort is sprawling profusely over the banks, with its heads of delicate pink blossoms; the ramping Fumitory, with flowers more than usually rich in colour, occurs, and even the spikes of the common Bugle are attractive to the eye, though the plant is somewhat coarse on examination. In the little grove above Watermouth, the wild Hyacinth is still profuse, and the purple Orchis is abundant, and many of its spikes particularly fine, both in the size and number of their constituent blossoms. In a pond, the Water-crowfoot was filling the margins with its many-split leaves, and its unpretending little white flowers. At the shore I found under a stone a species of Arenicola, an uncouth creature, of a deep black hue, or rather what a tailor would call "invisible green." It is about six inches long, and $\frac{1}{4}$ inch in greatest thickness, which is nearest the head, but not abruptly. The whole is divided into 28 segments, each consisting of 6 annuli, of which the foremost on each segment is stouter, and preceded by a deeper incision than the rest. The 16 posterior segments are furnished with branchial tufts, and pencils of bristles; the former are two on each large annulus, on the dorsal aspect; they are protrusile, and consist of a great number of short filaments, incurved, which have the power of independent motion. When I first examined it, these little filaments were freely pushed out and retracted, and moved with a sort of grasping action; but after a day or two they were still. They were largest near the tail, gradually dimin- 
ishing to the middle of the body. On the outer side of each tuft is a small tentacle, or rather a fleshy tubular sheath, from wbich issues at will a flat pencil of fine bristles, arranged transversely to the line of the animal : they point upwards and slightly outwards. The bristles are very fine and gradually tapering to a point; they are plain, except near the tip, where they are clothed with the most delicate barbules, which however are closely appressed. These pencils of bristles do not cease with the branchial tufts, but are continued on every great annulus to the head. The mouth is constantly being everted and retracted; in the former process a trumpet-shaped mouth is unfolded, the edges and interior of which are set with dense papillæ; sometimes, especially after a day's captivity, this mouth is evolved to a still greater extent, so as to project the interior itself in a convex or almost globular form, which assumes a pellucid appearance, and a pale-brown hue. The rings of the body are occasionally adorned with a blue iridescence ; they are longitudinally wrinkled, and hence there is a sort of reticulation on the animal. When I first touched it, it discharged (I think from the tufts) a yellow fluid, which strongly stained my fingers: and on being kept in a saucer of clean sea-water, I found the latter in 24 hours tinged with olive; as was the water, with which I replaced it, the following day.

I subsequently found another specimen of this animal in similar circumstances. The colouring fluid was poured out in this case much more profusely. I stained some writing paper with it; the tint was at first a full greenish-yellow, but after a day or two it 
changed to a purplish-brown, quite permanent, neither alterable with water nor with time. The specimens came near to Arenicola branchialis of Aud. et M. Edw., but did not quite agree with the characters given to the species by those zoologists.

\section{A CRAB AT HOME.}

At the water's edge at the outer base of the Capstone at low water, spring-tide, I was looking about for Actinias, when peering into a hole $\mathrm{I}$ saw a fine Crab, not of the very largest, but still of very nice table dimensions. I poked in my arm and took hold of him, and though he made vigorous efforts to hold fast the angles and notches of his cave with his sharp toes, I pulled him out and carried him home. I I noticed that there came out with him the claw of a crab of similar size, but quite soft, which, 1 supposed, might have been either carried in there by my gentleman to eat, or accidentally washed in. After I had got him out, for it was a male, I looked in and saw another at the bottom of the hole, which appeared to me considerably smaller. I debated whether I should essay this one also, but reflected that I could only eat one at a supper, and that moderation in luxuries is becoming; "So," said I, "friend Crab, stay there till next time; I may find you here again on some other auspicious morning." When I arrived at home, however, I discovered that I had left my pocket-knife at the month of the crab-hole; a fine strong-bladed implement, that had already stood me in good stead on several occasions, cutting holes for my footsteps 
in the soft rock in climbing up the precipice, when embayed by the tide, and so forth. I felt loth to part with my old knife, and therefore at once put on my hat, running hard for fear the tide, which had already turned, might be too high. I got to the place, however, just in time, found my knife, and then took another peep at the Crab. It had not moved, and thinking that if I could not eat it myself I might ask my neighbour's acceptance of it, I drew it out with my fingers, as I had done with the former. But lo! it was a soft Crab; the shell being of the consistency of wet parchment, and the colours (all except those of the carapace) being pale. It was a female too, without any sign of spawn, and had lost one claw ; strange ! that I had not thought of connecting the soft claw that I had drawn out before, with this Crab that I saw at the bottom. But I carefully put the helpless creature into the hole again, and saw that it settled its legs and body comfortably in its old quarters; and there I left it : for our Crab is worthless for the table in this condition, unlike the Land Crabs of the West Indies, which are esteemed peculiarly delicate in their soft state.

What then are we to infer from this association? Do the common Crabs live in pairs? and does one keep guard at the mouth of their cavern, while its consort is undergoing its change of skin ? If this is the case, it is a pretty trait of cancrine character, and one not unworthy of their acute instinct and sagacity in other respects. The male displayed no appearance of the moult, its coat being of a shelly hardness. I have no doubt that the claw of its mate 
was unintentionally torn off, in its efforts to grasp some hold when resisting my tugs in dragging him out.

LEE.

A three miles' walk to the westward brings the pedestrian to a romantic little spot called Lee. The road lies over the downs, along the margins of those very precipitous cliffs that so characterize the coast hereabout. It does not present any unusual features, to be sure, in a country where grandeur and variety of scenery are the rule, but even if these were wanting, green lanes and downs, hedges covered with flowers, the glittering insects and the singing birds, the surge of the sea far below, the sun, and the breeze, would make any walk enjoyable at this season. Hither then, basket in hand, I strolled, to discover what the shore might afford me of the minuter works of God, which are so eminently worthy of being studied, so eminently calculated to afford the contemplative mind food for wonder, delight, and meditation, though nine hundred and ninety-nine out of every thousand of mankind never bestow a thought upon them, and even the great bulk of those who seek recreation by the sea side, tread them beneath their feet in the most absolute unconsciousness of their very existence.

Lee is the opening of a beautiful valley, which bends to the right as you look at it from the sea. The bottom is chiefly occupied by meadows, to whose carpeted surface the late rains had imparted the most brilliant verdure. The hedge-rows are profusely 
planted with elms and other trees, which, whatever may be thought of their utility in husbandry, do certainly improve the landscape wonderfully, affording the finest contrasts between their dark masses of foliage, and the tender green of the fields, as bright as an emerald in the sunlight, seen in peeps between them. A few farms and villas, embowered in orchards and gardens, constitute the hamlet of Lee, and being scattered over the bottom and along the slopes are very picturesque. The valley rises a little inward, and is presently lost to view by bending round to the right, where it is shut in by the steep rounded hill that forms that side. The whole of this hill, from its base to its lofty summit, is covered with wood, while the hill on the opposite side, equally lofty and equally steep, is an open down, varied only by a few scattered clumps of furze. A little stream turns the huge wheel of a mill at high-water mark; then spreads itself over the sand and shingle in broad shallow sheets rather than channels, till it finds the receded tide. The character of the rocks is rather peculiar: around on either side of the cove there are the same sharp rugged upslanting ridges and pinnacles as elsewhere, and some pretty little deep nooks are formed in the high rocks on the western side, enclosing sloping beaches of sand, entirely dry at low water but covered by the flood-tide. The whole lower part of the cove itself, however, that is, all between tide-marks, consists of the usual rocks, grey friable slate, cut off as it were to one level, about three or four feet above the shingle, and these intersected by a thousand irregular channels, and now and then interrupted by broad areas of sand 
and gravel. At the extreme of low water (it was spring-tide), the points where these channels, (the drainage of the sea-water from the weed-covered rocks, mingled with the stream from the land) debouched into the sea, were strewn with loose stones and boulders of various sizes, partly embedded in the deposit of mud which this formation so copiously supplies; for the ease with which the substance of this grey slate is abraded by the action of the waves covers the bottom with a fine whitish slimy mud, very umpleasant to the feel, and ever ready to be stirred up when a little sea is on. 'The water here therefore scarcely ever has the brilliant clearness which characterizes it among the limestones and sandstones of South Devon.

Stones found in such circumstances afford a good hunting ground for the naturalist; fishes, crustacea, amnelides, and star-fishes in particular haunt under their shelter, and an hour's turning will, unless his fortune be unusually inauspicious, vield him material for days' study. Beneath one of these stones I found a specimen of our smallest native Pipe-fish, which Mr. Yarrell has described under the name of the IVorm Pipe-fish (Syngnathus lumbriciformis). It is a much more beautiful little creature than you might suppose from either the figure or the description of that eminent zoologist, who probably has had no opportunity of seeing its living grace and elegance. Mr. Yarrell simply says that its " colour is dark olive green"; this howerer very imperfectly expresses its various tints, a want which I will endeavour to supply with the little beauty before my eyes; premising that 
it is not very easy to describe in detail an agile creature that is every moment gliding in and out among the sea-weeds in its vase. (See Plate VIII. Figs. 6 and 7.) The general hue of the body is a warm yellow olive, becoming silvery grey on the under part of the lengthened tail, from the vent backward. The sides of the head and neck are profusely marbled with conspicuous spots of pure white, of varying form and size, the effect of which is heightened by each being surrounderl by a border of black; on each side of the crown also there passes oft from behind the eye to the occiput, an interrupted streak of white, bordered below with black. A flush of red purple suffuses the middle of the operculum, covering without concealing the spots and clouds of that part. Between the gills and the vent there are numerous rows of white dots, arranged perpendicularly on each side of the body at regular intervals; these doubtless mark the plates of the mailed corering, a row to a plate, but whether they are placed in the middle or at either edge of the plate, I cannot say, for all my efforts will not avail to make out the limits of the plates in the living fish ; the contour of the body is perfectly smooth and flowing, not cylindrical, but compressed and forming an edge on the back and on the belly. Scattered specks of white lie between the perpendicular rows. Behind the vent the body is perceptibly constricted between the plates, and this alternate swelling and constriction extends to within half an inch of the extremity of the tail; the remainder being abruptly attenuated and smooth. Each of the plates on the tail is marked at each edge of the under side, by a roundish well- 
defined white spot, succeeded by one of black; and the whole of this part, which glistens with a lustre like that of tin-foil, is sprinkled with numerous irregular white and black spots. The eye is very beautiful; it is particularly large, full, and glassy; the pupil is encircled by a fine ring of golden red, and the iris is marked with alternate divergent bands of grey and brown. The fin-rays are simple, and, with the membrane, which is very subtle, are studded with very minute olive specks, except in diagonal spots and bands of clear space.

The muzzle is abruptly narrowed immediately before the eves (looking at it vertically), and widens a little towards the tip: the mouth opens, as in other Pipefishes, perpendicularly. The nostrils form minute projecting warts. The line of the belly is gently curved to the vent, from which point the body is much more slender, both laterally and ventrally. The tail is compressed, and terminates in a flattened point. I observed a curious bladder-like tumour, under the throat, just behind the gill-covers, but whether it is normal or accidental I cannot say.

In captivity the manners of this pretty little fish are amusing and engaging. Its beautiful eyes move independently of each other, which gives a most curious effect as you watch its little face through a lens; one eye being directed towards your face, with a quick glance of apparent intelligence, while the other is either at rest, or thrown hither and thither at various other objects. I was strongly reminded of that strange reptile, the Chameleon.

Another point of resemblance to that animal our 
little Pipe-fish presents in the prehensile character of its tail. It curves just the tip of this organ laterally round the stem or frond of some sea-weed, and holds on by this half-inch or so, while the rest of its body roves to and fro, elevating and depressing the head and foreparts, and throwing the body into the most graceful curves. The immediateness, with which the prehensile action followed contact of the part with any object, reminded me of what I have observed in the tails of the American Monkeys, in which the slightest and most accidental touch of the tail-tip instantly excites the grasping action. Perhaps it is in a measure involuntary.

All the motions of the Pipe-fish manifest much intelligence. It is a timid little thing, retiring from the side of the glass at which it had been lying, when one approaches, and hiding under the shadow of the sea-weeds, which I have put in both to afford it shel ter, and also to supply food in the numerous animalcules that inhabit these marine plants. Then it cautiously glides among their bushy fronds, and from under their shelter peeps with its brilliant eyes at the intruder, as if wondering what he can be, drawing back gently on any alarming motion. It was only by taking my opportunity, presenting my pocket lens, and approaching my face to the side of the glass very slowly and cautiously, that I could examine it sufficiently for the purposes of delineation and description.

In swimming it is constantly throwing its body into elegant contortions and undulations: often it hangs nearly perpendicular, with the tail near the sur- 
face, and the head near the bottom of the glass, only bent upwards with a sudden curve: now and then it butts against the side of the vessel, or even against the bottom, with reiterated blows of its nose as if it could not make out why it should not go forward where it can see no impediment. Now it twists about as if it would tie its body into a love-knot; then hangs motionless in some one of the "lines of beauty" in which it has accidentally paused; its airbladder conspicnous as a pellucid oblong spot about halfway between the nose and the vent, as you look at its body between your eye and the light; and then if you apply your lens carefully you will see the constant action of the gill-covers, and the periodical currents of water shot forth behind in two forcible jets, from a minute orifice on each side, just above the operculum edge. The little fin that rides on the middle of the back, so filmy as to be scarcely noticeable while unmoved, is constantly, while the fish is swimming, and at frequent intervals while it is at rest, fluttered with a rapid vibration, like that of the gauzy wing of an insect. This is a very charming action.

My specimen is about five inches long, which is the size given by Mr. Yarrell as that of adult age ; but I do not see any trace of ova, or of the pouch proper to the male ; it is probable it is a female.

It does not appear to be nocturnal in its activity : it ordinarily lies quiet, if undisturbed, and concealed among the more bushy of the sea-weeds, for the gieatest portion of its time, but usually comes forth once or twice in the day for a half-hour's play, when it swims about in contortions in the manner I have 
described. I think I have observed that the afternoon is a favourite season for these exercises; not, however, that it adheres with any regularity to time.

June 23rd.-I have had my little Pipe-fish now nearly three weeks. The terminal portion of the tail, that I mentioned above as abruptly attenuated, flattened, and smooth, has grown considerably : it was at first not quite half-an-inch in length, it is now nearly an inch: the appearance is exactly like that of a renewed tail, like that of a Lizard for instance. But there is another change in $\mathrm{my}$ little captive, that is less pleasing. The bladder-like tumour beneath the throat has increased, and spread, so that above, on the sides, and below, all about the body, the fish is nearly covered with large patches of bladders, many of them contiguous to each other, evidently filled with water or air. It is probably air ; for the effect is to float the fish on the surface; and it is only by muscular energy in swimming that it can get down again when once at the top; and when among the weeds it is fain to take hold with its prehensile tail to keep itself there. It is evidently a disease; analogous, one might say, considering the difference of the elements in which we respectively live, to the dropsy among ourselves. I endeavoured to tap some of the largest bladders with a needle, and fancied it felt some relief ; but I was afraid to attempt much at this kind of chirurgery, lest I might be found guilty by a jury of fishes of the crime of fish-slaughter. What little I did, however, seemed to do good, for the next day many of the bladders had disappeared, but only to return in greater numbers and size than ever. The 
poor little fish now could only float at the surface; and as that could not last long, I resolved to attempt a more extensive puncturing. I accordingly took it into my fingers, and pierced the bladders here and there in various parts of the body, and then returned it to the water. At first I was afraid I had killed it by keeping it out of water, though only for so brief a period as a few minutes (certainly not more than two or three); for it floated belly uppermost, and appeared much exhausted, but gradually recovered. Though it did not appear immediately that the bladders communicated with each other, yet they certainly did, for the next day they had greatly diminished, and in a few days they had entirely disappeared; the skin had healed and become smooth and healthy, and the little creature was able to enjoy itself again.

July 6th.-I found my pet dead, on my return after a week's absence from home; it had apparently been dead about three or four days; so that it has lired in captivity rather more than four weeks.

The difficulty of delineating with accuracy objects that can be defined only with microscopic powers would hardly be imagined by those who have never attempted it. In the case of this little fish, every glance at its form or colours, in order to transmit them to the paper, was taken through a triple pocketlens, which had to be exchanged for the pencil at each stroke. The focus of this glass was about half an inch, but the fish was swimming freely in a large glass vase five inches wide; so that it was only when it spontaneously approached close to the side of the transparent vessel, that I could get a sight. It was, 
of course, of no use to try to pusl it to the required spot; the attempt only alarmed the little creature, and made it dart hither and thither; I could only wait patiently its wayward will. When it came, perhaps it would be with the wrong side presented towards me, or the part which I wanted would be turned to one side, or in some way altered from its former position. And very often indeed, just as I had got my glass to the focus, and my eye to the glass, after waiting perhaps for a quarter of an hour,--before I could get a glance with sufficient distinctness to impress an image on my eye for delineation, the fish would dart over to the other side, and leave me to exercise patience for another quarter.

This is the perpetual experience of those who draw living animals with the microscope. The camera lucida is an admirable aid for motionless forms, but it is powerless for such as are agile and fitful. Nor is the case of those minute creatures that are viewed through the compound microscope at all better than that of my Pipe-fish watched through a lens held in the fingers. In order to see it to adrantage, you must allow your Zoophyte or Annelide space sufficient to expand or move in ; when, if it be a lively species, probably, just as you have got it steady enough to delineate the first two or three lines, away it suddenly starts, its position is quite changed, the relation of its parts to your eye is altered, or perhaps it shoots clean off, out of the field of vision. 


\section{CHAPTER VIII.}

Rock-pools - Their Abundance-Southey's Description-Its truth to Nature-Their Loveliness-Chondrus-Its brilliant Reflections-The branching Coryne-A Parasite-A Beautiful Sea-weed-Structure of the Zoophyte-Origin of its nameTentacles-Their Structure-Egg Capsules-Escape of the Eggs--The Bird's-head Coralline-Elegant Shape of the Polypidom-Advantage of studying living Animals-The Cell -The Polype--Its Organization-Muscles-Economy in God's works-A Populous Stone-Enumeration of its TenantsReflections-God's Purpose in Creation-The hopeful Future - The Sessile Coryne-The Belgian Pedicellina-Its Form and Structure-Production of its Young-Its Habits-Its Affinities-The Slender Pedicellina-Its singular Bulb.

\section{ROCK-POOLS.}

What a delight it is to scramble among the rough rocks that gird this stern iron-bound coast, and peer into one after another of the thousand tide-pools that lie in their cavities! They are particularly abundant here; and indeed it is to the peculiar character of the rocks, their rugged unevenness, depending upon their laminated structure, and the inclination of their strata, that we are indebted for the pools, which make the coast so rich and tempting a hunting ground to the naturalist. I do not wonder that when Southey had an opportunity of seeing some of these beautiful quiet 
basins hollowed in the living rock, and stocked with elegant plants and animals, having all the charm of novelty to his eye,-they should have moved his poetic fancy, and found more than one place in the gorgeous imagery of his oriental romances. Just listen to him.

It was a garden still beyond all price, Eren yet it was a place of Paradise :

And here were coral-bowers, And grots of madrepores, And banks of sponge, as soft and fair to eye

As e'er was mossy bed

Whereon the wood-nymphs lie With languid limbs in summer's sultry hours.

Here too were living flowers,

Which like a bud compacted,

Their purple eups contracted,

And now, in open blossom spread,

Stretch'd like green anther's many a seeking head.

And arborets of jointed stone were there, And plants of fibres fine as silkworm's thread;

Yea, beautiful as mermaid's golden hair

Upon the waves dispread.

Others that, like the broad banana growing, Rais'd their long wrinkled leaves of purple hue,

Like streamers wide outflowing.

(KеHAMA, XVI. 5.)

A hundred times might you fancy you saw the type, the very original of this description, tracing line by line, and image by image, the details of the picture; and acknowledging, as you proceed, the minute truthfulness with which it has been drawn. For such is the loveliness of nature in these secluded reservoirs, that the accomplished poet, when depicting the gorgeous scenes of eastern mythology, scenes the 
wildest and most extravagant that imagination could paint, drew not upon the resources of his prolific fancy for imagery here, but was well content to jot down the simple lineaments of nature, as he saw her in plain homely England.

It is a beautiful and fascinating sight for those who have never seen it before, to see the little shrubberies of pink coralline,- the "arborets of jointed stone,"that fringe these pretty pools. It is a charming sight to see the crimson banana-like leaves of the Delesseria waving in their darkest corners; and the purple fibrous tufts of Polysiphonice and Ceramia, "fine as silkworm's thread." But there are many others which give variety and impart beanty to these tide-pools. The broad leaves of the Ulva, finer than the finest cambric, and of the brightest emerald-green, adorn the hollows at the highest level; while at the lowest wave tiny forests of the feathery Ptilota and Dasya, and large leaves, cut into fringes and furbelows, of rosy Rhodymenia. All these are lovely to behold, but I think I admire as much as any of them, one of the commonest of our marine plants, Chondrus crispus. It occurs in the greatest profusion on this coast, in every pool between tide-marks; and every-where,except in those of the highest level, where constant exposure to light dwarfs the plant, and turns it of a dull umber-brown tint,-it is elegant in form and brilliant in colour. The expanding fan-shaped fronds, cut into segments, cut, and cut again, make fine bushy tufts in a deep pool, and every segment of every frond reflects a flush of the most lustrous azure, like that of a tempered sword-blade. Professor 
Harvey, than whom no higher authority can be cited on the subject of marine botany, says that this species "has been observed to be occasionally iridescent." But he has surely not seen it around Ilfracombe; for, with the exception of the stunted fronds that grow near high-water, I have never seen it otherwise, and I have seen roods upon roods of the plant. This iridescence is common to it also around Torquay; it is not lost nor even diminished when the plant is kept in an aquarium, for I have specimens that have been growing for many weeks in my pans and glass vases, and which are as brilliant as when they were first procured.

THE BRANCHING CORYNE.

Peeping about among the pools that lie clear and calm in the hollows of the rocks below the Torrs, my eye was attracted by a tuft of that feathery sea-weed, Ptiluta sericea. It is not uncommon, fringing the perpendicular sides of the ragged ledges and outcropping strata, near the lowest tide-mark, wherever the form of the succeeding ledge allows the water to lie in a long, narrow and sharp-bottomed pool. The colour of this sea-weed is not particularly attractive, for it is of a dull brownish red, and the fronds have frequently a ragged appearance; but if it be carefnlly spread out in a saucer of sea-water and examined, there will always be some branches to be found of a livelier hue than the rest, and these will best show the exquisite plumose structure. Each branchlet resembles a tiny feather regularly pinnated; and if 
examined in a microscope of rather high power, each of the ultimate nerves of the pinnation, as well as the vanes or pinnules themselves, is seen to be composed of a single row of red transparent cells, of an oblong cylindrical form sometimes swollen in the middle, attached to each other end by end, looking something like the back-bone of a fish, when all the ribs and spines are detached.

But what attracted me on this tuft of sea-weed whose soft feathery branches were hanging from the sides of the rock iuto the calm and dark pool, was a slender branching filament that was evidently a parasite. I separated the Ptilota with as much of the base as I could, and put it into a broad-mouthed phial of clean water, I could not wait till I got home, but looked out for a dry smooth stone on which to sit, pulled out my pocket-lens, and looked at it. To my gratification it was a polype that I had several times vainly wished to find; I had no difficulty in recognizing its similitude to Mrs Johnston's beattiful figure of Coryne pusilla in Brit. Zooph. pl. ii. (2nd. Edit.); though I think it rather belongs to the species distinguished as ramosa. It may possibly be the C.glandulosa of Dalyell (An. of Scot. Tol. ii. pl. 21);-but hardly of pl. 22.

It was not however, until I could institute a closer examination of it at home, that I fully apprehended its curious structure or its elegant beauty, and this, by the aid of a sketch that I immediately made of its microscopic appearance, I will endeavour to convey to you.

The animal as seen by the naked eye looks like a 
Mute $\mathrm{X}$

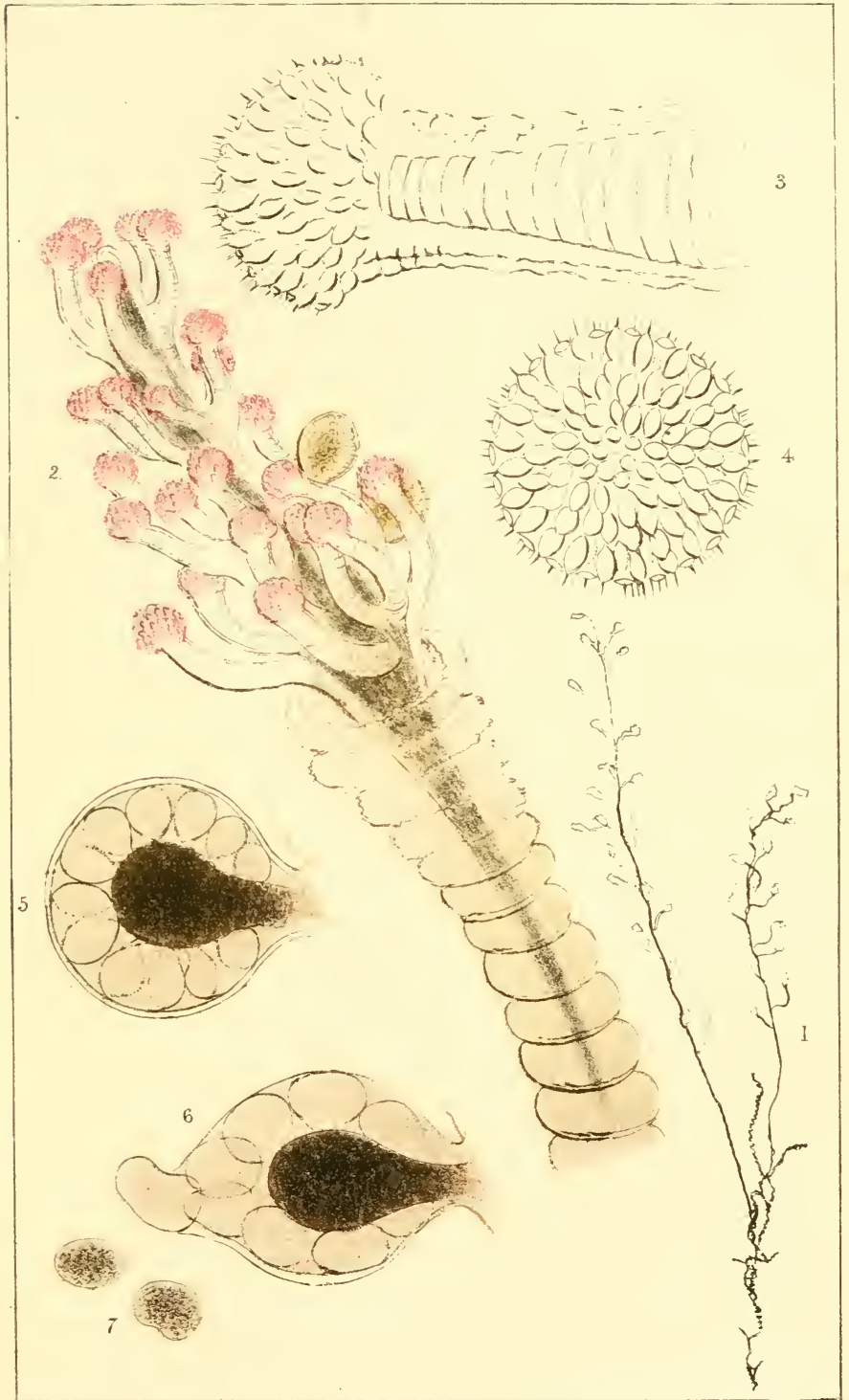

in iei

Printed by Hulimaidel \& Wulton

CORANE FAMOSD 

very slender branching plant. (Plate IX. Fig. 1.) It is altogether about as thick as fine sewing cotton; an irregularly winding thread creeps along the frond of the sea-weed, clinging firmly to it as it goes, yet not so tenaciously but that it may be pulled away without dividing. This creeping root sends off frequent rootlets, which crossing each other appear to anastomose, making a sort of net-work of a few oblong areas. Free stalks shoot up here and there from the creeping stem, one of which in my specimen is upwards of three inches in length: they show a very slight disposition to ramification; but send forth at short intervals the polype-branchlets, irregularly on all sides. A few of these are compound, one branchlet giving origin to another from its side. The creeping fibre, the stalk, and the branchlets are seen under the microscope to be tubular, aud the two latter are marked throughout their course with close-set rings, or false joints, apparently produced by the annular infolding of a small portion of the integument. (Fig. 2.) The tube is of a yellowish-brown colour, sufficiently translucent to reveal a core or central axis of flesh running along its centre, and sending off branches into the polype-branchlets, from the open tips of which the flesh emerges in the form of a thickened oblong head, somewhat club-shaped, whence the name Coryne, (from ropúrn, a club) which has been assigned to this genus by naturalists. The tube or sheath becomes membranous, or I think gelatinous, (like that of some Rotifera) at its margin, the ultimate three or four rings being evidently soft, scarcely consistent, viscid (entangling extraneous matters), almost colourless, 
of undefined outline, and larger than the rest. The polype-flesh, which is very slender within the tube, enlarges rapidly as it emerges. The clubshaped head of the polype is studded with short tentacles of curious and beautiful structure. They vary much in number on each polype, but the full complement appears to be from twenty-five to thirty; they are arranged in somewhat of a whorled manner, in four or five whorls, which are, however, (especially the lower ones) often irregular and scarcely distinct. Four tentacles usually constitute the final whorl; about six the next, the others respectively contain seven or eight, and ten or twelve. The tentacles spring from the axis with a graceful curve, they are rather thick and short, when contracted, but slender when elongated, nearly equal in diameter, except at the termination, where each is furnished with a globose head. This head (See Figs. 3 and 4 ) is studded with minute tubercles on every part, which reflect the light, and which viewed by transmitted light are seen to be the terminations of numerous oval cells or follicles set in a divergent manner around the centre. Each tubercle is tipped with a minute bristle. The neck or body of the tentacle is perfectly transparent, pellucid, whitish or nearly colourless, and appears to be a tube with thin walls slightly hairy on the surface, but containing a colourless thickish axis, freely permeating its centre, marked with delicate parallel rings. The globose knobs at the tips of the tentacles remind me of the unexpanded blossoms of an Acacia: they are generally tinged with pale red, and in some polypes, especially terminal ones, they 
are of a fine rose colour, and have an attractive appearance.

The tentacles are endowed with the power of free motion, and they frequently throw themselres to and fro with considerable energy; when perfectly at ease they are carried projecting at right angles from the polype, but are more commonly curved up towards it. The whole polype can be also tossed from side to side at pleasure. The tentacles are contractile and extensile in some degree; for if the animal be taken out of water for an instant, and again replaced, these organs are found to be shrunk up to less than half of their former length. In a few minutes they recover their extension.

Some of the polype heads are furnished with organs of another kind. Among the tentacles, chiefly of the lower whorls, are seen one or two oval bodies, about twice or thrice as large as a tentacle-head, which are attached by short footstalks to the polype-body. They are composed of a clear jelly-like granular mass, with an oval dark nucleus in the centre, connected with the attachment: the nucleus is of an orange or yellow hue, and is coarsely granulated. In some that I kept, this dark nucleus became larger until it almost filled the interior; but the death of the animals prevented my seeing the full development. These are egg-capsules, as I afterwards ascertained.

About the end of August a fine specimen in one of my glasses fell under my notice, as having an appearance which made me think that it had just renewed its polype-heads after the old ones had decayed away. But in looking at it I saw that one head bore two 
ovigerous vesicles of so large a size that $I$ at once jsolated the head in hopes of witnessing the development of the embryo.

The capsules showed the same structure, but as one was larger and evidently more developed than the other, I selected that one for particular examination. (Fig. 5). It was perfectly spherical, with a short footstalk, through which a neck of dark brown substance connected with the central nucleus, which was also dark brown, round or slightly oral, and welldefined. This nucleus is not an aggregation of ova, as Dr. Johnston seems to suppose (Br. Zooph. 39), but a sort of placenta around which many ova are arranged, in the manner shown at Fig. 5 (representing for clearness' sake a section). 'These ova fill the whole space between the nucleus and the walls of the capsule; they are of a clear, yellowish-brown hue, slightly granular in texture, rondo-triangular in form, with one angle resting on the placental nucleus.

I had not been watching the capsule many minutes before its gelatinous walls burst at the side the farthest from the footstalk; and the ova began to issue forth in quick succession, as shewn at Fig. 6 . It appeared that the elasticity of the walls was the immediate cause of their exit, for they were evidently pressed out; and towards the end of the process when few remained, the collapse of the walls became quite evident, and when the last ovum was excluded, the capsule had shrunk up so as to leave scarcely any appreciable space between the skin and the nucleus, which latter remained unchanged

Twenty five ova were thus excluded from one cap- 
sule, the process being all over in about a minute. To my surprise they were neither medusoids, nor ciliated planules, but soft gelatinous inanimate eggs, closely like those of Rotifera, without the least appearance of cilia, or of spontaneous motion (Fig. 7). They all sank immediately to the bottom of the glass cell, and remained motionless, as far as respects change of place. But after several hours I perceived that each egg was undergoing a constant change of shape, reminding me of those alterations of outline seen in the Amaba among Infusoria. Sometimes a constriction would appear across one end of an egg, which would move towards the middle, eutting it into two portions, then be slowly obliterated. Or from some point in the circumference little swellings would protrude, and these I have reason to think separated, for though I did not actually see this done, I saw several small globules lying by, of exactly the same substance and colour as the ova themselves. Or an egg would imperceptibly become from round to oval, thence to pear-shaped, and thence assume some irregular form, and gradually revert to its original appearance. These changes were slow in operation, but they indicate that the ovum remains soft and shell-less, and that there is a principle of volition within it. They one by one decomposed.

THE BIRD'S HEAD CORALLINE.

In one of the shallow pools near the base of Capstone Hill, I took several beautiful specimens of one of the prettiest of the Polyzoan polypes, Cellularia 
avicularia. Well does it deserve the name of Bird's head Coralline, given it by the illustrious Ellis, for it possesses those curious appendages that resemble Vulture's heads, in great perfection. All these specimens of mine were most thickly studded with them, not a cell without its bird's head, and all seesawing, and snapping, and opening the jaws, with the most amusing activity, and (what was marvellous) equally active on one specimen from whose cells all the polypes had died away, as in those in which the polypes were protruding their lovely bells of tentacles.

The polypidoms were distinctly visible to the naked eye, and attracted my attention before I touched them, while yet in their native pool ; though of course I did not know what they were until I examined them to better advantage. Some of them stand two inches in height, and are about one third of an inch in widest diameter. The cells are set in longitudinal series, two or three rows abreast, and closely adhering; the branchlets thus formed divide dichotomously, (that is, into two, and each of these into two more, and so on,) and so make broad fan-shaped branches, which are segments of funnels: and the peculiar elegance of this zoophyte consists in the mode in which these ultimate branches are set on the stem, viz. in a spiral turn, so that the effect is that of several funnels set one within another, but which yet are seen, on turning the whole round, to compose one corkscrew band of fans. (See Plate X. fig. 1.)

The stem ascends perpendicularly from a slender base which is attached to the rock, or to the cells of 


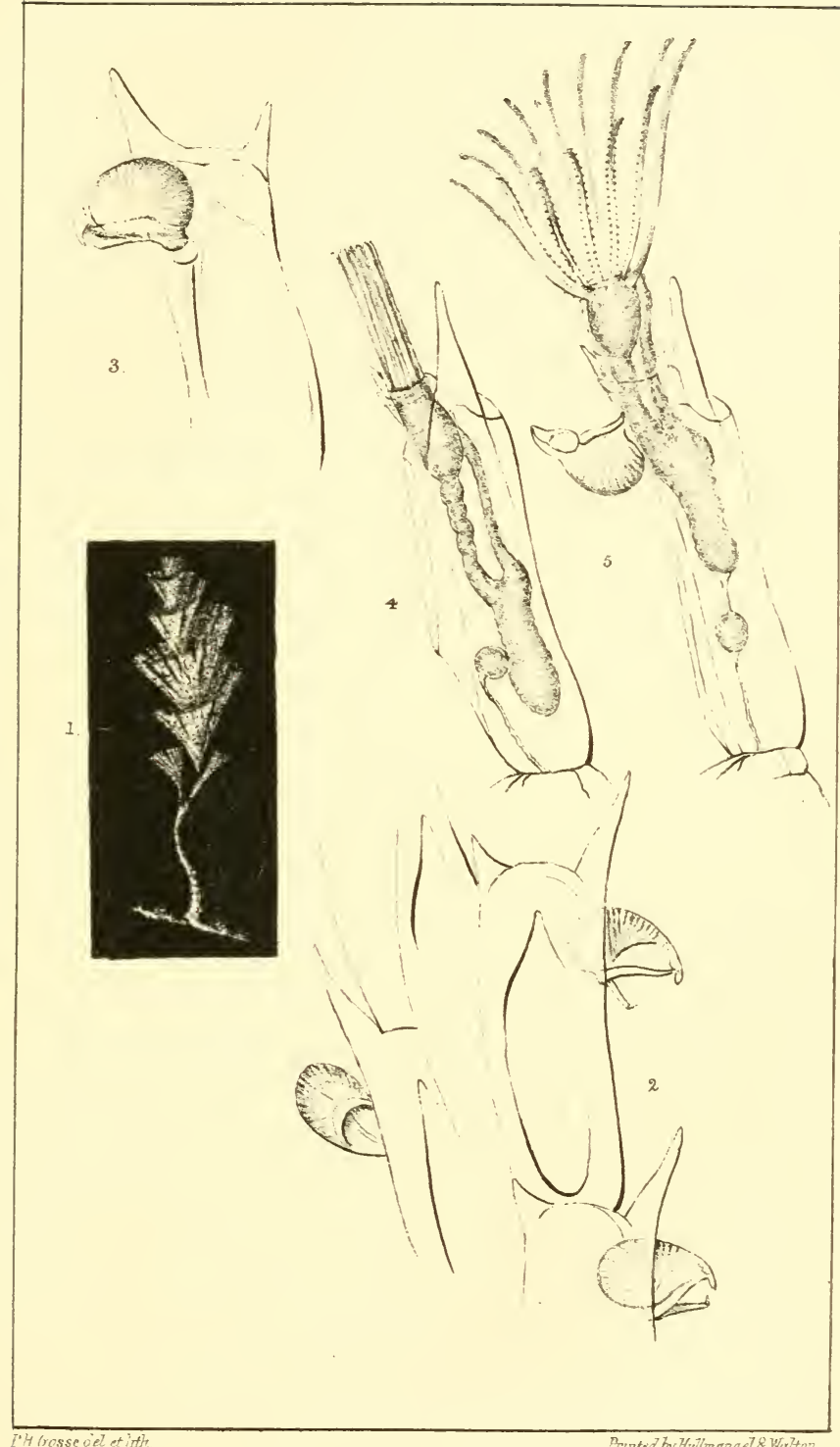

Prented by Yind maracl \& Hater?

CELLUIAARIA AVICULARIA. 

a Lepralia which encrust the rock; the midmost part of the spire is most expansive, whence the diminution above and below is pretty regular, The general colour, while alive, is pale buff, but the cells become nearly white in death.

When examined microscopically it is, however, that the curious organization of this zoophyte is discovered, especially when examined in full health and vigour, with all the beautiful polypes protruded and expanded to the utmost, on the watch for prey. It seems to me a poor thing to strain one's eyes at a microscope over a dead and dry polypidom, as it does to examine it shrivelled and blackened flower out of a herbarium; though I know well that both the one and the other are often indispensable for the making out of technical characters. But if you want to get an insight into the structure and functions of any of these minute animals, especially such as are so transparent that all the offices of life are discernible in active operation, or if you want to be charmed with the perception of beauty, or delighted with new and singular adaptations of means to ends, or if you desire to see vitality under some of its most unusual and yet most interesting phases, or if you would have emotions of adoring wonder excited, and the tribute of praise elicited to that mighty Lord God who made all things for his own glory,- - then take such a zoophyte as this, fresh from his clear tide-pool, take him without injury done by violently tearing him from his attachment, and therefore detach with care a minute portion of the surface-rock itself, and then drop him with every organ in full activity into a narrow glass cell with 
parallel sides, filled with the purest sea-water, and put the whole on the stage of your microscope with a power of not more than 100 linear, at least for the first examination;-I greatly mistake if you will not confess that the intellectual treat obtained is well worth, aye, ten times more than worth, all your trouble.

The cells of the Bird's-head Coralline are oblong, shaped somewhat like a sack of corn, with a spine ascending from each of the upper corners. (See figs. 2 and 3.) Each stands on the summit of its predecessor in the same row, and side by side with those of its fellow rows, in such an order that the top of one cell comes opposite the middle of the one beside it. The top of the cell is rounded and appears imperforate, but we shall presently find an opening there. The broad side that faces inwardly has a large elliptical transparent space occupying nearly its whole surface, which, from its well-defined edges, I was long tempted to think, was really a great aperture, though delicate manipulation appeared to give a very subtle surface to it; this, as I subsequently found, is covered with a very thin and elastic membrane, and answers a peculiar end. Just below one of the spines that crowns the summit of the cell, on one of the edges, rather on the interior than on the exterior, is situated a little tubercle, to which is attached, by a very free joint, a bird's-head process, in all essential particulars agreeing with that of Cellularia cilitata wbich I have already described. The lower mandible in this case is, however, set farther back, and the upper is destitute of those tooth-like serratures that characterize it 
in the kindred species. The motions are exactly the same in both cases. I observe that sometimes the place of the bird's head is occupied by an oval or pear-shaped body, which is probably an early stage of its development; and when perfectly formed there is much difference of size, some of these curious organs being twice as large as others on the same specimen.

Now let us come to the polype itself. It is when we get a good lateral view of a single inhabited cell, that we obtain a knowledge of the structure of the tenant. The summit of the cell is then seen to protrude, diagonally towards the inner side,-(i.e. towards the axis of the spire) a tubular mouth, which is membranous and contractile. When the animal wishes to emerge, this tubular orifice is pushed out by evolution of the integument, and the tentacles are exposed to view, closely pressed into a parallel bundle (See fig. 4); the evolution of the integument, that is attached at their base, goes on till the whole is straightened, when the tentacles diverge and assume the form of a funnel, or rather that of a wide-mouthed bell, the tips being slightly everted (See fig. 5). They are furnished with a double row of short cilia in the usual order, one set working upward, the other downward. Their base surrounds a muscular thick ring, the entrance to a funnel-shaped sac, the substance of which is granular, and evidently muscular, for its contractions and expansions are very vigorous, and yet delicate. Into this first stomach passes with in sort of gulp any animalcule, whirled to the bottom of the funnel by the ciliary vortex, and from thence it is 
delivered, through a contracted, but still rather wide gullet, into an oblong stomach, the lower portion of which is obtuse. An extremely attenuated duct connects this, which is probably the true stomach, with a globular, rather small, intestine, which is again connected by a lengthened thread with the base of the cell. By an arrangement common to the ascidian type of the digestive function, the food is returned from the intestine into the true stomach, whence the effete parts are discharged, through a wide and thick tube that issues from it close behind the point where the gullet enters. This rectal tube passes upwards parallel to the gullet, and terminates by an orifice outside and behind the base of the tentacles. All these viscera are beautifully distinct and easily identified, owing to the perfect transparency of the walls of the cell, the simplicity of the parts, and their density and dark yellow colour. All of them are manifestly granular in texture, except the slender corrugated tube which connects the stomach with the globose intestine: this is thin and membranous, and is doubtless, if I may judge from analogy, capable of wide expansion for the passage of the food-pellet.

The sudden contraction of the polype into its cell upon disturbance or alarm, and its slow and gradual emergence again, afford excellent opportunities for studying the forms, proportions, and relative positions, of the internal organs. In contraction, the globular intestine remains nearly where it was, but the stomach slides down into the cell behind it, as far as the flexible duct will allow, and the thick gullet bows out in front, shewing more clearly the separation between it 
and the rectum, and the insertion of both into the stomach. This retractation is in part effected by a pair of longitudinal muscular bands, which are inserted at the back of the bottom part of the cell, and into the skin of the neck below the tentacles. The contraction of these bands draws in the integument like the drawing of a stocking within itself, and forces down the viscera into the earity of the cell, which is probably filled with the vital juices. (See Fig. 4).

Besides the hind bands there is one or a pair of similar muscular bands attached on each side of the front part of the base of the cell, and inserted similarly into the neck. It was while watching the contraction of these that I discovered with pleasure the use of the membrane-covered aperture up the front of the cell. At the moment of the retractation of the viscera into the cell, a large angular membrane was forced outward from the front side, which was protruded more or less in proportion to the degree of withdrawal of the polype, and as the latter emerged again, the membrane fell back to its place. It is evident then that this a provision for enlarging the cavity; the walls are horny and probably almost inelastic, but when the stomach forces the intestine forward, and the thick gullet is bent outward by the withdrawal of the neck and tentacles, the needful room is provided by the bulging out of this elastic membrane, which recovers its place by the pressure of the surrounding water, when the pressure of the fluids within is removed. 
A POPUlOUS STONE.

The economy with which God works in nature has been often noticed, and especially that phase of it which consists in the profusion and variety of existance that can be crowded and sustained in a given space. A plant is growing in the earth; it occupies a certain amount of room, and appears, to speak loosely, to fill it. But on examination we may find other plants growing on it; its back, the angles of its branches, its buds, its leaves, the interior of its blossoms, its seed-ressels-are occupied by many species of spiders and insects, which find ample room for the carrying on of their respective functions and the enjoyment of their lives; not to speak of the birds, and butterflies, and bees, and flies, that are but temporary visitants, mere comers and goers. Many of these minute animals have other creatures living on them as parasites; the earrig that is snugly ensconced in the tube of that flower is tenanted by a long intestinal worm; yonder caterpillar so calmly gnawing out sinuous cavities in the edge of a leaf, supports within a colony of infant ichneumons; the little wild bee that has just alighted on this blossom would be found to carry about sundry maggots whose black heads peep out from beneath the rings of his abdomen. Even the very juices that circulate in the vessels of the plant probably bear along in their course the germs of invisible animalcules; for if we take the leaves, or the flowers, or the stems, and make an infusion of them, carefully covering the vessel to 
prevent intrusion from without, we shall find in a dav or two that the water is swarming with living creatures of rarious kinds, known to microscopic observers as infusory animalcules.

But I think nowhere is this economy seen to better advantage now nowbere here is it more admirable than in the sea, especially about the rude rocks that fringe our coast, and that we are apt to think so barren and repulsive. The rough stony surface of the rock between tide-marks, is quite alive with beautiful and interesting creatures both animal and regetable; and as we find the profusion increase the nearer we approach to that line whence the nutrient water nerer recedes, we have a right to conclude, that it extends to an indefinite distance below tide-limit. The tiny pools that lie in the hollows, renewed twice erery day by the influx of the sea, are perfect nurseries of plants and animals of the most curious forms, and of the most interesting structure.

I will endeavour to enumerate the diverse kinds of organic life that I have detected on a small fragment of rock now before me. It is a bit scarcely bigger than a penny-piece, which I detached the other day from a little rock-pool near low-water mark on the sea-ward side of Capstone Hill. One single polype on it attracted my notice by its beautr; and when I applied my chisel to the fragment, I did not suspect that it was particularly rich in animal life; nor is it richer than usual in the amount of animal life that it supports, but the variety certainly struck me as remarkable on so small a surface, when I came to examine it. 
First of all, the surface is largely encrusted with the cells of a Lepralia, the species of which I shall probably better know when the development of some of its granules that I am watching is further advanced. Orer these cells a yellow Sponge has spread itself, very thin, and profusely spiculous; and patches of a scarlet Sponge of another kind occur. Another portion of the surface is occupied by the rose-coloured crust of the common Coralline, overspreading like a beautiful smooth lichen, but without a single shoot or many-jointed stem as yet thrown up, to indicate its true character.

These then may be called the ground-work, for we have not yet got.higher than the surface. From this spring up two or three tiny Sea-weeds. That very elegant plant, Bryopsis plumosa, is represented by several of its fronds, of a most lovely green hue, pectinated on each side like a comb, with perfect regularity. Then there is a little specimen of Ptilota sericea, also a pectinated species, something like the Bryopsis in delicacy, but of a brownish red colour, and much less beautiful. Besides these, there are growing parasitically on one of the polypes presently to be mentioned, several very minute ovate fronds, not more than one eighth of an inch in length, of a rose-red hue, which are probably very young specimens of some of the Rhodymenice.

Now let us look at the Zoophytes. Most conspicuous are several of the corkscrew-funnels that first caught my eye while undisturbed in the quiet pool, and induced me to secure the fragment of supporting rock,-the spiral polypidoms of Cellularia avicularia, 
one of the most curious of our native zoophytes. The specimens are particularly fine; the cells tenanted with healthy polypes in great numbers, protruding their crystal stars of tentacles, and covered with scores of birds' heads nodding to and fro their bald heads like so many old men sleeping at church, and opening and shutting their frightfully gaping jaws like snapping turtles.

Up the stem of one of these Bird's head Corallines a colony of Pedicellina Belgica has entwined its creeping clinging roots, and is displaying its clubbed polypes with unfolded tentacles in every direction. This is a very common species in our rock-pools, parasitic on many sea-weeds and calcareous polypes.

The most abundant thing of all is Crisia aculeata, a delicate and pretty species, easily recognised by its long slender spine springing from the margin of every cell. The multitude of these spines gives a peculiar lightness to the little shrubs in which this species delights to grow.

Several other species are parasitic on the Crisia. I detect the curious tiny snake-heads of Anguinaria spatulata, entwined about its stems. A stalk of Bowerbankia imbricata also is here, studded with little aggregations of cells in dense clusters, set on the slender thread-like stem at wide intervals. And a few of the pitcher-like cells of that singular zoophyte, Beania mirabilis, set with hooked prickles, I find; in one of which I can see the polype snugly packed, though I cannot get him to display his beauties outside his door.

Besides all these, there are at least two kinds of 
Hydroid polypes, both species of the family Corynide. The one is a minute sessile Coryne, I believe undescribed; the other is either Clava multicornis or a Hydractinia, for though two specimens occur of it (as well as of the former) I cannot, from their youth, determine to which genus it is to be referred.*

When I first looked over the fragment with a lens, I was sure that I saw Eucratea chelata, with active polypes; but as I cannot by close searching again find it, it is possible I was mistaken.

But even at this moment I discover something new ; for two little Balani have just opened their valve-like shells from amidst the yellow sponge, and are now throwing out their curled fans of most exquisitely fringed fingers, with precise regularity.

The minute Crustacea that hide and play among the tangled stems of the zoophytes I will not mention, because their presence there may be considered as only accidental. But I cannot reckon as transient visitors a brood of infant Brittle-stars which I find creeping about the bases of the Cellularia, because I perceive that they have quite made the spot their home, and though they have been now several days in a vessel of water, free to leave their tiny fragment and visit others, or to roam over the expansive bottom of the the glass, if they will, they have no such desire; but

* Its head is rose-coloured, and this agrees with Clava, but the tentacles are covered with whorls of pointed tubereles, which Dr. Johnston states is not the ease in that genus. On the other hand I cannot trace any echinated crust from which the polype springs, which is characteristic of Hydractinia. There are about nine tentacles, which appear to me to be set nearly in the same plane. No appearance of ovarian capsules is to be traced. It is probably a young Clava. 
cling to the circumscribed limits of their native rock, with as unconquerable a partiality as if they were Swiss, and these fragments of stone were their own dear Alps. They crawl and twine over the surface, and round the edges; but it is with the utmost reluctance, and only by the use of force and stratagem combined, that I can get one off from the hold to which he tenaciously clings. I am watching the development, and I may say metamorphosis, of the little brood with interest, and cannot yet say what they are ; but I think they will turn out to be either Ophiocoma rosula, or O.minuta, probably the latter.

Now is not this a very pretty list of the tenantry of a bit of slate-rock two inches square? And does it not read us an instructive homily,-one of those "sermons in stones" that the poet speaks of,- - on the beneficent care of Him who "openeth his hand, and satisfieth the desire of every living thing" ? What a family is his to be provided for day by day, and yet erery mouth filled; - not one of these hungry polypes going unsupplied! What a rast amount of happiness we here get just a glimpse of! for life, the mere exercise of vital functions in health, and in suitable circumstances and conditions, - the circumstances and conditions, I mean, for which the creatures themselves are fitted-is undoubtedly enjoyment, probably of as high a nature as the inferior animals are capable of receiving. We need not then ask for what purpose God has made so great a variety of creatures of no apparent benefit to man. Is it not an end worthy of a Being infinitely wise and good, that He has stocked every nook and corner of his world, even to overflow- 
ing, with sentient existences, capable of pleasure, and actually enjoying it to the full, hour by hour and day by day? It is sin alone that is the cause of suffering; and though as a whole the domain of man partook of the lapse of its federal head and lord, and so "the whole creation groaneth and travaileth together until now," "by reason of him who so subjected it to vanity," yet we may suppose that at least the invertebrate portions of the animal creation suffer their share of the fall rather corporately than individually, rather nominally, in dignity, than consciously, in pain or want. And yet I suppose that at that glorious "manifestation of the sons of God," when creation shall be more than reinstated in primal honour, and shall be permanently established, so as no more to be liable to lapse, in the immutability of the Manhood of the Son of God, who is able to "bear the glory," even these low-born atoms of almost unseen and unsuspected life, shall in some way or other, get an augmentation of happiness, and thus take their humble share in the blessing of the redeemed inheritance.

\section{THE SESSILE CORYNE.}

The little Coryne that I have mentioned in the preceding enumeration, appears to differ from any of those mentioned by Dr. Johnston. It may possibly be the young of some recognised species, but meanwhile I shall describe it provisionally, as Coryne sessilis. (Plate XIV, fig. 3). The polypes, about $\frac{1}{16}$ inch high, stand erect from the creeping stem, without any portion of the tube being free. They are long, 
slender, club-shaped, transparent, colourless except near the extremity where the core is dark red. The surface is much wrinkled transversely, and there is a very distinct polygonal reticulation, as if of cells, visible, beneath the integument, since it is not in the same focus as the wrinkles. The tentacles are very numerous, (I counted forty-five on one head, and there were probably some unseen,) shaped as in the larger species, with which their structure agrees, with a hyaline wrinkled neck enlarging abruptly into a globular yellowish head; they are arranged in about six whorls, and stand out just as in the other species. They are greatly smaller than those of ramosa, as is the whole polype, but especially the tentacles, their diameter not being more than one-fourth that of the tentacles of $C$. ramosa. I see no capsules on any head. (Fig. 1.)

Several of these polypes were standing up, not very near together, from a crust of Lepralia (on the stone just mentioned as chiselled from a rock-pool at Capstone) close around the base of a cluster of Cellularic acicularia. On very carefully separating one from its root, I found that the creeping stem was very small, not more than one-fourth the length of the free polype ; it appeared to consist of a horny transparent tube not distinguishable from the integuments of the polype, with which it was evidently continuous. If the animal is young, is the encasing tube not formed until some advance is made to maturity?

Another specimen, sessile on the Lepralia without any apparent creeping stem, was much taller and more slender, apparently by voluntary elongation, 
being undisturbed. The polype was almost quite hyaline, with the red core only near the tip. The tentacles were still smaller than in the other, the necks tapering evenly to the junction of the globose heads, where they were very attenuated: the necks were hyaline with a few distant rings. They stood out at right angles, generally quite straight. The only tube appeared to be a very few investing folds of gelatinous matter lying like a loose stocking about its foot. Fig. 2 represents this variety. After a day or two, both specimens shrank up into a shapeless club, with all the tentacles agglutinated together and around the body, in a mass.

\section{THE BELGIAN PEDICELLINA.}

One of the most common of the ininute zoophytes on this part of the coast is a species of Pedicellina. Dr. Johnston informs me that it is the P. Belgica of Van Beneden, a species which, when the "History of the British Zoophytes" was published, had not been recognised on our shores. I find it in great abundance parasitical on the bases of the smaller sea-weeds that grow at low water, and trailing over other objects also.

The base of the animal consists of a cylindrical stem (Plate XII. fig. 1.) about $\frac{1}{300}$ inch in diameter, which creeps in an irregular twining manner over the support, branching at intervals irregularly, the branches intertwining and crossing each other, and sending forth, at more or less remote intervals, rounded buds, which soon elevate themselves upon a foot-stalk. 


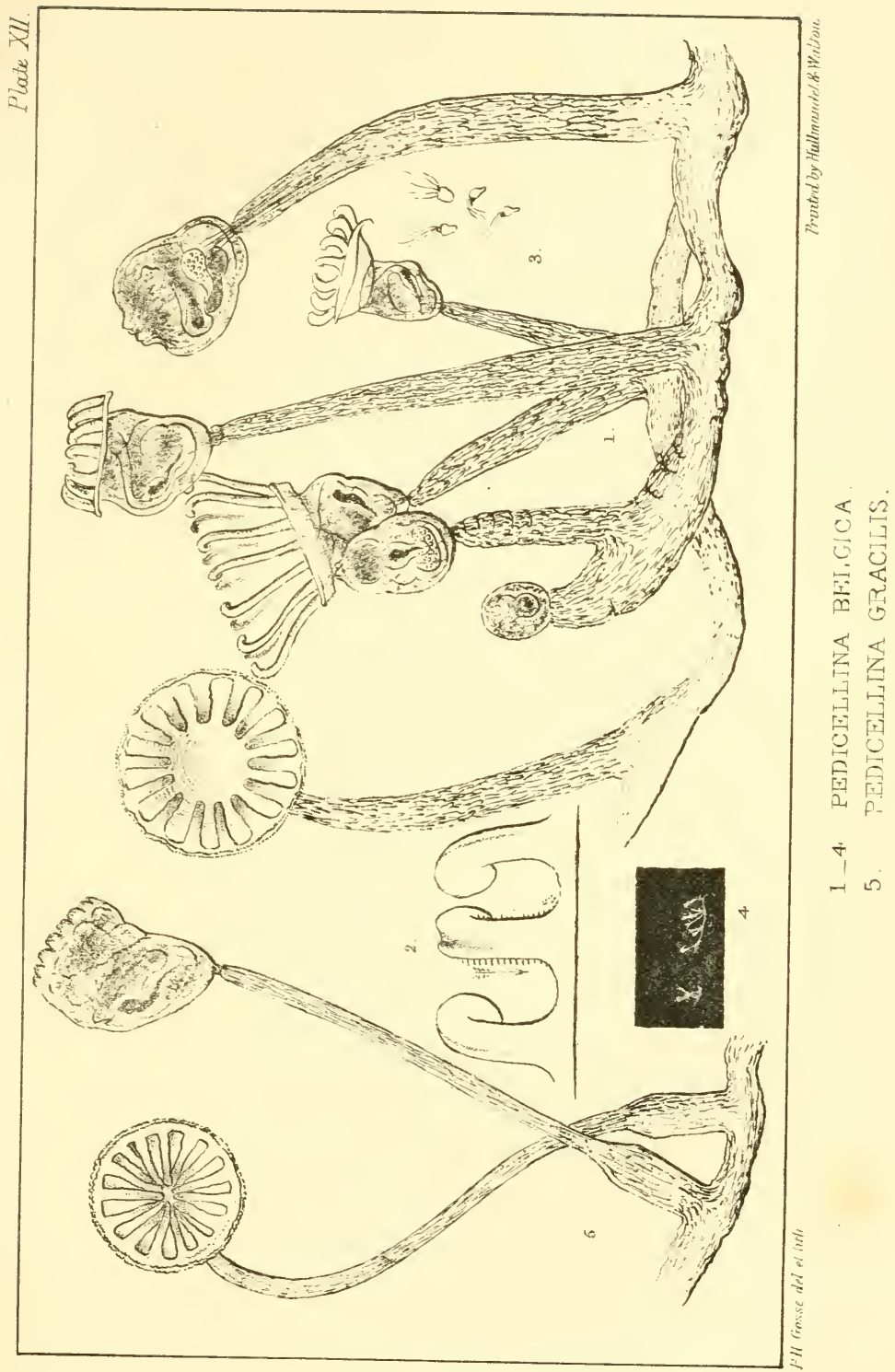



Both the stalk and the head now develop themselves in length and thickness, until the stalk attains a length of about $\frac{1}{12}$ inch, and a thickness of about $\frac{1}{250}$. The head or body of the Polype has now become somewhat bell-shaped, more gibbous, however, at one side than elsewhere; and this side, for distinction's sake I shall call the back. The edge expands into a wide circular: disk sometimes slightly reverted, around which are set, a little within the extreme rim, fourteen rather short cylindrical tentacles, separated from each other by somewhat more than their own width. They do not expand (so far as I have seen) beyond the limits of the disk, but rising perpendicularly from the edge, they curl over their tips in an elegant manner towards the common centre. The sides of these tentacles are set with delicate cilia (Fig. 2), the waves of which pass up on one side and down on the other. I think that the cilia are confined to the sides, for at either edge of the tentacular circle, where the exterior came between the eye and the light, I could not detect the least ciliary action. By means of the motions thus produced I saw minute, floating particles drawn within the disk, and others shot forcibly out.

The tentacles do not appear to be capable of contraction or elongation, but when expanded their incurved tips are continually being thrown inward, so as to increase the curl, and again opened. This action, which is almost constantly being performed, is a little spasmodic jerking or grasping, very slight in its degree. When alarmed, however, they are drawn inward by the common contraction of the 
disk, the edges of which then close together and form a puckered nipple, and the whole head becomes pearshaped, in which state the animal might be mistaken for some large species of the stationary Rotifera.

The colour of the whole animal is pellucid white, and viewed by reflected light, gives us no insight into its internal structure. It is only when examined as a transparent object that its interior is at all revealed. Even then the intguments are but imperfectly transparent; the whole animal, body, stalk, and stem, is covered with a thick coat of gelatinous matter, which is viscous, and in which Diatomacee, and other extraneous bodies, become entangled; the whole external surface is either granular or slightly corrugated, and transmits the rays of light tinged with yellowish brown; these circumstances, combined with the overlying of the viscera in the globose body, render the internal parts difficult of determination. It appears, however, that the funnel of the disk proceeds diagonally downwards, until it nearly reaches the wall of the abdominal cavity on the ventral side. It then sud. denly turns, and (as I think) performs several convolutions transversely across the body. At length it merges into a capacious sac which occupies the whole of the lower part of the cavity of the body. It appears, however, as if the centre only of this sac were void, for granules of the food may be observed, in almost every individual, agglomerated into a somewhat locse lengthened pellet, which continually revolves on its long axis. This food-pellet becomes visible as a slender thread near the middle of the sac, and passes diagonally upward, increasing in size as it advances 
towards the middle of the back, where it terminates. An outline, a little larger, is visible around it, which I conjecture to be the internal wall of the intestine, within which an energetic vermicular ciliary action goes on ; the rest of this viscus is composed probably of a thick glandular tissue, a structure not uncommon among the Rotifera. Within the substance of this sac, or else overlying it is a large transversely-oval viscus, of a yellowish brown hue, punctured all over with close-set round dots. The large intestinal sac passes in a narrow tube, from the point where the food-pellet terminated, forwards and upwards towards the front, and probably opens into the funnel; for under pressure the contents of the intestine were forced out at the mouth, following the course of this tube. Such is the digestive system, no gizzard or manducatory organs being visible in any part.

By one of those fortunate accidents which sometimes occur unexpectedly, but which cannot be commanded, I obtained some light on the generative function of this zoophyte. Looking at one through the microscope, I perceived seated on the front, which was in a semi-expanded state, a minute oval hyaline body set with long cilia, with which it seemed to be struggling to free itself from the contact of the parent animal. Presently I saw another emerging, and I then observed what had escaped my notice before, that several more were lying in the free water around, sluggishly waving their cilia, but not swimming. On this I applied a slight pressure with the compressorium, and presently a mass of some twenty or thirty was protruded from the mouth, most of which mani- 
fested independent action. These bodies, (germs I may surely call them) are somewhat pear-shaped (Fig. 3 ) with a little tubercle at the larger end, around which are set a few (about four or five) long cilia or setæ, twice or thrice as long as the body. These are not used for vibratile action, but as oars slowly waved through the water, or apparently to push withal, when the gemmule is making good its exit. When this is effected, it proceeds only a short distance; the waving motion then becomes more feeble, and presently ceases. Under stronger pressure a larger mass was forced out, consisting mostly of germs immature, in which the cilia appeared as a broad thin band stretching out from the neck forwards, but without any motion. I could distinctly trace the course of these germs through the pellucid body, and found that they proceeded from a large opaque mass, lying across the cavity, between the buccal funnel and the large intestinal sac; and they appeared to issue by the same orifice as that which gave exit to the contents of the intestine. I hence infer, that like other animals whose adult character is to be fixed to a changeless base, the young of this species are endowed for a brief period with the faculty of locomotion, sufficient to enable them to transport themselves to a site more or less remote from the parent, where then each fixes itself and becomes the founder of a colony.

The motions of this zoophyte are lively and energetic; and hence we may infer the existence of a well-dereloped system of muscles. The body is occasionally tossed to and fro by the forcible bending of the foot-stalk; this latter is in some degree capable 
of contraction, though not to any great extent. The creeping stem, however, which appears to be homogeneous with the foot-stalks, has no power of contraction. The stem and stalks are transparent, of a yellowish hue, shewing a fibrous texture, or perhaps one composed of irregular lengthened cells. By contraction and flexure it is thrown into anmular wrinkles, from the appearance of which I should judge the substance to be coriaceous. Something like a fibrous core can be discerned traversing its axis, which can be traced through the slender constricted joint into the body, whence it dilates as it passes upward. From analogy in stalked Rotifera, I conclude this to be a fascia of muscles, perliaps becoming two bands in the body, and passing upwards on opposite sides to the head; their office being the retractation of the tentacular disk. The opacity of the integument precludes the sight of any other muscles, or of any nervous cords, if such exist.

The structure of this zoophyte seems to point it out as osculant between the Anthozoa and the Polyzoa, though manifesting no very close affinity with the normal genera of either. It is interesting also as being evidently a link by which the Zoophyta are connected with the Rotifera, since it certainly approaches nearer to Stephanoceros, and Floscularia than any other Polype yet discovered.

After these observations were made, I obtained specimens of much larger size and in great profusion, entwined among the stems of a Crisia, from lowwater off the Tunnel. It was a beantiful sight to look at the hundreds of heads all in active motion, the 
moment after they were detached from the rock (a piece of stone being chiselled off) and put into a phial of clear water. The crown of arching tentacles was much more elevated than I had yet seen it, the tips only being incurved; and the floating atoms were ever and anon shot forcibly from out the disk. Some excellent views with the microscope enable me to correct and augment my observations. The tentacles are nearly square in section, or slightly grooved down the back. Their bases interiorly may be traced a good way down the funnel. The marginal part of the disk that surrounds and connects their bases is like a hyaline web, marked with close-set concentric lines or wrinkles. The lateral ciliary current of each tentacle runs down until it meets a stronglymarked ring of cilia, set round the funnel a little below the origin of the tentacles, and it was interesting to see in a vertical aspect each individual current merge into this great vortex. The walls of the funnel below this circle are more thick and opaque, and are perhaps muscular and endowed with the power of various contraction; like the œsophageal funnel in Stephanoceros, \&c. Two that I counted had each fifteen tentacles.

They associate with other Polypes. In this intsance Pedicellina, Anguinaria spatulata, and Bowerbankia imbricata, had all entwined their creeping steems together around the Crisia, which was also intermingled with Crisidia cornuta.

When the tentacles are much extended and expanded, the resemblance to some conditions of Stephanoceros is very striking, and they are every instant 
twitched inwards at the tips, in the same manner as those of that genus.

I find two other species of the same genus: the one is $P$. echinata, much like the above in every. respect, except that the stalk is more or less studded with thick bristles or prickles standing ont at right angles. The other is marked by a very slender stalk, sometimes gently swollen in the middle, and having its base abruptly enlarged into a bottle-shaped bulb. The tentacles nearly meet in the centre of the disk. (Plate XII. Fig. 5). This species chiefly occurs on the common Coralline. I have little doubt that it is the P.gracilis of Sars; though I find the bulbous base much more abruptly angular than in his figures; my specimens also have fifteen tentacles, whereas twenty are assigned to the species by this eminent Norwegian zoologist. 'This character, however. depends probably upon age rather than upon species. 


\section{CHAPTER IX.}

Metamorphosis of Lepralia-Appearance of the GemmuleBudding of the Cell-spines-Development of the PolypeGrowth-The 'Three-headed Coryne-Singular Use of its Disk-Beania-Coralline Light-Lime Light-TubuliporaMarine Viviaria-The Principle explained-Elegance of Seaplants-Facilities for Study-Details of ExperimentsMode of procuring the Sea-weeds-Success-Anticipations -A curious Coincidence-Sponge-Crystals-Their elegant Form-Immense Numbers-Mutual Entanglement-Ciliated Sponge-Its crystal Coronet-Powers of Restoration.

\section{METAMORPHOSIS OF LEPRALIA.}

June 11th.-I detached a minute atom of a red colour swimming rapidly in gyrations in the water in which were fragments of polypiferous rock. I caught it with a tube and examined it. It was a globose, or rather semi-elliptical body, of a soft consistence, covered on its whole surface with strong bristly cilia, in rapid vibration. Near the rounder end, was evidently an orifice, with amorphous lips; and when the globule was submitted to slight pressure, just sufficient to confine it, it made efforts to get away by slightly lengthening itself, and drawing in the sides around this mouth, which was in a manner protruded forcibly 


\section{TUBULIPOPA FLABELLARIS.}

June 21.-At Hele, in a dark tide-pool between overhanging rocks, I gathered a frond of Nitoplyyllum laceratum, on which were several patches of a pretty zoophyte, evidently identical with the Tubulipora Alabellaris of Fabricius, which though known to inhabit the shores of Europe from Greenland to the Mediterranean, has been, only lately recognised as a British species by Mr. W. Thompson, who found it on the North coast of Ireland. It consists of a great number of long, slender, cylindrical tubes of pellucid coral or shelly substance, set side by side and overlapping each other on the frond of the sea-weed, to which they adhere for a portion of their length, and then curve upward so as to be free at their terminal portions. The tubes are somewhat crowded, but diverge from each other, so as to form a resemblance to a curling feather. The margins of the tubes are oblique in some cases, in others quite transverse; and the edges are slightly expanded. The exterior of the tube is set with many annular ridges, which are evidently the expanded rims of the tube at various periods of its growth; the new shelly matter being deposited not from the very edge, but from a ring a little way within it, so as to leave the narrow expanded lip projecting as a permanent ridge, in a manner common in many shells. The walls of the tubes are sparsely studded with minute round grains, like those of Crisia ; and similar ones are found far more thickly in the shapeless mass of shelly matter that envelopes the bases of some of the tubes, connecting them like a web. 
MARINE VIVARIA.

One prominent object that I had in view in coming to the coast was the prosecution of a cherished scheme for the conservation of marine animals and plants in a living state.

For several years past I have been paying attention to our native Rotifera, and in the course of this study had kept fresh water in gláss vases unchanged from year to year, yet perfectly pure and sweet and fit for the support of animal life, by means of the aquatic plants, such as Vallisneria, Myriophyllum, Nitella and Chura (but particularly the former two), which were growing in it, Not only did the Infusoria and Rotifera breed and multiply in successive generations in these unchanged vessels, but Entomostraca, Planarice, Naides and other Annelides, and Hydra, continued their respective races; and the young of our river fishes were able to maintain life for some weeks in an apparently healthy state, though (perhaps from causes unconnected with the purity of the water) I was not able to preserve these long.

The possibility of similar results being obtained with sea-water had suggested itself to my mind, and the subject of growing the marine Algæ had become a favourite musing, though my residence in London precluded any opportunity of carrying out my project. My notion was that as plants in a healthy state are known to give out oxygen under the stimulus of light, and to assimilate carbon, and animals on the other hand consume oxygen and throw off carbonic acid, the balance between the two might be ascertained by 
experiment, and thus the great circular course of nature, the mutual dependence of organic life, be imitated on a small scale.

My ulterior object in this speculation was twofold. First, I thought that the presence of the more delicate sea-weeds (the Rhodosperms or red families especially, many of which are among the most elegant of plants in colour and form), growing in water of crystalline clearness in a large glass vase, would be a desirable ornament in the parlour or drawing-room; and that the attractions of such an object would be enhanced by the presence of the curious and often brilliant-hued animals, such as the rarer shelled Mollusea, the graceful Nudibranchs, and the numerous species of Seaanemones, that are so seldom seen by any one but the professed naturalist.

But more prominent still was the anticipation that by this plan great facilities would be afforded for the study of marine animals, under circumstances not widely diverse from those of nature. If the curious forms that stand on the threshold, so to speak, of animal life, can be kept in a healthy state, under our eye, in vessels where they can be watched from day to day without being disturbed, and that for a sufficiently prolonged period to allow of the development of the various conditions of their existence, it seemed to me that much insight into the functions and habits of these creatures, into their embryology, metamorphoses, and other peculiarities, might be gained, which otherwise would either remain in obscurity, or be revealed only by the wayward "fortune of the hour."

Nor have these expectations been wholly unrealized. 
My experiments, though not yet entirely successful, and needing much more attention and time to complete them, have yet established the fact, that the balance can be maintained between the plant and the animal for a considerable period at least, without disturbance of the water; while my vivaria have afforded me the means of many interesting researches, the details of which form the subject of these pages.

The first thing to be done was to obtain the Algæ in a growing state. As they have no proper roots, but are in general very closely attached to the solid rock, from which they cannot be torn without injury by laceration, I have always used a hammer and chisel to cut away a small portion of the rock itself, having ready a jar of sea-water into which I dropped the fragment with its living burden, exposing it as little as possible to the air. The red sea-weeds I have found most successful : the Fuci and Laminarice, besides being unwieldy and unattractive, discharge so copious a quantity of mucus as to thicken and vitiate the water. The Ulva and Enteromorpha on the other hand are apt to lose their colour, take the appearance of wet silver-paper, or colourless membrane, and presently decay and slough from their attachments. The species that I have found most capable of being preserved in a living state are Chondrus crispus, the Delesserice, and Iridea edulis. The last-named is the very best of all, and next to it is Delesseria sanguinea, for maintaining the purity of the water, while the colours and forms of these render them very beautiful objects in a vase of clear water, particularly when the light (as from a window) is 
transmitted through their expanded fronds. Many of my friends, both scientific and unscientific, who have seen my vases of growing Algæ at various times during the present year, both at Torquay and at this place, have expressed strong admiration of the beautiful and novel exhibition.

I have not as yet been able to preserve the water to an indefinite period. Sometimes the experiment has quite failed, the plants decaying and the animals dying almost immediately; but more commonly, the whole have been preserved in health for several weeks. The following are the particulars of the most successful of my efforts.

On the 3rd of May I put into a deep cylindrical glass jar (a confectioner's show-glass) 10 inches deep by $5 \frac{1}{2}$ inches wide, about three pints of sea-water, and some marine plants and animals.

On the 28th of June following, I examined the contents of the jar as carefully as was practicable without emptying it, or needlessly disturbing them. It had remained uncovered on the tables in my study, or sometimes in the window, ever since, a little water only having once been added merely to supply the loss by evaporation. The water was perfectly clear and pure. A slight floccose yellow deposition had accumulated on the sides of the jar, but there was very little sediment on the bottom. I had taken no note of the plants or animals when $I$ had put them in ; but as none of them had died, and none had been either abstracted or added, the following enumeration gives the original as well as then present contents.

There were at this time in the jar the following 
Algæ, all in a growing state, and attached to the original fragments of rock:-

Two tufts of Delesseria sanguinea, each with numerous leaves.

Two of Rhodymenia jubata, one small, the other a large tuft.

A small Ptilota plumosa, growing with one of the last-named.

A Chondrus crisms, with

An Ulva latissima, growing parasitically on one of its fronds.

These seven plants had supplied for eight weeks the requisite oxygen for the following animals, which were at this time all alive and healthy:-

Anthea cereus.

Actinia bellis, a large specimen.

- bellis, a half-grown one.

- anguicoma, large.

- anguicoma, small.

- nivea.

- rosea.

- rosea, a small specimen.

- mesembryanthemum, young.

- mesembryanthemum, young, another variety.

Crisia denticulata, a large tuft.

Coryne-?, young.

Pedicellina Belgica, two numerous colonies.

Membranipora pilosa.

Doris (bilineata?).

Polycera 4-lineata, very small.

Phyllodoce lamelligera, about 11 inches long.

A coil of small Annelides. 


\section{Several Serpule.}

Acarida.

\section{Entomostraca.}

Infusoria.

Grantia nivea. And other smaller zoophytes and sponges which I could not identify.

Soon after this examination I went on a journey, and did not return till the 7 th of July. The weather had set in very hot: whether this, combined with the closeness of the room, had had any effect I do not know ; but on my return I found the water beginning to be offensive, a sort of scum forming on the surface, and the animals evidently dying. Some were already dead, but most of the others recovered on being removed to fresh sea-water. This result, though it puts an end to my experiment at this time, I do not regard as conclusive against the hypothesis; for of course animals are liable to death under any circumstances, and the corrupting body of one of these in so limited a volume of water would soon prove fatal to others, even though there might be no lack of oxygen for respiration. It is possible that one of the large Actinice may have casually died during my absence, the timely removal of which might have averted the consequences to the others; but this is only conjecture. Perhaps there was too large an amount of animal life in proportion to the vegetable; but the maintenance of all these in health and activity for nearly nine weeks seems hardly to agree with such a supposition.

Should these experiments be perfected, what would hinder our keeping collections of marine animals for 
observation and study, even in London and other inland cities? Such a degree of success as I have attained would admit of so desirable a consummation, for even in London no great difficulty would be experienced in having a jar of sea-water brought up once in a couple of months. I hope to see the lovely marine Algæ too, that hitherto have been almost unknown except pressed between the leaves of a book, growing in their native health and beauty, and waving their delicate translucent fronds, on the tables of our drawing-rooms and on the shelves of our conservatories.

It is a curious circumstance that experiments exactly parallel to these, founded on the same prineiples, have been simultaneously prosecuted with the same results by another gentleman, whose name is well known in the scientific world. Mr. Robert Warington of Apothecaries' Hall has now (Dec. 1852) at his residence in London a marine aquarium, with living Algæ and Sea-anemones in a healthy condition. I find, on comparing notes, that Mr. Warington has precedence of me in instituting these experiments; but the particulars that $I$ have above detailed of my own success were fully recorded before I had the slightest knowledge that the thought of such a project had ever crossed the mind of any person but myself. (See Appendix).

GRANTIA BOTRYOIDES.

Highly curious are the needle-like crystals or spiculæ of flint or lime that enter into the composition of many of our Sponges; and I would hardly wish to 
give a greater treat to an intelligent but unscientific friend then by placing an atom of woolly stuff, scraped from the surface of a rock with a pin's point, beneath a good microscope with a rather high power on, and bidding him peep. I am sure you would have been charmed with the sight I have had this morning; I was both surprised and delighted myself.

Going carefully over, with a triple lens, a frond of Nitophyllum laceratum, that I obtained a day or two since at Hele, - the same frond, by the way, that had already yielded me the interesting Tubulipora flabellaris,-my eye was canght by what appeared to be the ends of the tubes of some larger species of the same genus projecting from over the edge of the sinuous and lacerated frond. I immediately transferred it to a glass cell, and applied it to the stage of the compound microscope with a power of 220 diameters. To my astonishment a mass of starry crystals met my view, entangled among each other almost as thick as they could lie, by scores, nay by hundreds. For a moment the eye was bewildered by the multitude of slender needle-like points crossing and recrossing in every possible direction; but soon the curious spectacle began to take some kind of order; the crystals were seen to be all of one form, though rarying considerably in length and thickness; they are three-rayed stars, diverging at an angle of 120 degrees: the rays, straight, slender needles, perfectly cylindrical except that they taper to a fine point, smooth and transparent as if made of glass, and highly refractive.

These spiculæ appear to me to be held together only by their mutual entanglement and interlacing; their 
points, in the process of formation, (I had almost said, of crystallization) have shot through and among each other, so that it would be almost impossible to extract one from any point withont either breaking off its rays, or tearing away a considerable portion of the whole surface. The rays shoot in the same plane, and in that plane the stars lie, not quite at random, as to their direction; for the great majority have one point directed lengthwise from the mouth of the tube towards the base. There are not wanting however many, which point in the opposite direction; and several at intermediate angles. Of course, it requires but little divergence from the first named direction to produce the second; still, however, the prevalent order appears to be this.

I cannot trace any fibrous or gelatinous or granular matter in which the spiculæ are set; but beneath the layer formed by their interlacing points, there is a surface composed of round granules of transparent or pellucid matter, set as close as possible, which are plainly seen between the crossing needles. This appears to be the interior lining of the tube, in fact the tube itself, around which the spiculæ are arranged as a loose outer casing, giving firmness to the whole. I could not detect spiculæ of any other form than the three-rayed stars; but several of these had one or more of their rays broken short; for from their composition they are very brittle, as I have often proved in other species.

The form of this specimen was so very irregular that but a poor idea can be conveyed of it by words: it may, however, be roughly described as an elliptical 


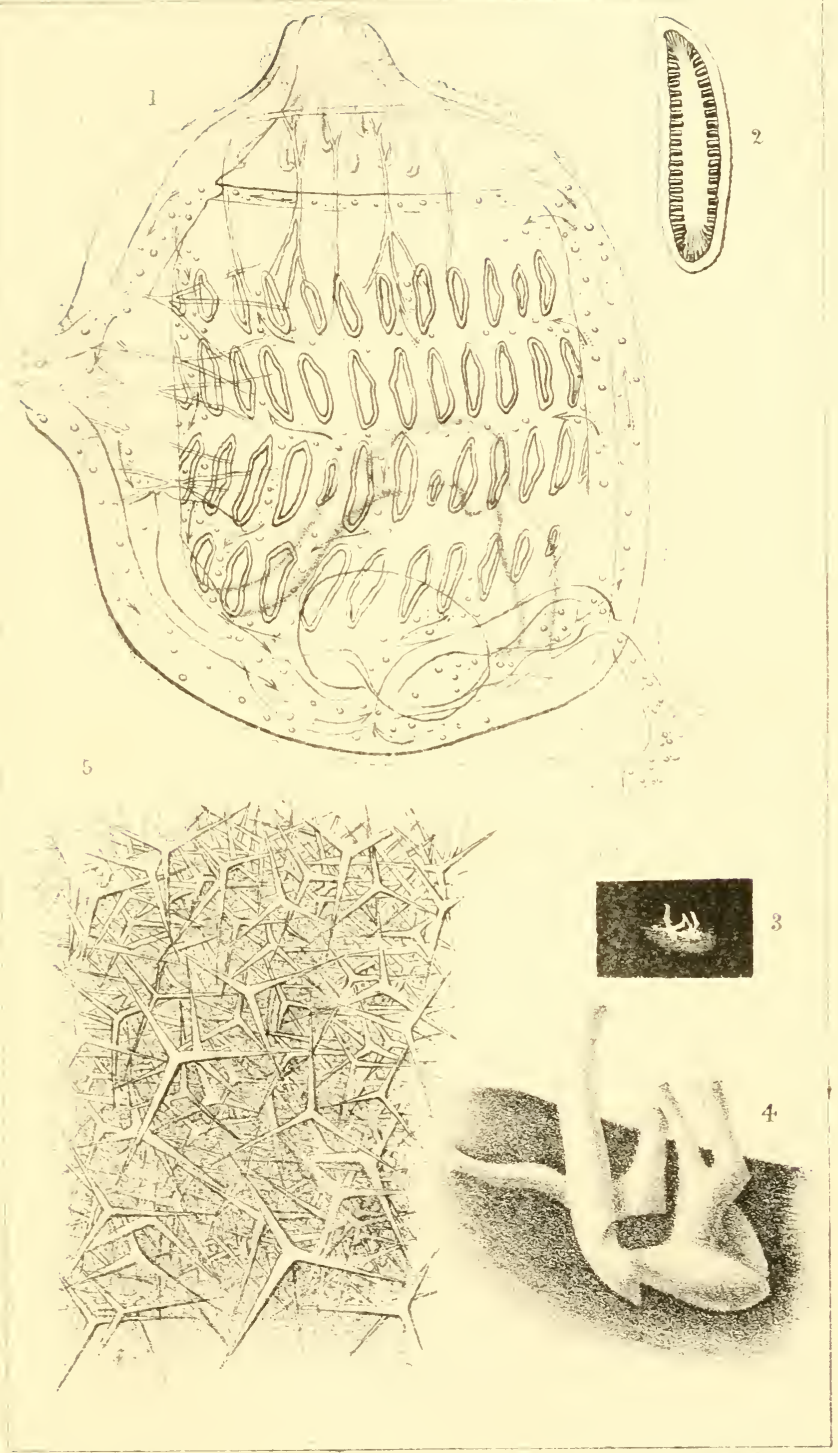



mass, sending forth from one side several tubes, which divide or branch into others. The former portion lies adhering to the face of the sea-weed, but most of the tubes project from the edge of the frond. The longest tube is about $\frac{1}{8}$ inch in length, and $\frac{1}{60}$ inch in greatest diameter. The tubes terminate with plain transverse orifices, without any thickening: in one the margin is slightly expanded, but this is evidently accidental. The spiculæ project from the edge their points in bristling array, as they do from the whole surface; and if it were an object of large size, one would say it was a formidable affair to take hold of with ungloved hands.

I watched carefully for any trace of vortex or current; but the particles and floating atoms in the vicinity of the apertures were perfectly still; and I could not detect the least appearance of motion in the water. If there be any circulation, as Dr. Grant has satisfactorily shown to exist in the genus, it is probably periodical.

The accompanying figures may assist you to form a notion of the general appearance of this sponge, and of the peculiar structure or armature which I have described above. Fig. 3, Plate XV., represents the natural size of the entire mass; Fig. $4^{\circ}$ the same considerably magnified, attached to the surface of a piece of the sea-weed frond; Fig. 5 represents the terminal portion of the largest tube, much more highly magnified, with the spiculæ, and the granular surface beneath. The colour is dull pellucid white. The characters of the species appear to identify it with the Grantia Zotryoides of naturalists, a sponge said to be rare in the south of England. 
GRANTIA CILIATA.

On the same Alga I find a compound specimen of another pretty and interesting sponge of the same genus, Grantia siliata. It is seated near the edge of the frond of the sea-weed, and sends up two little oval lobes with short necks, of which a very exact notion may be obtained by comparing them with the bottles in which soda-water is sold; but they are not more than $\frac{1}{8}$ inch in height. The oval body is bristled over with slender simple spiculæ, all pointed, some abruptly, others very gradually : they vary much in thickness and length, some being of excessive tenuity; they stand out in all directions from the surfuce, like the quills of a porcupine, but there is a slight tendency to point forward. Abundance of loose granulous or floccose matter is entangled among the spines, but this is probably accidental and unconnected with the organization of the sponge. The colour is dead-white; and this I should suppose to be produced by the reflection of light from the thousands of shining spiculæ, just as the whiteness of snow is merely the light reflected from a vast number of minute crystals of ice.

The neck of this bottle-like sponge consists of a dense fringe of the ordinary spiculæ, perhaps more slender than the average, which are set around the orifice like a crown, pointing forwards and a little outwards; so as to perfect the resemblance to a bottle-neck.

I incline to think that the stream of water periodi- 
cally projected from this orifice may be the mould, if I may so say, upon which this coronal fringe is modelled, or at least a means of restoring its form if accidentally injured. I had a specimen at Torquay, much larger than this, globose in form and about half an inch in diameter. The neck of fringing spines had been accidentally crushed and distorted; but after it had lain for some dars in a ressel of sea-water I was agreeably surprised to find it restored to its original regularity and beauty. I cannot detect any jet of water from this specimen before me, but in that obtained at Torquay, (unless my memory greatly fails me,) I distinctly and repeatedly saw it. 


\section{CHAPTER X.}

Respiration and Circulation-A Transparent Ascidia-Organs of Sight-Play of the Gills-Ciliary Waves-The Heart-Coursing of the Blood-globules-Reversal of the Current-"Nature," what is it ?-The Praise of God-Luminosity of the Sea-A Charming Spectacle-Light-producing ZoophytesLuminosity a Vital Function-Noctiluca, a luminous Animalcule-Its Structure-Production of its Embryo-The Slender Coryne-Description-Parasites.

\section{RESPIRATION AND CIRCULATION.}

To take a stolen peep into the Adyta of nature's mysteries, to surprise, as it were, LIFE, carrying on its more secret and recondite functions, must always afford a peculiar pleasure to the reflecting and curious. This the microscope often allows us to do; and when our eye is brought to the little dark orifice of the wondershewing tube, we may fancy that we are slyly peeping through the keyhole of Madam Nature's door, her laboratory door, where she is actually at work, concocting and fashioning those marvellous forms which constitute the world of living beings around us.

I have been for the last two or three hours engaged in watching two of the most important vital functions, respiration and circulation, under circumstances of unusual felicity for the study. In looking over one 
of my vivaria, a pan containing marine plants and animals that have been undisturbed for several weeks, I found, attached to a sea-weed, a tiny globule of jelly, not bigger than one of those little spherules wherewith homœopathy supplants the jalaps and rhubarbs that our grandmothers believed in, and swallowed. It is an Ascidian mollusk, one of that tribe of humble animals that form the link by which the oyster is comnected with the zoophyte; and it appears to belong to that geuus that the learned Sarigny has named Clarellina. Transparent as the purest crystal, it needed only to be transferred in a drop of its native sea-water to the stage of the microscope, and the whole of its complex interior organism was revealed. The old sage's wish that man had a window in his breast, that we might see into him, was more than realised in this case: the whole surface of the little animal was one entire window ; its body was a crystal palace in miniature. (See Plate XV., fig. 1.)

To form a correct notion of this tiny creature, imagine a membranous bag, about as large as a small pin's head, with an opening at the top and another very similar in one side; the form neither globular nor cubical, but intermediate between these two, and rather flattened on two sides. One of the orifices admits water for respiration and food; the latter passes through a digestive system of some complexity, and is discharged through the side aperture. The digestive organs lie chiefly on one side, the opposite to that which forms the principal subject of my examination: they are but dimly indicated in the accompanying sketch, and I shall not further notice them. 
The two orifices scarcely differ from each other in form or structure; from what I know of them in other animals of this tribe, they are protrusile tubes of flesh, terminating abruptly, and fringed around the interior with short filaments or tentacles; the exteriors of the tubes are furnished with minute oval specks of crimson, which are doubtless rudimentary eyes; they look like uncut rubies or garnets, set in the transparent colourless flesh, without any sockets; and probably convey only the vague sensation of light, without definite vision. How many there are around each aperture I cannot say from observation, (probably eight on one and six on the other) for I have not seen either so far protruded as to be properly opened: each is slowly thrust out in a puckered state for a little way, slightly opened, then suddenly and forcibly drawn in, and tightly constricted.

The whole animal is inclosed in a coating of loose shapeless jelly, that appears to be thrown off from its surface, rather than to be an organic part of it; still, at one corner of the bottom it forms a thick short foot-stalk, by which the creature is attached to the sea-weed; and this foot-stalk evidently has an organic core into which there passes a vessel from the body of the animal.

What first strikes the eye on looking at this little creature, and continues long to arrest the admiring gaze, is the respiratory organ in full play. The gills are large; they form a flattened bag, nearly of the same shape as the animal itself, but a little smaller every way, which hangs down like a veil on one side of the general cavity, - the side nearest the eye as 
you look on the accompanying figure; the digestive organs lying beyond and beneath it. The inner surface of this transparent sac is studded with rings of a long-oval figure, set side by side in four rows. These rings appear to consist of a slight elevation of the general membranous surface, so as to make little shallow cells, the whole edges of which are fringed with cilia, whose morements make waves that follow each other round the course in regular succession. In truth it is a beautiful sight to see forty or more of these oblong rings, all set round their interior with what look like the cogs on a watch-wheel, dark and distinct, running round and round with an even, moderately rapid, ceaseless motion. (See fig. 2). These black rumning figures, so like cogs and so well defined as they are, are merely an optical delusion; they do not represent the cilia, but merely the waves which the cilia make; the cilia themselves are exceedingly slender, and close-set hairs, as may be seen at the ends of the ovals, where a slight alteration of position prevents the waves from taking the tooth-like appearance. Sometimes one here and there of the ovals ceases to play, while the rest continue; and now and then, the whole are suddenly arrested simultaneously as if by magic, and presently all start together again, which has a most charming effect. But what struck me as singular was that while in general the ciliary wave ran in the same direction in the different ovals, there would be one here and there, in which the course was reversed; and I think that the animal has the power of choosing the direction of the waves, of setting them going and of stopping them, individually as well as collectively. 
I am afraid my attempt to describe these phenomena is but partially successful: I am sure it cannot convey to you any adequate iden of the spectacle itself. Have you ever gazed with interest on a complicated piece of machinery in motion, such as is common in our large manufacturing houses? If so, I dare say you have felt a sort of pleased bewilderment at the multitude of wheels and bands, rolling and circling in incessant play, yet with the most perfect steadiness and regularity. Something of that sort of impression was made on my mind by the sight of the respiratory organ of this tiny Ascidia, coupled as it was with another simultaneous, equally extensive system of movements, yet quite independent, and in nowise interfering with the former. I mean the circulation of the blood.

At the very bottom of the interior, below the breathing sac, there is an oblong cavity, through whose centre there runs a long transparent vessel, formed of a delicate membrane, of the appearance of which I can give you a notion only by comparing it to a long bag pointed, but not closed, at either end, and then twisted in some unintelligible manner, so as to make three turns. This is the heart; and within it are seen many minute colourless globules, floating freely in a subtle fluid; this is the nutrient juice of the body, which we may, without much violence, designate the blood. Now see the circulation of this fluid. The membranous bag gives a spasmodic contraction at one end, and drives forward the globules contained there; the contraction in an instant passes onward along the three twists of the heart, (the part behind 
expanding immediately as the action passes on) and the globules are forcibly expelled through the narrow but open extremity. Meanwhile, globules from around the other end have rushed in, as soon as that part resumed its usual width, which in turn are driven forward by a periodic repetition of the systole and diastole.

The globules thus periodically driven forth from the heart now let us watch, and see what becomes of them. They do not appear to pass into any defined system of vessels that we may call arteries, but to find their way through the interstices of the various organs in the general cavity of the body.

The greater number of globules pass immediately from the heart through a ressel into the short footstalk, where they accumulate in a large reservoir. But the rest pass up along the side of the body, which (in the aspect in which we are looking at it, and as it is represented in the figure) is the right. As they proceed, (by jerks of course, impelled by the contractions of the heart) some find their way into the space between the breathing surfaces, but how I can hardly say, if the breathing organ is indeed, as I had supposed, a sac; - they certainly do slip in between the rows of oval rings, and wind along down between the rings in irregular courses. Of course, I know that I am liable to mistake here, confounding, through the transparency of the organs, those globules which are outside the breathing sac with those that are within it; still after the utmost care by focusing, I think I am sure the globules do pass as I have said; besides those which wind along on the outside, or 
between the outer surface of the sac and the interior surface of the body; for many take this course, on both sides of the sac.

But to return to the current which passes up the right side: arriving at the upper angle of the body, the stream turns off to the left abruptly, principally passing along a fold or groove in the exterior of the breathing sac, until it reaches the left side, down which it passes, and along the bottom, until it arrives at the entrance of the heart, and rushes in to fill the vacuum produced by the expansion of its walls after the periodic contraction. This is the perfect circle; but the minor streams that had forked off sideways in the course, as those within the sac, for example, find their way to the entrance of the heart by shorter and more irregular courses.

One or two things connected with this circulatory system are worthy of special notice. The first is that its direction is not constant but reversible. After watching this course followed with regularity for perhaps a hundred pulsations or so, all of a sudden, the heart ceased to beat, and all the globules rested in their circling course, that I had supposed incessant. Oh, ho! said I,-

"Thy stone, O Sisyphus, stands still, Ixion rests upon his wheel ;-"

when, after a pause of two or three seconds, the pulsation began again, but at the opposite end of the heart, and proceeded with perfect regularity, just as before, but in the opposite direction. The globules, of course, obeyed the new impulse, entered at their 
former exit, and passed out at their former entrance, and performed the circulation in every respect the same as before, but in the reverse direction.

Those globules that pass through the ressel into the foot-stalk appear to accumulate there as in a reservoir, until the course is changed; when they crowd jnto the heart again and perform their grand tour. Yet there is a measure of circulation here, for even in the connecting vessel one stream ascends from the reservoir into the body as the other (and principal one) descends into it from the heart; and so, vice versa.

I have spoken of these motions as being performed with regularity; but this term must be understood with some qualification. The pulsations are not quite uniform, being sometimes more languid, sometimes more vigorous; perhaps forty beats in a minute may be the average; but I have counted sixty, and presently after thirty; I have counted twenty beats in one half-minute, and only fifteen in the next. The period during which one course continues is equally uncertain; but about two minutes may be the usual time. Sometimes the pulsation intermits for a second or so, and then goes on in the same direction; and sometimes there is a curious variation in the heart's action, - $-\mathrm{a}$ faint and then a strong beat, a faint and a strong one, and so alternately for some time.

Several other points in the organization of this animal I might notice; as the forked muscular bands that ramify from each aperture, the use of which is doubtless to perform the strong retractations of those orifices; and the curious knobbed or hooked processes 
that hang down freely like so many walking-sticks into the cavity of the body from the oral orifice, to the number of ten at least, the nature and use of which organs I am not aware of.

Wishing to see the course of the food into the stomach, I mingled indigo and carmine with the water; but though I saw the particles of pigment continually taken in (not, as I had expected, by the oral aperture but by the anal), I could not trace them beyond the immediate vicinity of the orifice; nor could I discern the least discoloration of the stomach or intestines by it. Indeed I conld not detect any distinct canal or tube leading from either aperture to the stomach. The gelatinous coat, however, which invests the whole animal, has apparently the power of imbibing water ; for on my removing it into clean water after two or three hours' immersion in the coloured, the whole of the investing coat was tinged with faint purple, which slowly disappeared. The admixture of pigment was probably injurious to its health, for both circulation and respiration were suspended, and were resumed only after some halfhour's immersion in the pure water.

When I spoke just now of these wonderful mechanisms and functions as "Nature's operations," I used the phrase in playfulness rather than in seriousness. For who indeed is Nature, and what are her attributes? Is not the term one in which we take refuge from the necessity of acknowledging the God of glory? "It has become customary," says the greatest of modern zoologists, to personify Nature, and to employ the name for that of its Author, out of re- 
spect." I fear it is rather out of shame than out of respect; the potent dread of that terrific word "cant," I much fear has effected the substitution. If we remember the word of Jehovah himself, "Whoso offereth praise glorifieth me" (Psalm 1, 23.), we shall not think it any mark of respect to conceal his name in speaking of his wondrous works, and to give the honour of their formation to a fabulous and imaginary power.

No, this little ball of animated jelly is one of the inventions of the Almighty Son of God; of Him who is the Brightness of God's glory, and the express Image of his Person, without whom there was not any thing made that was made. Its intricate machinery, all its clock-work circles and revolutions, were originally the contrivance of his infinite wisdom, the workmanship of his matchless skill. And they are maintained in their beautiful order and precision, not by any inherent force implanted in them at first, but by his perpetual sustaining will. He, upholding all things by the word of his power, maintains the vital functions of this tiny globule, as truly and with as absolute a volition as $\mathrm{He}$ maintains the motions of the solar system, or they would instantly collapse into nothing. He made this also for his own glory ; and it is included in that extensive category, of which it is declared, "For his pleasure they are, and were created."

Every word of the above description was penned, and my drawing was made, long before I was aware that this little animal had been already described and 
figured by Mr. Lister in the Phil. Trans. for 1834. He assigned to it no name, but it has since been called Perophora Listeri. Whatever points of agreement are found between the observations of that eminent naturalist and my own, are due to our having drawn from a common original : and I will not cancel this paper, since a concurrence of independent research is valuable in all science.

\section{LUMINOSITY OF THE SEA.}

I was coming down lately by the Steamer from Bristol to Ilfracombe in lovely summer weather. Night fell on us when approaching Lynmouth, and from thence to Ilfracombe, the sea, unruffled by a breeze, presented a phenomenon of no rare occurrence, indeed, to those who are much on the water, but of unusual splendour and beanty. It was the phosphorescence of the luminous animalcules; and though I have seen the same appearance in greater profusion and magnificence in other seas, I think I never saw it with more delight or admiration than here. Sparkles of brilliance were seen thickly studding the smooth surface, when intently looked at, though a careless observer would have overlooked them; and as the vessel's bow sploughed up the water, and threw off the liquid furrow on each side, brighter specks were left adhering to the dark planks, as the water fell off, and shone brilliantly until the next plunge washed them away. The foaming wash of the furrow itself was turbid with milky light, in which glowed spangles of intense brightness. But the most beautiful effect of 
the whole, by far, and what was novel to me, was produced by the projecting paddle-boxes. Each of these drove up from before its broad front, a little wave continually prolonging itself, which presently curled over outwardly with a g]assy edge, and broke. It was from this curling and breaking edge, here and there, not in every part, that there gleamed up a bluish light of the most rivid lustre, so intense that I could almost read the small print of a book that I held up over the gangway. The luminous animals evidently ran in shoals, unequally distributed; for sometimes many rods would be passed, in which none or scarcely any light was evolved, then it would appear and continue for perhaps an equal space. The waves formed by the summits of the swells behind the ship continued to break, and were visible for a long way behind, as a succession of luminous spots; and occasionally one would appear in the distant darkness, after the intermediate one had ceased, bearing no small resemblance, as some one on board observed, to a ship showing a light by way of signal. The scene recalled the graphic lines of Sir Walter Scott:-

Awak'd before the rushing prow,

The mimic fires of ocean glow,

Those lightnings of the ware;

Wild sparkles crest the broken tides,

And flashing round, the ressel's sides

With elfish lustre lave ;

While far behind, their livid light

To the dark billows of the night

A blooming splendour gare.

LORD OF THE IsLes, i. 21.

While on this subject I will mention the charming 
spectacle presented by some of the Sertularian Zoophytes, in the dark. Other naturalists, as Professor Forbes, Mr. Hassal, and Mr. Landsborough, have observed it before me, and it was the admiration expressed by them at the sight that set me upon witnessing it for myself. I had a frond of Laminaria digitata, on whose smooth surface a populous colony of that delicate zoophyte Laomedea geniculata had established itself. I had put the frond into a vessel of water as it came out of the sea, and the polypes were now in the highest health and vigour in a large vase in my study. After nightfall I went into the room, in the dark, and taking a slender stick struck the frond and waved it to and fro. Instantly one and another of the polypes lighted up, lamp after lamp rapidly seemed to catch the flame, until in a second or two every stalk bore several tiny but brilliant stars, while from the regular manner in which the stalks were disposed along the lines of the creeping stem, as before described, (See p. 90 ante), the spectacle bore a resemblance sufficiently striking to the illumination of a city; or rather to the gas-jets of some figure of a crown or V. R., adorning the house of a loyal citizen on a gala-night; the more because of the momentary extinction and relighting of the flames here and there, and the manner in which the successive ignition appeared to run rapidly from part to part.

It has been a question whether the luminosity of these polypes is a vital function, or only the result of death and decomposition. I agree with Mr. Hassal in thinking it attendant, if not dependent, upon vitality. The colony of Laomedea in the preceding 
experiment was still attached to its sea-weed, and this had not been washed up on the beach, but was growing in its native tide-pool when I plucked it; it had never been out of water a single minute, and the polypes were in high health and activity both before and after the observation of their luminosity.

\section{LUMINOUS ANIMALCULE.}

Some weeks afterwards I had an opportunity of becoming acquainted with a minute animal to which a great portion of the luminousness of the sea is attributed. One of my large glass vases of sea-water, I had observed to become suddenly luminous at night on being tapped with the finger; the light was in minute but brilliant sparks, chiefly at various points on the surface of the water, and around its edge. It is possible, however that the vibration of the glass produced a more powerful effect on the animals in contact with it, than on those in the water at some distance. After the first tap or two, the light was not again produced, and no jarring or shaking of the vessel would renew it. I determined to examine the water carefully in the morning.

In the mean time, however, in the course of examining some polypes from another vessel, I unintentionally isolated a minute globule of jelly, which I presently recognized as Noctiluca miliaris. Remembering that this animalcule is highly luminous, I immediately suspected that the luminous points of my large vase might be owing to the presence of this same little creature. I accordingly set the jar in the 
window between my eye and the light, and was not long in discovering, without the aid of a lens, a goodly number of the tiny globules swimming about in various directions. They swam with an even gliding motion, much resembling that of the Volvox globator of our fresh water pools, but without any revolution that I could perceive. They appeared social, congregating into little groups, of half a dozen or more together ; and when at rest affected the surface and the side of the glass next the light. A jar or shake of the vessel sent them down from the surface.

It was not very easy to eatch sight of them, nor to keep them in view when seen, owing rather to their extreme delicacy and colourless transparency than to their minuteness. They were in fact distinctly appreciable by the naked eye, for they measured from $\frac{1}{50}$ th to $\frac{1}{30}$ th of an inch in diameter.

With a power of 220 , each was seen to be a globose sac of gelatinous substance, ordinarily smooth and distended, but occasionally roughened with fine wrinklings in the surface. At one side there is a sort of infolding, exactly like that of a peach or plum (see figs. 6 and 8, Plate XVI.); and this if viewed directly sidewise appears to be a deep furrow, from which the two rounded sides recede, with two minor lobes between them. (See fig. 7). From the bottom of the furrow springs a small slender proboscis of a thickened ribbon-form, very narrow, and about as long as two-thirds the diameter of the globe, with the tip slightly swollen. (Fig. 11). It is frequently twisted with one curl, but is moved sluggishly in 

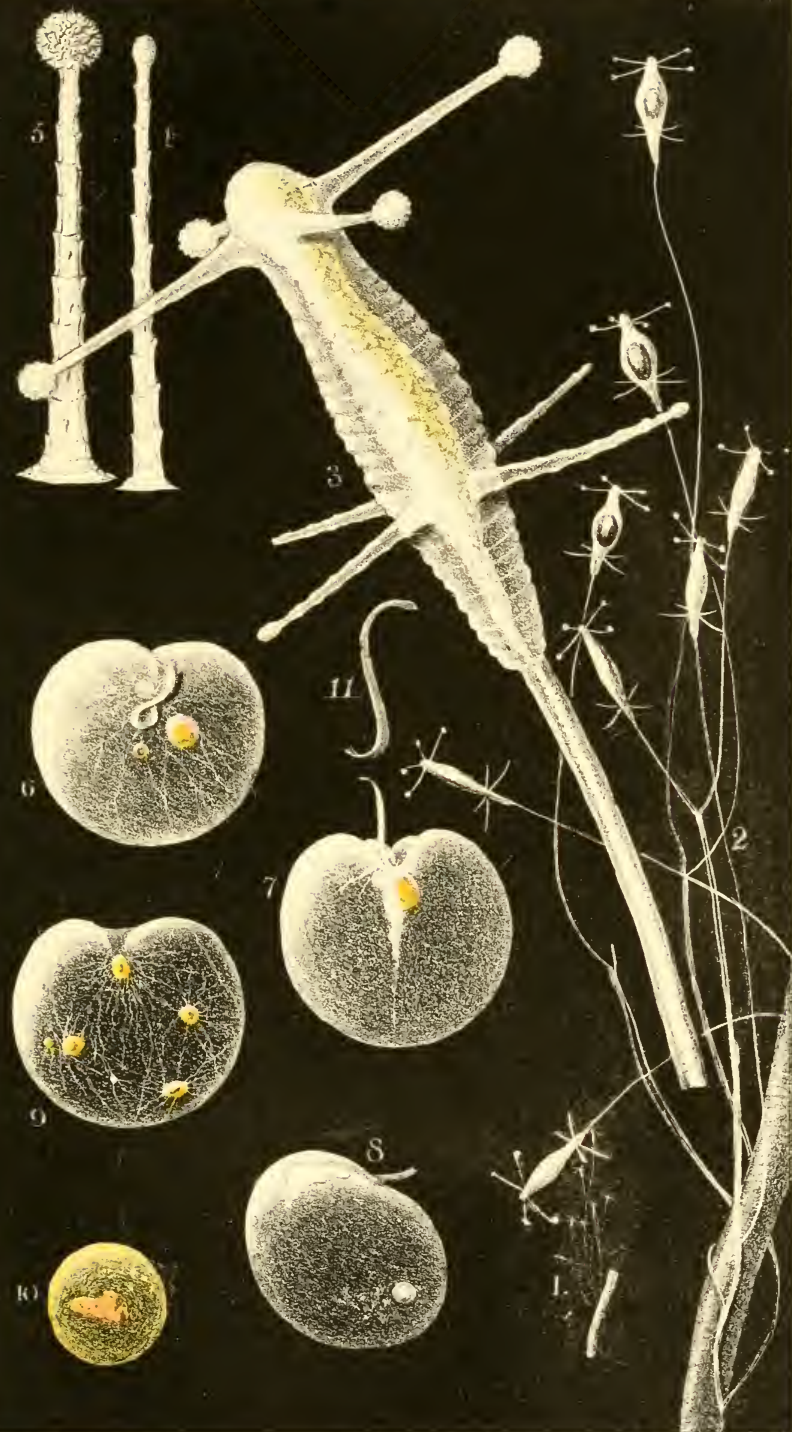

various directions. I could not detect the least trace of ciliary action on it, or indeed on any part of the surface.

Within the sac, which appears to have thin walls, there is a mass of viscera suspended from the bottom of the furrow, and hanging down in a gradually tapering cone nearly to the bottom of the interior, to which in some specimens (not in all), the mass was tied by a slender thread or ligament. Among the viscera were two or three globular organs, one of which was yellow, and appeared larger and more filled with food, or less and more empty, in different degrees, in different individuals. I should have little hesitation in pronouncing this, from its resemblance to a similar viscus in the Polyzoa and Rotifera, to be the stomach. The other globose riscera were colourless, but had a turbid nucleus.

The arrangement and bulk of this mass of viscera vary much in individuals, and in some the whole is almost obsolete. In one or two there was an isolated globose viscus far down in the carity near the bottom. As these specimens were smaller, I thought of the male of Asplanchna, (a Rotiferous genus of which these animals strongly reminded me,) in which the digestive viscera are obsolete, and suggested the possibility of this isolated viscus being a sperm-sac. On pressure, however, to the extent of bursting the viscus, the extruded contents were granular, and I could not trace any Spermatozoa. I believe that it was only the stomach, got loose by the decay or absorption of the connecting membranes, and floating freely in the cavity. Fig. 8 is the representation of one of these. 
From the point whence the viscera hang, a number of vessels diverge on all sides, in the substance of the integument. They narrow speedily, ramify, and connect with each other by the branches. The distance to which they can be traced, and their number, differ greatly in individuals.

I endeavoured to excite the light-producing action under the microscope. For this purpose I isolated two drops of water on the compressorium, the one fresh, the other salt containing one or more Noctiluce: then screwing up the glass-plate, the drops were made to unite. I had expected that the contact of the fresh water would kill the animal, but that a spark would be evolved at the moment. None however appeared, though I tried the experiment repeatedly with different specimens. The contact seemed to be fatal ; the gelatinous integument shrivelled and puckered up, and the beautiful globe became shapeless in a ferw seconds. I then caught two or three in a glass tube, and blew them into a vessel of fresh water in a dark room, but not a spark was elicited in this case.

Aug. 13.-Examining other individuals I find some in which there are several of the isolated vesicles, which I had supposed above to be the stomach. That conjecture is doubtless erroneous. They consist of yellow clear globules, with a central well-defined nucleus more or less developed, of a rich reddish hue. I perceive they are not strictly isolated ; each is connected with a thick arbuscule of vessels, which diverge from its vicinity in all directions, with many branches, many anastomosing unions, and thickened web-like 
points of contact. Each of these globules is connected with its fellows, by a long straight vessel, and also with the mouth. They do not therefore float freely, but are moored within the cavity, at a little distance from the internal walls, by threads which pass in various directions to the walls. I incline to think them germs, but am not certain.

This last conclusion has been just confirmed ; for having found one with a single vesicle, much larger and evidently more developed than any before, I continued to watch it. I presently saw that the vesicle was being drawn nearer to the fissure, very slowly and gradually, but uniformly : at length it became evident that it was about to be discharged; and after about two hours from the time I first observed it, it was clear of the parent, though still sessile on the part from which it had escaped. It was now a perfect sphere, about $\frac{1}{300}$ inch in diameter, of a granular surface, of a horny yellow hue, containing within it a small, well-defined, but irregular-shaped mass of dark red substance, near the centre. Its appearance is shown at figure 10, more magnified than the other figures. Twelve hours produced no change in the appearance of the excluded ovum, and the next morning, in shifting the water, I unfortunately lost it.

\section{THE SLENDER CORYNE.}

I find in a vase of old sea-water kept pure by living sea-weed, a Coryne which appears to have a very distinct character and habit from the others that have fallen under my notice. It is adhering to the 
cylindrical footstalk of a Rhodymenia, about which it creeps irregularly in the form of a white thread, of about the same thickness as a human hair, as I found by placing both beneath the microscope together. This thread is cylindrical and tubular, perfectly hyaline, and without any vestige of rings or wrinkles, but permeated by a central core apparently cellular in texture, and hollow, within which a rather slow circulation of globules, few in number and remote, is distinctly perceived. The thread is very long in proportion to its thickness, and here and there starts from the support and sends off free branches, or $r$ ather divides; the ramifications generally forming an acute angle, and continuing of the same thickness, form, and structure as before. Some of the branches send off others, some soon form the terminal head, others run to a great length, even to ten-times the the length of the head. This excessive length and tenuity of the branches constitute a character very unlike that of C. ramosa. (See Plate XVI. figs. $1-5)$.

The polype-head appears to be a clavate enlargement of the branch, no open end of an investing tube being visible in any part of the zoophyte. The head is oblong, usually cylindrical, rounded at the end; but sometimes considerably ventricose in the middle; and wherever this form occurred, I invariably found a large bubble of air in the midst of the swollen part. The head is transparent, slightly tinged with yellowish; corrugated with coarse annulations. The core of the stalk enters into its lower part, and soon dilates into a semi-opaque granular mass, becoming more 
dense at the very extremity, where it quite fills the interior. At the extreme point are fixed four tentacles of the usual form, directed to the cardinal points, they are long, slender, and furnished with globular heads. The number was four, neither more nor fewer, in every head on the zoophyte, as also in each head of another specimen near. Near the lower part of the polype-head, viz. at about one-third from its commencement, four tentacles project in the same manner, exactly similar to the terminal ones, but without dilated heads. I had thought, in examining a similar phenomenon in Coryne Cerberus, that these were tentacles from which the heads had sloughed; but their appearance in this animal is too healthy to allow me to maintain that opinion; and the constancy of their number and position in every example induces me to conclude them normal. Are they male tentacles as described by M. Loven in Coryne Sarsii? Both these and the capitate ones are seen on close examination to be studded with tubercles, somewhat whorled, from which short bristles project at right angles. (See figs. 4, 5). The inferior tentacles are furnished with rounded extremities, somewhat globose, but not larger than the diameter of the tentacles themselves.

The form of the polype reminds one of a familiar kind of turnstile, or of those presses the screw of which carries arms loaded at their extremities with globes of metal to increase their impetus when turned. It seems more closely allied to C. Cerberus than to the other species that I have met with, though differing in the ramified habit, and in the number of its 
capitate tentacles. It is much infested with parasites : a Vorticella grows on it; and a sort of Vibrio. The latter is in immense numbers, forming aggregated clusters here and there, the individuals adhering to each other, by mutually twisting in several turns around each other, and projecting in bristling points in every direction. These animaleules vary in length, some being as long as $\frac{1}{80} \mathrm{inch}$, or more; with a diameter of $\frac{1}{7000}$ inch. They are straight, equal in thickness throughout, and marked with distinct transverse lines; they bend themselves about with considerable activity, and frequently adhere to the polype by one extremity, or by a small portion of their length, while the remainder projects freely.

Fig. 1. Represents the Coryne of the natural size, which is distinctly perceptible to the naked eye

2. The same magnified.

3. The polype more highly magnified.

4. An inferior tentacle.

5. A capitate tentacle.

The species, I find, has been well figured by M. Dujardin, in the Ann. des Sci. Nat. for 1845, by the appellation of Stauridia; though I do not very clearly apprehend whether he intends this for the designation of the species. If so it must be called Coryne stauridia. 


\section{CHAP'TER XI.}

Hillsborough-Meaning of its Name-Its Grandeur-Its Flowers -Commanding Prospects-View Westward-Inland-Eastward-Seaward-Formation of a Beach-A Rock-slip-Anthea-Its Tentacles retractile-Their Structure-ThreadCapsules-A Summer Morning Walk-Autumnal FlowersLangley Open-The IIangman-Curious Legend-Coast Scenery-Lee-A Ship's Travels - Solitude-Caves-Sponges - The Hispid Flustra-Its Appearance and StructureExpansion of its Bells--Ciliary Action-A miniature Whirlpool-Visit to Braunton-Carn Top-Tragical LegendScore Valley-Squirrels-Trentistowe-White BindweedOak Hedges-Reaping-Braunton-Curious monumental Inscription-Braunton Burrows-Sea-side Rocks-Marine Animals-Rare Plants on the Cliffs-Snails-Botany of the Burrows-Insects-Shells-The Feather Plumularia-Its Egg-Vesicles-Young Polypes-Their Development from Planules-Structure of the Polype.

The most remarkable object in this neighbourhood is the noble mountain-mass that forms the eastern headland of the harbour of Ilfracombe. Its name is now spelled and pronounced Hillsborough, but there can be little doubt that the essential part of this word is cognate with Hele, the village that lies at the foot of the hill. The element "borough" or "burrow" is commonly found hereabouts in the names of elevated rounded hills, especially such as are tenanted by rab- 
bits. Thus we have Saxon's burrow, at the entrance to Watermouth, and Braunton Burrows; and the word is continually used as an appellative, synonymous with rabbit-warren.

Hillsborough is sure to catch the eye of a stranger from nearly all points of the vicinity. From the promenade of Capstone its gigantio form is broadly conspicuous; its loftiness brings its summit into view the first of the eminences that surround the town, as you mount any of the other hills; and as you walk down the steep and narrow street that leads to the quay, there is the bold and picturesque mass straight in front, filling the field of view. There is something particularly grand and noble in its appearance: the highest point is nearly 500 feet above the sea, and from this point there descends to the water's edge one broad ample face of cliff almost perpendicular, its naked majesty unbroken from top to bottom, except by the variations of light and shadow, and the slight diversities of the warm brown tints that mark its surface. It is the character of the friable shale which is the prevalent formation here, to form great breadths of surface, and to this I think is owing much of that grandeur for which the coast scenery of North Devon is so remarkable.

It is a pleasant, though somewhat toilsome exercise, to climb to the summit of this hill in summer, and enjoy the wide expanse of prospect visible thence. I do not mean that you must climb the precipice, for you might almost as well essay the side of a church, but ascend the grassy slope from the landward side, which, though steep, is not impracticable. We go by 
the pleasant path across the Quay Fields, and just where this leads into the dusty road, turn down a lane for about a dozen yards, instead of going on to Hele, clamber over a gate,-and we are on the mountain.

It is near the end of July. The pale blue Scabious and lilac Knautia are now in blossom; the vellow spikes of the Agrimony, with battlemented calyx, and the rosy flowers of the Rest-harrow, elegant in form and beautiful in colour; these are about the foot of the slope. As we get up higher, the turf becomes shorter and finer; the cheerful little Bird's-foot Lotus appears; large patches of Thyme occur here and there, as soft as a feather-bed, where the wild bee is humming; the tiny star-like flowers of the yellow Ladies' Bedstraw are grouped by hundreds; and not rare is the lovely little Centaury, timidly displaying its tufts of pink blossoms, that hardly renture to protrude their pretty heads above the short turf. The yellow Hawkweeds and Cats'-ears are flaunting here and there, one species of which, the Mouse-ear, of a delicate lemon-yellow tint, is both beautiful and curious, for its leaves are studded with fine erect hairs of great length and slenderness, and are corered on their under surface with a close downy wool. On the summit, two kinds of Stone-crop, that known as distinctively English (Anglicum), and the much rarer White (album) are growing profusely about the clefts and weather-beaten sides of the rocks; the latter distinguished by its large silky blossoms, with purple anthers; the inflated calyxes of the Bladder Campion, so prettily marked with delicate purple 
veins, are seen on the abrupt face of the precipice itself, and bushes of the Bramble and the Sloe with beds of Fern fringe the very yawning edge, giving a sense of protection and security more apparent than real.

But though I mention these plants and flowers first, they are not the first things that claim attention here. He would indeed be an enthusiastic botanist who could look at flowers, until he had somewhat satiated his eyes with the glorious prospect around. One knows not where to commence the admiring survey -sea-ward, land-ward; up the coast, down the coast;all is magnificent, or beautiful, or both. Let us turn westward first; overlooking the harbour and the town of Ilfracombe, the craft in the one, and the streets and terraces of the other, looking almost as in a map. Here is Lantern Hill just beneath us, crowned with the old chapel of St. Nicholas, the supposed patron of mariners in the times of Papal ignorance, then Compass Hill, and the conical Capstone with its conspicuous walks and its signal-staff; then come the green slopes of the Runnacleaves, and the seven peaks of the Torrs, and the rounded outline of Langley Cleve, a loftier elevation than this on which we stand: the rugged rocks, and coves of the coast line are seen here and there, and far away on the dim horizon lies Lundy, blue and hazy, like a sentinel keeping his guard at the entrance of the channel.

Now for a gaze inland. Under our feet is the village of Hele, embosomed in gardens and orchards, and half hidden by tall and shaggy elms. A valley winds up to the left, with a little stream running 
through its wooded bottom, of which, however, we can scarcely catch a glimpse here. Another lovely vale, that of Chambercombe, leads off to the right, and then curves round parallel with the former; the sides of its bounding hills are covered still more luxuriantly with woods of oak and ash, the dark shadows of which contrast finely with the sunny fields between, cut up by roads and cross-paths like a ground-plan of an estate in a land-agent's office.

We walk on a little way to the eastern brow of the hill, which is less precipitous than the other. Hence we look down upon extensive gardens sloping away from our feet to the cottages on the road side. Opposite us rises a broad hill-side covered with fields of corn and potatoes. Between there is the valley, the village-mill, the "one arch'd bridge" crossing the brook, and the brook itself now in full riew brawling and sparkling away to the cove. The sea is breaking on the beach in rolling waves; and the black rocks of Rillage Point that runs out in a bristling ridge, like a ruined wall, are fringed with a snowy line of foam, from the beating surf, whose hollow roar falls loud upon the ear. Overtopping the whole is the dark outline of Great Hangman, a mountain of regular form nearly 1200 feet in height.

Once more. In another direction we gaze far down upon the lovely face of the sea, bounded in part by the blue line of the opposite shore running out to a dim, almost invisible, point, but for a considerable expanse of the horizon so mingling with the sky that the separation is with difficulty defined 
Silent and steadfast as the vanlted sky

The boundless plain of waters seems to lie :-

Comes that low sound from breezes rustling o'er

The grass-crowned headland that conceals the shore?

No ; 'tis the earth-roice of the mighty sea,

Whispering how meek and gentle he can be :-

WORDSWORTH.

These views are very diverse from each other. I know not which most to admire, the wild magnificence of the iron-bound coast, the soft luxuriance of the fields and woods, or the busy scenes of activity and industry, the occupations and homes of human life.

This hill affords an instructive example of the formation of a shingle-beach. About two years ago, one winter's night, the inhabitants of the town were affrighted by a tremendous and unaccountable noise, and in the morning perceived that a large portion of old Hillsborough had fallen. It had before presented an uneven and broken slope, covered with bushes and herbage nearly to the water; but now they saw all this gone, and an abrupt precipice in its stead, as if a giant had taken a rick-knife of suitable dimensions, and had eut off a huge slice from the top to the bottom. The fallen mass of debris formed a vast heap piled against the side to nearly half the height. Up to this time there had been no beach at the foot; the water had been deep to the cliff, and bristled with projecting masses and points of rock.

The action of the waves and the weather soon took down the piled heap of rubbish; and in a very few months the whole had assumed its present state. A wide beach was formed by the debris settling itself into the sea; the projecting rocks are quite corered 
by it; and the fragments of the fallen mountain are already worn into round and smooth pebbles by the rolling surf, so that no one would think on looking at it that it had not been a shingle-beach ever since the deluge.

ANTHEA.

On sereral occasions I have touched the tentacles of Anthea cereus with my fingers, but have never experienced any other sensation than the slight adhesion common to the Actinice: not the least stinging. At Hele, too, where the species is rery numerous in shallow rock-pools, a laid gathering periwinkles assured me that it did not sting, and as a confirmation of his assertion, immediately touched the tentacles of one before me, with impunity.

Very fine specimens are common in the pools below the Tumnel, near extreme low water. They are of tints varying from the most silky emerald green to plain drab; some are of very large size, fully three inches in diameter of disk; much more in expanse of tentacles. I perceive, what I had noticed also in specimens kept in captivity, that when the animal is distended and expanded freely, the tentacles are arranged in clusters or tufts of a dozen or twenty, which are united at their bases, somewhat like the stock of a very branching shrub.

Ehrenberg is right in affirming that this species has the power of retracting its tentacles. $M_{y}$ white specimen described in an early page of this rolume, after having been in my possession more than six weeks 
without showing any tendency to do so, at length performed this feat. On the evening of the 6 th of June, I observed it in the ordinary bell-form assumed by Actinix when at rest, with the tentacles protruded only as regards their tips. I immediately touched it both on the body and the tentacles, in the hope of inducing further contraction, by the irritation; but the power seemed to have reached its limit, for the animal opened under the annoyance instead of closing. But on the next night I observed it quite contracted ; the campanulate shape was again assumed, and the tentacles rere quite withdrawn. I have no reason to suppose that the specimen was unhealthy; it afterwards expanded its tentacles, and allowed them to hang loosely about, just as before.

The finest specimens that I have seen are at Ilfracombe, between Capstone and Lantern Hill; there is a group of the fine green variety in a tide-pool, all of which expand fully six inches in diameter, with tentacles four inches long.

The crimson extremity of one of the tentacles I submitted to examination under pressure. The walls, which were very mucous, seemed almost wholly composed of filiferous capsules of a linear form, slightly curved, about $\frac{1}{800}$ th of an inch in length. The pro. jected thread raried much in length, from four to twenty five times that of the capsule. Those of the body of the tentacle did not differ from those of the tip.

The numerous convoluted bands with which the body is filled, and which are considered to be ovaries, are covered with close-set short cilia, the vibration of 
which produces strong currents in the surrounding water, and suffices to carry away the bands themselves if they be cut off from the mass. The walls of these tubes seem also to be mainly composed of filiferous capsules set in a gelatinous matter; they agree exactly with those of the tentacles.

\section{A SUMMER MORNING WALK.}

Who does not know the delightful feelings excited by a walk in the early morning of a hot summer's day? The freshness, the coolness, the thimness of the air, the unclouded clearness of the blue sky, the warm glow that himgs all about on the horizon, the silvery dew that lies upon the grass and herbage like a veil of fine muslin,- all combine to produce a buoyancy and exhilaration of spirits, peculiar to the time. I set out on a walk to Lee on such a morning about the end of July; the sun was not yet up, but the long vermillion clouds that stretched across the glowing sky in the north-east, told of his presence, like the gorgeous stimdard that floats over the parilion of a ling.

The great black slugs were crawling on the wet turf by the road-side; creatures any thing but attractive in themselves, and yet, associated as they are with the mornings and evenings of the most charming season of the year, not only tolerated but even welcomed.

Before I had reached the end of the long steep lane that terminates in Langley Open, the sun was climbing his steeper course, and pouring down such con- 
centrated rays as foretold a calm burning day. The hills were covered with a hot haze, in which their outlines were tremulously quivering. The air was filled with a constant buzz from the two-winged flies that were hovering about the hedges; and the dull brown butterflies were flitting along in their dancing jerking flight all around.

1 marked the change in the appearance of the hedgerows and banks produced by the progress of the season. The spring flowers had all departed; there were no primroses now; no germander speedwells, no violets, no pileworts, scarcely any red campions; but purple loosestrife and the great willow-herb sprang up in the ditches; the long straggling shoots of the brambles were covered with flesh-coloured blossoms; and the dense spikes of Teucrium were every where prominent. The abundance of yellow flowers indicated the approach of autumn; the handsome spikes of the yellow toad-flax with its curiously spurred flowers crowned the tall hedges, and a Potentilla was seen here and there on the bank; but the composite flowers that botanists term Syngenesia were chiefly characteristic; the hawkweeds, and groundsels, and ox-tongues, and sow-thistles.

The foliage of the hedges and all the herbage had lost the delicacy of spring, and had grown rank, and coarse, and sprawling; seeds were ripening on all sides, and ferns were putting on their under-clothing of brown tracery.

"Not seldom did we stop to watch some tuft

Of dandelion seed or thistle's beard, 
That skimmed the surface of the [grassy field]; Suddenly halting now,-a lifeless stand! And starting off again with fieak as sudden."

WORDSWORTH.

Langley Open is a wide undulating down of great elevation: it is, indeed, with the exception of Langley Cleve, a large rounded hill on the left, the loftiest land in the vicinity. Hillsborough, which is nearly 500 feet above the sea level, is considerably inferior, for the eastern horizon was visible above its summit. It was a lovely scene. From my feet the green down sloped away a few hundred yards to the edge of the precipice, in one direction indented to form a deep, fern-covered glen, which appeared as if it would afford an easy access to the beach; a deceptive promise, however; for the adventurer, after wending his difficult and hazardous way through the gulley, would at length find himself at the margin of a yawning chasm, with angular, almost perpendicular, sides, and see the inviting little beach, perfectly inaccessible, a hundred and fifty feet below him.

From the position in which I was, however, I could not see any portion of the shore except the terminations of one or two projecting points of rock; but the hollow sound of the surf that was breaking over those points, and rolling in annong the boulders and pebbles, came pleasantly on the ear. The deep blue sea lay spread out in wide expanse, studded with shipping and bounded by the distant coast: tiny waves ruffled up by the western breeze were speckling the surface with those snowy masses of foam that mariners call "white horses ;" or, to use the poet's similitude,- 
"Ocean's mermaid shepherdess

Drives her white flocks afield, and warns in time The wary fisherman ;"

and the dark shadows of the floating clouds were chasing each other over the sparkling plain, turning the brilliant whiteness of the ships' sails into a dusky grey, as they fleeted by.

Tuming, I saw the valley up which I had been toiling; the town of Ilfracombe embosomed among the hills, the shipping in the harbour, Hillsborough and other bluff headlands that distinguish this part of the coast receding in succession, until they faded into a dim and untraceable line far up the channel towards Bristol. But prominent among them was one conical mass, attracting notice as well by, its superiority of magnitude to all the others, as by the simple majesty of its uninterrupted outline, rising to a peak from the land, and then descending with a similar angle to the sea. This mountain, which is between eleven and twelve hundred feet above the sea-level, bears the sin gular name of the Hangman, derived from a romantic incident which legendary tradition has preserved.

Many, many years ago, it is said, a man went out one night and stole a sheep from the flocks, which then, as now, grazed on the slopes of these lofty downs. He had killed it, and was carrying it home on his back, having tied the legs with a single rope which he had passed over his head, and held in his hands. As he was crossing the down he came to one of the low stone walls which form the fences in this part of the country, and being tired he rested his burden for a few minutes on the top of the wall. By 
some accident, however, the sheep slipped orer the wall, and the wretched man, being off his guard, was not quick enough to prevent the rope from catching him by the throat, nor could all his efforts then succeed in relaxing the pressure. He was found in the morning in this position quite dead, the providence of God having ordained that thus suddenly he should meet the felon's doom, and that his ill-gotten booty should itself become his executioner.

As I turned to pursue my walk, another fine example of coast scenery lay before me. The bluff and bleak promontory known as the Bull was there, projecting its abruptly precipitous head far into the blue sea, and between me and it was the little bay of Lee, a lovely spot, whose beauty I have before recorded. The cliffs on the opposite side, covered with small wood, bushes, fern, and iry nearly to their foot, and inclosing, as if with lofty walls, on all but the searvard side, little quiet bathing coves with beaches of white sand, attracted my admiration; surmounted as they were with a pretty villa embosomed in orchards and surrounded by cultivated fields. A flagstaff crowned one of the peaks that rose above this scene, and far beyond all, on the distant horizon, was stretched the lone blue isle of Lundy.

A steep and rocky lane wound down from my elevated position to Lee, where the road runs along the beach at the head of the cove. The tide was already far out, and revealed the weed-covered rocks, intersected by narrow channels, through which the little stream that flows down from the valley, was pursuing its meandering way to the sea, after spreading itself over the sandy beach. 
I stood beside the water-wheel of the mill at the end of the lane, and gazed over the wide-spread area of broken rocks that I have described on a former occasion, before my eye met the sea. It seemed incredible that under any circumstances of tempest or tide, a ressel of size could be carried to the spot where I was standing. Yet if trustworthy persons are to be trusted, a brig called the "Wilberfurce" was a few years ago lifted by the violence of the surf clean over the floor of rocks, and lodged high and dry here by the side of the mill. The crew, it is supposed, had in despair taken to their boat previously, and were all unhappily drowned, their precaution proving their destruction. The brig was comparatively little injured; she was bought by a shipwright of Ilfracombe, repaired and floated, and has continued ever since to trade from the harbour.

I wended my way, over the rocks and through the matted sea-weeds that were crisped and blackened by their brief exposure to so burning a sun, to the coves that I had seen from the heights. The rugged cliff's rose perpendicularly like walls, inclosing the most charmingly smooth beaches, whose invitations to bathe in the clear wave I found irresistible.

On either side

The white sand sparkling to the sun; in front Great Ocean with its everlasting voice, As in perpetual jubilee, proelaim'd The wonders of the Almighty.

SoUther.

It was indeed a glorious scene: the majesty of the lofty precipices, their rugged sides leading the eye up 
to dark shadowy bowers among the iry and bushes at their summits, combined with the bold outlines of the far-receding coast, and the expanse of the sea, to convey an impression of great grandeur; an impression unmarred by the presence of any object mean or little or common-place ; for where I stood no trace of the proximity of man, of his buildings, or his cultivation, was visible, nothing but the works of God himself. It was one of those times and scenes in which probably most thinking persons have occasionally found themselves, in which we are unfit for study or for action, but in which the whole soul seems alive and arrake to enjoyment.

THE FLESHY FLUSTRA.

When I was at the beach, a shower coming on induced me to seek a shelter in a narrow cleft between the perpendicular rocks; and heing within I found a shallow cavern on each side, which afforded me sutficient protection from the rain-drops, though a briny shorrer was dripping freely from the stony roof. Of course I could not stand there without looking to see if I could do anything in the way of business. From one of the cares a narrow hole ran slanting upwards many yards, till it opened at the top of the rock and let the light streaming in. The floors of both were covered with the curious cells of the honeycomb seaworm (Sabella alveolata), all composed of minute fragments of gravel imbedded in a delicate mosaicwork, of which two broad spoon-like blades projected around the mouth of every tube, exquisitely thin and 
delicate in their texture. About the wet walls were scattered irregular patches of a scarlet sponge ( Halichondria sanguinea) as big as one's hand, or bigger, and many specimens of a smaller kind of a yellowish colour, more projecting into teat-like eminences $(H$. panicea). Many limpets were about, some of which were very evidently stationary inhabitants, notwithstanding their power of free locomotion, for the surface of the rock on which they were seated was in many cases eroded to the depth of an eighth of an inch, for a space just large enough comfortably to embrace the margin of the shell. Other such oval depressions, from whence the limpet had either fallen or wandered away, showed the spots where this little shell-fish had certainly taken up his abode for a time.

On the roof of one of the caves I observed a roundish encrusting substance of a dull olive-brown colour, which attracted my curiosity, and induced me to attempt its removal. I found I could easily get it off by forcing the blade of my pocket-kniife under it, though it adhered with considerable tenacity I afterwards observed other patches of the same substance in the vicinity, some of which I took away in a manner less liable to injure its vitality, viz., by chiselling. off a portion of the rock itself. On examining it at home, I cannot find that it disagrees with an encrusting polype that is found commonly enough investing the fronds of the serrated Fucus, and which I presume to be the Flustra hispida or carnosa of naturalists. It forms a rough surface, about one twelfth of an inch in thickness, and spreading in all directions to an indefinite breadth; some of these 
patches were an inch and a half in width. The microscope reveals that in this substance, which is gelatinous, and of a consistence somewhat between flesh and cartilage, are imbedded numerous oblong cells, set as close to each other as they will lie, with the orifices slanting outward to the surface, and so arranged as that each opening shall be in a line between the two that are just behind it; in other words, disposed in quincunx. The upper and free portion of each cell is stirrounded by short spines standing up and diverging a little, their number varying from one or two to five or six. Between them is the opening of the cell, a transverse slit, or pair of lips capable of separating and of allowing the integuments to be protruded by evolution; the usual mode of expansion among the Polyzoan polypes. You would fancy it was the finger of a fairy glove, slowly turning inside out; the membranous tube lengthening all the while upwards from the midst of the spines, and unfolding with more and more rapidity, until at length a bundle of fine threads appear, and in a moment expand on all sides into a most lovely bell of thirty tentacles. Meanwhile another and another is protruding in like manner, and presently the uncouth skin that looked like a piece of rough leather, is adorned every where with these beauteous bells as thick as they can stand. They appear as if they were spun out of glass thread, so crystalline is their substance; and the double curve of their outline is peculiarly elegant. To add to their beauty, every filamentous tentacle is furnished with a double series of minute cilia, the rapid play of which is perpetually passing up one side from the base to 
the tip, and down the other in ceaseless waves, an appearance which no familiarity enables one to look on without admiration and delight. Every moment too, one and another of the tentacles is thrown inward with a sudden jerk towards the centre, bending over the head, and then gracefully recovers its place. This action, which seems odd and unaccountable at first, is an instinctive effort to secure food, the great object of life, the end for which the protrusion of the polype, the bell-like expansion of its tentacles, and the unceasing play of their cilia are alike ordained. In order to make this action intelligible it is necessary to premise that a stationary polype, being unable to seek its food, must be provided with means to bring it within reach: the cilia accomplish this; they create an impetuous current in a certain definite direction, and form a vortex in the surrounding water, whose effects are felt to an incredible distance. Any minute floating animalcule near is drawn into this whirlpool, the centre of which is the bottom of the polype's bell ; once within the circle; it is whirled round and round, descending at each gyration till at length it is within the fatal circle; the glassy tentacles encompass it with a wall on every side, and it still whirls round with ever increasing velocity in the giddy dance, and at length is sucked into the yawning abyss at the bottom, the gaping throat, which expands with a treacherous embrace as the helpless atom enters, and then closes over it with a strong muscular contraction, forcing it down into the stomach, no more to emerge alive. But if, in performing the gyration within the bell, the floating atom should be driven too near the 
margin, it might possibly escape through the interstices of the tentacles, for they do not stand in actual contact. To prevent the contingency, the cilia of the tentacles are endowed with an exquisite sensibility; and if an object but touch the tip of one of these most minute hairs, the irritability of the tentacle is excited, and it immediately moves inward with that sudden jerk, which throws the poor animalcule right back into the very whirl of the vortex.

\section{BRAUNTON BURROWS.}

The next day I set out to visit Braunton, a place whose origin is said to date as far back as the third century. The road, a little way from Ilfracombe, lies between the peak called Carn Top on the right, and the lovely valley of Score on the left. Both of these were beautiful. The conical hill, with its groves of oak, and its top sheeted with furze, is a striking object, and always reminds me, from something in its form and general appearance, of the representations that I have seen of Mount Tabor. From its lofty summit a wide and varied prospect is commanded; it is, however, precipitous and difficult to climb. There is another reason why its romantic height is seldom scaled; it has the reputation of being haunted. Some seventy years ago, a tragical deed of violence was committed here. A Jew pedlar, travelling with a richer pack than pedlars usually carry at the present day, was murdered on this lonely hill. The head and a part of the body of the unfortunate man were dis- 
covered on the very summit of the hill by an inquisitive $\mathrm{dog}$; the rest of the mutilated remains were afterwards found wrapt in a woollen apron, and concealed in a brake on the hill-side. The peasantry of the neighbourhood believe with an undoubting faith, that the ghastly head of the murdered Jew is still to be seen, in the gloaming, among the bushes of Carn Top.

On the opposite side of the road Score presented an appearance still more attractive. It is one of the loveliest vales in the vicinity. A flourishing farm, with its cultivated fields of varied hues, its animals, its agricultural operations, its out-buildings, and other appurtenances, oceupies the bottom, through which flows a clear little stream. The sloping sides of the hills, projecting irregularly in bold masses into the valley, are well wooded; a feature which greatly contributes to the beauty of the scene. A pair of squirrels, with erected feathery tails, scampered across the field as we passed, and took refuge in the shelter of these woods.

Farther on Trentistowe displayed a similar combination of smiling fields and dark woods. The blne blossoms of the sheep's-bit studded the banks, and there was a wall covered with the Comolvulus arvensis, in which the white flowers were so thick, that it looked as if a pall of green velvet had been thrown over it, studded with silver stars.

We pass West Down, a pretty village on a hill to the left, and come to Buddicombe Barton, where the rounded hills are covered with coppice of small oak; out the trees become finer as we approach the bottom. 
The hedges hereabout are composed of oak and hazel, and the nuts, which were very plentiful this season, hung enveloped in their green coats, in inviting clusters.

The country around Braunton is so fertile that it is frequently called the Goshen of Devon. A great deal of corn is cultivated, and it was more advanced to maturity than any that I had seen elsewhere. Reaping had just commenced, and the fields were lively with the voices of the cheerful husbandmen, gathering in the gifts which a bounteous God had so richly provided. "Thou crownest the year with thy goodness, and thy paths drop fatness: they drop upon the pastures of the wilderness, and the little hills rejoice on every side: the pastures are clothed with flocks; the valleys also are covered over with corn: they shout for joy, they also sing."

Braunton possesses little to attract notice, except the ancient church, which I did not enter. It is said to contain some curious carvings in good preservation; one of these, in a pannel of the roof, represents the singular subject of a sow with a litter of pigs; in allusion to the ridiculous legend, that St. Branock, its founder was directed by a dream to build a church on the first spot on which he might find a sow and pigs.

I found in the church-yard a monumental stone, elaborately carved, and inscribed with the following epitaph; which I copy for its curiosity, and not from any sympathy with the doctrine inculcated in it, of the excellence of celibacy, nor with the perversion of scripture which it contains. 
Here lieth interred Mrs.

Deborah Keene late owner of the Mannor of Braunton Arundell in this parish; shee Was bapt'd Febr' the 21th 1627,

Lived unmarried and was bur,d Decem. the 31. 1694.

\section{Virginity was had in estimation}

And wont to be observed wth veneration

Above tis still so, single life is led

In Heav'n none marry nor are married

But live Angelick lives, \& virgins Crown ${ }^{\circledR}$

All wth their coronets the Lamb surround

This maiden landlady has one obtaind

Wch tho much sought in marriage still rettain,d And now the inheritance undefild obtain,d.

\section{IIæreles posuere.}

A tall and ancient elm tree in the centre of the street, where four ways meet, indicated the spot at which I turned off for the sea-side, the immediate object of my ramble. I found the botanical character of the neighbourhood very different from that of Ilfracombe. The beautiful flowers of the wild succory, large and blue, were so abundant along the road-sides between Braunton and Santon, as to be quite characteristic. The Knautia, and different species of Centaurea, particularly fine, were growing on the banks; and from the crevices of a wall near Santon I noticed that 
tufts of the wood horse-tail were springing in considerable numbers.

Between Santon and the sea is an extensive tract of ground called Braunton Burrows, consisting of more than a hundred acres of sand-hills. It seems to have been at one time a wooded district; for a peasant, excavating the sand about a century ago, uncovered the top of a tree, which proved to be thirty feet in height. The origin of the ehange is doubtless to be found in the exposed position of the district, and in the character of the adjacent shore. The latter is a smooth beach of fine white sand, several miles in length, and of great breadth, especially when the tide recedes; the westerly winds, blowing full upon the shore, have in the course of ages drifted the fine sand upon the land, to such an extent as to cover what was once a forest, and reduce it to its present desolate condition.

These Burrows, so called because they are perforated by the holes of myraids of rabbits, present many interesting plants to the botanist, some of which are of great rarity. The round-headed club-rush (Scirpus holoschocus) one of the most uncommon of British plants, is found here.

Before I examined the sands, however, I songht the rocks towards Croyde Bay and Baggy Point; for it was nearly low water and spring tide, and I wished to see what this locality would afford of novelty in the littoral animals, which were the chief object of interest to me. The sands terminate at this extremity in a belt of ridgy shale, occupying the space between the sea and low cliffs of a yellow sandstone, disposed in 
thin horizontal strata, and covered at the top with a layer of poor soil, on which barley was growing.

At the edge of the rocks, near low water mark, the points and projections of the shale were covered with the curious honey-combed tubes of Sabella alveolata; a covering which gave to the rocks an appearance of rounded masses, singularly suggestive of the brainstones of tropical seas. Pretty tide-pools and deep inlets occurred between the rocks, with sandy bottoms; their sides densely fringed with Sertularian zoophytes and Polyzoa, sponges and various sea-weeds. Actiniæ of the species mesembryanthemum, crassicornis, and gemmacea, I observed; the lastnamed more than usually fine: the common shore shells, whelks and purples, tops and periwinkles, were crawling about in profusion. One of these creatures I shall return to presently.

I climbed up the sandy cliffs. The great sea-stock (Mattliola sinuata), a rare plant, was numerous on these cliffs, now displaying its purple flowers, I was struck with the curious large yellow glands on the leaves and pods. The samphire in dark green tufts, the pretty sea lavender, and the common thrift were likewise clothing the cliffs; and on the top, between the barley and the very edge, was a narrow belt of wild plants, which I had scarcely time to look at before a peasant came along and cut them all down with his merciless scythe.

There was the rest-harrow, the little centaury, both beautiful; the fragrant yellow-bedstraw; the woad, or wild mignonette; the brilliant azure flowers of the viper's bugloss: and the golden heads of the 
ragwort. The large purple musk-thistle was attracting in considerable numbers the pretty burnet hawkmoths, which were flying about and sucking the flowers; and the herbage generally was crowded with two little banded snails, proper to the sea-shore, the cone-snail (Bulimus acutus), and the navel-snail (Helix virgata). The clift' in one place, rather less precipitons than usual, was entirely faced with honeysuckle from the top to the bottom.

As I returned, I spent an hour in examining the botany of the Burrows; though it would require days to go over the whole ground, even cursorily. The privet grows on the sand-hills in large thickets of beautiful glossy green foliage, thick and dense; the stems lean away from the sea, and the surface of the thickets is as smoothly rounded by the winds as if cut by the shears of a gardener. Near the sea was the small bugloss (Lycopsis arvensis), with blossoms like those of a forget-me-not growing on a rough sprawling prickly herb. I found the rare musky stork's bill, a plant with little pretension to beauty, nor does its rank odour please me, though it is said by Sir William Hooker to be cultivated in gardens for its scent. The vipor's bugloss was again numerous, and the contents of its nectariums were eridently attractive to the bees of different species, which were thronging around the spikes, half-burying themselves in the blossoms, with a shrill deprecatory hum. Two species of spurge, Euphorbia peplus, and the much finer and more uncommon E. Portlandica, occurred. That singular plant, the prickly saltwort, was found near the sea, and farther inland the fuller's teasel, 
which I had seen also on the road. A few tufts of the stinking iris, so common in Suuth Devon, but scarce almost everywhere else, were growing near the sea, but not in flower; and the more elegant yellow iris was abundant in a ditch that bounds the Burrows interiorly, with other common hedge-plants.

The sand of the hills was beaten quite hard on the seaward side by the force of the drift; but inwardly it was soft and loose: great tracts were covered with a slender rush of a glaucous hue, but as I saw none in flower I do not know the species. The ragwort also covers extensive areas. Towards the interior side I passed through a large tract of the brake-fern, with an under-growth of rest-harrow, and a few plants of the yellow mountain violet in blossom. These I think were pretty nearly all the plants that fell under my observation, except such as were common everywhere. Of animal life I did not notice much. Rabbits indeed were numerous, popping out of their holes at every turn, gazing at the intruder for an instant, and then jumping away with elevated rump and tail. Two insects, an Asilus and a Cicindela, were taking short impatient flights over the sand; singularly alike in manners, though of widely different orders; the one a two-winged fly, the other a beetle. On the sand and beneath its surface, were thousands of shells of the common garden-snail; the heat and the dryness had, as it were, embalmed them, and they appeared in the finest preservation. One might have been tempted to think, but for the familiar form and pattern of the marking, that it was some foreign species of superior beauty, for the dark colours were 
changed to a fine chestnut-red, while the lighter parts had become pure ivory-white.

\section{THE FEATHER PLUMULARIA.}

A tuft of weed that I had pulled off from the side of one of the rock-pools, and brought home screwed up in a bit of paper, was almost covered with the elegant plumes of Plumularia pinnata. I put it into sea-water as soon as I arrived at home, after it had been out of water about eight hours, carried within my hat. When I came to examine it, many of the Polypes appeared alive, though contracted. Many of the lower stalks were nearly denuded of branches, except at their tips, but were densely crowded for the most of their length, with the ovigerous vesicles. (Plate XVII, fig. 4.) These are placed in a single series, on the upper side of the arching stems, as thickly as they can stand, about twenty-five on each. By single series I mean only that they are all seated on one side of the stem, and all point the same way, (with an occasional exception); for they are two, three, or even four abreast. Their substance is hyaline, but the contents are opaque and flesh-coloured. Their shape is sub-oval, larger at the tip, but the sides are fluted so as to form about six rounded angles and as many furrows. Near the tip several divergent tubercles or blunt spines are given off. Fig. 5 represents a lateral view of one; Fig. 6 a vertical, from a very good view: the opaque ova in the middle.

The tuft alluded to I put into a glass vessel made 
of the chimney of an ordinary lamp, with the bottom closed by a plate of glass: this was about half-full of sea-water. In three or four days, examining cursorily with a lens, I was surprised to see the bottom crowded with young polypes growing erect from every part. They were there by hundreds; I detached a few for more particular examination. Each consisted of an irregular dilated glassy plate, adhering to the bottom: from some point of which sprang up erect a slender tube, with one or two joints, and terminating in a cell of the same form as those above described. The medullary core permeated the tube, and was developed into a perfectly-formed polype inhabiting the cell, and freely expanding from it. The tube, the cell, and the polype, were of the same dimensions as in the adult. Some of the cells already shewed, in the form of a tubercle budding from their bases, the commencement of a new joint of the lengthening polypidom. (Fig. 13.)

Along with these, on the floor of the glass-vessel, were many minute animalcules of an opaque white hue, somewhat planaria-like, which crawled slowly and irregularly, protruding the anterior portion of the body in a blunt point, but often contracting the whole outline into a sub-globose form. (Figs. 7, 8, and 9). These worm-like animalcules I found to bo the primal form of the young polype, and though I have not been able to trace the metamorphosis through every stage of its development in the same individual, the facts I have observed leave it indubitable.

I took two plates of thin glass, and suspended 


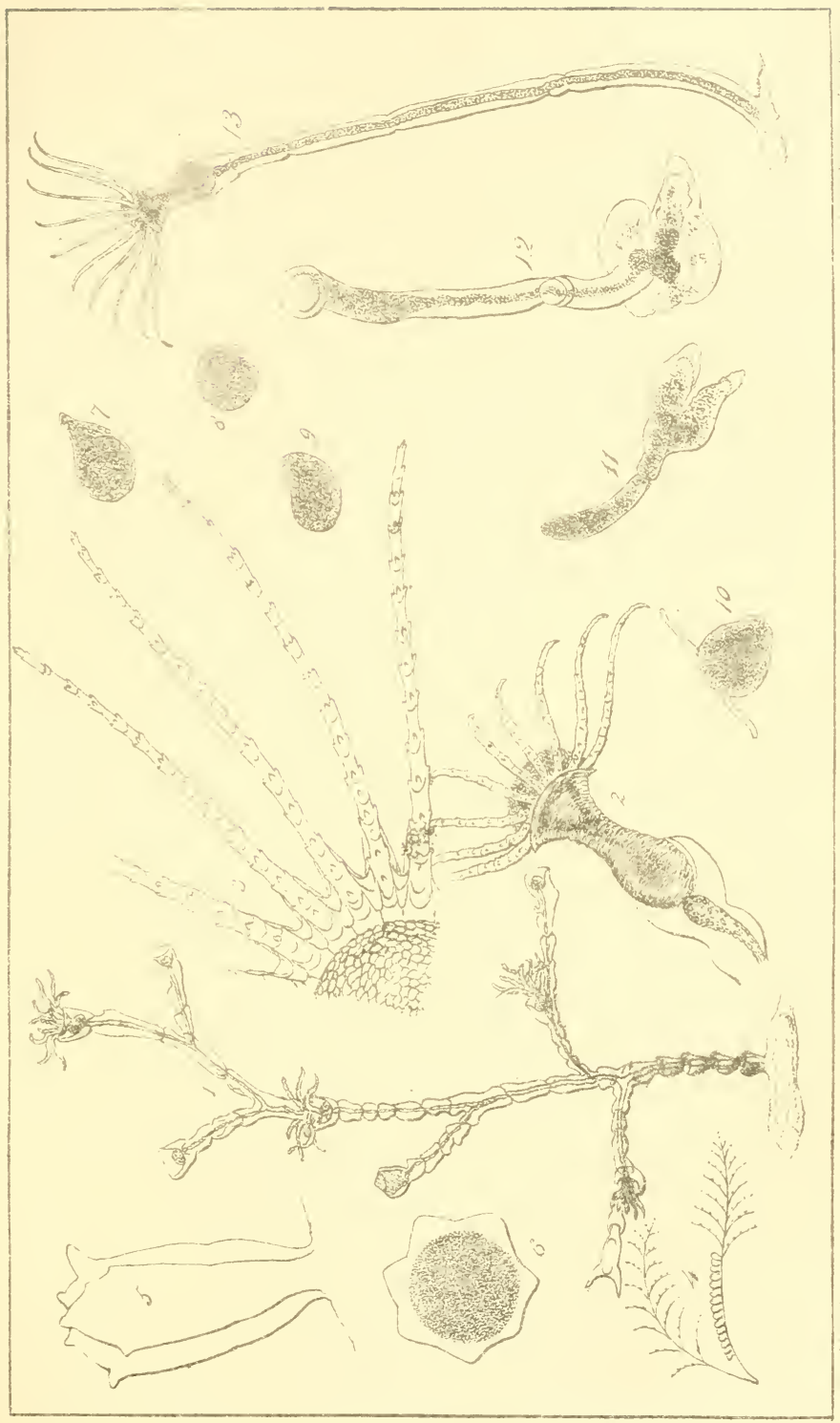



Plate XIII

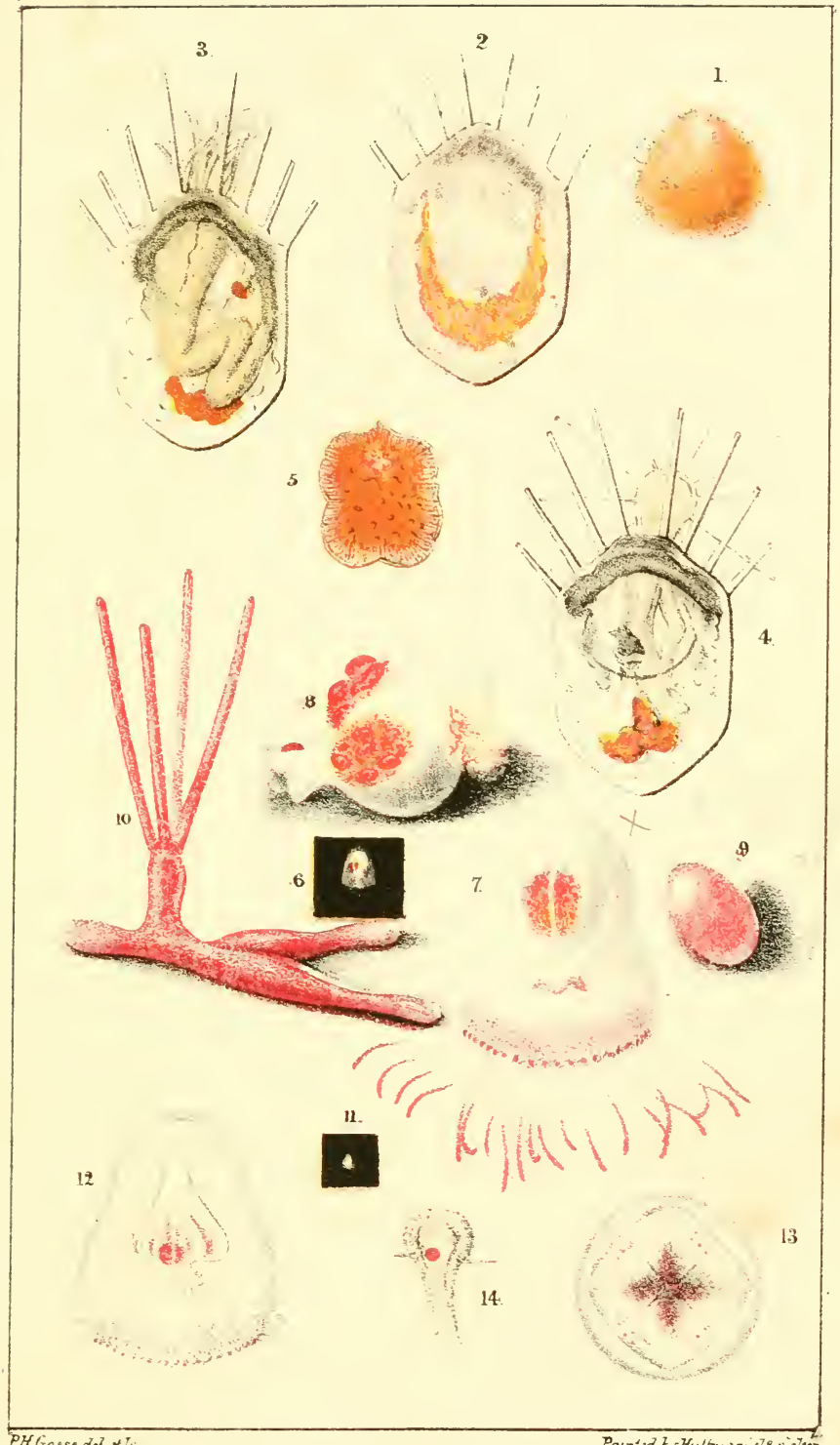

PHGossedel at

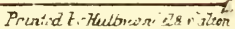

$$
\begin{aligned}
& 15 \text { LEPRALA COCONTAE } \\
& \text { PIC, TLRRTA NEULECTA } \\
& \text { "I-H, JUEANIA PUBILIA }
\end{aligned}
$$



and repeatedly. Presently on the restraint being continued, the globule threw out from different parts of its periphery, long lancet-like flexible pointed bristles twice as long as the cilia, with which it pushed here and there. These lancets I perceived were ordinarily bent at an acute angle near their base, so as to lie flat on the body unperceived; and I think there were many of them, for I fancied I saw the minute basal parts of many that were so concealed. Those that were exposed were ever and anon suddenly bent up again and so concealed, and again protruded. After examining it awhile, I carefully put it without injury into a glass of sea-water alone. Its diameter was about $\frac{1}{110}$ th inch (See Plate XIII. Fig. 1).

$I$ afterwards saw another in the original vessel, and both this and the former had the habit of coming into contact with the side of the vessel, and continuing in one spot for a considerable while, (half an hour or more) not moving a hair's breadth from the place, and yet evidently not adhering, because gyrating uniformly all the time by the ciliary action. One of these I lost, and the one that I isolated got into a corner of the cell, and decayed. But carefully looking at the original vessel, I found some half a dozen scattered over the sides, but in a more advanced condition. 'These were all firmly adhering to the glass, and that so inseparably that the most careful touch of a pin's point to detach one, tore it into a shapeless mass of broken flesh. The youngest of these had taken the form of a flattened oval, or long hexagon, with one end more pointed than the other, in which the redness was curdling and separating into masses. The others 
showed eight points budding from the more acute end; and in one the most advanced, these were already produced into eight slender spines, set around the end like the teeth of a comb, and slightly divergent. In this the the general hue was a pale pellucid flesh colour; and an opaque band of deep red was arranged in a horse-shoe form, around the end opposite the spines. (See fig. 2).

During the next day little change took place except the lengthening of the spines; but by the following evening, forty-eight hours after I had observed it in the state just described (fig. 2) it had made importan advances. The spines, without increasing in thickness, had shot out, until the middle and next pair were nearly as long as the transverse diameter of the body; the other two pairs were much shorter. A touch with a pin broke short off two of these, proving that they were very brittle, whence, and from their crystalline appearance, I infer their calcareous or siliceous nature. But while $I$ was examining it I was surprised to observe a bundle of filaments among the spines, and much resembling them, except that they were bent irregularly, and slowly moved among themselves, while the spines were fixed. Lo! the bundle is gently protruding, and presently the whole is withdrawn like lightning out of sight into what I can no longer hesitate to call the oval cell. A simultaneous jerk in the contents of the cell set me upon trying to make out the form of these, in which, notwithstanding the confusion of the parts, I had already traced (or fancied) the body of an ascidian polype, doubly bent up, like that of a Membranipora or Flustra. By careful 
watching during many protrusions and retractions, I was enabled to make out this with sufficient distinctness; though some portions of the area were still semiopaque, and therefore obscure. I could see also an ample aperture on the surface opposite to that at which I was looking (viz. the adhering base, for as it was in a glass vessel, 1 could apply my microscope only to the outside, and therefore only saw it through the glass to which it had attached itself); this aperture on the upper surface, was excentral, and situated on the half nearest the spinous end. Possibly this aperture was covered with a membrane, (like that in Cellularia avicularia) for I think that the bundle of tentacles were not protruded through it, but through an orifice more terminal, yet still above the plane of the spines. The body of the polype, of a horny yellow hue, was doubly bent to one side, and behind the angle was an irregular transverse mass of deep red matter, and another small spot of the same was a little on one side of the centre. These were all the remains of the scarlet substance left. (See fig. 3).

On the morning of the third day I found the polype perfectly formed and well-expanded, a circle of thirteen tentacles; these were usually protruded in the form of a funnel, with the rim so slightly everted as scarcely to entitle it to be called a bell, but now and then they were momentarily spread out quite flat so as to make a beautiful plane star, the tips forming a regular circle. I could now distinctly see the intestinal tube, which is inserted into the stomach low down in the body, and proceeds nearly parallel with it to the aperture. The body of the polype is con- 
siderably protruded from the cell, below the divergence of the tentacles. The great circular aperture on the upper surface, appears to have a rim. (See fig. 4).

June 18th. A week old: no material alteration from last record. I found, however, the next day a gemmule represented at fig. 5 , which perfects the series. It was in a state intermediate between figs. 1 and 2. Its length is $\frac{1}{70}$ th inch. The edges are pellucid, and have an appearance of radiating fibres. The redness is curdled, but not wholly separated. This continued for several days, the red mass slowly concentrating; but no spines appeared; and at length $I$ fear it was broken accidentally; granular matter came out, leaving a glassy cell attached to the side of the vessel. The species was probably Lepralia cuccinea; but eight spines are more than are ascribed to any of our species.

THE THREE-HEADED CORYNE.

June 18.-In the glass jar that contains Actiniæ, \&c., that I brought from Torquay, I found on the Membranipora, a rery young specimen of Polycera 4-lineata, about $\frac{1}{8}$ inch long: very pretty. Some of the cells of the polype appeared to have been recently . gnawed, probably by this little mollusk.

In the same vessel I found another species of Coryne. (Plate XIT, figs. 4-6). It is sessile on a decaving frond of some Alga, about $\frac{1}{50}$ inch in height in medium extension, with no appearance of tube. The polype is sub-cylindrical, slightly clavate, round- 


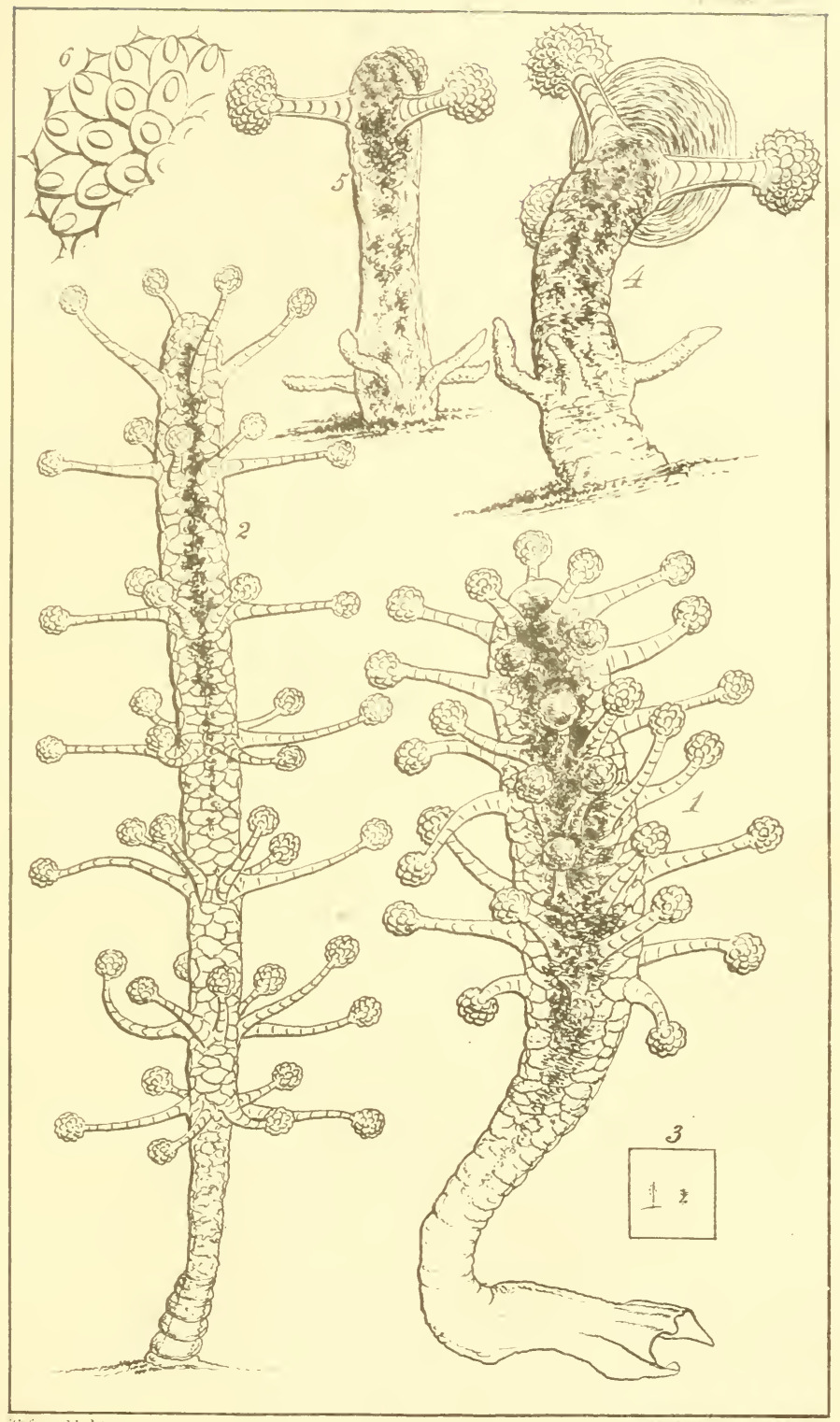

$\because$ Gosse delet lith

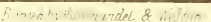



ed at the tip, where there are three tentacnla formed exactly like those of $C$. ramosa, but the round heads are much larger in proportion, and more coarsely granulated; their diameter is nearly equal to that of the polype: the head is flattened vertically; the oval grains of which it is composed are very distinct, and each is furnished with a conical transparent point ending in a short bristle. This point is distinct from the oval granule, and its outline is perfectly discermible when seen vertically, as well as laterally. (Fig. 6). Near the base of the polype, at a slight swelling, there are four or five arms, which seem to be the withered remnants of former tentacles, from which the round heads have sloughed off. The specimen may be the young of C.ramosa. (Fig. 5.) The animal is active, bending both the tentacles and the body in all directions: the latter especially is frequently curved round into a circle, so that the tip touches some part of the side, or one of the tentacles. The very extremity above the tentacles is surprisingly flexible; and its walls are contractile and expansile. I saw the terminal orifice often partially opened by evolution of the skin, and then partially closed by a puckering of the surrounding margin: sometimes the interior was turned out so far as for the head to form a longish cylinder. But to my surprise, I find that this orifice is a great sucking disk. I had put the animals in what microscopists call a live-box, and the two glass surfaces were just wide enough apart to allow the animal free liberty to turn about in all directions as far as it wished. On my looking at it after a momentary interval I saw that the extremity had suddenly become a large circular 
disk, of thrice the diameter of the body ; its substance was gelatinous, full of oblong granules arranged concentrically. (See fig. 4.) I neither saw this disk evolved nor retracted; but after some time, on looking at it, the same phenomenon was repeated. In order to obtain a better sight of it, but without a suspicion of what I was about to effect, I slightly turned the tube of the box, carrying with it the alga to which the polype was attached, my eye upon it attentively observing all the time. The base of the polype moved away from its position, but the broad disk was immoveable; I continued to turn the upper glass, until at length the body was dragged out so as to be considerably attenuated; still the disk maintained its hold of the lower glass, with no other change than that of being elongated in the direction in which it was dragged. At length it slowly gave way, and resumed its original shape by gradual and almost imperceptible diminution of the circumference.

The oval grains of the tentacle-heads appear to be packed in a gelatinous substance which fills their interstices, and envelopes the whole, which is then (I think) inclosed in a thin calcareous shell, for it breaks with a loudish crepitation under pressure. It is possible however, that this crackling may have indicated the crushing of the grains themselves.* They often get loose from the heads without pressure, and then

* At this time I was not familiar with the filiferous capsules of the Ilelianthoid Zoophytes. I will not cancel my recorded impressions of the actual observation; but I now think that it is likely the granules were filiferous capsules, the crepitation that which marks the emission of the thread, and the "film of jelly," possibly the filament itself. 
appear to drag a film of the jelly in which they are inclosed. Each granule is hollow at the centre, the cavity being oblong, and connected with the surface by a slender orifice at the interior end of the oval. I am astonished that Van Beneden should say there is no globosity in these tentacles in the active and rigorous polypes, and that this is merely the result of contraction. On the contrary I do not believe that the head is capable of contraction; and I am sure that it is globular in polypes in the highest health and activity.

I venture to assign to this little Coryne a provisional appellation, subject, of course, to future correction. Its triple head suggests the name of Coryne Cerberus.

\section{BEANIA MIRABII 'S.}

The Beania mirabilis before-mentioned was parasitical on the same Cellularia avicularia, and consisted of only a few cells springing from their creeping thread. Dr. Johnston's figure is very good, but the spines in my specimens were more regularly curved, and tapered to a point. Their direction moreover is not fully expressed by him, they shoot partially around the cell, following the curve of its transverse outline, but diagonally also, towards the point. The spines of both series thus curve diagonally towards each other, and if sufficiently projected, would meet and cross at obtuse angles, and embrace the cell. I cannot see any keels; the spines appear to me to spring from the smooth glassy side of the cell. 
CORALLINE LIGHT.

The common Coralline, if held to the flame of a candle, burns with a most vivid white light. If we take a shoot and let it dry, and then present the tips to the flame, just at the very edge, not putting them into the fire, the ends of the shoot will become red first, snapping and flying off with a crackling noise ; some, however, will retain their integrity, and these will presently become white-hot, and glow with an intensity of light most beautiful and dazzling, as long as they remain at the very edge of the flame, for the least removal of the Coralline, either by pulling it away, or by pushing it in, destroys the whiteness.. It will however return when again brought to the edge. The same tips will display the phenomenon as often as you please. I did not find the incrusting lamina that spreads over the rock before the shoots rise, show the light so well as the shoots.

The brilliant light obtained by directing a stream of oxygen gas upon a piece of lime in a state of combustion, occurred to my mind as a parallel fact ; and I experimented with other forms of the same substance. The polypidoms of Cellularia acicularia, and of Eucratea chelata, one of the stony plates of Caryophyllia, and a fragment of oyster-shell, I successively placed in the flame, and all gave out the dazzling white light exactly as the Coralline had done. The horny polypidom of a Sertularia, on the other hand, shrivelled to a cinder. 
them by threads in the ressel, near the bottom, hori. zontally; with a view to obtain some of the embryos rooting themselves thereon, which I might afterwards take out, to watch their progressive development under the microscope. Meanwhile I secured the first step in the inquiry, by.opening with needles some of the crowded vesicles of the adult polypidom, from which I obtained some of the minute white worms. In two or three days I drew out the plates of glass, and put them in shallow cells of sea-water, fit for the stage of the microscope. I found upon them the young animals in various stages. Some of the worms were yet vagrant, and crawled freely about the surface: others had selected their position and were adherent, but still retained the power of motion, to such a degree as enabled them to change their form by protruding certain portions of their outline: others were contracted into a globule fixed and changeless, with the matter produced in the form of a creeping rootlet (Fig. 10).

The next stage that I observed, was that in which the adherent mass had become shelly; as I presume, for the marginal portions were perfectly transparent and colourless; and the opaque granular matter had retired to the centre, where, irregular in form, it had given rise to a tube (Fig. 11). This tube had already formed one joint: its extremity was closed and rounded, and had not yet begun to dilate into a cell. The medullary matter, proceeding from the granular mass at the base, passed through the lower portion of the tube as a central cord, but completely filled the terminal moiety. Another specimen had 
proceeded so far as the formation of the cell, the bottom of which was filled with the granular matter as yet amorphous, no trace of the polype being yet discoverable (Fig. 12). This was the most matured phase of the development that appeared on the experimenting plates of glass; but the transition from this state to that of the young polypes already described at the bottom of the ressel is short and obvious; and the progress from one of them to a perfect polypidom is but a matter of increase and aggregation. There is, however, a hiatus in this chain; I should have particularly wished to see one or more specimens between the condition of the adherent globule, and that of the formed and growing tube: but of this intermediate stage my glass plates presented no specimen. And whether the water in the shallow stagetroughs, to which I removed the plates for microscopic examination, afforded insufficient nutriment, I know not; but I could not find that any individual specimen continued to grow after the removal from the larger vessel; and they shortly gave evident tokens of death and decay.

In examining a cluster of the same polype from the Bathing Pool, I was struck with the great similarity of the expanded disk to that of the embryo of Laomedea geniculata. I have figured a segment at fig. 3 . I cannot find any trace of the so-called auditory capsules. The tentaclos are very distinctly armed with whorls of tubercles, some of which have two, and even three points. They are as it were jointed, being crossed at regular intervals by well-marked transverse lines (i. e. planes). The centre of the disk is protu- 
berant; and there is a dark granular disk, which is sometimes contracted considerably within the circumference, and at others expanded so as to reach beyond the webs which conuect the bases of the tentacles. Fig. 2 shers a well expanded polype, as seen laterally: there is a neck below the disk, and then a flask-shaped body; this latter fills the narrow limits of the cell, so that the polype has no power of withdrawing itself; it can do no more when alarmed than draw the tips of its tentacles together, and contract them into a ball; and this it does with that spasmodic grasping clutching sort of action that I noticed in the young of Laomedea geniculata. A beautifully distinct circulation of granules in a fluid was seen pervading the medulla of the stem and branches to the cells. The whole polypidom was much infested with fine radiating fibres, doubtless parasitic ; and with some Vayinicole. I counted seventeen tentacles in one, nineteen in another. 


\section{CHAPTER XII.}

A Visit to Smallmouth Caves-Chasm formed by a Rock-slipView of Samson's Bay-Samson's Cave-SmallmouthNatural Tunnel-View of Combmartin Bay-Brier CaveAbundance of Animals-The Twining Campanularia-Form of its Cells-The Polypes-The Egg-Vesicles-Birth of a Medusoid-Its Form and Structure-Tentacles-Eyes-Circulating Canals-Alternation of Generations-Ride towards Barricane-A Showery Journey-Lee-Damage Farm-A romantic Dell-Devonshire Wells-Rockham Bay-White Pebbles-Morte Stone-Shipwreck-Gallant Exploit-Morte - Tomb of De Tracy-Approach of a Storm-KestrelsParasites on a Crab-The Bristle Plumularia-Birth of its Young-Dissolution-The Lobster's Horn Coralline--Secondary Cells-Suggestion of their Purpose-Egg-VesiclesBirth of the Planule-Its Development into the Polype-form -Death.

\section{SMALLMOUTH CAVES.}

Aug. 2nd.-I paid another visit to Watermouth and Smallmouth, principally for the purpose of seeing the perforations and caverns of the latter place. The road thither was of course the same as when I had traversed it three months before, but the almost entire change of the accompaniments made the effect different. The flowers that had adorned the banks in May had left searcely a representative, and comparatively few new ones had sprung up in their place. Of these few, however, one of the prettiest was the perfoliate 
yellow-wort, which, though I had not met with it elsewhere, was somewhat numerous in Hockey Lane above Hele. The enchanter's night-shade, the eyebright, and the centaury were likewise growing here; and near Watermouth the mountain willow-herb, and the com. mon vervain were numerous.

At the most elevated part of the coast-line where the down comes to a precipitous edge some hundreds of feet above the sea, there is a narrow but deep cleft in the land, into which we can gaze down from the road. It is an awful chasm, with nearly perpendisular sides; and was formed, as I was told, in one night, about a year ago, by the sudden falling in of the earth. There was still the hedge running along the margin of the precipice, interrupted by the chasm, which had cut it right through. These land-slips are by no means of rare occurrence, and they frequently alter and modify the appearance both of the cliffs and of the sea-margin below.

A little way beyond this point the traveller looks down upon a cove called Sampson's Bay ; it is girt in with rocky cliffs of great massiveness and wild grandeur, too abrupt and perpendicular to be scaled, even by the most expert climber. An ample cavern yawns on the western side of the bay, into whose depths, as the tide was high, the surf was dashing, with a roar that rivalled the discharge of artillery. I thought of the fine simile of Moore;-

" Beneath, terrific carerns gave

Dark weleome to each stormy wave,

That dash'd, like midnight revellers, in." 
This, however, was not one of the caverns of which I was in search. They are situated at Smallmouth, about a mile farther to the eastward. "The stream that runs in front of Watermouth Castle, expands into a little pond, the water of which is made to pour down a square well of stone, from the bottom of which it escapes again as a brawling brook. Just at this point, a path leads off from the main road, which presently conducts the traveller to a steep descent into a sort of glen, rough with boulders, and unpleasant to walk in, from the admixture of sand and mud which forms the bottom. This glen is the head of a long and narrow inlet, confined between precipices, and up which the sea enters, to an extent which varies with the condition of the tide. A stranger might readily leave this cove with the impression that he had seen all it had to display; but if he turn into a narrow opening in the rock on the right hand, he will be rewarded by a sight of more than ordinary sublimity and beauty. A great natural tumel opens before him, perforated in the solid rock. The roof is nearly horizontal; but the sides spring out into angular groins and projecting buttresses. The interior of this archway is as dark as night; its obscurity being heightened by contrast with the brilliancy of the sunlight, that illumines the scene without, visible at the far end. The prospect beheld through this cavern is a lovely one, and reminds the beholder of a sunny picture, set in an ample black frame. His eye ranges across the beautiful bay of Combmartin, on the surface of which, when I looked at it, the fresh breeze was raising hillocks of foam upon the green 
water, that flashed and sparkled in the sun. On the opposite side were the red cliffs of the Hangman, with their verdant turfy crown, sloping down to an abrupt point; the caves and various irregularities of their sides distinctly visible, though in hues softened and mellowed by the distance. The floor of the cavern is rough with weedy rocks, on which the foot finds but a slippery and precarious hold; among these lie shallow tranquil pools, tranquil because protceted from the wind without, and reflecting, with mirror-like precision, the form of the aistant coast, and every white cloud that skims over the azure sky.

If the visitor now retrace his steps, and, crossing the cove, examine the rock on the opposite side, he will find a long perpendicular fissure just wide enough to permit him to squeeze his body through. After pursuing this gallery for a score yards or so, he finds himself in an area, open to the sky and leading away to the right and left. On either hand is another natural archway: that to the right resembles the one just described (except that it is narrower), and looks out upon the same scene. The one to the left is essentially similar, but as it leads inland, it may be traversed; and the explorer will find himself, at the end of the arch, at the bottom of a deep circular pit, about as wide as an ordinary room. The sides are precipitious, about thirty or forty feet high, and fringed all round at the top with matted brambles, whence the hole has aequired the name of Brier Cave. At first there seems no mode of escape from this prison, except through the gallery by which the 
visitor entered; but a careful examination reveals a narrow pathway among the bushes, which climbs up one side, to daylight and liberty on the downs above.

These natural perforations are among the most curious phenomena which a visitor can see in the vicinity of Ilfracombe; as the tunnels which lead to the public baths are the most interesting of the works of art: though, from the readiness with which they may be overlooked by strangers, even when close to them, many go away without seeing them.

To the littoral naturalist these caves and the surrounding rocks present a fruitful field of observation. The surface is broken and uneven, and covered with tide-pools of varying level, most of which are richly stored with plants and animals. The water's edge at low tide is strewn with stones, not difficult to lift, beneath which are found Crustacea, Annelides, and Star-fishes, in abundance. The perpendicular sides of the bounding rocks themselves, and the interior of the fissures, are studded with Madrepores, many of which are fine specimens both for size and colour; these are exposed and readily accessible at the lowest spring-tides.

THE TWINING CAMPANULARIA.

From the rocks around Smallmouth Caves, I obtained a little tuft of that very elegant Sertularian zoophyte, Campanularia volubilis. The cells were numerous, and many of them were inhabited by their polypes, expanding freely in full health and vigour. 


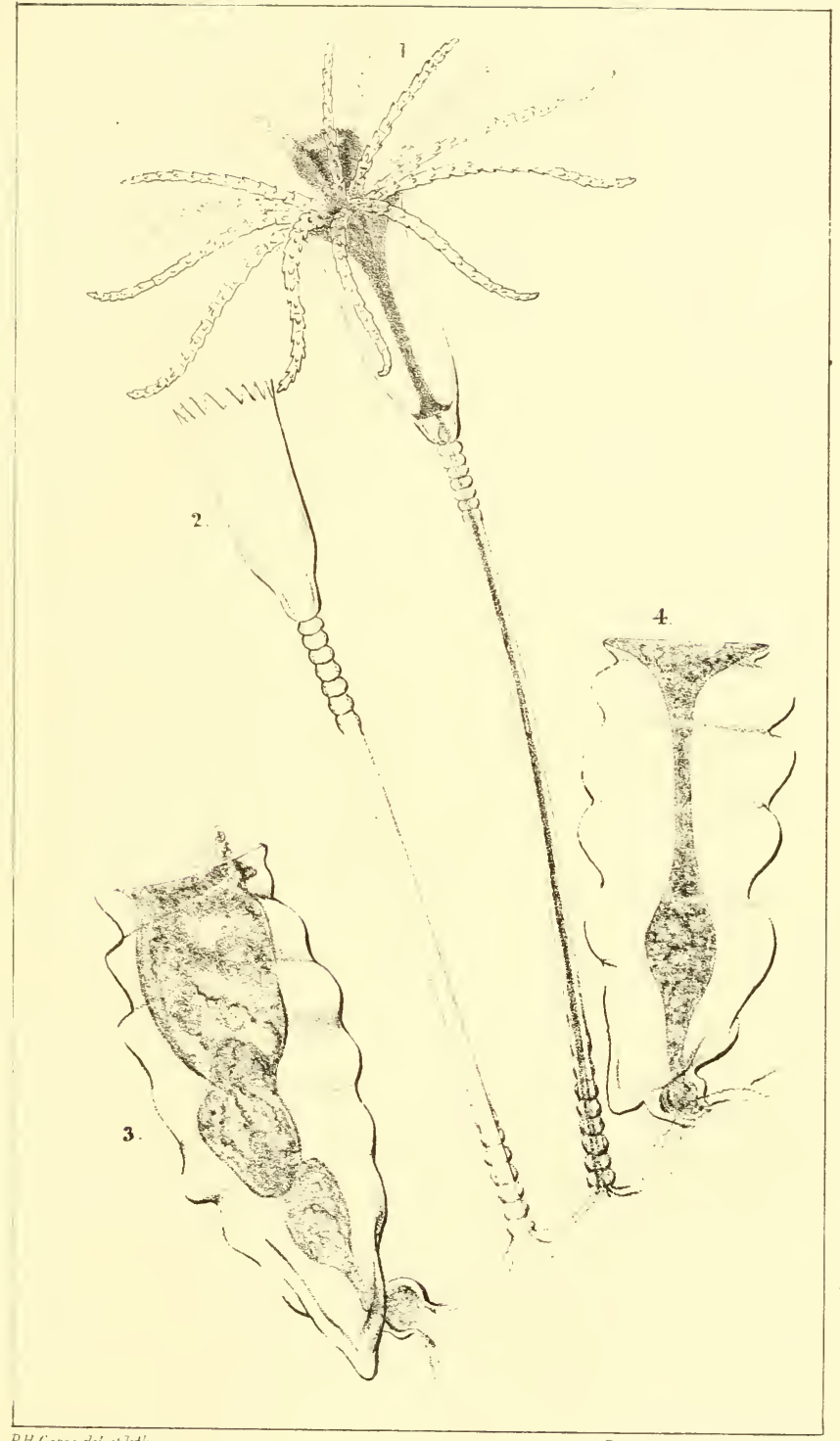

PH finsse dei et lith

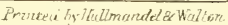

CAISHI LAF:- TOLITEIS. 

The genus is distinguished from Laomedea by the cells being placed on long ringed footstalks, which spring in an irregular crowded manner from a creeping adherent stem. The stem in this instance had twined about the slender fronds of a small sea-weed.

The cells in this species are shaped like an oldfashioned ale-glass, being long and narrow, with a slight constriction just above the point of their connexion with the footstalk; and at this constriction, a sort of false bottom, or diaphragm, runs across, which is perforated with a narrow hole in the centre. (See Plate XVIII, fig. 1). The margin is cut into about eleven deep equal teeth, and expands in a very slight degree (fig. 2). The stalk has usually about six or eight well marked rings at each extremity, the middle portion being smooth. The walls, both of the stalk and cell, are thin, and perfectly transparent and colourless; the former is permeated, but not filled, with the medullary core, through which a fluid circulates, carrying minute granules with a quivering jerking motion. This core is exceedingly attenuated to pass through the perforated diaphragm of the cell, after which it merges into the body of the polype.

The polype (fig. 1.) is slender (when protruded); dilated at the base into a sort of foot which spreads over the diaphragm, and widening still more at the top, where it fills the mouth of the cell, and gives origin to about twenty (less or more) slender tentacles, roughened with whorls of tubercles, and set in two or three series. In the central space surrounded by the tentacles, a large fleshy mouth protrudes, 
somewhat funnel shaped, but capable of great alteration of form. Its lips are endowed with the power of protrusion and contraction to a great degree, and appear to be very sensitive: they are pushed out, and turned in and out, and modified in various ways, with much energy. Its walls are thick and granular, and the cavity which they inclose can be traced for a considerable distance down the body.

Among the foot-stallis were several of the egg-vesicles springing from the common stem. (Figs. $3 \& 4$ ). They are somewhat like the cells in form, but are about twice as large, both in height and diameter. They are pointed at the bottom, and are attached to the stem by a very short bulbous foot-stalk, which joins the vesicle on one side, a little above the point, which thus forms a sort of spur. The walls of the vesicle are transparent, but corrugated with many coarse irregular rings, and the mouth is somewhat trumpet-shaped, though not quite so wide as the middle part. The core, which permeates the stem, sends off a branch into the vesicle through the footstalk, where it is swollen into a little node. It then passes through the centre of the vesicle, being slender, but dilates at the extremity, and becomes commensurate with the shelly mouth, to the margin of which it is adherent. Thus it closely resembles in appearance the polype-inhabitant of a cell, supposing the latter to be divested of its proboscis and tentacles. It is however seen in this condition, only after it has performed the office for which it was made. Ordinarily it is swollen into three or more oval knobs, of which the outermost are the largest; through the 
development within its tubular walls of as many embryos. These, as they develop themselves in succession, show evidence of life, in their contraction and change of form; the outmost one sometimes occupying the mouth of the fleshy duct and filling its diameter, at others retiring to some distance, leaving the duct long and slender, between the extremity and the embryo.

I have not seen the escape of the embryo, but perceiving that one and another had escaped, I searched the water of the minute glass box in which the animal was kept. There I found the little new-born creatures I was seeking, but in a shape that surprised me not a little. A moment's recollection, however, of what I had seen as the progeny of the allied Laomedea, diminished my astonishment. (See Plate XIX.)

The embryo, then, of Camp. volubilis is a gelatinous globose sac, about $\frac{1}{30}$ inch in diameter, somewhat orange-shaped, perfectly circular in vertical aspect (figs. 1 and 2), but flattened at the top, and as it were cut off at the bottom (fig. 3). The whole surface is smooth until we arrive at this truncate bottom, round the edge of which runs a tubular cord or canal of wrinkled gelatinous substance, through which, as I believe, circulates a fluid. At least, I perceive minute clear globules, one here and there, in different parts of the canal, playing backward and forward with a dancing morement, which indicates some fluid in motion there, though I am not sure that it strictly circulates. The truncate surface sometimes appears slightly funnelshaped, the sides inclining inwardly to a central orifice, larger or smaller at the will of the animal, by 
contraction or expansion. No thickened edge marks the orifice, which can be discerned only by delicate manipulation. The whole of this truncate surface is marked with the most evanescent concentric corru. gations.

We return now to the marginal canal. At each of four equidistant points, quadrating the circle, there springs from the canal a filamentous tentacle of great length, with a bulbous root. When extended it may be about twice as long as the diameter of the whole globe, but it is ustially much contorted ; and especially when swimming, the whole filament being then so contracted and twisted together, as to appear only an oblong knob, very little larger than the bulb alone in its ordinary state. The filament is distinctly tubular throughout; and the bulb has an enlarged cavity proportioned to its size, which evidently communicates with the marginal canal (Fig. 6). The bulb is filled with a yellowish granular matter, which does not extend into the tube of the filament. The walls of the filament are composed of oral grains (filiferous capsules, no doubt) set in a clear glairy matter, transversely to the length, and radiating from the centre, their tips projecting on all sides. Towards the extremity, the surface becomes more and more tubercled and rugged, and at length is studded with sharp conical points irregularly set: the very tip being slightly dilated into a rounded bulb (Fig. 7).

I observe that the globe no sooner is at rest by touching the bottom of the vessel, that it unfolds and extends the four filaments, still however corrugated and contorted: probably for the purpose of entwining 


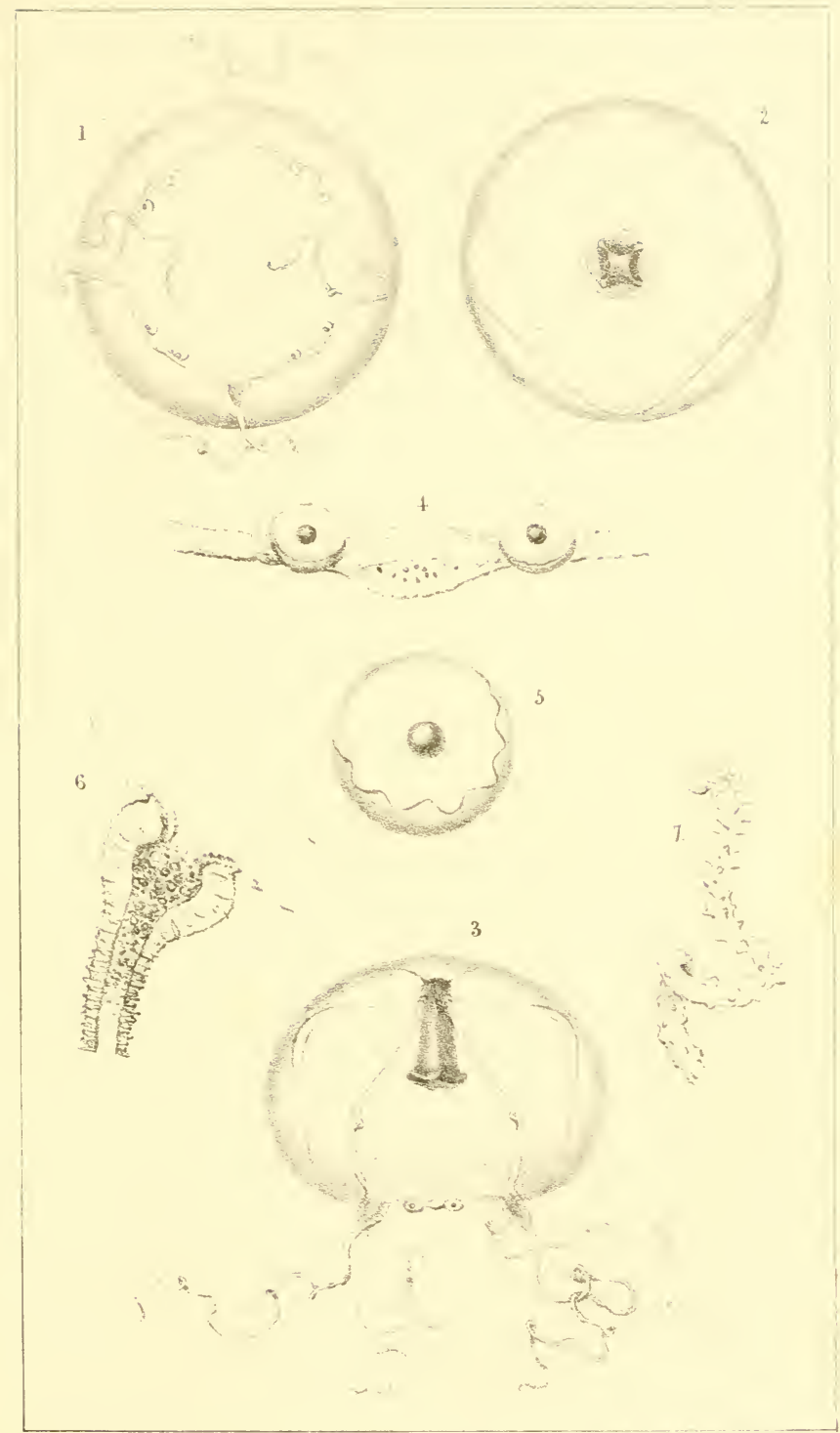



around any objects they may meet with, and so mooring the animal. That contact stimulates the tentacle to grasping I infer from the frequency with which I see one or more inserted into the sentral orifice of their own umbrella, and bent round the edge. The tips, probably, accidentally get in, in roving about, when the touch of the edge stimulates the filament to bend tightly round it.

Midway between each pair of tentacles, and thus quadrating the circle at four other points, the marginal canal carries on its exterior side a little swelling, within the cavity of which are contained half a dozen or more minute granules, in which I could not detect any motion. Its cavity is isolated from the course of the canal, which can be traced independently. (See fig. 4). And close to this bulb, on each side, projecting from the interior of the canal, but sessile thereon, is a globular capsule furnished with a narrow waved veil or membrane hanging from its interior surface, and formed apparently of the same, substance as the canal, but containing in its centre a spherule, transparent, colomrless, and of high refracting power-a crystalline lens, in fact (Fig. 5). The vesicle which carries this spherule is furnished with a very minute tubercle, projecting from its edge towards the interior of the animal.

These vesicles, of which there are eight altogether, I should without hesitation have set down as visual organs, but for the weight of authority which has pronounced them organs of hearing. Mr. Busk, however, in his memoir on a species of Thaumantias (Trans. Micr. Soc. 1850 , p. 22), has given what ap- 
pear strong reasons in favour of the former conclusion. Whether the intermediate cavities containing granules, be auditory organs, or rudimentary tentacles, I cannot determine. It is interesting to see in this case, as well as in that of the Feather Plumularia, before described, the presence of eyes in the free roving Medusoid, while they are absent in the fixed and stationary Polype. Where these organs are of service, they are provided; where they would be useless, they are not only denied, but obliterated. The very same phenomena are presented by the tubicolous, and therefore stationary, Rotifera, as Stephanoceros, Floscularia, \&c., which are sightless when adult, but have two brilliant ruby-like visual specks in the active and swimming young. How beautifully such discriminations show the minute, individualising care exercised by the Only Wise God in creation!

From the lateral aspect of the globe, carefully depicted at Fig. 3, I infer that the substance of which it is composed varies in thickness in different parts; being thickest at the top, and thinnest towards the marginal canal. From the centre of the roof, hangs down freely within the cavity an organ of granular flesh, somewhat trumpet-shaped and four-sided, its free extremity forming four thickened lips, capable of much alteration of form, and apparently very sensitive. From its base diverge four canals, passing apparently along the interior of the globe, and joining the marginal canal at the four points where the bulbs of the filaments originate. These four canals are permeated by a circulating colourless fluid; for at a point about midway in their course, where each en- 
larges into a little sac, I perceived two minute granules, which quivered and jerked about in a vacillating but rapid motion, just as if under the influence of a strong current, they not being free to be carried along by it.

The substance of the globe carries many scattered oval bodies, apparently imbedded 11 it. They are very minute, are set with their long diameter always pointing from the centre, but are not arranged regularly.

I need scarcely say that this embryo of the Sertularian Zoophyte, Campanularia, like that of Laomedea before described, is a veritable Mednsa; in no essential point to be distinguished from those Naked-eved forms so exquisitely figured and described by Professor Edward Forbes, in his beautiful Monograph. And the case is illustrative of one of the most startling and most interesting series of facts that modern science has discovered, those connected with the Alternation of Generations. Here is a fixed and celled Polype, giving birth to free-swimming Medusæ; hereafter we shall have occasion to describe a Medusa producing an embryo which presently assumes the form of a fixed and celled Polype. In both cases, the law appears to be established, that there is an alternate put. ting on of the two forms by successive generations; neither the one nor the other being a phase in metamorphosis, tike the caterpillar, and chrysalis of a butterfly, but each form producing the other in the way of generation; and thus, as has been cleverly said, any one individual is not like its mother or its daughter, but is exactly like its grandmother and its grandaughter. 


\section{ROCKHAM BAY.}

My first attempt to see Barricane was a failure. The weather had been unsettled for some time, and though it gave a treacherous promise of truce when I set out, the cessation of hostilities lasted only long enough to beguile me as far as the romantic valley of Lee, when the artillery of the clouds began to batter away at my head, with the energy of a garrison that has reserved its missiles, to pour them on the besiegers, when almost at the summit of the scaling ladders.

A hasty run for the nearest tree; -half an hour's tedious idleness under the drip of some poplars ; - frequent longing glances at the sky;-and an occasional sally out into the rain to take an observation of the weather to windward. Black and threatening enongh it looked, especially over the sea, where the sky was filled with ragged pillars driving perpendicularly along in misty grandeur; or, as the poet has said, with the torn fragments of a canopy:-

" The day is low'ring;-stilly black

Sleeps the grim wave, while heaven's rack, Dispers'd and wild, 'twixt earth and sky Hangs like a shatter'd canopy.'”

Moore.

I had taken the precantion to cover the saddle of my steed, when I alighted for shelter, with an impromptu eloth of weeds from the ditch, binding it on with a flexible root of ivy snatched from an old wall; so that when I mounted again after the shower, I had the satisfaction of a tolerably dry seat. 
At length patches of blue sky, as brightiy and purely blue as if it had never been sullied by a cloud, began to open, and grow, and coalesce, until the storm was fairly put to the rout, and fled from the aërial field.

I rentured to proceed. On the steep road up from the cove the traces of the shower were still strong. The rain ran in gutters and ruts, and hung in drops, like thousands of diamonds, from the brambles and cornels of the hedges. The lovely white bindweed presented its beautiful trumpet-blossoms to the sun, as smilingly as though not a drop had fallen on them. The fields, however, gave sadder proofs of the viulence of the storm; for large breadths of the brown wheat, more than ready for the sickle, were beaten down, and laid by the rain; and the precions grains, shed out, were lying on the sodden earth by handfuls.

Thus I came to a farm bearing the inauspicious name of Damage. Streams of muddy water corered with brown froth poured across the road; the sky looks black again; the clouds have rallied, and are mustering to renew the assault; they gain ground upon the azure, and now they have fairly orerpowered it. An archway of the farm-buildings offers a kindly shelter, and I dismount, despite the growlings of a suspicions mastiff, the Cerberns of the place. The view to sea-ward, over Bull Point and the neighbouring head-lands, is magnificiently grand, almost worth the disappointment and the wetting to behold. A dark dim veil of mist passes over the sea, gradually enveloping and concealing every thing, and spreads away to leeward. The rain descends, first in great 
drops, then in bucketfuls, then in drops again,- -and the shower is over.

Thence through a little shady dell, where the wet branches of the trees hang down so low that they deposit their drops upon the traveller, as he brushes past them ; - a romantic little dell, half-encircled by a rivulet, now swollen into a turbid torrent; and I come to a place where the stream pours over a wall in two tiny cascades, each of which is received into a high trough, for the benefit of thirsty cattle. It is now a hilly road, and a winding one, across fields, and through a multitude of gates, to Houseworth, another farm. Here a little object struck my eye quite characteristic of Devon. One of those enclosed wells, which we so often see by the road-side, was here erected in the very centre of the highway, or rather in the spot whence three ways diverge. It was built with more than ordinary care, a regular four-sided house, except that the front was open, and covered with a bungalow roof, as tidily as a cottage. It was pleasant to look in, and see the water beautifully clear and pure, shadowed over with ferns of various kinds, depending from the walls all round the interior, the nakedness of the stone above the brim of the water being concealed by a thick drapery of liverwort of the most refreshing greenness.

Still over cultivated hills, now commanding a fine view of the sea-ward horizon, and Lundy Island. I arrive at Morte; but before entering the village, I wished to explore Rockham Bay, situate about a mile to the right. Dismounting, therefore, I waded through the wet litter of a farm-yard, and along a narrow 
zigzag road, through fields, to the edge of the cliffs, and by a footpath down to their base. The wild and romantic bay opens before me; but the sky again threatens, and compels a search for refuge. I find a little cavern that looks as if it had been made on purpose, and get into it just as the first drops fall.

It is a narrow indenture of the rocky const, as wild and silent as a desert island in the midst of the Pacific; enclosed with lofty and inaccessible cliffs of hard blue slate, hollowed into many small and shallow caverns. The floor of the cove, if I may be allowed the expression, is of the same slate; there is indeed a coating of sand in some places, and of pebbles in others; but everywhere the slate crops out in blue ridges and hillocks, rubbed smooth (though still uneven) by the constant action of the waves. Farther out the rock forms long bristling ridges rumning into the sea, draped in their lower parts with yellow seaweed and tangle, and holding in their angular hollows many a perpetual pool of still water; while here and there, between the ridges, are lanes of the finest yellow sand. In some spots there are extensive beds of minute pebbles, most of them of quartz of dazzling whiteness, and in general not larger than children's sugar-plums, which they closely resemble in form and colour.

The most absolute solitude reigns here: no hamlet is nearer than Morte; no fisherman's hut stands upon the shore; no net is spread upon the sands to dry; no boat lies at anchor in the offing. One might wander beneath these blue cliffs for days,- 
Hearing no voice save of the Ocean-flood, Which roars for ever on the restless shores;

$\mathrm{Or}$, visiting their solitary caves, The lonely sound of winds, that moan around, Accordant to the melancholy waves.

КенАма, хv. 8.

The southern boundary of this Bay is formed by a promontory, which juts out far into the sea; the angle where the coast abruptly bends to the sonthward. From the point, a long line of sunken rocks projects, at the extremity of which is an insulated rock, called Morte Stone, or the Pock of Death. This name is supposed to owe its origin to ancient Norman mariners, and to have been given in allusion to the extraordinary fatality of this iron-bound shore. Partly owing to the form of the coast, partly to the fogs which so frequently prevail in winter, but chiefly to the set of the currents, this rock has always been infamous in the annals of shipwreck. Scarcely a winter passes, without one or more vessels striking upon it; and to touch it is almost equivalent to immediate destruction. The months of January and February of last year witnessed the loss of five vessels on this point. One of them was the occasion of a daring and successful exploit of which this little Bay was the scene.

It was on the seventeenth of the former month, that the ship "Thomas Crisp," of Bristol, struck on the Morte Stone in a thick fog, and immediately went to pieces. The crew, ten in number, had recourse to their boat, though ignorant of the character of the 
coast, and unable to discern it through the fog, although so near.

By God's good providence it happened that the "Cornwall" steam-packet was passing at the time, on her way to Hayle. Captain Vivian, her commander, heard what at first he took for the wailing cry of a sea-bird. The sound was, however, repeated; and, straining his eyes in the gathering dusk of evening, he saw a black speck. The experienced seaman obssrved that no spray broke over it, whence he conclided that the object was afloat, and that it was probably some ship's boat.

It was five o'clock, a January evening; the sky obscured with fog, and a heary gale blowing from the westward: a narrow bay was before him, which he knew to be bristling with sunken and exposed rocks, among which the sea was breaking and foaming, like a field covered with snow. But humanity called, and the gallant commander, supported by his willing crew, took no counsel with fear, but at once resolved on the perilous adventure of steering his steamer into Rockham Bay. With much labour and danger he succeeded in rescuing the nine ship-wrecked men, one of the number having been drowned in leaving the ship; but so dangerous was his position, the rocks not allowing him to turn his vessel, that he was obliged to back her out of the bay.

I return along the cliff-path to Morte, an ancient village, celebrated for having afforded refuge to Sir William de Tracy, one of those who executed their Monarch's vengeance on the haughty prelate Becket. The remains of the knight lie interred in the village 
church, which is said to have been founded by him; and on his tomb the curious stranger still beholds his effigy clothed in priestly vestments, and reads in old Norman characters,-

\section{" SYRE WILLIAME DE TRACE. \\ DIEU DE SA ALME EYT MERCY."}

Here terminated my day's excursion, or at least the exploring part of it; for a return through torrents of rain yet remained. Before I set out homeward, however, I could not but admire the awful grandeur attendant upon the approach of a heavy thunder-storm, as I witnessed it from the gate in front of the little village inn. From this spot the eye ranges over a coast-line of nearly thirty miles. Hartland Point extends, like a long wall, upon the horizon, over which the storm is darkly brooding. The wind is driving it rapidly along towards me; the wall-like promontory is soon shrouded beneath the lowering cloud. Now it comes pouring over Baggy Point in perpendicular, black, misty lines. Woollacombe Sands, a beach of three miles in length, are below; the tide is far out, and the surf is breaking upon the sands in a long curving band of white foam; while the expanse of sea outside is as black as ink, beneath the rain-cloud. During the whole approach of the storm I was amused by observing two red-backed hawks, hovering over the edge of the cliff almost close to me; they continued to occupy the same spot in the air, without shifting in the least, for many seconds; now and then the wings were flapped vigorously, but still without any change of position. By their colour, I had no doubt 
they were Kestrels ; and this curious habit of remaining suspended on the wing in the face of the wind, has acquired for them the provincial names of Standgale and Windhover. The pelting storm drove me into the house; but when it had abated, after some halfhour's duration, I again looked out, and there were the hawks hovering yet, just where I had left them.

\section{THE BRISTLE PLUMULARIA.}

Any. 14th.-I found a Spider-crab in a hole, whither he had retires for the purpose of sloughing. The carapace and limbs were thickly studded with Antenmularia antennina, and Plumularia cristata, many stems of each well set with ovigerous vesicles. One of the stems of the latter bore, parasitically springing from it, many stems of a more delicate congener, Plum. setacea, and some of these were also furnished with resicles, which I presently submitted to examination.

I selected a specimen with many vesicles, some empty, some broken off in the middle, others containing more or fewer gemmules, or "planules;" and one in the midst of the last-named, uniformly filled with the common granular matter of the medullary core, not yet condensed into ova. About five or six seemed to be the complete number of gemmules in one vesicle, of which those nearest the narrow neck were alive and active, while the most remote was a small motionless sphere.

My attention was presently attracted to a gemmule free in the water, which I knew to have just escaped, 
though without my seeing it: and I sat down to watch a vesicle. Presently one of the contained worm-like gemmules began to elongate its body, and to move slowly along the narrow neck of the bottlelike vesicle, toward the mouth, with a steady progression, which the power I was using (220 diam.) enabled me to see was ciliary. It soon began to emerge, the soft shapeless body taking a globose form as it protruded, and swelling upon the mouth of its prison, like a large globular head of a decanter. (See Plate XX, Fig. 6). As soon as it was well out, however, it took a definite form, that of a sub-conical oval, of which the larger end progressed foremost. Its length was about $\frac{1}{150}$ th of an inch, and its breadth about half as much; but as it moved, it became rather shorter. In appearance it exactly resembled an Infusory animalcule, being of an uniform granular texture, and covered with minute vibrating cilia in every part of its surface. (Fig. 7).

At first it revolved on its long axis, but presently this action gradually ceased, and it proceeded steadily in the same direction as it at first set out, until it had reached about twenty times its own length, when it came to a rest, about half an hour after its emergence; the vibration of the cilia still continuing.

In an hour and a quarter the ciliary action was but just discernible; it had not moved from its place of rest, though its whole mass slightly quivered and vibrated. The outline was now become ragged, and set with minute clear globules projected and isolated, as if the connecting gelatinous substance which bound them together was dissolving. I was now called away, 
and when I returned in two or three hours, the animalcule was a mere loose mass of granules, as were those which were as yet confined in the parent vesicle. I presume therefore that the quantity of water which I had allowed to the specimen (a large drop in the live-box of the microscope), was not sufficient to support life longer than an hour or so, and that this little embryo was thus prevented from contributing any further to my knowledge of its development.

THE LOBSTER'S-HORN CORALLINE.

Aug. 14th.-There was a sort of appropriateness in the circumstances under which I became acquainted with the Lobster's-horn Coralline: it was thickly studding the shell and limbs of a Crab, which was thus formidably bristling with hairy horns. I am not quite sure, however, whether the Zoophytes were growing there, though many of them were furnished with their slender waving root-fibres, and stood erect. As stones in sand, and the sand itself are mentioned as the localities affected by the species, it is probable that the Spider-Crab, having casually been roving over a forest of the stems, had got many of them entangled among the close-set stiff hairs that everywhere cover his shell, and had carried them away when he departed. I think this the rather because many of the specimens were fragments of stalks, evidently so entangled.

The Antenmlaria has an aspect very diverse from the Sertularia, Plumularia, and Campanularia with which it is allied, in its more robust form, its deep- 
yellow colour, and especially in the branchlets being set in close whorls, like the Horsetail among plants. These branchlets are slender, and look to the naked eye like bristles, closely girding the stem throughout its length. The polype-cells are confined to them, and are arranged along the upper or inner side, as they form an acute angle with the stem. The cells are small funnel-like cups, and among them are interspersed, on the same aspect of the branch, more numerous minute cellules, deep in proportion to their width, which exactly resemble those on $\mathrm{Pl}$. setacea. The use of these secondary cells has not been explained. Their constancy and number, I think, preclude the supposition that they are abortive cells, as Dr. Johnston suggests. Each is inhabited by what seems a living tenant, destitute of tentacles, connected organically with the common core. As more perfect observation is continually finding a bisexual distinction among animals in which it was before unsuspected, may it not possibly exist in these zoophytes, and may not these minute cells be those of the males? In the Rotifera, the male is always smaller, and always destitute of the digestive system; this might perhaps explain the absence of tentacles in the small polype. (See Plate XXI. fig. 1.)

I could not find one specimen that contained living polypes; but several were crowded with the egg-bearing resicles. These are rather large, glassy, somewhat oval, but more flattened on the inner side, and cut off with an oblique aperture, on the same aspect. (Fig. 2.) They are seated, with a small stalk, in the axils of the branchlets; and have a false bottom, evi- 
dently perforate, through which the common core communicates with the yelk until its development into a planule. None that I saw contuined more than a single ovum, which is large, regularly oval, and of a rich buff-yellow hue, conspicuous to the naked eye, especially when there are many crowded on the stalk. This ovum gradually developes itself, within the resicle, into a pear-shaped planule, covered with minute cilia in every part, the ribratile action of which can be detected by the microscope before its extrusion. As its escape draws near, it slowly moves about in its prison, lengthening and shortening its body, and slightly altering its outline in different parts.

I observed a planule (and afterwards another) in the act of escaping from the resicle ; the animal was sluggish and the process tedions, as compared with the emergence of the planule of Plum. setacea. This may perhaps be accounted for by the extreme minuteness of the cilia in the Antennularia, they being very much smaller than in Plumularia, though the planule itself is three or four times as large. The body was constricted by the margin of the vesicle as it slowly emerged; but it was not until the posterior extremity was quite freed that I perceived the presence of an unsuspected impediment. The vesicle is furnished with a lid, fastened like the cover of a box, at that side which looks towards the stalk of the polypidom, by a sort of hinge; it was forced open by the emerging planule, and fell down nearly close (see Fig. 6), as it finally quitted, by the elasticity of the hinge.

The freed planule is about $\frac{1}{30}$ th inch in length, but 
grows much larger in the course of the first day, attaining to about $\frac{1}{24}$ th inch. It is of a lengthened pear-shape, the larger end being the anterior. It moves evenly and rather rapidly, by means of its cilia, which cover the whole surface, but which are very minute. Its appearance and motion greatly resemble those of a Stentor, when gliding moderately along through the water. (Fig. 3.)

One which I selected for examination glided freely about on the surface of its glass prison for about a day and a half; at the end of that time it took up its position in one of the angles, and the next morning I found that it had not moved again. But it had undergone changes which I rightly supposed to be the first steps in the development of the polype. (See fig. 4). The large end of the pyriform rests in the angle; the small end is become bulbous and is separated from the body by a constriction, and there is another slighter constriction in the middle of the body. The orange-colour is retiring from the circumference, especially from what appears to be the budding bulb, the whole of which is pellucid white, a little more translucent down its middle.

Twelve hours afterwards, this budding extremity I found produced into an indubitable tube of considerable length (Fig. 5.), with glassy walls, one joint already formed near the extremity, and the termination rounded. The contents were white and granular, separated from the walls in the basal parts, but filling the whole interior near the tip. There was a clear opening through the substance of the granular medulla in one place, dividing off a portion of it into a 


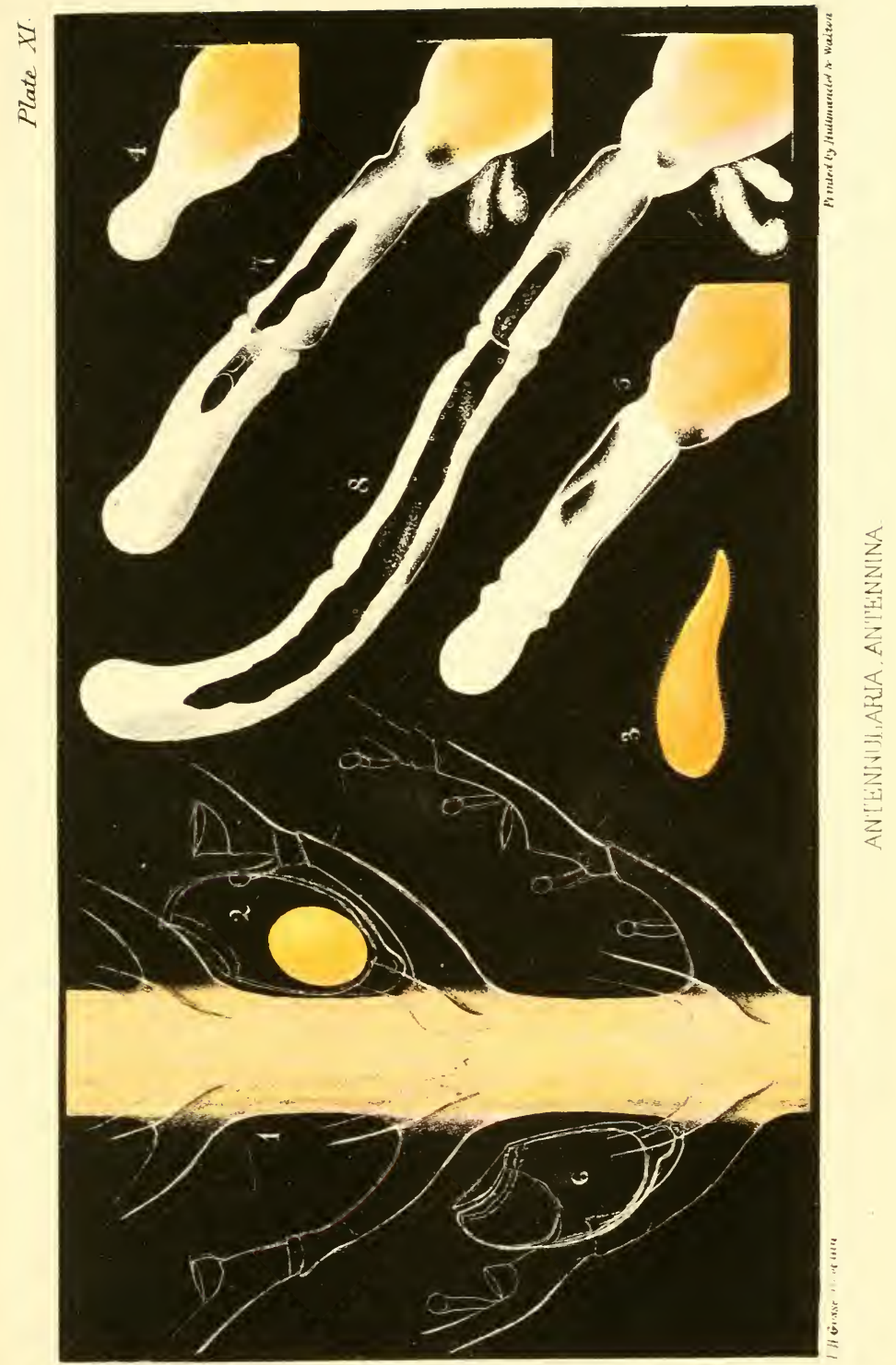



slender branch, which presently united again with the main core. The total length was now $\frac{1}{24}$ inch, of which the tube was $\frac{1}{42}$ inch, the diameter of the latter, just below the joint, being about $\frac{1}{185}$ inch. I could not discover, with the closest watching, any circulation or other motion among the granules of the medulla. No indication of sensitiveness was given, though an Euplotes with its bristly feet was running rapidly to and fro about the tube, and occasionally crossing the tip.

The next morning, Aug. 20th, I could perceive no increase over the condition of twelve hours before; but slight changes in the form of the medulla were taking place, that shewed life was active. Throughout this day I perceived the extremity slowly lengthening, not quite uniformly, but pushing out a portion in a little tumour, the depressions around which would be presently filled up, and the surface would become smooth and round again; then in a little while, another swelling would appear, which would again be obliterated, and thus the increase went on. The clear opening in the granular core also lengthened, and another formed above it, the two at length merging into one, thus dividing the medulla into two lateral columns; sometimes a very delicate film was partially sketched across the interspace, which was gradually reduced to a thread as of viscid substance, and then obliterated.

On the morning of the 21st, the budding portion exterior to the joint was equal in length to that portion below it. (See fig. 7). The young portion appears to be very soft and flexible, for on my incau- 
tiously pouring off the water to change it, the whole part outside the joint being deprived of the support of the dense fluid, fell down by its own weight to a right angle with the other part, and so remained bent, ever after the water was repoured in, until I carefully lifted it with the point of a pin to its original position which it was then able to retain. This morning I first perceived the creeping root, in the form of two slender cylindrical shoots springing from one side of the basal bulb.

About the middle of this day the separation of the medulla extended to within a short distance of the tip ; this part was quite filled with it in a very dense condition, and from it the medulla descended in two columns, separated from the walls of the tube, for some distance downward.

23rd.-The tube increases in length, but not in diameter, (See fig. 8). the division of the medulla into two slender lateral columns is complete, except in the budding tip. The two rootlets have grown a little, and one of them has sent forth an irregular lateral plate of colourless shelly substance.

Increase proceeded no further than this point; though it was manifestly alive for a day or two longer, during which the condensation of the granular pulp still went on;-but on the 26 th the multitude of active Infusoria swarming around the tube warned me (though none of them seemed to have as yet attacked it, and though no change in its appearance could yet be detected) that death had ensued. It is remarkable how immediately these minute creatures appear to have notice of the decay of any animal matter in 
water, both fresh and salt, and how rapid is their multiplication in such circumstances. Some of these were of the genus Euplotes, a large and a small species; but the swarming multitudes were of simpler structure, more like the family Monadina of Ehrenberg.

The next day I found the indication but too true; decomposition was going on in the granular pulp, which was becoming undefined in outline; and had retired from the shelly tip of the tube.

The minute details of such observations as these, especially when prematurely terminated, some of my readers may possibly think needless, and therefore worthless: but the phenomena connected with the reproduction of the Zoophytes, are among the most important of those which are now receiving the attention of naturalists. And it is only by carefully watching and accurately recording such phenomena, in every species, as they may occur, that we may hope to establish a sure basis for philosophic generalization. Isolated facts are better than none. 


\section{CHAPTER XIII.}

Capstone Spout-Holes-Purple Hue of low Rocks-Tadpole of a Mollusk-Its Habits-Visit to Barricane-A Beach of ShellsRock-pools-Their Contents-Antiopa-Its Spawn-Hatching of the Ernbryos-Immense Number in one Brood-The Torrs-Bloody Field-Flowers-View from the Cliff-Torr Point-Rocky Staircase-White Pebble Bay-Tide-poolsMaidenhair Fern-The Precipice-A curious MedusoidMedusa Fishing-Mode of Operation-Difficulties-Thaumantias pilosella--Its Luminosity-Description of its Structure-The Umbrella-The Sub-umbrella-The PeduncleThe Radiating Vessels-The Ovaries-The Tentacles-Pigment-cells-Eyes.

CAPSTONE SPOUT-HOLES.

At the most precipitous part of the promenade round the Capstone, the N. W. corner, the rock is broken into angular buttresses and projections of more than usual massiveness. You look down over the low parapet upon an area of flattish rock of considerable size, raised but a little above low-water mark. By taking a round, you may scramble down over the ledges to this part, and admire the wild grandeur of the scene. On two sides is the sea, and on the other two sides the precipice forming an angle. That on the south side rises perpendicularly like a 
wall; and its base is separated from the area where you stand, by a long but narrow fissure, through which the sea rushes and recedes with every wave. In the shadow of this great wall of rock there are several round deep basins, always full of water, fringed with the finer sorts of sea-weeds, and empurpled all round their interior with the encrusting corallines. If you go down at extreme ebb, in a low spring-tide, you will see the whole of the surface of rock, that is covered in ordinary tides, but now exposed, tinged with the same reddish purple hue, very pleasing to the eye; a colour derived in part from the number of red and purple sea-weeds that flourish at this level, but principally from the common coralline, not only in its free tufted state, but also, and chiefly, in its form of a shelly crust, that spreads like a lichen upon the surface of the rock.

At the extremity of the rocky wall, there are two small holes in a ledge, which communicate with the sea by funnel-shaped orifices. Through these the sea spouts in an interesting manner. The wave rushes in under the ledge with its hollow roar, and dashes up forcibly beneath it. At the same instant there issues from the first hole, which is only a narrow slit, a powerful jet of steam-like vapour, resembling the rush from the waste-pipe of an engine. This is the pioneer: the next instant a cloud of water and foam shoots upward and outward from the second hole with terrific force, and is thrown to a distance of twenty or thirty feet. The regularity of the succession, the suddenness of the outburst of 
white foam from the dark purple rock, and the rushing sound of the explosion, all add to the effect.

The ragged rock-pools that lie in the deep shadow of the precipice on this area are tenanted with many fine kinds of alye, zooplytes, crustacea and medusce. In one of these I took with a ring-net about the end of August, when fishing for meduse, what seems from its resemblance to published figures to be the tadpole of Amaroucium proliferum, one of the aggregated Tunicata. Its resemblance to the tadpole of a frog is curiously close, though its total length, including the tail, is not more than $\frac{1}{10}$ th of an inch. It consists of an oblong oval body of a pellucid yellow tinge, with a central nucleus of rich vermillion, deepest in the centre, which sends off some indistinct branching vessels towards the front part, and is continued posteriorly all through the tail, nearly to its extremity.

The activity of this tiny creature is remarkable; its motions are like those of a fish, executed by the vibration of the long flat tail from side to side. By this means it scuttles along through the water with great rapidity, in a tremulous manner. Its beantiful colour makes it conspicuous in a glass of clear water, notwithstanding its minuteness; it looks like a brilliant little ruby. Yet it is as evanescent as beautiful; a very brief confinement puts a period to its existence.

\section{BARRICANE.}

A few weeks after my former disappointment, I again set out for Barricane. It is one of the places in this neighbourhood invariably mentioned as nota- 
bilia, which every visitor to the town must see without fail. Its peculiarity is, that it has a beach entirely composed of shells, some of which are rare, or at least are not found anywhere else in this ricinity. The scenery around is also varied and beautiful, and would of itself present sufficient attractions to reward a visit. It lies about half a mile below Morte, at the foot of the cliffs of the promontory, and at one end of that long incurved shore, known as Woollacombe Sands.

From the grassy slope at the top of the cliffs a narrow footpath leads steeply down to an area of what seems to be small pebbles; but which, on examination, prove to be shells, of many kinds. Nost of these, having been washed up by the tides, are broken into fragments ; but a good number are found in tolerable integrity. Groups of women and girls from the neighbouring hamlets may always be seen, during the summer months, raking with their fingers among the fragments, for unbroken specimens; collections of which they offer for sale to risitors.

Among the shells of which the beach is composed, there were some which were interesting to me. Besides two or three little kinds of whelk, and the common marex and purpura, which are everywhere abundant, and the beantiful little cowry, which cannot be considered rare, there is the elegant wentle-trap (Scalaria communis), the elephant's tusk or hornshell (Dentalium entalis), the cylindrical dipper (Bulla cylindracea), called by the local collectors "maggot," and the beaded Nerite (Natica monilifera), a large and beautiful shell, to which the 
women have given the emphonious appellation of "guggy."

I wished to procure some of these species in a living state, and hoped that I might be able to find them about the rocks at extreme low water, as it was now spring-tide. Therefore, learing the shell-collectors, I strolled down the long narrow inlet, of which the shell-beach was the head, torards the tide-pools at the water's edge. It was a long way down the core, which resembles a narrow lane, bounded by high walls of sharp and rugged rock; and as I walked domn, I perceired that the accumulated shells were found only at high water mark; below this there was nothing but soft yellow sand to the edge of the sea.

The black and rough bounding rocks, however, inclosed in their hollows many pools, some of which were of large dimensions. Those near the water's edge were generally deep, narrow, wall-sided, and dark; all of which qualities made them excellent exploring ground for a naturalist. Their steepness and depth rendering them difficult of examination from without, I stripped and jumped in, the weather being warm, and worked away with my hammer and chisel, as long as I dared in water breast-high.

I could find not a single indiridual of any of the rarer species of shells alive; but other objects occurred, which were not devoid of scientific interest. Among other sea-reeds there were two growing in this deep pool, far under water, which I had not before met with. One was Cladostephus verticillatus, consisting of stalks much branched, no thicker than threads, but set round at short intervals with close 
whorls of minute, olive-coloured hairs. The other was a rare species, though sufficiently abundant here; Taonia atomaria, resembling a thin yellowish leaf, split into several divisions, and cut to somewhat of the shape of a fan. The whole leaf is crossed by many dark brown lines, which on being magnified are seen to be composed of dots, clustered together in this manner. These are the spores, or seeds of the plant.

Among the animals was a creature of exquisite beauty, which I now saw for the first time. It was the Crested Antiopa, one of the naked-gilled Mollusca, closely allied to the Eolides, some of which formed the subjects of observation in an earlier part of this volume. The breathing organs are rery numerous; they consist of oral bags, delicately pellucid, arranged all round the sides and front of the animal, and hare an extremely elegant appearance. Each one has a brown line running throngh its transparent substance, and is tipped with silver-white. The general colour of the animal is pellucid-grey, with spots and lines of opaque white, that have the lustre of silver. It is about an inch in length.

This beautiful little animal I brought carefully home, and placed in one of $m y$ large glass rases of sea water, kept in a fit state for the support of animal life by growing sea-weeds. It immediately became at home in its new residence, and remained in good health for a considerable period. In about a week it laid on the side of the glass, just beneath the surface of the water, a beautiful coil of spawn, which looked like a necklace of white beads arranged in successive 
furbelows or figures-of- 8 , in a spiral form, making just a coil and a half. A closer inspection showed that these folds were inclosed in a band of clear transparent jelly. A most beautiful object it was, even when cursorily looked at; but when examined with a lens, each of the beads, which at first I had supposed to be the ova, was really a nidus of many : a perfect sphere of clear jelly containing about sixty embryos, arranged in crescent form in the globule, filling more than half of its volume.

Five days after the deposition I saw that the embryos were in rapid motion within their spherules; I therefore detached two from the gelatinous band, and placed them in a cell beneath the microscope. The little nautilus-like embryos were now seen, each in his tiny shell of one spire, vibrating his eilia with energy, and all swimming rapidly among each other within their sphere, seeking an outlet. The soft walls yielded and protruded here and there, as one and another pressed forcibly against them, and at length burst, and the embryos came out in turn, as they discovered the breach.

Taking sixty to be the average number of embryos in each spherule, I endeavoured to estimate the total number in this coil of spawn. I found about 25 spherules in each figure-8, which gives 750 embryos; then there were about 30 such convolutions in the whole coil, which gives the total 45,000 embryos. Yet this coil was not all the spawn perfected by this animal in the season, for a large contorted roll is yet visible in the ovary through the pellucid body of the Autiopa; and these creatures are well known to 
lay their spawn at short intervals all through the season.

THE TORRS.

The back-windows of the house where I reside look out upon a sort of amphitheatre, the boundaries of which are lofty hills, with slopes green to the summit. Those to the right terminate in several pointed peaks, the principal of which are known as the seven Torrs. Though their inland side presents a gradual grassy slope, seaward they form precipices of tremendous abruptness, descending perpendicularly more than four hundred feet to the water's edge.

The ascent of these peaks, and the walk round their summits by a narrow path which has been cut for the purpose, is a most agreeable promenade; but as the Torrs are private property, a small toll is exacted for the admission of visitors. We approach it by the pleasant path which winds beside the Wilder, now called Church-path, but formerly bearing the repulsive appellation of Bloody-field, from a fatal duel which legendary tradition reports to have been once fought there.

A light ornamental iron gate admits us within the precincts. We cross the little stream, and pursue our way along its side, beneath the willows and alders that hang over it, and almost hide it. It is near the end of August, and the banks are fringed with a rank, coarse herbage, adorned with many autumnal flowers. The great willow-herb and the purple loose-strife are conspicuous from their fine crimson blossom; the hemp agrimony, the teasel, and the knapweed, are 
here in coarse profusion, with the ragwort, and other yellow composite. The thorn bushes are blushing with their ripening scarlet haws, among which the foliage of a white convolvulus has gracefully entwined itself, now starred with its noble snowy flowers. Robin-redbreast is pouring forth his simple song by broken stanzas in an elm over-head; and a rabbit pops out from a bush, and runs into a sort of quarry on our left hand; a corner half-inclosed by walls of perpendicular rock, some twenty feet high, ivy-clad, and crowned with furze.

A winding path, with a hedge at one side, leads steeply upward; and presently we stand at the edge of the cliff, with a beach of rocks and boulders below. A fog from the sea is driving up before the wind, and rises in flocky masses and shreds of mist, veiling the lofty precipices in dim undefined grandeur. The mist lifts a little, and we recognise, away to the right, the Ladies' Bathing Pool, with its wide area of quiet water. The path winds along the verge of the cliff, fringed with bramble, heath, and fern, among which the modest little milkwort charms by its elegant beauty, and the meadow-sweet by its delicious fragrance.

A narrow green promontory runs from this part into the sea, sloping rapidly to the extremity: it is about a hundred yards in length, and less than half as wide. At first you would suppose its close verdant turf to be grass, but when you examine it carefully you see that it is almost exclusively composed of the common thrift, which forms a bed, softer, more spongy, and more elastic than any grass turf. This projection is called Torr Point. 
Such green sloping promontories, with precipitious sides, seem characteristic of this part of the coast. There are several which I know of, succeeding each other at short intervals, just here: one of them bears the name of Greenaway's Foot. They are all exactly alike in structure and appearance; so much so, that it is almost impossible to distinguish them, except by their mutual position, or by their relation to the hills above.

I walked down to the end, thinking that as the slope had been so steep, I might find it easy to gain the beach from the extremity. But no ; the precipice was as abrupt and perpendicular here as anywhere, and the sea still far below: where a huge angular rock of picturesque form raised its brown head out of the clear greenish-blue depths.

From near the middle of the western side, however, a zigzag staircase of steps, rudely cut in the living rock, leads down the face of the lofty cliff, to a narrow cove of blue sand, quite inclosed by rocks; which, at least at the back and sides, are almost perpendicular, and two hundred and fifty feet in height. By clambering over the piled masses that project into the sea, I found myself in White Pebble Bay, an indentation of more ample dimensions, strewn with large rounded pebbles of white quartz, thick veins of which are seen pervading the ridges of blue slate that run along the beach. The slate, being softer than the quartz, is more rapidly worn away by the action of the waves and the weather; and the latter is left projecting, until a heavier sea than ordinary breaks off fragments, which by rolling soon acquire a rounded form. 
Capacious tide-pools occur among the rocks far down the beach, presenting at low-water excellent bathing pools, some of them large and deep enough to swim in, and sheltered from the wind by surrounding walls of solid rock. I enjoyed the amenities of a bathe in one of these, in whose pure waters Laminaria saccharina and digitata, and Halidrys siliquosa, were waving, and the delicate crimson tufts of Rhodymenia jubata were fringing the sides, while colonies of Anthea cereus were stretching abroad their green and snaky tentacles.

This little bay is one of the few recognised localities for the true maiden-hair fern; and it so happened that while I was looking about to discover a specimen on the cliffs, I met with a gentleman who was here with the same object. He, however, was better instructed where to procure it, and how; for he had brought servants with him, and had taken the trouble to provide himself with a ladder, which he had reared against the side of a glen or chine at the back of the bay. Here, some fifteen or twenty feet up, among the debris fallen from above, grows the maiden-hair in little tufts, to obtain which without injury it is necessary to detach fragments of the rock with a hammer.

Returning to the top of the green slope, I pursue another path along the margin of the cliffs, over the head of White Pebble Bay. The scenery, as I sit on the turf at the edge, is most magnificent. There is a dark gulley on the left, cleaving the rocks down to the cove, and then, above this, immediately in front of me, is a broad and rugged precipice of dark grey 
slate, nearly four hundred feet in height, in one unbroken mass. Grass and ivy grow on the narrow ledges and slopes, and the towering summit is crowned by a conical peak of verdant turf, the loftiest of the Torrs.

Up to this giddy height the path still winds by a zigzag course; every step bringing the traveller into a purer atmosphere, and giving him a wider and more exhilarating prospect; just as a child of God, the more his walk approaches heavenward, obtains fuller and sweeter communion with his Father, and enjoys clearer and more expanded views of his purposes, both of providence and grace.

\section{A NEW MEDUSOID.}

Aug. 26th. In a large glass jar containing seaweeds and many kinds of zoophytes, \&c., alive, I found swimming in the water among the medusoids of Campanularia volubilis, and Laomedea geniculata, a single medusoid, in general resembling the former, but a little smaller, and differing in the following particulars. (See Plate XXII.)

The tentacles were eight pairs, each pair set in contact with each other: at first they seemed only twin bulbs, but after a time they lengthened into short cylindrical wrinkled flexible arms, each terminated by a globular head, of nearly twice the diameter of the arm. The globose head contained an irregular number of clear oval grains, each of which had an oval mark within it; the form and structure closely resembling those of the tentacles of Coryne. 
Between each pair of tentacles and the next pair was set a single visual or auditory capsule, comparatively large, sessile on the outer border of the circular canal: its substance was transparent and colourless, and the higly refractile spherule within was connected with an oval cell or vesicle, forming apparently the end of it.

The sub-umbrella was campanulate, dense in structure, with longitudinal fibres or rugæ. The umbrella contained many oval clear granules scattered in its substance, proportionally larger than those of the medusoid of Camp. volubilis.

After some time I perceived that it was reversed; the pedicelled stomach being on the outside, and the visual capsules being within the margin. Figs. I and 2 represent the Medusoid: 3, a pair of tentacles: 4 , an organ of vision.

\section{MEDUSA FISHING.}

A sail for a mile or two along the coast opened up to me a new field of interesting research, and made me acquainted with a tribe of beantiful creatures that I had hitherto known only by report. I had provided myself with a ring-net of fine muslin, a foot wide and two feet deep, affixed to a staff six feet in length, for capturing my prey; and a basket containing two or three glass jars of different sizes, for preserving the specimens and bringing them home. At first I sat in the stern-sheets and held the net at the surface perpendicularly, with the staff against a thole-pin, as if it had been an oar; drawing it in for examination after 


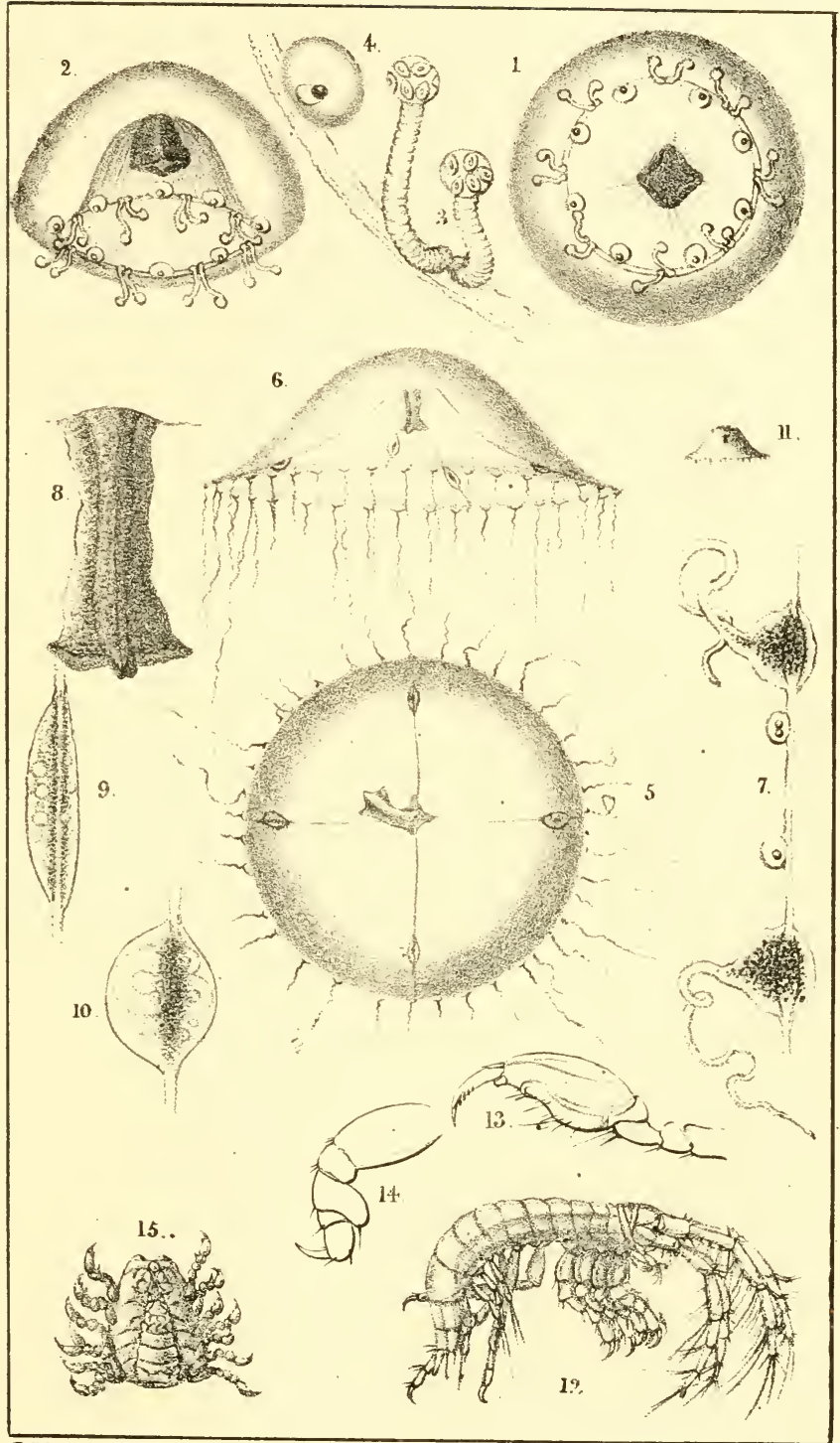

P B.6osse, del ef bth

Printed by Hullmandele Walton

1-4, MEDUSOID OF CORYNE? 5-11, THAUMANTIAS BUSKIANA. 12-14, CERA PUS NHITEI 15, YUUNG OF HYPERIA. 

every two or three minutes. But I found that though I took many specimens thus, they were of little value; for the way of the boat, though there was only a light breeze, pressed them so strongly against the muslin of the net, that they were generally dead and shapeless when transferred to the jars.

Finding that little effective was to be done thus, I determined to try the rocks. We steered for Samson's Cave, a huge cavern, the entrance to which is guarded by two large masses of projecting rock. The tide was high, however, and the sea was breaking into the cave's mouth, and dashing against the perpendicular cliffs, forbidding a landing here. But within the inner point there was a little sheltered beach, where the rocks shoaled so as to allow landing to an agile foot, and to afford standing place for the use of the net. Here then I took my station, and soon perceived several of the little beauties floating in the clear and comparatively calm sea within reach; and these I dipped out readily.

I adopted the plan recommended by Prof. Forbes for transferring the captives to the jar, viz., turning the bag of the net inside out into the water within the jar, and letting the animals float off. But it seemed to me that this mode injured many; perhaps because the mouths of the jars were somewhat too narrow to admit the net without its falling into folds. If a Medusa of considerable size happened to be between the folds, it would probably become spoiled by the pressure, before it could be freed under the water. Some of the smaller ones, moreover, say about the size of a pea or a small button, would occasionally 
adhere to the muslin so firmly as not to float off when immersed. I found it best, therefore, to look into the net as soon as I had dipped, and notice all the knobs of jelly that were visible, taking them one by one, then putting my finger beneath each on the opposite side of the muslin, push it under water, giving it a slight jerk if it did not detach itself at once. Then, when all that were perceptible were thus freed, I reversed the net in the jar for the minute and inconspicuous ones. Thus I obtained in a little while a great multitude of specimens, many more than I could identify when I arrived at home. I made out, however, about ten species, and I am sure there were many more; but by the time I had taken sketches of such as were not mentioned by Prof. Forbes, and had identified some of those that were, the rest were lying a dead confused heap at the bottom of the jars.

By far the most common species hereabouts is Thaumantias pilosella. It occurred by scores about the rocky points; it was sure to be in the net when I looked at it in the boat, and it occurs in tide-pools and recesses below the Capstone, and in the bathingponds at the Tunnel. It is about three-fourths of an inch in diameter, like a watch-glass in form, but rather deeper, crossed at right angles by four narrow lines of a faint purple tint, and margined by a great number of short slender threads, each of which has at its base a bulb, with a dark purple speck in it. This circle of dark dots is visible even to the naked eye, and they are conspicuous when a pocket lens is brought to bear on them. But there is a way in which they may be made most beautifully and brilliantly con- 
spicuous. I went into my study after dark without a candle, to try whether any of the captives in the different rases were luminous. I took a slender stick and felt about in the water at random; presently I tonched something soft, and instantly a circle of bright little lamps was lighted up, like a coronet of sparkling diamonds, or like a circular figure of gas jets, lighted at a public illumination, and seen from a distance; more especially as some of the constitnent sparks appeared to go out, and revive again, just as do the gas-flames if the night be windy. The phosphorescence, though but momentary, was renewed as often as I touched the animal, which was not very often, as I feared to injure it.

As this was the commonest species of Medusa here, as its structure is simple and may be taken as normal in the tribe, and as it belongs to a genus that includes by far the largest number of British species, I will describe it in detail as a sample of the rest.

It consists of an umbrella-shaped bell of clear colourless jelly, like a watch-glass, if you imagine it a great deal thicker in the centre than at the margins; but sometimes becoming hemispherical in outline. The inner surface of the bell is lined with a skin equally gelatinous transparent and colourless with the former, but often minutely wrinkled, and generally easy to be distinguished by its appearance: this is called the sub-umbrella. From its centre depends a very moveable, flexible peduncle, composed of more substantial flesh than the bell, and evidently cellular and fibrous. In this genus it is small, but in some it protrudes beyond the margin of the bell; it gene- 
rally terminates, as in the present case, in four expanded fleshy lips, extremely flexible and versatile, and capable of seizing prey, which is transferred to a stomach situated in the interior of the peduncle.

From the base of this hanging stomach, four slender vessels diverge at so many right angles, and passing across the surface of the sub-umbrella, proceed to its margin, where they communicate with another vessel, that runs completely round the edge. The circulation of a nutrient fluid can be very distinctly traced in all these canals.

The four radiating vessels are bordered in the outward half of their course by the ovaries, which in this species are narrow and linear, but are more or less conspicuous according to their degree of development. In a specimen now before me, these ovaries are full of clear globose ora with central nuclei; they are of various sizes, some being so large as to bulge out the side of the ovary.

The sides of the marginal canal are thick and granular, and give rise to a number of bulbous processes, composed apparently of the same substance, and running off into slender thread-like tentacles very flexible, extensile, and contractile. The bulbous bases frequently contain highly-coloured masses of matter, which are considered by Prof. Forbes and others as rudimentary eyes. In the species before us, these spots are crescent-shaped, and of a deep purple hue, forming a conspicuous circle of specks around the margin, even to the naked eye. In general the tentacles, whether many or few, are all of the same kind; but in this species there are several (from four to 
seven) minuter tentacles without bulbs, between every two of the larger sort. 'The latter vary much in number and size, and are not at all symmetrical, either in position or arrangement, some being twice as close together as others. In the specimen before me, the quadrants of the margin formed by the radiating canals present respectively the following numbers of primary tentacles: $-16,10,9,14 ;=49$. Some, too, of these are small and apparently dereloping.

Besides these organs, the margin is furnished with others, which, by those who consider the pigment masses to be eyes, are believed to be organs of hearing, but which seem to me rather to be the true media of vision. They consist of cells, usually more or less globose, containing one or more spherical bodies of high refracting power. Prof. Forbes has not noticed them in his description of this species; they are, however, large and peculiar;-first in shape, being semielliptical swellings of the substance of the marginal canal, and secondly in the number of their spherules, which raries from about 35 to 50 in each capsule. The spherules are arranged in a double crescentic row, those which form the middle being generally larger than those at the extremities. The capsules are eight in number, two in each quadrant, nearly equally distributed; but not holding any fixed relation of position to the tentacles. 


\section{CHAPTER XIV}

Rapparee Cove-Strange Gravel-Its singular Origin--The Glassy Equorea-Its Form and Structure-The Forbesian Equorea-The Bathing-Pool-Meduse therein-Description of a new Species-Its Habits-Luminousness-Distinctive Characters-The Ruby Medusa-Its first Occurrence-Wigmouth-Production of the Gemmules-Their AppearanceMotion of the Turris-Metamorphosis of the GemmulesTheir Polype-form-Goodness of God in the Beautiful- $\mathbf{A}$ Christian's Interest in Nature-The Redeemed InheritanceThe Crystalline Johnstonella-Its Beauty-Its Doubtful Affinities-The Starry Willsia-Parasitic Leech-Tmread Capsules-Nature of these Organs.

As the visitor pursues the pleasant walk leading through what are called the Quay Fields, he cannot help seeing, here and there, a rather obtrusive direction-board with a finger pointing towards a certain point of the shore, accompanied by the announcement that such is the way to Rapparee Cove, whose claims to notice as a bathing place, on account of its privacy and comfort, are somewhat boastfully set forth.

I visited it, and found it indeed, like so much of the scenery hereabout, sufficiently wild, romantic, and picturesque. It is situated immediately opposite the entrance to the harbour, under the shadow of the 
gigantic Hillsborough. The Cove itself is a spacions area, almost locked in, being protected seaward by rocks, and environed on three sides by cliffs, more than usually lofty, and much too steep to be climbed. In fact there is no access to it, when the tide is in, but by a narrow foot-path, that has been cut in one part of the rock, the entrance to which is guarded by a gate. Precipitious as are these cliffs, however, they are green with ivy, that trails and hangs in graceful freedom over their surface, and with fern which grows upon them in great luxuriance. Tufts of samphire spring from the rugged ledges; and at the foot of the cliff's, which jut out in projecting buttresses, like the great spurs of the cotton-trees in tropical climates, the white goose-foot was growing, with its large angular leaves curiously covered with a sort of web, easily removeable with the fingers, and having on their under surfaces an appearance and texture that closely resembled fine flannel. There, too, was the corn sow-thistle, a fine plant with large yellow flowers. eminently characteristic of the season, for it was the month of September.

The floor of the cove is principally composed of sand, which changes, as it approaches low-water mark, to small shingle. Among the latter, the observant stranger notices a quantity of yellow gravel, scattered all along the water-line between tide-marks. This at once strikes him as a remarkable feature, seeing that nothing of the kind is found on other parts of this coast, nor does any analogous formation exist in the vicinity.

On inquiry, he learns that these yellow pebbles are 
strangers, and not natives of the place; that they are, in fact, the enduring records of a tragical event that occurred some fifty years ago.

It was in the war with France, which ushered in the commencement of the present century, that two transports returning from the West Indies, with black prisoners from some of the French Islands, were driven on shore in this cove, while attempting to enter the harbour of Ilfracombe in stress of weather. Most of the people escaped with their lives, but almost everything else on board was lost; and for years after the sad event, the people of the town used to find gold coins, and jewels, among the shingle at low-tide. The vessels were ballasted with this yellow gravel, which though washed to and fro by the rolling surf, remains to bear witness of this shipwreck, and to identify the spot where it took place; a curious testimony, which probably will endure long after the event itself is lost in oblivion, and perhaps until the earth and all the works therein shall be burned up.

\section{TIIE GLASSY AQUOREA.}

Among the treasures which rewarded my first attempt at Medusa fishing was a beautiful translucent species of a genus, which when Professor Forbes published his Monograph had not been recognised as British, but a species of which has been lately described by that accomplished naturalist. Though the genus contains many species, I cannot find any description that agrees with the present, which I designate as the Glassy Equorea (Equorea vitrina). It may be thus described. 
Umbrella hemispheric, or sub-conic, about $1 \frac{1}{4}$ inch wide and $\frac{3}{4}$ inch high. (Plate XXIII. fig. 1). Subumbrella very low, depressed and funnel-shaped in in the centre, which is quite perforate, the sides of the funnel descending into a peduncie, which expands into many (about 20) narrow, pointed, divaricating, reflexed, furbelowed points, reaching to about the level of the margin. The peripheral half of the sub. umbrella is traversed by about ninety radiating lines, (See fig. 2) which are colourless but resemble bands of frosted or ground glass upon a body of clear glass. They are swollen irregularly or attenuated in parts, and where swollen appear to be penetrated by a central ressel. The central portion of the sub-umbrella, a perfect circle, into which these lines run, is of the frosted appearance, with radiating fine lines of orystalline, proceeding from the centre of each of the marginal lines. In the fumnel of the sub-umbrella, lines of opaque white commence, alternating with the crystalline lines, and gradually emerge into the furbelows of the peduncle (fig. 5).

The vessels of the sub-umbrella appear to be in many cases lost just before reaching the marginal canal; some however can be traced into it. The marginal canal is very slender, and gives origin to a great number of excessively attenuated white tentacles, two or three to each vessel, or more than 200 in all. Their bulbous origins are minute; they are generally much wrinkled and contorted, and adhere to any object they touch. (See figs. 3 and 4).

I had turned the animal back-downwards for examination, and presently saw the funnel-like peduncle 
dilate into a wide circular orifice, of which it formed merely a delicately-membranous margin, the white lines radiating through it (as seen at fig. 7) and prolonged into long narrow furbelowed filaments, remote from each other, and connected by a sort of a web, waved at its edge. Where the stomach can be I cannot conceive, since the peduncle is nothing but this membranous circle. I passed a slender stick through the orifice without meeting any resistance until it touched the clear, perfectly transparent substance of the umbrella, at the level of the highest part of the sub-umbrella.

Not a trace of colour appears in the whole animal, which yet is exquisitely beautiful. It was swimming near the surface, a mile or two off shore, near Watermouth, when I dipped it, on the afternoon of August 26th. In captivity it was moderately active, swimming gracefully, but keeping the tentacles generally contracted and inconspicuous. It was luminous when irritated in the dark.

A day or two afterwards I obtained another specimen much smaller, not more than $\frac{1}{2}$ inch in diameter, to which I was enabled to apply a higher power. The tentacles in this specimen (perhaps from its condition of adolescence) alternated with bulbs not developed into tentacles; and each had at its base a verry minute but perfect colourless ocellus, with from two to five highly refractile spherules unsymmetrically included within the globule. Two or three was the most common number; and they were not always of the same size, one being frequently present not half the size of the others. Fig. 6 shows a portion of the 


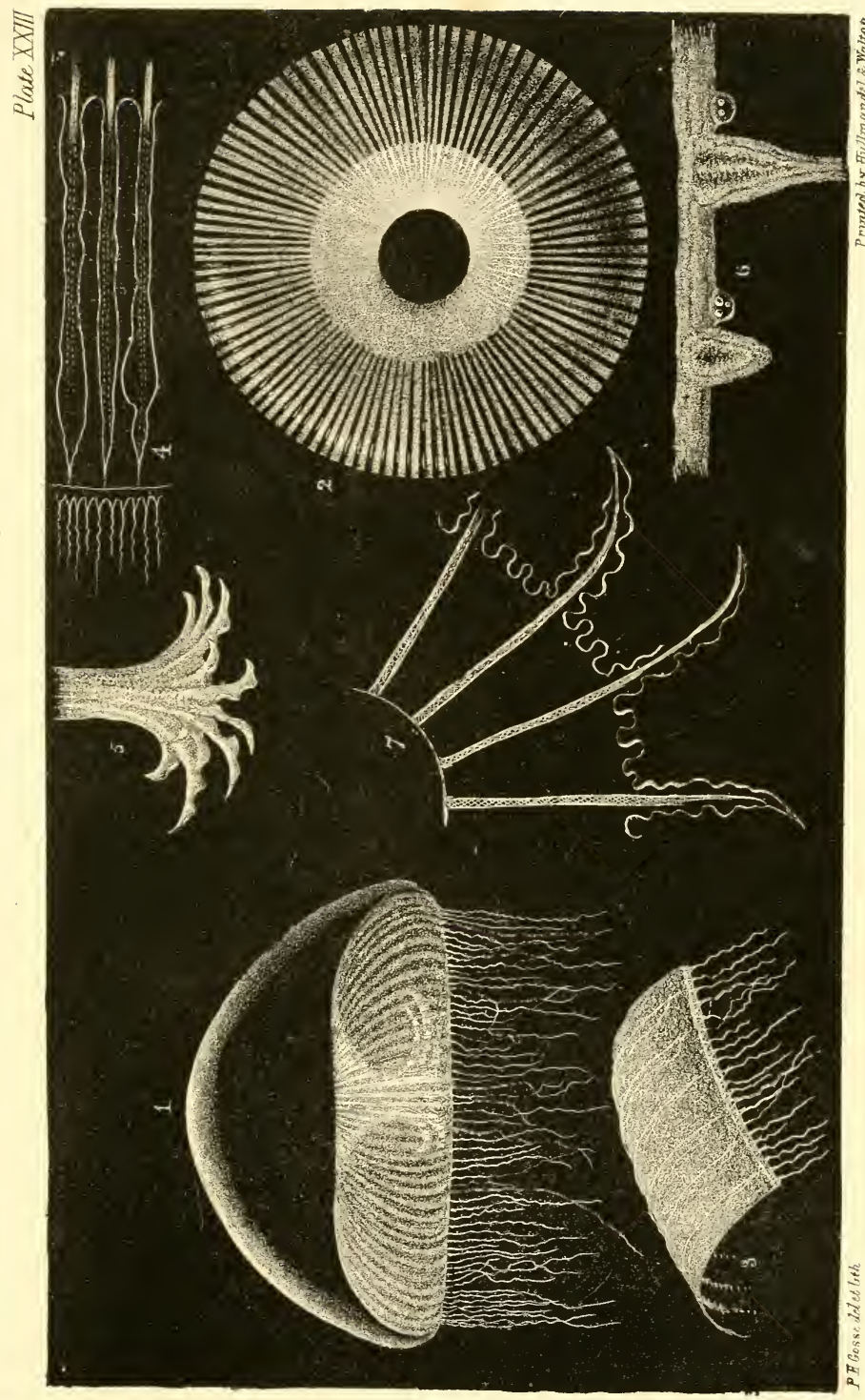



marginal canal, much magnified, with two tentaclebulbs and two ocelli.

The white lines that run down into the filaments produced from the edge of the peduncle are composed of oblong polyhedral cells set transversely. The web which borders them and fills the interspaces is composed of minute close set granules.

The radiating bands of the sub-umbrella, that I have compared to ground glass, are vessels, and do run into the marginal canal; the irregular dilatations are not ovaries, but simple enlargements of the vessels: a fluid circulates in them, carrying granules along rather rapidly: the current appears to pass up from the margin towards the centre of the sub-umbrella, near the walls of the canals, while a reverse current occupies the middle part, the granules frequently passing from one into the other current. At the point where the canals enter the circular frosted disk, they have thickened fleshy lips, capable of closing so as to make tubes, or of separating to form grooves. A longitudinal texture of fibres is plainly visible in these grooves.

\section{THE FORBESIAN EQUOREA.}

Sept. 7th.-There had been a heavy breeze all night and this morning from the N.E. which had set a good deal of sea in upon the shore. I took down my Medusa-net and jars to the shore at the Tunnel rocks, more for the sake of a walk than with the expectation of obtaining any thing, for the wind and sea were still high. But my first glance at the water revealed many Medusæ.

There is on the shore here a large pool, partly 
formed by nature; but it has been built up in some places so as to make it a perfect reservoir. Being overflowed by the sea at high-water, its purity is renewed twice every day, and as it retains its contents when the tide recedes, it remaius always full, a pond of nearly an acre in extent, and of considerable depth. Though far above low-water mark its depth and constant fulness make it a favourable locality for many sea-weeds, which under ordinary circumstances would thrive only at a level very much lower. The shelving sides, especially in the deeper parts, and where the artificial wall has been supplied, are densely fringed with Laminaria, and many fine species of the Floridea in great luxuriance.

It was at the leeward side of this pond that I hap. pened first to look, and there in the nooks and corners, driven up by the wind, were several very flat Medusæ of large size lying motionless upon the floating weeds, and many more of a smaller species crowded together upon the surface of the water. The latter were, as I guessed at the first glance, Thaumantias pilosella, all dead, mostly covered with minute air-bubbles, and in many cases totally deprived of the sub-umbrella, with all the organs, leaving nothing but the gelatinous umbrella.

I walked around the pond, and found the same accumulation in most of the corners on the lee side. Thence down to the edge of the rocks, where the sea was dashing in with fury; there too in the inlets and crevices of the rocks, were the same two sorts driven in, the former by dozens, the Thaumantias by hundreds. 
On examination the larger flattened ones resolved themselves into tro species. One was the colourless frosted Equorea that I had obtained before, several specimens of which appeared in no wise to differ from the former. But the majority of individuals now east ashore were of a much larger and finer species of the same genus. (See Plate XXIV).

It differs from the former species in the following particulars. It is much larger, being from two to three inches in diameter, but lower in proportion, being about $1 \frac{1}{4}$ inch in height, and resembling a cake or bun in shape. The umbrella is smooth, clear, and apparently colourless; but when viewed sidewise, against a dark back-ground, the rays of light that pass through the whole diameter of the umbrella are tinged of the most brilliant azure blue, which colour prevails for about a quarter of an inch above the summit of the sub-umbrella, and is then gradually lost, doubtless by the rapid diminution of the thickness of substance through which the rays are transmitted.

The sub-umbrella is very low and depressed, about $\frac{1}{2}$ inch in height: its substance is colourless, but the radiating vessels that traverse it, and which were frosted in the former species, are here of a delicate rosy hue, which is the colour also of the dependent margin of the central circle that occupies the place of a peduncle. They are fewer (about 65 or 70 in all) and more slender, than in $\mathbb{E}$. vitrina.

The sides of this circle are cut into four triangular lobes of membrane (more or less developed), which are fringed with delicate attenuated pink filaments, depending and floating freely in the water. The 
microscope shows them to be furbelowed slips of membrane, as in the former species, but here they are much finer, and instead of being equal and continuous, are graduated and interrupted. Each triangular lobe has them longest at its middle point, whence they decrease in length on either hand; and there is a space between every lobe and the next, which is quite destitute of fringe.

The marginal vessel is very slender, and carries about thirty-six very fine thread-like tentacles, usually contracted in close spirals to $\frac{1}{4}$ inch in length, but sometimes depending to the extent of several inches, in which case they seem as fine as a spider's thread. They are not symmetrically disposed, nor do they bear any regular relation of position to the radi. ating vessels. Their colour is pale pink or flesh colour. Their texture is minutely granular, and their bulbs present a similar appearance to those of the former species. As in that also, so here, there are numerous auditory or visual capsules, with from one to four spherules in each.

This very fine Medusa commonly floats at the surface in captivity; and seems to have little locomotive power, contrasting strongly with the minute Turres and Oceanice that shoot along with vigorous leaps in various depths. It maintains a pretty uniform, not very rapid, contraction of its sub-umbrella, but with occasional intervals of quietude. I observe that at the beginning of contraction after repose, the action of one side is frequently not simultaneous with that of the opposite, but presently they become so.

At night I tried its luminous power. When I 


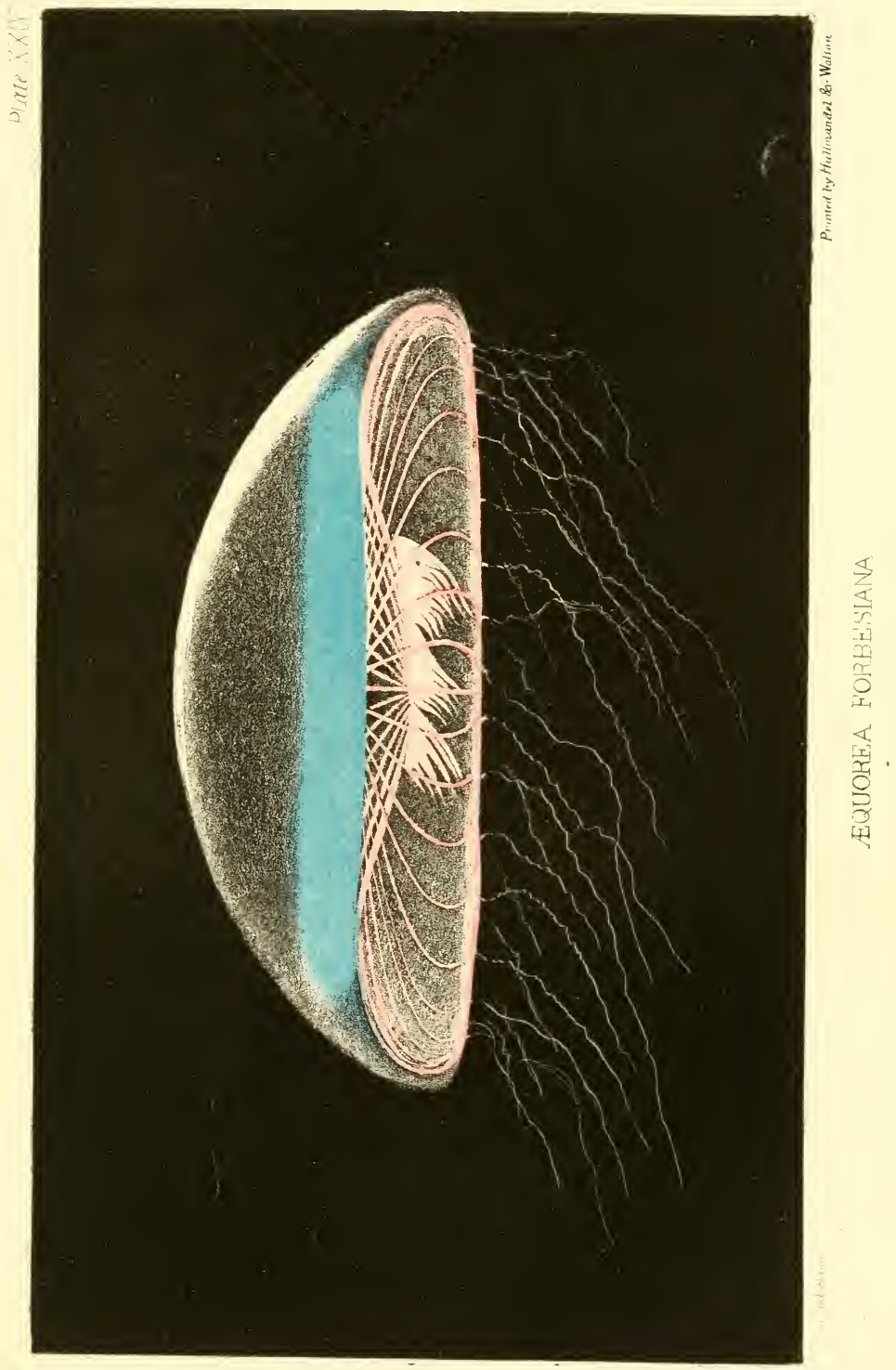



tapped the glass jar in which two specimens were floating at the surface, with my finger-nails, instantly each became brilliantly visible as a narrow ring of light, the whole marginal canal becoming luminous. On my touching them with the end of a stick, the light became more vivid, and round spots appeared here and there in the ring, of intense lustre and of a greenish-blue tint. These were, I doubt not, the tentacle-bulbs, ana any one of them would be excited to this intensity by my touching that part of the margin with the stick. The luminosity of the ring was not so evanescent as in some species, lasting several seconds, and continuing to be renewed as often as I molested the animal. 'The two circles of light, two inches or more in diameter, were very beautiful as they moved freely in the water, sinking or rising according as they were touched, now seen in full rotundity, now shrinking to an oval, or to a line, as either turned sidewise to the eve; and reminded me of the rings of glory in the pictures of the Italian school, round the heads of saints.

A very fine Equorea has lately been found by Professor Forbes inhabiting the Scottish seas, and has been described by him under the name of Equorea Forskalii, in a Memoir read before the Zoological Society of London. The present differs in many important particulars from that species, which I think it surpasses in beauty, and nearly equals in size. The proportionate thickness of the umbrella and sub-umbrella; the radiating canals, in the one abruptly, in the other very gradually merging into the stomach; the simply furbelowed lips of the sto- 
mach in one, and the angular ciliated processes in the other; the number of the radiating canals and of the tentacles: the colour of the former, violet in one, roseate in the other; the pendent membranes that are attached to them in the one case, and not in the other; the colour of the stomach, foxy-brown in the one, rose-pink in the other; and the difference in the size of the tentacles and their bulbs in the two cases; -are diversities so prominent and obvious, that I hesitate not for a moment in pronouncing the two species distinct. I cannot any better succeed in identifying my beautiful Medusa with any of the same genus that I can find described by foreign anthors. I therefore propose to distinguish the present species as Equorea Forbesianc, in unfeigned honour and respect for a naturalist of the highest eminence, whose pen and pencil have alike served to elucidate, above all his compeers, these very lovely forms.

THE RUBY MEDUSA.

Throughout the autumn the sea around Ilfracombe was thickly peopled by that charming little Medusa, Turris neglecta. It was found in the quiet rock-pools between the tides, in the harbour, and in the open sea, so that the net could scarcely be dipped without bringing up one or more, looking like "beads of coral" on the muslin. And when put into a glass vessel of sea-water, few sights could be more pleasing than a dozen of these tiny gems stretching their delicate tentacles, and shooting along by vigorous strokes in various directions through the clear element. Nor 
was it difficult to protract the pleasure; for the little creatures. are kept alive with great ease for many days. (See Plate XIII. fig. 6, nat. size; fig. 7. magnified).

My first acquaintance with the species was made on August 28th. A tiny specimen, not more than $\frac{1}{10}$ th of an inch in height, was caught among other Medusæ off the little cove of Wigmouth. This is a beautiful little nook for bathing, being quite unfrequented, about two miles from the town, and having a smooth sandy beach evenly sloping down, without rocks, except at each side, where rocky walls inclose it about fifty yards apart. These rocky sides projecting into the sea allow of our walking out on their points and ledges close to the water's edge. Here I stood, and with a muslin net at the end of a pole dipped for the smaller Medusæ that were enjoying the afternoon sun at the smooth clear surface. Nany of these the rays of the sun made risible against the dark depths, and such I could select; but the more minute kinds were not perceptible, and these I could only dip for at a venture, unconscious of their presence, until the erersion of the net in the collecting jar discovered them as prisoners.

This pigmy Turris was inert when I examined it ; the gelatinous umbrella turbid and almost opaque, and the peduncle large and dull crimson. But in the course of the next day considerable alteration had taken place in its appearance. (Plate XIII. fig. 8). The margin was contracted and turned back, exposing a great part of the peduncle, which had become both thicker and longer; its redness was also more intense 
and inclined to orange, and many oval gemmules of dark lake-crimson, or purple, were seen in its substance. On the floor of the cell in which it was confined were more than a dozen of the gemmules already escaped; I at first supposed them eggs, but on closer examination, found that they were active little swimming creatures with a will of their own; that they were in fact gemmules, perfectly oval in form, about $\frac{1}{100}$ inch in length, and of a fine lake hue: their whole surface covered with vibratile cilia, by means of which they glided about with an even quick motion. (See fig. 9).

Two days afterwards these gemmules were still active, and possessed the power of locomotion. They were not perceptibly changed in appearance, except that they seemed a little larger.

On the 4 th Sept. I noticed one lying at the bottom of the phial in which I had put them. I extracted it by means of a glass tube, and found that its colour had become paler, being now of a rose-pink, that its surface was irregularly granulose as if decomposing, and that motion had ceased.

On the same day I took two specimens about $\frac{1}{6}$ in. high, brilliantly conspicuous from the orange coloured or pale vermillion ovaries studded with large ova of a rich purple hue. The umbrella is remarkably turbid, being scarcely more than pellucid, and appearing quite white against a dark background. When resting in a phial of water, the tentacles are elongated, like white threads of an equal thickness throughout, and are extended in every direction, some perpendicularly upwards, some downwards, and some arching 
outwards. Thus it lies quite motionless, but on the slightest jar being given to the vessel, or to the table on which it stands, all the tentacles at the same instant are contracted into minute contorted balls, so suddenly that it seems the work of magic. If undisturbed, however, they are quickly unrolled again, almost as quickly as they were contracted. If the tentacles when thus extended are carefully examined, they are seen to be slightly club-shaped at their extremities.

The tentacles in this species, when subjected to pressure, are resolved into a multitude of minute oval granules set close together, without any variation of density in different parts. Their length is not more than $\frac{1}{3600}$ inch. I suppose these, from analogy, to be filiferous capsules, though their minuteness prevents me from seeing (with a power of 300) more than an evanescent indication of the filiferous cavity; and the plates of the compressorium were not able to produce a projection of the filament.

The lips of the peduncle are furnished with eapsules exactly similar, crowded together in groups, and (as it appears to me) forming little tubercles, from which their points diverge in every direction.

The motion of the Medusæ through the water seems to be performed on the same principle as that of the larva of the Dragonfly; viz. by a jet of water forcibly expelled, and impinging on the surrounding fluid. In Turris, whose motions, owing to its muscular development, are very energetic, the jet is very distinct and strong. This appears to be the modus operandi: four muscular bands, as Prof. Forbes has shown, pass across the surface of the sub-umbrella, from the root 
of the peduncle to the margin. This course is not a straight but a curved one. When therefore these bands are simultaneously and forcibly contracted in length, they are drawn from a curved into a straight line, and the eavity which was bell-shaped becomes more conical, and its capacity is considerably diminished; a portion of the water which it before held is therefore driven out at the mouth, and by its reaction forces the animal forward with a jerk in the opposite direction. I think, however, that the action of the radiating bands of muscle is aided by circular bands lining the sub-umbrella, as well. as by the marginal one; for when a Turris in strong contractions is attentively watched in an upright position, there are seen indrawings of the sides from the perpendicular at every contraction, that the shortening of the radiating bands is not sufficient to account for.

Fig. 8 represents a Turris in the state of ovipositing; the peduncle enormously swollen and become globose, with its lower part showing the four orange ovaries, distended with purple gemmules. It lies on its side on the bottom, the four lips protruded at one extremity, and around the other the diminished and reverted umbrella gathered in small vesicular puckers. In this condition one would not recognise it as a Medusa, if not familiar with it.* The oval purple

* Of the scores of this species that I have kept, this was the common, and therefore, I presume, the natural, termination of life. Mrs. Davis, in the interesting note of one kept by her, communicated to the Ann. N. H., vol. vii, alludes to it. "At the end of a fortnight one of my pets turned itself inside outwards, and remained in this state for some time, when it died, and left only a few floculent particles at the bottom of the vessel." I do not doubt that if the sediment had been carefully examined with a microscope, the intelligent observer would have discovered among it inany of the crimson oval gemmules. 
gemmules (fig. 9) seem to escape from the walls of the ovaries, working their way out at the sides. They drop down on the bottom of the vessel, where they move about slowly for a while, to no great extent, by means of their vibratile cilia.

All through September, as this species was very numerous in the harbour and in the neighbouring coves, I procured great numbers of them, most of which I placed in a deep cylindrical glass vessel,the chimney of a lamp, in fact, with a plate of glass cemented across one end for a bottom. By examining this bottom-plate from beneath with a lens, I found early in September that a good many of the gemmules had affixed themselves to it, and were changing their form. By watching them, I ascertained the following facts. The gemmule, having adhered to the glass, grows out into a lengthened form, variously knobbed and swollen, and frequently dividing into two branches, the whole adhering closely to the glass. After a day or two's growth in this manner, a perpendicular stem begins to shoot from some point of this creeping root, and soon separates into four straight, slender, slightly divergent tentacles, which shoot to a considerable length. The whole is of a crimson hue, with the exception of the growing extremities of the creeping root, which are pellucid white. The little creature is now a Polype of four tentacles. (See fig. 10).

I could not follow the development farther, for though I had perhaps, a dozen in this stage, on the bottom of the glass, they all died without farther growth. And though, for weeks after, many gemmules were deposited, and I could see plenty every day 
crawling about the glass, not one manifested the least inclination to become adherent, or to grow into a Polype. Indeed, they differed in appearance from those first produced, for these were all true planules, being elongated and produced at one end in to a blunt point, with considerable power of change in the outline.

When we look at a lovely object like this, we are conscious of a positive enjoyment, arising from the gratification of our sense of beauty; a sort of appetite, if I may so call it, implanted in our nature by the beneficent Creator, expressly for our satisfaction. The garden which the Lord God prepared for unfallen man was furnished with "every tree that was pleasant to the sight," as well as "good for food." And surely it is not too much to suppose that even in the Infinite Mind of God himself there is a quality analogous to this in us, the sense of material beauty, the approval of what is in itself lovely in form and colour and arrangement, and pleasure in the contemplation of it; distinct from and independent of the question of relative fitness or moral excellence. If such a supposition needed proof, I would simply adduce the profuse existence of beauty in created things, and refer to the word that "For His pleasure they are, and were created."

But there is another point of view from which a Christian,-by which expression I mean one who by believing on the Lord Jesus Christ has passed from death unto life, and not one who puts on the title as he would a garment, merely for convenience or custom's sake-looks at the excellent and the beautiful 
in nature. He has a personal interest in it all; it is a part of his own inheritance. As a child roams over his father's estate, and is ever finding some quiet nook, or clear pool, or foaming waterfall, some lofty avenue, some bank of sweet flowers, some picturesque or fruitful tree, some noble and wide-spread prospect, - how is the pleasure heightened by the thought ever recurring,-All this will be mine by and by! And though he may not understand all the arrangements, nor fathom the reasons of all the work that he sees going on, he knows that all enhances the value of the estate, which in due time will be his own possession.

So with the Christian. The sin-pressed earth, groaning and labouring now under the pressure of the Fall, is a part of the inheritance of the Lord Jesus, bought with his blood. He has paid the price of its redemption, and at the appointed time will reign over it. But when the Lord reigneth, his people shall reign too; and hence their song is, "Thou hast redeemed us to God by thy blood,....... and we shall reign on the earth." For unto the angels hath He not put in subjection the world to come, but unto Him who though Son of God is likewise Son of Man,-even to Him in association with the "many sons" whom $\mathrm{He}$ is bringing to glory.

And thus I have a right to examine, with as great minuteness as I can bring to the pleasant task, consistently with other claims, what are called the works of nature. I have the very best right possible, the right that flows from the fact of their being all mine, -mine not indeed in possession, but in sure reversion. And if any one despise the research as mean and little, 
I reply that I am scanning the plan of my inheritance. And when I find any tiny object rooted to the rock, or swimming in the sea, in which I trace with more than common measure the grace and delicacy of the Master Hand, I may not only give Him praise for his skill and wisdom, but thanks also, for that $\mathrm{He}$ hath taken the pains to contrive, to fashion, to adorn this, for me.

\section{THE CRYSTALLINE JOHNSTONELLA.}

I have the pleasure of announcing a new animal of much elegance, which I believe to be of a hitherto unrecognised form. I shall describe it under the appellation of Johnstonella Catharina. (Plate XXV).

Body $\frac{3}{4}$ inch long, $\frac{1}{6}$ inch in greatest diameter, flat, thin, as transparent and colourless as glass.

Head dilated on each side into two lobes, which are flat, pointed, and leaf-like, extending laterally to a considerable distance. Along the posterior pair are soldered a pair of excessively long, slender antennæ, tapering to a fine point; they appear simple unjointed filaments, directed divergently backwards to a greater length than the body, and incapable of change in direction. The basal moiety of their length is invested with a loose skin, which corrugates into folds.

Eyes two, black, small, on the summit of the head, between the posterior lobes: a line of minute black specks runs down the middle of the neck behind the eves.

Body narrow at each extremity, widening in the middle: furnished on each side with sixteen fin-like narrow lobes, each of which bears at its extremity two oval 


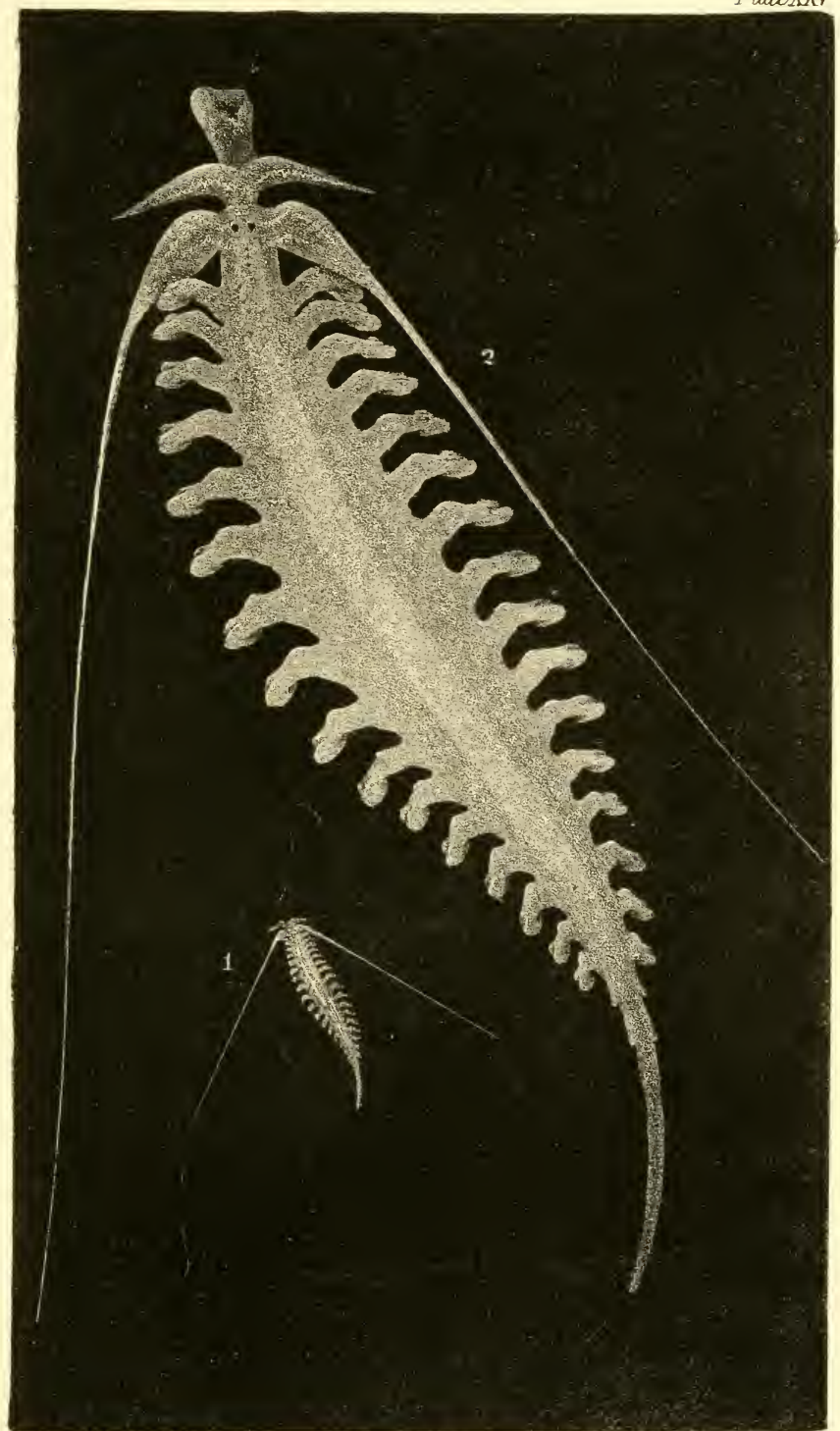



branchial (?) leaves, set on obliquely. The ultimate pairs diminish gradually, and are succeeded by a few pairs of rudimentary processes on each side of a slender tail.

Viscera, a simple, clear, rather wide canal running through the whole length; ordinarily parallel sided, but sometimes constricted so as to form a succession of spindle-shaped divisions, which pass from the head to the tail in rather slow pulsations, like the dorsal vessel of a caterpillar. A thick œsophageal proboscis was once protruded from the mouth, of an ob-conic form, with a large somewhat four-sided orifice obliquely terminal. No other internal structure was visible, notwithstanding the perfect transparency of the animal.

The elegant form, the crystal clearness, and the sprightly, graceful movements of this little swimmer in the deep sea, render it a not altogether unfit vehicle for the commemoration of an honoured name in marine zoology.

The skilful pencil of Mrs. Johnston, employed in the delineation of the interesting forms that stand on the verge of animal life, has succeeded in presenting them to us with peculiar truth and beauty; and has rendered an invaluable aid to the verbal descriptions of her indefatigable and eminent husband. I venture respectfully to appropriate to this marine animal, the surname and christian name of Mrs. Catharine Johnston, as a personal tribute of gratitude for the great aid which $I$ have derived from her engravings in the study of zoophytology.

Three specimens of the Johnstonella have come 
into my possession; all of which were dipped from the surface of the sea off the harbour of Ilfracombe, about the end of August. In a glass jar their motions were excessively vivacious; they swam with great swiftness by the rapid vibration of the lateral fins; so incessantly that it was with the utmost difficulty I could examine them with the microscope. They darted through the water in all directions, across and around the jar; and when they rested, their translucency rendered them almost invisible. They soon died in captivity; I think I did not keep one of them longer than the second day.

The form of this animal is so anomalous that it is difficult to assign it a place in the system of nature. At first sight it has somewhat the aspect of a Branchiopod Crustacean; but the evertible œsophagus, the numerous lateral lobes, and the leaf-like expansions with which they are terminated, rather indicate an affinity with the Annelida. It is possible that it may prove a larva of some known form in this Class. The specimens that I have found, however, presented no differences in size or development.

My description and figure are both less complete in details than I could have wished to render them, owing to the agility and to the evanescence of the animal. I loped to supply the deficiencies by the study of other specimens, but this hope was disappointed. The structure and form of the leaf-like appendages of the lateral lobes, in particular, need further revision.

Fig. 1 represents it of the natural size, fig. 2, magnified. 
Sept. 8th.- In the clear quiet water of the bathing pool I dipped this afternoon many Medusæ, almost all of these two species, Thaumantias pilosella and Willsia stellata. One of the former presented a curious deviation from ordinary structure, in that one of the radiating vessels was divided into three branches at about one third of its length from the marginal canal, the ovary likewise branched correspondingly. The other vessels were quite normal.

Less numerous than this, but sufficiently common, was the pretty Willsia, a little gem, with its six-rayed star of yellow ovaries, and its circlet of black eyes. (Plate XX, fig. 1). The radiating vessels in this species, six in number, are naturally divided into branches, each entering the marginal canal by four mouths, like the Delta of some great continental river. The sub-umbrella is not evenly round, but lobed, the radiating vessels running along deep depressions or valleys, between which the surface rises into hills. (See fig. 2).

I found in one of the Willsia a curious parasitic Leech. I know not on what part, for I first discovered it after I had subjected the Medusa to the compressorium. It is an active little animal, with two suckers, of which the anterior is imperfect and mouth-like, and the posterior is circular, produced into a thick wart, and set on the ventral surface at about one third of the whole length from the tail. There are eight 
eyes, very minute, colourless, and set around the frontal margin of the anterior disk; the anus is terminal. The ovary is large, and filled with a number of clear, globular, highly refractile ova. Close-set transverse annuli were conspicuous on the fore half of the body.

When the Medusa was subjected to pressure, I observed several vesicles of exceedingly subtle membrane, loosely wrinkled, containing a number (varying from one or two to thirty) of clear oval bodies, about $\frac{1}{1500}$ th inch in longest diameter. (See fig. 3). The vesicles were placed at the end of a short canal, or neck, or footstalk, of similar membrane, originating from the marginal canal, and freely standing up on the outside of the umbrella, as I believe. Each of the oval granules had a body within it, which I at first supposed a cell, but in one I distinctly saw that it was composed of a number of oblique parallel lines (See fig. 4). On pressure being increased, all the oval capsules simultaneously shot forth, from one end, a thread of great tenuity and of excessive length. I could trace them to about fifty times the length of the oval, and am not at all sure that I saw their extremity, for with a power of 300 they became undistinguishable farther. The thread, in an instant so brief as to be inappreciable, assumed perfect straightness, (except a slight curve in some cases), just as if composed of some highly elastic substance, that had hitherto been compressed Butclose examination showed an appearance like that of a corrugated sheath enveloping it for a considerable portion of its length, perhaps one third, from the oval capsule (See fig. 5). 
Plate XI

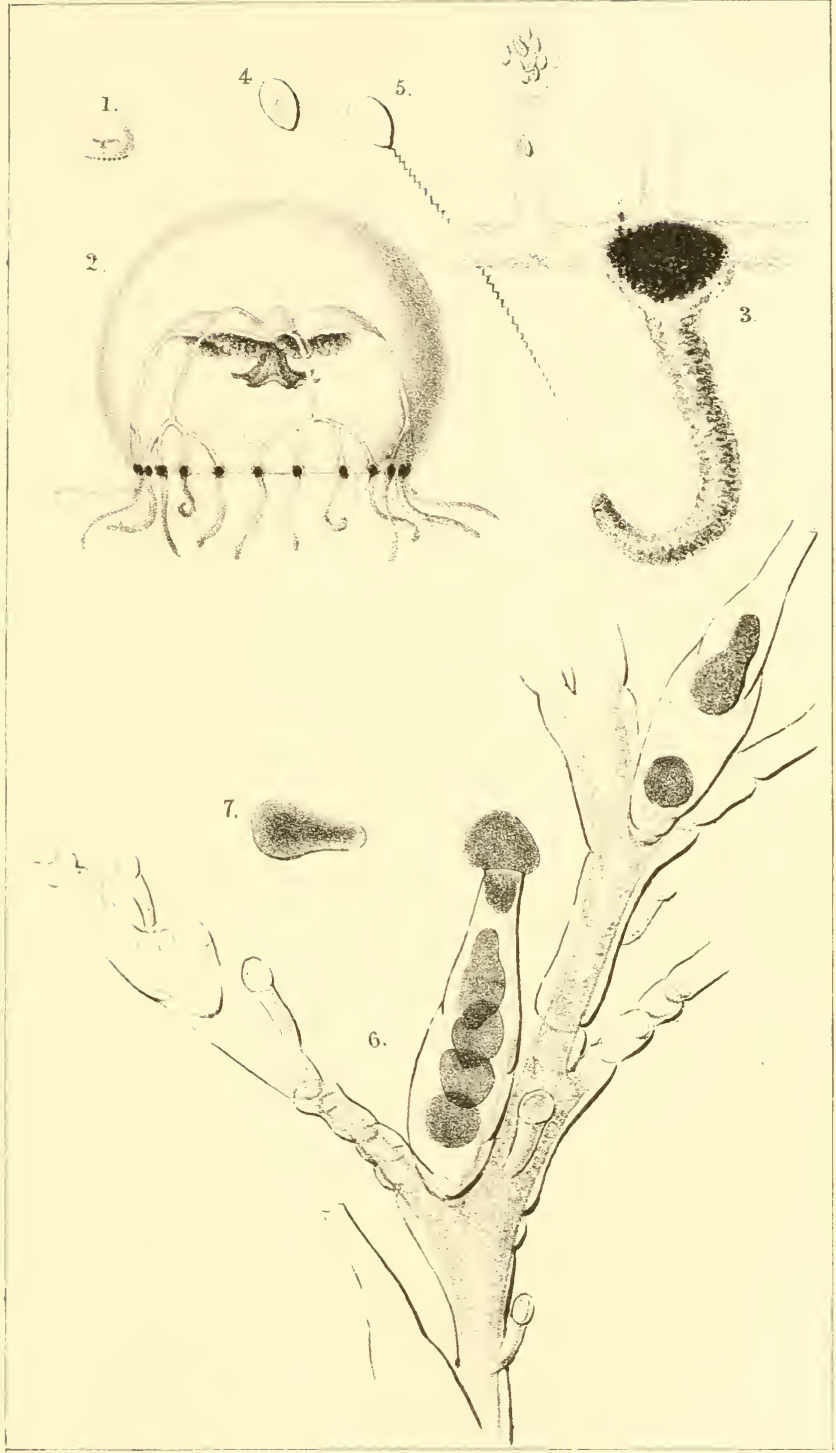

FH/ iosse det er lith

Pirivted by Flallmardeikivaiton.

I-5 WILLSIA STEIIATE.

67 DLUMILPIA SETAI- 

This was the first occasion on which I had an opportunity of seeing the filiferons capsules, as these bodies are called, for though I have described, in previous parts of this volume, similar organs, the actual observations so recorded were, in point of time, subsequent to this.

The presence of these aggregations of capsules appears to be subject to much variation. In some specimens of the Willsia that I examined, there were several, perhaps five or six; in many I could not by strict searching, find more than one or two solitary capsules, seemingly scattered in the substance of the umbrella near the margin, yet shooting out the thread on pressure, exactly like those aggregated in a vesicle. But perhaps in these they may have been present, though overlooked, in a situation where I afterwards found them numerous in each specimen that I examined, viz. within the substance of the double ovaries, and chiefly near their termination. In each lobe there were many capsules, not arranged nor gathered into resicles, but apparently loose in the yellow granular substance. But none of these had developing ova; only one that I examiner had ova in the form of transparent globules with a central clear nucleus; and that specimen I had destroyed before I had detected this situation for the capsules. However, in that specimen I know that, after pressure, I could find no more than a single capsule, all over the Medusa.

These facts suggested the thought that possibly these organs that look like ovaries may in some cases be testes, and the filifercus capsules be organs of 
conjunction. I do not think them analogous to Spermutozoa, though these appear to be present also ; for when the ovaries (or testes) gave way under pressure, their substance contained with the coloured granules a multitude of excessively minute bodies with spontaneous vibratile motion. They were evidently oblong, but too minute for me to discern their tails, if they had any. 


\section{CHAPTER XT.}

This Coast favourable for Oceanic Productions-The Red-lined IIedusa-Its Form and Structure-The Eyes-The Furbelows-A parasitic Shrimp-Its supposed Young-Beauty of the Medusa-Its Prehensile Powers-Capture of PreyCurious Mode of eating-Experiments-New Use of the Furbelows-Derelopment of the Eggs-Their StructureThread-Capsules-Synonymy-The White Pelagia-The Mantis Shrimp--Its spectral Figure and strange ActionsIts Weapons-The Caòdis Shrimp-The Tiny OceaniaBusk's Thaumantias-The Fairy's Cap.

\section{THE RED LINED MEDUSA.}

The conformation of the Bristol Clammel, and of the adjacent coasts, offers peculiar facilities for the study of those marine animals whose proper sphere of existence is the wide ocean. The prevailing westerly winds, driving up the surface-waters of the Atlantic, impel them along the shores of Portugal, Spain and France, whence a large portion passes through the English Channel into the German Ocean. But another large portion, turned northward by the projecting point of Cornwall, finds itself in a vast fumnel, between the Irish and English coasts, which has two terminations, the one open and leading into the North Sea, the other closed and confined within the 
narrowing limits of the Bristol Channel. Each of these three localities,- the shores of the English Channel, the Irish Sea, and the Bristol Channel,receives its portion of oceanic productions brought by the winds and currents; but the former two are open passages, while the last-named, being closed, retains such as are brought within its boundaries. And the southern side of the Channel is likely to receive the greatest part of such deposits; for the winds setting them upon the Cornish coast, the current would naturally follow the bending line of the shore; and thus the rocky coves and inlets of North Devon might be expected to be more than usually rich in those rare and accidental stragglers, which the waves bring in from their roamings in the boundless sea.

So I have proved it. Two new species of Aquorea I had already found here, a genus of which but one example had been recorded as British; and I have now to add a magnificent species of Chrysaora, which, though not new, appears to be rare on the British coast. It occurred to me on the 14 th of September, at low water, embayed in a little tide-pool in the rocks below the Tunnels, where it attracted my attention by its vigorous and regular pulsations. (See Plate XXVII, where it is represented about half the natural size).

The umbrella (fig. 1.) is about three inches in diameter, depressed and sub-conic in expansion, hemispheric in contraction, pellucid and nearly colourless, but tinged about the summit with a delieate flush of rose-colour. The surface is slightly frosted or tomentose, and studded with a multitude 
of minute orange warts, most conspicuous in the central parts. About thirty-two fine orange lines radiate from near the centre, which are lost before they reach the circumference. The margin is cut into thirty-two concave ovate lobes, a tentacle being between every two, with the exception of eight of the interspaces symmetrically disposed, where a pedicled ocellus takes the place of a tentacle. The pair of lobes which inclose each ocellus are larger than the rest, and are of a rich sienna-brown; the other lobes are not associated in pairs, are smaller, and are of a paler tint of the same warm colour.

The tentacles, twenty-four in number, are all alike : their substance is pellucid-white with the tips crimson; the latter, however, are very liable to be torn off. Their base can scarcely be called bulbous, but this part is dilated into an ovate form in one direction (viz. that from the centre outward) and thin in the ofyosite. They are long and attenuated, being frequently stretched to the length of a foot, and as slender for most of their length as the finest sewing-threarl. They are waved and contorted in various free and elegant curves, but are never drawn up into spiral roils; their contraction, which is sometimes so great as to reduce them to an inch in length, being effected entirely by the shortening and thickening of their substance. They are very adhesive, but I did not find in them any power of stinging.

The eyes, eight in number, are minute oval bodies, opaque yellowish-white, each placed at the tip of a rather long, slender footstalk, depending perpendicuarly from the margin of the umbrella, and protected 
by a tubular fold of the common pellucid membrane, which extends to about double its length. (See fig. 2). On crushing one of these eyes with graduated pressure beneath the microscope, it was most interesting to find its substance entirely composed (so far as I could perceive) of an infinite multitude of regular colourless crystals, the greater number of which were short six-sided prisms, and, as I thought, with convex extremities. (See fig. 3). Of this latter point, however, I am not quite sure; but their hexagonal form was perfectly distinct; and I could not but conclude these to be true visual lenses, perhaps as perfect as those of Crustacea or Insects. 'Their diameter was about $\frac{1}{1500}$ th of an inch.

The sub-umbrella agrees in general form with the umbrella, but is much more depressed. From its centre depends an ample globose peduncle, which after being constricted, terminates in four membranous arms of excessive delicacy and beanty. Each arm consists of a cylindrical, or rather insensibly tapering, process, resembling a tentacle in length and slenderness. All along one side of this filament is attached a ribbon of pellucid membrane, more delicate than the finest cambric: it is upwards of an inch wide above, but gradually tapers to a point; and is so attached by one of its edges to the filament, as to fall into ample folds or furbelows, exactly like the flounces of a muslin dress. The grace and beanty which these appendages impart to the animal can scarcely be imagined by those who have not witnessed a similar spectacle. Sometimes, indeeed, they are contracted into a shapeless mass, only two or three inches in 
length, so puckered and confused as to render their disentanglement apparently hopeless; but in a few moments we see their graceful folds, all separated, stretching their taper length to a distance of ten inches from their base, and waving slowly through the water with every contraction of the ever-pulsating nmbrella. The colour of these elegant organs is white at their upper part; but a faint tinge of rosered becomes perceptible about their middle, and gradually increases in intensity till it becomes at their extremities a decided pink. This hue, however, seems in some way to be dependent on the will of the animal, frequently becoming stronger or fainter in the course of a few minutes.

The interior of the peduncle is divided by four perpendicular septa into as many ample chambers, which are visible from above. Other folds of membrane partially cross their area, causing them at times to appear six or more in number. From beneath, large round openings are seen communicating with the interior of these chambers, into which the surrounding water is thus freely admitted.

Whatever other purposes these cavities may fulfil in the economy of the Medusa, they serve the convenience of another animal of widely different organization. A little shrimp-like creature, about half-an-inch in length, with large lustrous green eyes (Hyperia medusarum), makes these chambers his residence, dwelling in them as in so many spacious and commodious apartments, of which he takes possession, I am afraid, without asking leave of the landlord, or paying him even a peppercorn rent. There however, he 
snugly ensconces himself, and feels so much at home, that he is not afraid to leave his dwelling now and then, to take a swim in the free water; returning to his chamber after his exercise.

That this is the natural habit of life followed by this Crustacean, I have no doubt. There were three or four specimens on this Chrysaora, and I have found it parasitic on other large Medusæ. But there were also on the one $I$ am describing a vast number of minute white specks, which on examination proved to be little Crustacea, and, as I suspect, the larvæ of this species. They are not larger than a grain of sand, shaped somewhat like a toad, with the abdomen distinctly separated, narrow, and bent abruptly under, in the manner of the Brachyura. (See Plate XXII. fig. 15).

To return, however, to our Medusa. Though this genus is described as peculiarly phosphorescent, I found this specimen scarcely at all luminous. A very slight and dull flash or two was all that I could obtain, with repeated pushings and other disturbances of the animal in the dark.

The appearance of this fine Medusa in captivity was noble and imposing. I kept it for several days in a deep glass vase of clear sea-water, where its chestnut-lobed umbrella, throbbing with a continual pulsation, throwing its circle of hanging tentacles into a succession of serpentine undulations, and its long four-fold fringe of gauze-like flounces, floating through the water, formed a sight which the beholders were never weary of admiring, and from which we could scarcely withdraw our eyes. Its pulsations 
were perfectly regular, leisurely, and energetic; yet their effect in moving the body seemed feeble and laborious; every stroke, for example, raising the disk an almost inappreciable distance, when it wished to ascend from the bottom to the surface; forming a marked contrast to the minute but agile Turris neglecta, which shoots at every contraction a distance three or four times its own diameter.

The Chrysaora does not rest at the surface as some Medusæ do; but occasionally allows itself to sink slowly to the bottom, where (or but slightly elevated above it) it intermits for a while its laboured contractions.

The furbelows, as well as the tentacles, are organs of prehension, used for the capture of prey. I have some reason to believe that the former, at least near their origin, perform an active part in digestion. Casually touching the animal with a stick, not only did several of the tentacles entwine round it, but the furbelows also presently adhered to it, partially embracing it; and I became conscious that the latter were drawing the stick towards the peduncle with considerable force; nor was it an easy matter to liberate it from the firm grasp. This circumstance suggested the thought that the animal might be hungry, especially as it had been in my possession several days without food.

I determined therefore to give it a dinner ; and, that there might be wanting no incentive to appetite, one which a prime minister would not have disdained-a Whitebait dimer. I had just before netted in a tidepool, half a dozen of these brilliant little fishes; and 
one of these I devoted to my experiment, and the Medusa's appetite. The fish was already dead, and I had no difficulty in guiding it so that it might touch the tentacles. These were immediately, as I had expected, entangled around the fish, and so were the furbelows. At first I was not aware that anything more was going on, for the weight of the fish had carried it to the bottom of the vessel, and the delicate membranes were lying in confused heaps over it.

After some time, however, I perceived that the fish had moved from that part of the furbelows which had first seized it; for whereas at first not more than half-an-inch lay between that part of one of the furbelows which embraced the head of the fish, and its extremity, the head was now several inches higher up towards the peduncle. This induced me to watch it closely. The tentacles had now no part in the matter ; having delivered the prey to the furbelows, they had disentangled themselves, and were now sprawling loosely about, as usual. Three of the furbelows had grasped the fish; one embracing the head, another the tail, and a third the middle of the body; the fourth had not touched it at all, and the middle one presently relinquished its hold, resigning the task to the other two. These embraced their respective parts in the most curious manner; not being twined about merely, but the fleshy membrane adhering to the surface of the fish, filling every hollow, and rounding every projection of its burden, so closely as to manifest not only the sensitiveness, but also the muscularity, of these filmy organs.

It was easy to perceive the constant though slow 
progression of the fish upward; the surface of the furbelow, with its closely adhering plaits and puckerings, being moved over the fish, with an runiform gliding, like that of the foot of a mollusk over the surface on which it is crawling. The crustacean larvæ already spoken of, like minute white specks scattered about the furbelows, enabled me distinctly to mark the advance of the fish, which proceeded at the rate of about a line in a minute. The contractions of the umbrella went on with the usual force and precision during the whole time; and as the fish was gradually brought nearer to the umbrella, the furbelows acquired the power to lift it from the bottom, and to suspend it between them in a horizontal position.

After two hours had elapsed from the first seizure, the fish was brought to the mouth of the peduncle, about half-an-inch abore the separation of the furbelows; and where it remained, without any further perceptible change, for a full hour. The head of the fish alone was so much elevated as this, for the furbelow at the tail had latterly ceased to act, while the other had proceeded; and consequently the fish had become nearly perpendicular. Its head was closely embraced by the lips of the peduncle, and the peduncle itself was protruded in a remarkable manner, by the partial inversion of the umbrella, the upper surface of which was slightly concave, though the margin was bent over, and continued its contractions.

At length, after about an hour, the Medusa slowly relinquished its prey, which fell again to the bottom. To my surprise, however, I could not discover, on examination, that the digestive efforts of the Chry- 
saora had produced the least alteration in the appearance of the fish; the surface of which was as clean, and its edges as smooth and well defined, as they had been three hours before. Yet I would not hence too hastily conclude that no nutriment whatever had been extracted by the pores of the stomachal membrane. It seemed possible, too, that the weight and unwieldy dimensions of the fish may have disappointed the animal of its expected feast; and that a smaller morsel might have been more completely inclosed.

Acting on the last suggestion, I offered to the Chrysaora, a day or two after the above experiment, a piece of cooked meat about half-an-inch square. It was caught by the furbelows, and slowly passed up to their base, where it was closely embraced for several hours. I know not how long it remained there, but the next morning I found that it had been received during the night into one of the four cavities, into which the peduncle is divided. It was visible through the pellucid integuments from above, and without any intervening substance from below, through the oval aperture of the chamber, which was not closed upon it. Here it remained two days and nights, being dropped to the bottom in the course of the third evening. I examined the morsel; it was white from the long maceration, but was not decomposed, nor surrounded by any mucus, as are the rejecta of the Actiniæ, \&c.; nor had it the least putrescent smell, a circumstance which appears to me to prove that a true digestive process had operated on it. For if the morsel had lain in the water for that time, it would undoubtedly have become offensive, whereas the gas- 
tric fluids are known to have an antiseptic power in the Vertebrate animals.

After I had kept this Chrysaora for about a week its manners underwent a change. It no longer swam about freely in the water by means of its pumping contractions, nor was its appearance that of a umbrella. It began to turn itself inside out, and at length assumed this form permanently, its shape being that of a very elegant vase or cup, with the rim turned over and the tentacles depending loosely from it, the furbelows constituting a sort of foot. The latter were new put to a new use: the animal began habitually to rest near the bottom of the vessel, or upon the broad fronds of Iridac, which were growing in the water and preserving its purity ; but occasionally it would rise midway to the surface, and hang by one or two of the furbelows. A fold or two of the latter would come to the top of the water, and dilate upon the surface into a broad flat expansion, exactly like the foot of a swimming Mollusk; from this the Medusa would hang suspended in an inverted position. All the other furbelows, and the parts of this one that lay below the expansion, floated as usual through the water, except that, on some occasions, an accessory power was obtained by pressing a portion of another furbelow to the side of the glass, and making it adhere, just like the part that was exposed to the surface air. The texture of the furbelows when thus stretched smooth was exquisitely delicate.

The eversion of the sub-umbrella was connected with the maturing of the ovaries. I had observed that in Turris the development of the ova was inva- 
riably accompanied by their protrusion, and the shrinking up of the umbrella; and in the case of this Chrysaora, I found the ovaries assuming a greater size and opacity. They formed frill-like expansions spread around the interior of the four stomachal chambers, and now began to protrude from the oval apertures in convoluted masses. A portion of one of the protruding masses I cut off with fine scissors, and submitted it to a magnifying power of 220 diameters.

The mass consisted of a plexus of gelatinous tubes, very numerous, not a single one many times convoluted, for the rounded and closed ends of many were traceable, though I could not follow any one to its other extremity, except where cut off by the scissors. They moved and twisted about, gliding along like so many worms, by means of the cilia with which their surface was clothed. I could not indeed see the cilia themselves, but the uniform currents that swept the floating atoms along left no doubt on this point. The diameter of the tubes was not equal, but varied from $\frac{1}{250}$ to $\frac{1}{500}$ inch; and their walls were rather thick. In the mass were scattered a great number of globose ova, of granular texture, and yellowish-brown hue; the most mature of which were about $\frac{1}{450}$ inch in diameter, but others were much smaller, and pellucid in the ratio of their immaturity. None appeared to have a clear nucleus. Some of the ova were certainly within the tubes, and though the greater part appeared to lie free among the convoluted mass, and a few were loose in the water, I am inclined to attribute this entirely to the tubes having been cut across by 
the scissors, causing the escape of the ova. Such as were quite loose gave indication of being ciliated, in that they had a feeble spontaneous motion, a quivering oscillation.

A week afterwards (October 2nd) I again examined the oraries: the one that most protruded was more opaque, of a creamy hue. With a lens I perceived that the free ends of many of the tubes were projecting, and hanging down like a short fringe of threads, with blunt tips. I again cut off and isolated a portion in a watch-glass. The appearance was much changed since I examined it last. The tubes, which had the same vermicular motion as before, and were similarly convoluted, were greatly swollen in irregular parts, and contained many ova much more developed than before. These were clear globules, yet evidently granular, varying from $\frac{1}{200}$ to $\frac{1}{400}$ inch in diameter. I soon found that they were escaping from the ovarian tubes, (not however, from the free ends, which were slender and contained no ova); and after the severed fragment had remained a night in the watch-glass a great number, of varying sizes, were found on the bottom, moving about.

Some of these I examined with a power of 300 diameters, Each was a soft globose body, not quite regular, nor even fixed in form, of a clear brownish hue, composed of a great number of irregular granules aggregated together, which projected from the general outline; as if a handful of roundish pebbles from the shore had been agglutinated by some invisible cementinto as good a ball as you could make of such materials. The globule revolved in all directions on its 
centre, and progressed slowly through the water, with a quivering jerking motion, exactly like that of many of the compound Monads. I could not detect the cilia which produced this motion, but infer their existence. On pressure being applied to flatten the globule, each component granule was seen to be itself composed of a multitude of minute granules. The pressure being heightened the primary granules at length separated from each other, leaving for an instant angular channels between them, which appeared to be occupied with a very subtile gelatinous fluid; and presently these granules themselves yielded to the pressure, and dissolved each into a vast number of pellucid secondary granules of almost inappreciable minuteness.

On submitting to pressure portions of the tentacles, I found the walls rather thick in proportion to the tubular cavity, and moderately densely studded with filiferous capsules of great minuteness. Their form was perfectly oval, the smaller end being that from which the thread projected. The largest were about $\frac{1}{2600}$ inch in length, the smallest about $\frac{1}{5000}$ inch, with the thread occupying an oval cavity about two-thirds of the entire volume. The projected thread from one of the largest reached to about $\frac{1}{22}$ inch, or more than a hundred times the length of the capsule; those of many of the smallest on the other hand were not more than $\frac{1}{450}$ inch in length, or about eleven times that of the capsule. I could not see the least appearance of barbs, hairs, or imbrications on the threads (fig. 4. represents a large capsule, magnified 300 diameters). 
I'he capsules of the furbelows do not differ in size or appearance from those of the tentacles; they are however distributed in groups, consisting of from thirty to sixty, large and small capsules together; these groups form the minute white specks that are seen dotting the whole surface of these organs. None were seen in the ovaries.

Notwithstanding this armature, the species appears to have no stinging power appreciable to our senses. I passed the back of my finger, where the skin is very sensible, over the surface of both tentacles and furbelows. They adhered, indeed, to my skin, but no sensation of stinging was felt, nor any other unpleasantness.

This Medusa lived about three weeks in a glass vase, and died at the end of that time what I may call a natural death; that of exhaustion from the discharge of ova. Reproduction, as is well known, is the great object of existence, in many of the invertebrate animals, and also its closing act. It may be so with this Medusa.

In the mean time I found another specimen, closely agreeing with the former in appearance, but slightly smaller,-floating in one of the nooks of the harbour of Ilfracombe.

The species is doubtless the Cyanea clirysaora of Curier's Regne Animal (Edit. 1836); of which is figure, not very accurate, is given in plate xlvii. The editors refer it to Chrysaora cyclonota of Péron and Lesueur. It was first described by Borlase in the Nat. Hist. of Cornwall; and his description and figure are quite recognisable. 
THE WHITE PELAGIA.

Two days after the capture of the Chrysaora, I obtained, in the bathing-pool near the same spot, a species of Pelagia. The disk is about an inch wide. The projecting lobes of the umbrella give it, when expanding, a hexagonal form. There are eight eyes, as in the preceding species; but only the same number of tentacles, instead of twenty four; these organs are white. The peduncle divides into furbelows proportionally lower down, and the furbelows themselves are much more simple, and extend only to about two inches in length. The ovaries are not purple, nor are the tentacles or the disk tinged with rose-colour; the whole animal being colourless, except for the whiteness which arises from the imperfect transparency of the membranes. The umbrella, however, is studded with minute and scarcely perceptible reddish warts.

Messrs. M'Andrew and Forbes have described and figured (Annals N. H. 1847, p. 390) a species of Pelagia (P. cyanella), which they met with on the Cornish coast. It is possible that the animal above described may have been a very young specimen of the same species; though the differences are great, not only in size and colour, but also in form and proportions. The umbrella in their P. cyanella forms almost a perfect globe, but in my individual less than a hemisphere, resembling in shape that of the Chrysaora (See Plate XXVII.) It would be rash, however, to constitute a species on a single specimen; and hence I leave the matter for future investigation. 


\section{THE MANTIS SHRIMP.}

One can never take a living specimen of that beautiful zoophyte Plumularia cristata, without finding its numerous pinnated branches inhabited by curious Crustacea of the genus Caprella. They are as much at home in the tree-like zoophyte, as a family of monkeys in their arboreal bowers, and indeed their agility as they run from branch to branch, catching hold of a twig just within reach and pulling themselves in an instant up to it, then stretching out their long arms in every direction, strongly remind me of the Spider Monkeys of South America. One needs little systematic knowledge to see that they are highly predatory: a glance at their form and manners would reveal that fact. Strange spectre-like creatures they are! or rather skeleton-like; with long slender bodies composed of few joints, and wide-sprawling limbs set at remote distances. And such limbs! Two pairs of stout antennæ bristled with stiff spines project from the head, then the first and second pairs of legs, (but especially the latter, ) have the last joint but one developed to a great size, while the terminal joint is so formed as to shut down upon it just as the blade of a clasp-knife does upon the handle. Then to add to the efficiency of this instrument of prehension, the great joint which represents the haft is armed with a double row of spines set at an angle so as to make a groove, into which the blade falls, and this latter is cut along each side of its edge into fine teeth like those of a file. I find several species even on the same 
small fragment of weed, if it be tolerably well peopled with Plumularia or Pedicellina, some much larger than others, and beautifully mottled with transparent ruby-colour on a clear horn, and distinguished by variations in the relative size, in the shape, and in the armature of these formidable weapons; and there is a species larger still, of a dull purplish-red hue. But all have pretty much the same manners, except that the smaller species are more agile.

These manners are excessively amusing. The middle part of their long body is destitute of limbs, having instead of legs two pairs of oval clear vesicles, but the hinder extremity is furnished with three pairs of legs armed with spines and a terminal-hooked blade like that already described. With these hindmost legs the animal takes a firm grasp of the twigs of the polypidom, and rears up into the free water its gaunt skeleton of a body, stretching wide its scythe-like arms, with which it keeps up a see-saw motion, swaying its whole body to and fro. Ever and anon the blade is shut forcibly upon the grooved haft, and woe be to the unfortunate Infusorium, or Mite, or Rotifer, that comes within that grasp. The whole action, the posture, the figure of the animal, and the structure of the limb are so closely like those of the tropical genus Mantis among in. sects, which I have watched thas taking its prey in the Southern United States and the West Indies, that I have no doubt passing animals are caught by the Crustacean also in this way, though $I$ have not seen any actually secured. The antennæ, too, at least the inferior pair, are certainly, I should think, accessory 
weapons of the animal's predatory warfare. They consist of four or five stout joints, each of which is armed on its inferior edge with two rows of long stiff curved spines, set as regularly as the teeth of a comb, the rows divaricating at a rather wide angle. From the sudden clutchings of these organs, I have no doubt that they too are seizing prey; and very effective implements they must be, for the joints bend down towards each other, and the long rows of spines interlacing must form a secure prison, like a wire-cage, out of which the jaws probably take the victim, when the bending in of the antennæ has delirered it to the mouth.

But these well-furnished animals are not satisfied with fishing merely at one station. As I have said above, they climb nimbly and eagerly to and fro, insinuating themselves among the branches, and dragging themselves hither and thither by the twigs. On a straight surface, as when marching (the motion is too free and rapid to call it crawling) along the stem of a zoophyte, the creature proceeds by loops, catching hold with the fore limbs, and then bringing up the hinder ones close, the intermediate segments of the thin body forming an arch, exactly as the caterpillars of geometric moths, such as those for example that we see on gooseberry bushes, do. But the action of the Crustacean is much more energetic then that of the Caterpillar. Indeed all its motions strike one as peculiarly full of vigour and energy.

I have seen the large red species swim, throwing its body into a double curve like the letter $\mathrm{S}$, with the head bent down, and the hind limbs turned back, the 
body being in an upright position. It was a most awkward attempt, and though there was much effort, there was little effect.

\section{THE CADDIS SHRIMP.}

On sub-merged tufts of that seaweed that is sold in a dry state under the name of Carrageen moss (Chondrus crispus), I have found in considerable numbers a Crustacean resembling in many points the Caprella, but belonging to another order of this great Class. Without perhaps actually confining itself to this particular species of weed, it seems to affect it more than any other. Not, however, that you would find it on those ample tufts of Chondrus that grow in shallow rock-pools exposed at half-tide, the fronds of which glow at their tips with the most refulgent reflections of steel-blue. It must be sought at extreme low-water, about the sides of rocks that are laid bare only at the spring tides of March and September, and the alga itself will be masked under a crowd of Laomedece, Sertularice, Anguinarice, Pedicelline, and other parasitic zoophytes, and half covered with a thick coat of dirty floccose matter, the ejecta, as I suppose, of these creatures.

Among these, and assisting to conceal and metamorphose the plant, you may find a number of eonical tubes varying from $\frac{1}{16}$ to $\frac{1}{8}$ th of an inch in length made of a somewhat tough papery or leathery substance of a dusky colour and of a rough surface. They are stuck upon the fronds of the sea-weed in all directions, without any order, some laid along, others 
standing erect; sometimes singly, sometimes associated. From the open extremity project two pairs of stout jointed antennæ, both of which are armed on their under edge with double rows of spreading spines, like those of the interior antennæ in Caprella. These well-armed organs are affixed to a large oval head just in front of two black eyes, and are thrown about incessantly, forcibly clutching at the water, or rather at whatever may be passing in the water, just as described above in the kindred and companion species. The head ordinarily just projects from the mouth of the tube sufficiently to see what is going on without, and what prospect there is of a successful throw, but sometimes the creature protrudes his first two pairs of feet. These, especially the second pair, have a great oval joint at the end, (See Plate XXII, fig. 13) with a sort of knife-blade shutting on it, all formed on the same model as in Caprella, but the next two pairs of limbs have the middle joint curiously developed into a large projection on the upper side (Fig. 11). Three more pairs of legs follow, long, hooked at the end, and directed backwards, and the body, which is arched downwards like that of a shrimp, has three pairs of swimming bristles, and terminates in two styles. But all these latter details can be seen only by opening the tube with a couple of needles, and extracting the lurking inhabitant; when you may place him in the live-box of your microscope and examine him at leisure (See fig. 12).

The animal in its tube much resembles the larvæ of the genus Phryganea, that anglers value under the name of Caddis-worms. There, however, the case is 
composed of a mosaic of minute pebbles, bits of shell, \&c., imbedded in a glutinous silk with which the interior is smoothly lined. In our little Crustacean, I do not know of what it is made, or how, but it seems to be homogeneous, and is certainly of home manufacture, and not the tube of a zoophyte surreptitiously obtained, as has been supposed to be the case with the Cerapus tubularis of North America. Perhaps, however, closer examination might refute the charge of piracy brought against that species.

Our little animal is somewhat longer than its tube, or from $\frac{1}{12}$ to $\frac{1}{6}$ inch in length. It belongs to the genus Cerapus as restricted, but appears to differ from either of the species hitherto recognised as British : I therefore propose to call it $C$. Whitei, after my esteemed friend Mr. Adam White of the British Museum.

MEDUS亚.

A single specimen occurred in my dip-net the other day of a very tiny Medusa, which I cannot certainly identify, and which I hardly know how to apportion to its proper generic place. It has some resemblance to the lovely little Modeeria formosa, but the number and arrangement of its tentacles seem to point out the Oceaniade as its allies. I do not see the conspicuous muscular bands which would indicate it as a Turris, and I shall therefore call it an Oceania. I describe it in the following terms. (See Plate XIII, fig. 11).

Oceania pusilla. Umbrella mitrate, constricted 
above the middle, with the summit rounded, $\frac{1}{12}$ inch in height. (Fig. 11). Margin with about 21 short tentacles, springing from globose, yellowish bulbs, each of which carries a red ocellus within. (Fig. 14). The tentacles are usually contracted, and bent upwards. (Fig. 12).

Sub-umbrella nearly as large as the umbrella; from its centre depends an ample membranous peduncle, somewhat vase-shaped, but seen vertically to be fourlobed, each lobe prriform in transverse section, the small ends meeting around a minute square central space. (Fig. 13). These lobes are marked with delicate veins, as if the structure were irregularly cellular, and are tinged with yellow. The greater part of the peduncle is occupied by the ovaries, four in number, altogether somewhat pear-shaped, the larger end below, and filling the peduncle; they are of an opaque yellow, and each contains a nucleus of dark red. The whole descends into a flexible many-lobed lip, the extremities of which are puckered up, and slightly fimbriated.

This minute species was energetic in swimming, shooting several times its own length at each contraction.

I have found also on two or three occasions a small Thaumantias, with the following characters. (See Plate XXII., Figs. o to 11.)

Umbrella when young, globose when older, hemispheric, or shallow-campanulate, "like a Chinese hat," (Forbes) from $\frac{1}{12}$ th to $\frac{1}{4}$ th inch in diameter, transparent, colourless. The margin fringed with about thirty-two tentacles; these are very slender, and extensile, occasionally reaching to four or five times the 
diameter of the body; their tips adhere with force to other substances, and moor the animal: their bulbs contain a yellow undefined nucleus. A colourless ocellus between each tentacle-bulb and the next. (Fig. 7).

Sub-umbrella moderately high, with a narrow veil. Ovaries small, oval, around the radiating vessels; each with a yellowish nucleus; one was lengthened and constricted in the middle; and one was wanting. In others the ovaries contained globular ova with clear centres in various degrees of development. (See figs. 3 and 10$)$.

Stomach small, quadrangular, almost colourless, with thickened edges not frimbriated. (Fig. 8.) Radiating and circular canals very slender.

The tentacles vary much in number, sometimes eight in each quadrant, at others not more than five: some of the bulbs are often small, without filaments, and as if developing. Sometimes two ocelli are between one pair. An ocellus occasionally has two spherules in it.

This little creature, which is very active in captivity, has occurred about the shore in the neighbourhood of Ilfracombe. I have little doubt that it is the species which forms the subject of a valuable memoir by $\mathrm{Mr}$. Busk, in the Transactions of the Microscopical Society. (Vol. iii., p. 22.) I would therefore propose to dedicate it to that gentleman, under the appellation of Thaumantias Buskiana.

The length to which the tentacles of the Medusæ can be extended is very great. I have seen those of this little Thaumantias about an inch long, though 
the bell was only one line broad; and yet the tentacle was even then corrugated, and seemed capable of almost indefinite prolongation. What is curious, too, is that they were stretched perpendicularly upwarl, and not pendent.

\section{THE FAIRY'S CAP.}

The elegance and beauty of the smaller Medus:e have been celebrated by poets and naturalists, and have sometimes excited the latter to use the enthusiastic phraseology of the former. Here is a tiny species, which I venture to think any one looking at it, or even at the magnified figure of it in Plate XXVI, will not hesitate to pronounce one of the gems of the sea, though I will not presume to back it against that lovely atom, of which Professor Forbes affirms that "there is not a Medusa in all the ocean which can match it for beauty."

I have met with only a single specimen of the species, which was taken in a rock-pool near the Spout-holes at the base of Capstone-hill, on the 29th of August. The following characters distinguish it.

Saphenia Titania. Umbrella somewhat pearshaped or campanulate, the summit round, and crowned with a largish cylindrical cap of colourless membrane, sometimes falling into folds, but capable of enlargement by inflation. (Fig. S). It is connected with the sub-umbrella, which is parallel and almost equal with the umbrella in all its dimensions. From it depends a parallel-sided peduncle reaching about two-thirds down the bell, composed of four 
lobes, and terminating in four lips slightly expanded, not fimbriated. The margin of the sub-umbrella bears, at the points where two of the four radiating vessels enter the circular canal, two tentacles with very large and thick bulbs; the filamentous portions can be produced to twice or thrice the length of the bell, but are more frequently coiled up or contracted, or both. The other two radiating vessels have a small oval bulb or swelling with a yellowish nucleus at their termination; and between each of these and the bulbs of the true tentacles, there are three smaller swellings almost obsolescent, of which the middie one is a little more developed than the others. (Fig. 9). A rather wide veil borders the margin inwardly, which is alternately sucked in and blown out at each vigorous contraction of the umbrella. The lower half of the umbrella is wrinkled transversely.

The whole animal is transparent and colourless, except the peduncle, which is wholly of a delicate lemon-yellow; and the tentacles, whose thick bases are of a rich purplish crimson, gradually fading to a carnation tint on the filaments. The whole animal is very minute, being only $\frac{1}{16}$ inch in height (Fig. 7) ; but the richness of its hues makes it conspicuous under a lens, especially in the sun's rays, and when viewed with a dark background.

Its little fairy-cap, and its beauty, suggested the name of the 'faery queen' for its specific appellation.

Its motions are vigorous, shooting by long leaps through the water by means of its contractions, at each of which the floating particles are forced in a jet out of the bell. 


\section{CHAPTER XVI.}

The Maritime Bristle-tail-Its Nocturnal Habits-Discovery of its Retreats-Its Companions-The Scarce Polynoe-Its Armoury of Weapons-A rocky Bay-Romantic IncidentChivalrous Self-sacrifice-The Tunnels-Crewkhorne Cavern - The Torr Cliffs-Precipitous Path-Torr Point-SolitudeThe Scarlet and Gold Madrepore-Scene of its DiscoveryDescription of the Species-Its Microseopical Structure-The Stony Skeleton-Thread-Capsules of Actinia-The Clubbearing Medusa-Entanglement of Air-Structure of the Tentacles-The Eyes.

THE MARITIME BRISTLE-TAIL.

Lingering one evening on the ledges of grey rock below the promenade on Capstone Hill, I accidentally learned some particulars in the economy of the Machilis. It was at the north-west corner, where a broad shelving slope affords standing room, and where a rude seat presents accommodation for visitors, who resort to the comparative seclusion of the spot, to watch the glories of the setting sun, or the first flash from the light-house on the summit of distant Lundy.

Just about the time when all objects but those immediately around were becoming indistinct in the advancing darkness, I perceived some little moving specks on the white rock, and stooping down to get a better view, I saw that they were insects, which were running nimbly about in great numbers, and which 
leaped away whenever I attempted to lay hands on them. With some difficulty I succeeded in taking two or three, by slapping my hand suddenly down upon them, and crushing them. Having brought home my captures in that improvised collecting-box, that every entomologist finds need now and then to resort to, - a scrap of paper screwed up at both ends, -I found that they were the same little active creatures that I had met with before, Machilis maritima.

I visited the spot the next day, but could not discover a single individual: at the approach of night, however, they came out as before by hundreds. I suspected therefore that night was the proper season of activity for these insects; and that during the day they would probably be found secreted in the numerous fissures, with which this slaty rock abounds.

Accordingly I took an early opportunity of examining the place, furnished with a hammer and chisel. It was as I anticipated. On my detaching a loose fragment of the slate, I disturbed about a score of the insects, varying in size,- - the old parents shining in all the lustrous radiance of their scaly coats, and their hopeful family of all ages clustering round them in duller raiment. A large heap of ejecta showed that the fissure had been their regular and constant dwelling. Not that the place however was confined to them; for several of the amphibious marine Woodlice (Lygia oceanica) were hiding there, and there were also some half-dozen of the tailed and horned pupa-cases of a two-winged fly, in one of which I found the perfect insect nearly ready for expulsion, but dead and dry. They were of the species named 
Eristalis tenax, that bee-like fly, that is so very common in every garden in the latter part of the summer, hovering motionless over the flowers for several seconds, and then shonting suddenly away to hover again in like manner. Its association here with the Machilis and the Oniscus was a rather curious circumstance.

\section{POLYNOE IMPAR.}

Sept. 27th.-In turning over stones at low water on the outside of the harbour, I found an Annelide, which appears to be the rare species described by Dr. Jolnston (Ann. N. H., Feb. 1839) by the name of Polynoe impar. It is not more than half-an-inch in length, and to the naked eye presents nothing conspicuous or worthy of special notice, but submitted to microscopical examination it proves highly curious. The kidney-shaped shields with which the back is covered, and which are detached with slight violence (though not quite so readily as those of P. cirrata), are studded over with little trunsparent oval bodies, set on short footstalks; the intermediate antennæ, the tentacles, and the cirri of the feet are similarly fringed with these little appendages, which resemble the glands of certain plants, and have a most singular appearance. If we remove the shields, we discover on each side of the body a row of wart-like feet, from each of which projects two bundles of spines of exquisite structure. The bundles expanding on all sides resemble so many sheaves of wheat, or you may more appropriately fancy you behold the armoury of some belligerent sea-fairy, with stacks of arms enough to 
accoutre a numerous host. But if you look closely at the weapons themselves, they rather resemble those which we are accustomed to wonder at in Missionary museums, the arms of some ingenious but barbarous people from the South Sea islands, than such as are used in civilized warfare. Here are long lances made like scythe-blades set on a staff, with a hook at the tip to capture the fleeing foe and bring him within reach of the blade. Among them are others of similar shape, but with the edge cut into delicate slanting notches, which run along the sides of the blade, like those on the edge of our reaping-hooks. These are chiefly the weapons of the lower bundle; those of the upper are still more imposing. The outmost are short curved clubs, armed with a row of shark's teeth to make them more fatal; these surround a cluster of spears, the long heads of which are furnished with a double row of the same appendages, and lengthened scymetars, the curved edges of which are cut into teeth like a saw. Though you may think I have drawn copiously on my fancy for this description, I am sure if you had under your eye what is on the stage of my microscope at this moment, you would acknowledge that the resemblances are not at all forced or unnatural.* To add to the effect, imagine

* It was not until after I had penned the above sentence that I met with the following remark in Andouin et Milne Edwards' "Littoral de la France" (ii, 40). Speaking of the bristles of the Annelides generally, these learned zoologists say,-_: Leur usage nous a été d'autant plus facile à comprendre que nous avons retrouvé dans ces petites armures les modèles exacts des diverses formes que l'homme a su donner, avec calcul, à ses armes de guerre, pour les rendre plus redoubtables et pour assurer leur coups; il n'en possède certainement pas de mieux adaptées à ce but que celles dont sont pourvues certaines Annélides." 
that all these weapons are forged out of the clearest glass instead of steel; that the larger bundles may contain about fifty, and the smaller half as many, each, that there are four bundles on every segment, and that the body is composed of twenty-five such segments; and you will have a tolerable idea of the garniture and armature of this little worm, that grubs about in the mud at low-water mark.

The spot where I found this Annelide is invested with a melancholy interest, from its having been the scene of a romantic incident that proved fatal to one of the actors in it. Let me bring before your mind the locality.

If at low water you descend the steep flight of steps from the north-east corner of Capstone Promenade, you will find yourself in a wilderness of rocky boulders, through which, partly by climbing over their slippery masses, partly by winding round and between them, you may pick your way eastward. After a little while you come to a part where the precipitous coast recedes, with a wide but shallow curve, to some distance from the water's edge. The whole area bristles with pointed rocks, except a narrow inlet or cove of coarse sand that runs up obliquely from the north-west to the foot of a wall of stone, which has been built up to the height of thirty feet, where the cliffs failed. This is the yard-wall of several of the houses that stand on the quay and face the harbour; and from a door at its summit, a triple zigzag flight of rude steps, the lower range of which is cut out of the living rock, leads to the beach. An iron rail at the top, almost eaten through with rust, tells that the beating of the sea is 
no stranger even at this height; and if you were to take your stand on these steps when the tide is in, you would look out on a wide bay of clear water, the margin of which would be washing your feet. On your left hand a projecting bluff mass of rock, jutting out from the harbour-head, forms the western boundary, or, if you please, you may consider the more imposing Capstone itself as the boundary, and this only as a projection into the curve of the bay, which then you must draw with a wider outline. Away to your right, you see the verdant summit of Lantern Hill, crowned with an ancient building that was once a Popish masshouse, helping to diffuse spiritual darkness, but now makes some amends by exhibiting a nightly light to guide mariners to the harbour-mouth. In the rugged side of the cliff you see a cavern, in which, during a brief shelter from a passing shower, I made these notes of the locality.

Four or five years ago the large house from which these steps descend was temporarily occupied by two ladies of rank, one of whom, among other accomplishments not very common to her sex, was distinguisherl as an expert and fearless swimmer. She was accustomed to plunge from these private steps when the water was high, and swim out to sea, over yonder belt of horrid rocks, in all weathers. On the occasion I speak of, a morning in autumn, she had boldly, nay rashly, sought her favourite amusement, though a gale of wind was blowing, and the foaming sea was breaking in furious violence almost to the very top of the wall.

The fishermen and idlers on the quay were just 
going to their breakfasts, when the sister of the strimmer rushed out of the house with a scream of distress. "A lady is drowning behind! who will save her?" was her eager demand, as she passed one young man after another. None replied, for the weather was tremendous; till a poor shoemaker offered himself. "I'll save her, if I can," said he ; and he followed her swiftly through the house and yard to the head of the steps.

There indeed was the lady still bravely breasting the rolling waves; she had taken her outward range, and was returning, but the rebound of the sea from the cliffs was so powerful that she could not come in to the steps; her strength too was failing fast, and it failed all the faster because she was thoroughly frightened.

The young cordwainer, throwing off his coat and shoes, and taking a rope in his hand, leaped at once into the wares, and being himself a skilful swimmer, he quickly reached the drowning lady. He managed to pass the noose of the cord round her, by means of which she was presently drawn up by other men who had congregated on the steps. "Take care of the poor man!" was her first exclamation, even before her own feet had touched the firm ground. But "the poor man" was past their care; he had saved her life chivalrously, but it was with the sacrifice of his own.

As soon as he had secured the lady's hold of the rope, he sought the shore for himself, but scarcely had he swam half a dozen strokes, when the spectators on shore beheld his arms suddenly cease their 
vigorous play and hang down; his legs too sank into the same pendent posture, and his head dropped upon his breast with the face submerged. Thus he continued to float for a short time, but moved no more. He had been subject to occasional swooning fits, from a severe blow which he had received on the head some time before; and his brother, from whose mouth I received these details, conjectured that one of his attacks had suddenly come upon him, his pre-disposition being perhaps aggravated by his having gone out without having broken his fast.

The tide soon carried the body away out of sight; efforts were made as soon as practicable to recover it by dragging; and it was once hooked and brought to the surface, but before it could be hauled into the boat it sank again, and it was not till more than a fortnight after that it was found at Comb-Martin, some five miles to the eastward.

Nothing could exceed the distress of the lady at the death of her courageous deliverer; for awhile she appeared inconsolable, and the effect of the whole transaction is said to have been a permanent melancholy. Her gratitude was shown in providing for the widow and children of her benefactor, who continue to this day her pensioners.

THE TUNNEL ROCKS.

On a coast where the sublime and the awful almost everywhere are characteristic, where the scenery generally is such as the savage genius of Salvator Rosa would have revelled in,-there are some parts where 
these characters are more than ordinarily prominent. The beach stretching away from the Tunnels on either hand, but especially that to the westward, is a scene which every lover of the picturesque cannot but admire. The Tunnels themselves, pierced through the solid rock, at an enormous expense of labour and money, to give access to the beach, are an object of curiosity, and the visitor, as he traverses these long sepulchral corridors, finds in their chilliness and darkness a not inappropriate prelude to the wild solitude of the shore below.

In one place the excavation of the tunnel has broken into the roof of Crewkhorne cavern, and the visitor, as he walks across a bridge of logs, passes over a gloomy den, which tradition affirms, perhaps without much foundation, to have afforded a temporary shelter to De Tracy, when first he sought a refuge after the assassination of Becket. Overwhelming indeed must be the torror which would impel a man to hide himself in such a place as this; for though it is a lofty cave, with an ample mouth, the interior is frightfully desolate; the sea closes the entrance at every tide, and at springs must wash up almost, if not quite, to the very extremity.

The Ladies' Bathing Pool, a lake partly natural partly artificial, and the beaches and coves where gentlemen enjoy the same luxury, are just before and around this cavern, and these spots are during the summer generally frequented by visitors. But I prefer to wander on towards the westward, beneath the precipitous Torrs, clambering over the huge angular spurs that jut out here and there from the base of the 
cliff, to enjoy the solitude and the magnificence. Far overhead, around the summits of the peaks, the busy and clamorous daws are flying, and the wailing cry of a gull issues now and then from some of the fissures with which the cliffs are rent. Perhaps the tide is in, and the wavelets are rippling on the shingle, or the green arching billows are dashing up with thundering roar. Perhaps the tide is out, and from the beach extends a broad area before the water's edge is reached, a wilderness of boulders and masses of rock of all forms and dimensions. As we proceed, the shore becomes more and more rugged, the strewn masses become larger, and are piled on one another in yet wilder confusion, until at length further progress is stopped by a lofty promontory that projects into the sea so far that no spring-tide leaves its base uncovered.

Yet, if the visitor have nerve for the enterprise, he may ascend to the top of this ridge; for there is a flight of steps, very narrow, shallow, and slippery, cut in zigzag lines up the face of the precipice, now passing over a slender archway of rock, but just wide enough for the foot, then climbing the edge of a sort of steep sloping ridge or wall by long steps, with nothing on either side but the thin air, and the points of rock far below. I have ascended and descended two or three times, but never without a shuddering coldness as I came to these parts, and an emotion of thankfulness when they were passed. Yet the prospect from the summit, the access into still more secluded coves and bays beyond, and the exhilaration always felt at a considerable elevation, make the ascent worth the risk. Besides that, there is in most persons 
a sort of appetite for hazard, the excitement itself, the pleasure of daring and of surmounting danger, being a sufficient remuneration.

The promontory is Torr Point, that long narrow slope of green turf which I have already described, in a walk by which it is attained from above. The projection and the elevation combine to afford the beholder a wide-spread range of prospect from its height, a prospect of sublime features.

This district of the coast, including not the Point only, but the bays and margining rocks on either hand, was one to which I chiefly delighted to resort; the rather because in its rugged recesses, the particular objects of my scientific inquiries were found in rather than ordinary profusion and variety.

To sit on rocks, to muse o'er flood and fell,

To slowly trace the forest's shady scene,

Where things that own not man's dominion dwell,

And mortal foot hath ne'er or rarely been ;

To climb the trackless mountain all unseen,

With the wild flock that never needs a fold;

Alone o'er steeps and foaming falls to lean ;-

This is not solitude ; 'tis but to hold

Converse with Nature's charms, and riew her stores unrolled.

Childe Harold ii. 25.

THE SCARLET AND GOLD MADREPORE.

Sept. 16th.-A very distinct species of Madrepore, and one of great beauty, I discovered to-day. It was spring-tide, and the water receded lower than I have seen it since I have been here. I was searching among the extremely rugged rocks that run out from 
the Tunnels, forming walls and pinnacles of dangerous abruptness, with deep, almost inaccessible cavities between. Into one of these, at the very verge of the water, I had managed to scramble down; and found round a corner a sort of oblong basin about ten feet long, in which the water remained, a tide-pool of three feet depth in the middle. The whole concavity of the interior was so smooth that I could find no resting place for my foot in order to examine it; though the sides all covered with the pink lichen-like Coralline, and bristling with Laminariæ and zoophytes, looked so tempting that I walked round and round, reluctant to leave it. At length I fairly stripped, though it was blowing very cold, and jumped in. I had examined a good many things, of which the only novelty was the pretty narrow fronds of Flustra chartacea in some abundance, and was just about to come out, when my eye rested on what $I$ at once saw to be a Madrepore, but of an unusual colour, a most refulgent orange. It was soon detached by means of the hammer, as were several more, which were associated with it. Not suspecting, however, that it was any thing more than a variation in colour of a very variable species, I left a good many remaining, for which I was afterwards sorry. All were affixed to the perpendicular side of the pool, above the permanent watermark; and there were some of the common Caryophyllia associated with them.

The new species may be at once recognised by its brilliant colours. The whole of the body and disk, exclusive of the tentacles, is of a rich orange, yellower in young specimens, almost approaching to vivid 

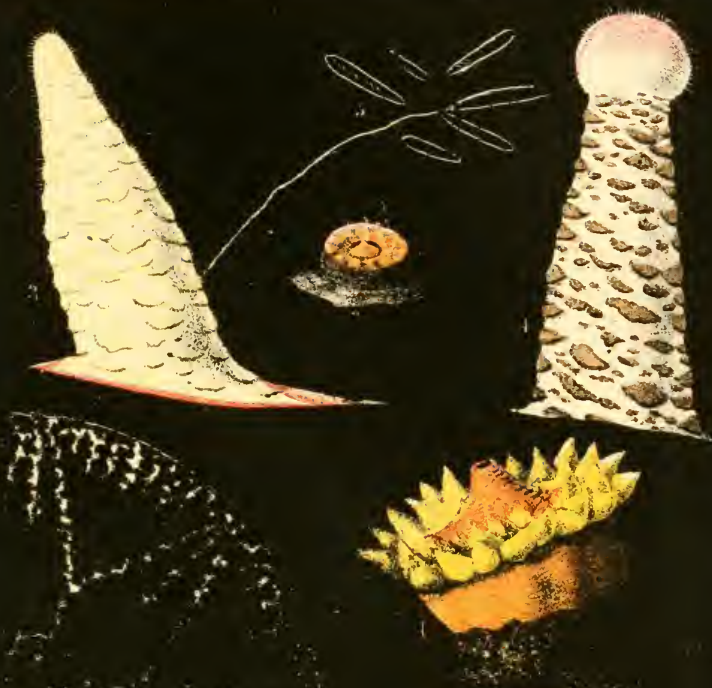

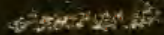

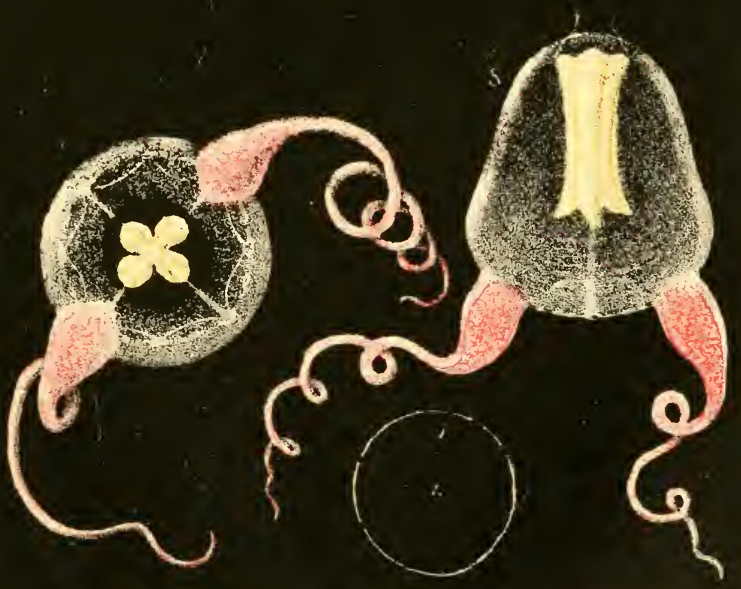



scarlet in adults, especially when contracted, for distension not only pales the hue, but causes the yellow element to be more apparent. The tentacles, about fifty in number, in my largest specimens, are of a fine gamboge-yellow. They are not terminated by a globose head, but are conical and obtusely pointed. When closely examined, indeed, the representative of the globular head may be recognised in the smooth rounded point, but it is not larger than the parts below, nor is it preceded by any constriction, nor distinguished from the other parts by its colour. Under a microscope the tentacle is seen to be diaphanous and colourless, but studded, like those of C. Smithii, with transversely oblong warts, which have a tendency to run in oblique lines; these warts give the colour, being of a fine yellow; and the rounded extremity of the tentacle is composed of a number of these warts aggregated into one. The tentacles are proportionally much larger than in C. Snithii, and fewer.

The animal is smaller than C. Smithii, the largest specimens $I$ have seen being about $\frac{1}{3}$ inch in diameter in the body, and rather more than $\frac{1}{2}$ inch when the tentacles are expanded. All that I have seen are circular in outline, and not oval, which is the most common form of Smithii. The plates are never visible, in any degree of contraction, the red flesh lying as a thick cushion over them, even when all the tentacles are withdrawn.

The mouth protrudes in the form of a high conical proboscis; this, though of course subject to some variation in form, appears highly characteristic of the species. The orifice is small, of the common colour, 
and does not form a conspicuously crenate white lip.

There is no coloured star on the disk, the orange hue running up around the bases of the tentacles as in an Actinia. Narrow radiating ridges from every tentacle meet in the centre. Indeed the resemblance to an Actinia is far more close and striking in this new species than in $C$. Smithii. The cylindrical body is somewhat furrowed.

Minute microscopical examination revealed differences between the two species more remarkable than any above-noted. All the red parts are clothed with vibratile cilia, but the tentacles, which in C. Smithii we have seen to be so furnisbed, are here entirely destitute of them. The ciliary currents flow down the sides of the body, but up the conical proboscis from the whole circumference of the disk, passing off outward from the mouth. The whole tentacle is covered with short motionless hairs, and not the tip only.

The warts on the tentacles, when subjected to high pressure, appear to be oval vesicles or saes of clear gelatinous fluid, in which float many yellow pigmentgranules, which are of a varying figure, generally more or less drop-shaped, with a sinuated outline, and one end drawn out. These warts appear also to be the chief seats of the filiferous capsules: these are not very numerous, oblong, and almost linear in form, varying from $\frac{1}{1200}$ th to $\frac{1}{650}$ th inch in length, and sending forth a filament about thirty times the length of the capsule; one that I measured reached to $\frac{1}{22}$ nd inch. Those of the convoluted ovaries agreed in all respects with these. 
If any additional evidence were wanting to show that this species approaches much nearer the Actiniæ than C. Smithii does, it would be found in the stony skeleton. This is very different in appearance from that of the kindred species, and is manifestly rudimentary. When the soft parts have been carefully removed by several days' maceration in fresh water, and the gelatinous matter all cleared away from the stony plates by a slender stream of water allowed to run upon it from a height, a vertical view shows the following arrangement:- First, at the very margin there is a narrow circle of white calcareous plates, small and very irregularly anastomosing, so as to resemble in miniature the honey-combed limestone rock that we find around Torquay and elsewhere. In the centre of the cavity, there is another loose spongy mass of similar irregular plates. Eighteen perpendicular radiating plates extend between the marginal circle and the central mass, arranged in six threes, so as to make a six-rayed star. The order of each trine series is as follows: the middle one is the thickest and shortest, reaching scarcely more than half-way from the circumference to the centre. On each side of this there is a longer thinner plate, neither parallel nor converging towards the centre, but diverging at a small angle, so that each of these lateral plates meets the lateral plate of the next trine series, at a point considerably short of the centre, whence a plate sometimes goes to the central mass. The arrangement will be better understood by a reference to Plate XXVI, fig. 6 , which represents a quadrant of the circle, much magnified. 
The plates are all very rough, with irregular projections and erosions. They do not rise in an arched outline above the level of the margin, but the whole surface is concave. I have described and delineated what appears to be the normal arrangement, though this in fact is adhered to in different degrees of precision.

The form of the calcareous skeleton identifies this interesting addition to the British Corals with the genus Balanophyllia of Mr. Searles Wood; a fossil species of which has been found in the Crag. The royal colours in which the present species is arranged - scarlet and gold-suggest the specific name of regia. The distinctive characters of the skeleton may be thus summed up.

Balanophyllia regia.-Corallum cylindrical or subconic, fixed by a rather broad base. Four cycles of septa. Cup circular, much depressed. Plates not rising above the border ; much crenulated, and roughened with grains. Margin thin, distinct. Columella strongly developed, spongy. Epitheca investing, to the edge of the cup ; beneath which extend low ridges, close-set, rough, and geniculate.

I afterwards found the same species in considerable number, especially during the very low springs of the October new moon, among the rocks off the Tunnels, all in the vicinity of the spot where $I$ found the first. They were always in the same circumstances, crowded into colonies; one little cavity, just large enough to turn in, containing perhaps a hundred, speckling the walls with their little scarlet disks, near extreme low water. Not one that I took presented the least varia- 
tion from the characters I had jotted down already; but one specimen had adhering to its base two very young ones, one about a line in diameter, the other not more than one-third of a line. Examination with a lens revealed no difference either in form or colour between these and the adult; the condition of their skeleton is unknown, as I did not choose to destroy the infant specimens.

Plate XXVI, fig. 1 represents the Scarlet and Gold Madrepore expanded ; magnified.

Fig. 2. The same of the natural size, contracted.

3. A tentacle, greatly magnified.

4. A tentacle of Caryophyllia Smithii, for comparison.

5. Filiferous capsules.

THREAD-CAPSULES OF ACTINIA.

I have been dissecting a fine specimen of Actinia crassicornis. The interspaces of the abdominal septa I found filled with the ovigerous tubes, so-called. When examined closely these are seen to consist of a narrow ribbon, about half a line in width, convoluted and puckered in a very irregular manner, but having a tendency to form spiral turns, of a whorl, or a whorl and a half, each; the ribbon itself being nearly flat, and one of its edges being the axis of the spire. The ribbon consists of two parts; a yellowish-brown mass occupies the portion next the axis, for about threefourths of the breadth; the remaining fourth is an exterior border of pellucid substance. I placed some of the whorls under the microseope, and observed the 
external edge beset with a fringe of delicate vibratile cilia, by whose constant action not only were the floating atoms in the water hurled in a rapid and regular current along the edge, but the spires of ribbon themselves were made to swim through the water, principally with a slow gyratory motion, sufficiently perceptible even to the naked eye.

On subjecting some of the whorls to the compressorium, an immense number of yellowish granules were discharged from the brown part, while the pellncid border displayed the filiferous capsules in considerable number, pointing towards its outer edge. They are club-shaped, or almost fusiform, with one end the larger, varying from $\frac{1}{500}$ to $\frac{1}{800}$ th inch in length; the contained thread occupies a slender linear cavity, extending about two-thirds through the length, and is thence continued as a line of almost invisible tenuity. (See Plate XXVIII., fig. 17.) When the thread is forced out by pressure, it sometimes extends to $\frac{1}{50}$ or even $\frac{1}{35}$ of an inch. The basal portion of the thread, for a length about equal to that of the capsule, is zigzagged, and each angle of the zigzag is furnished with a short bristle, projecting in the direction of the joint from which it springs. There are about four or six angles, the first being removed a little from the tip of the capsule. (See fig. 19).

The capsules of the tentacles are much smaller, being from $\frac{1}{800}$ to $\frac{1}{1500}$ th inch in length, and more properly linear than any I have yet seen. (Fig. 18). I could not force the ejection of the thread.

In the ribbed coriaceous skin that surrounds the mouth, the capsules are the most developed of all, 
both in size and numbers. They are pretty uniformly about $\frac{1}{400}$ inch in length, with the linear cavity reaching more than $\frac{3}{4}$ ths of the total length. (Fig. 20.) Multitudes are scattered loosely in the mucus that is copiously discharged from the surface, and many appear to be irregularly distributed in the coriaceous tissues; but others are crowded into groups, whence the threads are projected in dense brushes, to the length of about a line, or thirty-three times that of the capsule. I observed in most of the evolutions, of which I witnessed a great many, that the filament was not projected with the rapid suddenness observed in many cases, but with comparative slowness, and by degrees; the tip being gradually lengthened, most commonly in a long spiral. In every instance that I could note the fact, the bearded part at the bottom was first projected, and was perfected before the length of the thread proceeded beyond that extent-a convincing proof that the process is one of evolution, and not of simple propulsion.

\section{THE CLUB-BFARING MEDUSA.}

\section{Thaumantias? Corynetes. (Plate XXT.)-Um-} brella about $\frac{1}{4}$ th inch in height; bell-shaped ; transparent; colourless. (Fig. 1, magnified; 2, vat. size).

Sub-umbrella, rather more than two-thirds as high as the umbrella, campanulate or sub-conical ; margined with a narrow scolloped veil. Ovaries elliptical, about the outer half of the four radiating vessels, irregularly ventricose, reaching to the marginal canal. Their substance, in one that I examined, was com- 
posed of delicate polygonal cells (fig. 7), without any developed ova.

Tentacles twenty-four, arranged in eight bundles of three each, at the points of junction of the four radiating vessels, and midway between them. One in each group is minute and rudimentary (fig. 4); the others are peculiar in form; they arise from conical bulbs set in twins close together, with a nucleus of dark red pigment in each; they are at first slender, but swell towards their termination into a thick ovate or fusiform club, surrounded by from sixteen to forty thickened rings, which are close or remote according to the degree of contraction of the tentacle. They are generally carried divergent, with a sigmoid curve.

The marginal canal carries about the same number of (visual or) auditory capsules as of tentacles; they are perfectly globular, hyaline, each with a single spherule. They are arranged three between two groups of tentacles, but not quite symmetrically. (Figs. 3 to 5 represent a group of tentacles, with their ocellated bulbs, and capsules.)

Peduncle small, ovate, with a neck, and slightly enlarged extremity; the outline seen vertically is quadrangular: it terminates in a thickened lip, puckered and obscurely four-fold. The whole is pellucid flesh-coloured, viewed by transmitted light; but in the sun's rays the basal part is of a lively yellow-green and the lips bright rose-pink. (Fig. 6.) It does not seem very mobile or extensile.

I have called this curious species Corynetes, from the resemblance of its tentacles to loaded clubs or 


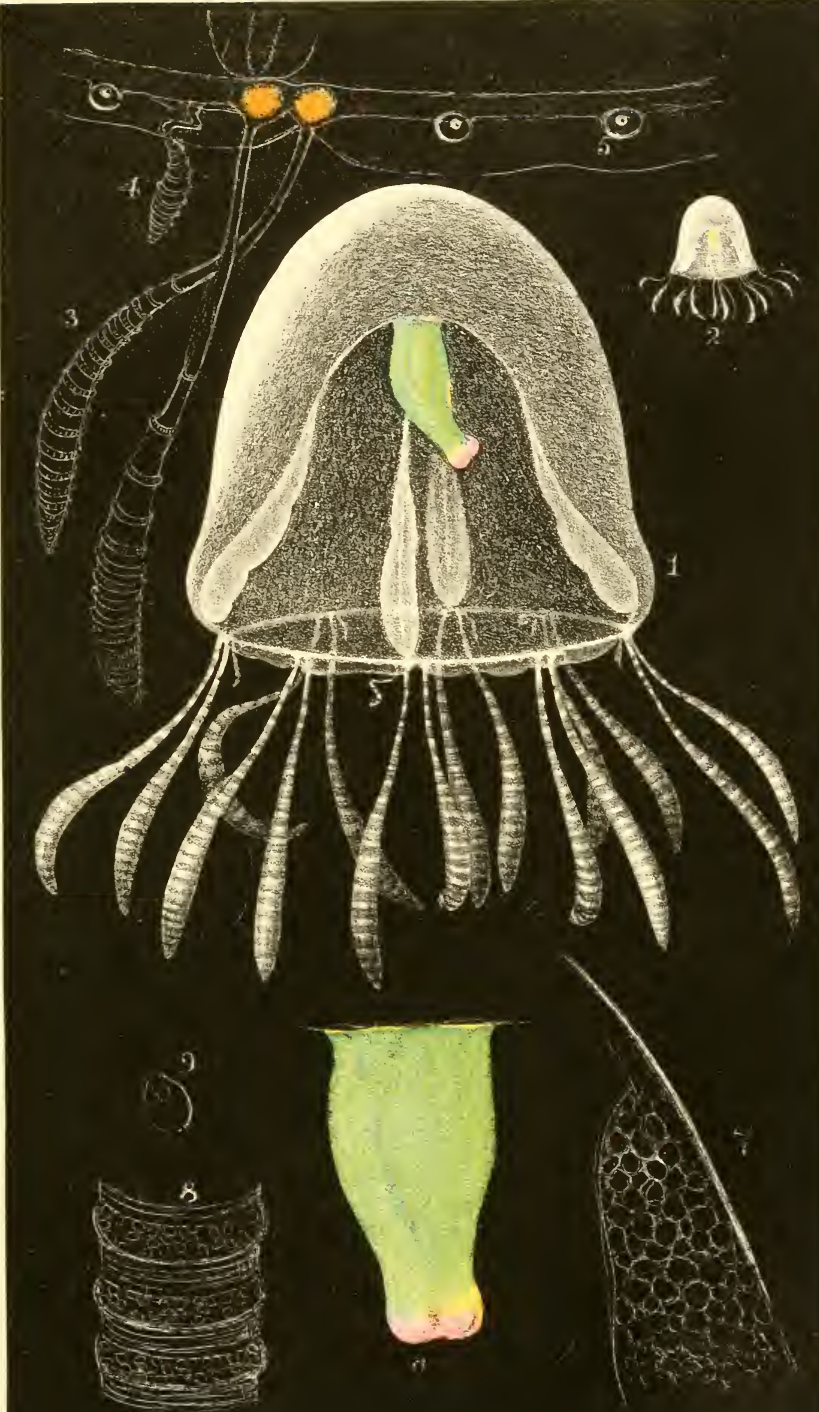



war-maces, in allusion to that hero of the Iliad who was so named,-

"For that he combated and burst his way"

Through the firm phalanx, armed with neither bow

Nor quir'ring spear, but with an iron mace."

Il. vii. 143.

Its peculiarities may perhaps warrant its separation from Thaumantias, especially the form of the peduncle, and the gathering of its tentacles into groups, which reminds us of the genus Lizzia.

I took the first specimen on the 6 th of September, by dipping at the outside of Warphouse Point, that forms the western boundary of the harbour of Ilfracombe. Its motions were lively in captivity. The thick tentacles are probably adhesive, for I had repeatedly to clear them of extraneous matter, which they dragged about with them. It orcasionally rested on the bottom of the vessel, back downward, with the tentacles lengthened to thrice the diameter of the bell, radiating in all directions, and lying on the bottom, motionless except that the terminal part of every one was continually vibrated in little jerks. It had thus a peculiar and curious appearance.

Sept. 25th.-I dipped three more at the Tumnel Rocks, one a little larger than the above, but none presenting any difference of character from it. The subsidiary tentacle in each group of three was less disproportionately small in these specimens.

The smaller Medusæ, when dipped and deposited in the collecting jar, are apt to be more or less covered with minute air-bubbles, adhering to the surface of the 
umbrella, to the interior, to the margin, to the tentacles; in short every part is sometimes studded with these little sparkling globules. This is especially the case with those dipped, as the specimens just named were, among the rocks, where the sea breaks and boils; and I suppose the air, which the waves take under in breaking, is entangled in the viscidity of their gelatinous coats. The effect is not only to hinder the examination of the animals, but will soon be fatal to them, for the air-globules act like so many floats, keeping the Medusa at the surface, and preventing its free swimming.

The best way that I know of to get rid of these pretty but annoying spangles, is to push the Meduse forcibly under water with a bit of stick or a glass rod, striking them gently when deep under the surface. Every blow dislodges some of the globules, which rise and disperse; by repeating this process you may rid the animal of its floats and enable it to swim at ease again. I do not find that the pushing about hurts them; though it frightens them a little, and causes them to pump with redoubled energy.

Oct. 6th.-I obtained several more specimens by dipping at Warphouse Point on a sunny afternoon in a heavy gale and sea, when nothing else occurred except a solitary Turris neglecta. The species appears, more than other small Medusæ, to be tolerant of rough weather.

On examining the tentacles with a high power, I find that the thickened rings are well-defined amnular swellings of the gelatinous substance, in which are imbedded the filiferous capsules, to the number of 
fifty or more in each ring, the interspaces being free from them. (Fig. 8.) The capsules are not regularly arranged. They are minute egg-shaped bodies, with a cavity of similar form towards the larger end, which I presume to contain the projectile thread. (Fig. 9.) But owing to the minuteness of the capsules, their longer diameter not exceeding $\frac{1}{1700}$ th of an inch, the plates of the compressorium would not aet upon them so as to effect the propulsion of the filament in a single instance that I could detect, even with many trials.

The secondary or small tentacles have not in general the capsules disposed in regular rings, but only a few scattered throughout, with the exception of their tips which are composed of a globose dense assemblage of these organs. A few are scattered through the substance of the peduncular stomach.

The risual organs (fig. 5) are from $\frac{1}{250}$ to $\frac{1}{300}$ th inch in diameter. They appear to be composed of gelatinous matter, with a central oval eavity about $\frac{1}{800}$ th inch in diameter, in which at one end is a globular, highly refractile, crystalline lens, about $\frac{1}{1500}$ th inch in diameter. On graduated pressure being applied, the vesicle is seen first to flatten, then the eavity; but when the plates of the compressorium act on the lens, it breaks into pieces like a crystal, and usually with a fracture that radiates from its centre. The fragments do not differ in appearance from the entire spherule. 


\section{CHAPTER XVII.}

Various Effects of Light on Scenery-Ode to Light-The Sabella -Its Tube-Its Crown of Plumes-Fatal Attack-Discovery of more Specimens-Laborious Mode of Procuring themThe Young-Reproduction of the Crown-The CorynactisA low Spring-tide-The Tunnel Rocks-Discovery of the Species-Its Form, Structure, and Colours-Manner of taking Food-Thread-Capsules-Their elaborate Structure-Propulsion of the Thread-Identification of the Species-The Purple-spotted Anemone-Its Locality and Manners-Its Form and Colours-Thread-Capsules-Nature of these OrgansSystematic List of Zoophytes-Conclusion.

\section{LIGHT.}

How much of the charm of scenery depends upon an element, which, if we have never accustomed ourselves to analyse our sensations and the causes of them, we may be apt to overlook, or at least not consciously recognise! I mean the diversity that is produced by the different degrees and combinations of light and shadow. How different the same scene looks at different times of the day, and in different states of the weather! The edge of a grove in full foliage, when looked at on a cloudy day, is not at all the same thing as when the sun-light falls slantingly on it, bringing out masses of rich bright green, and throwing intervals into black shade. There is the 
broad side of Capstone Hill visible from my window; all through the day, indeed, it is a fine object, though only a mass of brown rock with a grassy top; but sometimes, just as the sum is setting, his red rays falling full upon the precipitous side, illuminate it brilliantly, and communicate to its ample surface a rich rosy hue most beautiful to behold; but as transient as charming; for we have scarcely nttered an involuntary ejaculation of surprise, before the old dusky appearance is put on again.

The sea, again ; - how many of its changing aspects depend on the lights that fall on it! On a bright sunny day, its sparkling, glittering, ripples break up the soft blue surface with tiny rays, like a plain of sapphire inlaid with diamonds. Fleecy clouds appear in the sky, and communicate a new feature to the sea below; for their dark shadows flit along and chase each other over the surface, in patches of grey or green of various shapes and sizes.

Look upon it in a calm summer's evening. How gloriously it reflects, as from a mirror, the flood of soft lustre in the western sky, and the sun itself sinking down that glowing path, like a shield of burnished gold! Watch till the fiery King has sunk to rest, and the burning glow begins to soften and to fade. How vividly do we see repeated below-

The canopy of eve

That overhung the scene with gorgeous clouds, Decaying into gloom more beautiful

Than the sun's golden liveries which they lost.

Montgomery.

Take it in another condition. The sky is overcast 
with clouds, with breaks here and there in the grey smoky canopy. Out seaward the horizon is of a dark purplish-blue tint, then indigo, blending into a bluegreen, and this into a dull leaden hue. But there is a wide patch just beneath the place of the sun, where the rays fall through an opening in the clouds on the sea, in form like an inverted fan; the water just there is a flood of light, in which the ripples sparkle and quiver as if thousands of silvery fishes were every moment leaping up. All round, the surface presents only the dull lead-colour, rendered more obscure by the contrast of this spot of lustre. Ships and smaller craft are scattered about the distance; one and another is suddenly illuminated by one of the streams of light falling on the spot where each happens to be; her sails, which before were scarcely distinguishable from the grey sea, in a moment become beautifully white and conspicuous. Just as a Christian, on whom the light of God's countenance rests, is bright and happy, while his fellows walking in comparative darkness, remain dull and covered with clouds.

These and other examples of the potent influence of light have often recalled to my mind a poem which was given me many years ago in Newfoundland. It was from the pen of a young clergyman, a native of the island, the Rev. Joseph Clinch. I possess it in manuseript; whether it has ever been published I know not, but in my judgment the beauty of the thoughts and the elegance of the versification are worthy of perpetuity. If the gifted author still survives, he will, I trust, pardon me for enriching my pages with some of the stanzas. 


\section{ODE TO LIGHT.}

Joy of the Universe sublime :

Thy beams have lit the waves of time,

E'er sinee the Almighty's hand

With worlds unnumber'd spangled space,

And urged them on their rapid race,

A bright and glorious band.

Yet 'twas not with the splendid sun,

That thy bright being was begun;

For ever hath thy ray

Of glory canopied the Throne

of the Eternal Three in One

In one uneeasing day.

'Twas not when Night in fear beheld

A brilliant universe impell'd

Through all her wide domain,

And fled in panie from her post,

Before that grand and glittering host,

That wide and mighty train ;

It was not then thy being bright

First flash'd to view, $O$ favouring Light !

Not then commene'd thy race ;

For God is light, and Heaven would be

No Heaven, fair beam, depriv'd of thee,

No envied resting place.

When Night's dark curtains were unfurl'd, And robe-like wrapp'd the new-born world,

And, on the wrathful deep,

Slept in a dark and grim repose,

Until that mighty voice arose

Which bade thee burst their sleep ;-

How grand, how glorious, was the sight,

When thou awok'st, triumphant Light,

Upon that eurtain'd sea,-

Pour'd forth the ocean of thy rays,

And wrapp'd all Nature in the blaze

of thy divinity?

And now, although the stream of years

So long hath roll'd, thy beam appears

As fair, as pure, as bright, 
As when the joyous Ocean gave,

To meet thy smile, his first-born wave

With foaming mantle white :

Yes! now thou art as fair to view-

When o'er the morning billows blue

By zephyr gently toss'd,

Or o'er the mountain's misty side

Thou pour'st the splendour of thy tide-

Fair Light! as then thou wast.

c

Most glorious Light ! how glad thy ray

To him who treads a trackless way

Through forests wild and high :

When Night displays no planet's gleam

To eheer him with its dubious beam,

And bless his anxious eye !

Or when, upon the midnight wave, (His ressel's and his comrades' grave,)

The sailor braves the sea,

And, grasping some precarious hold,

Prays, with his wild eye heavenward roll'd,

For safety and for thee.

And glorious art thou, when thy rays

Play on the prisoner's startled gaze,

Dejected, sunk, and wan ;

When, from the dungeon and the chain,

Freedom to thee and life again

Restor'es the wretched man;

Or when upon the couch of woe

Sickness, with many a bitter throe

And dim and wakeful eye,

Counts the long night, and raptur'd sees

Thy first ray touch the dewy trees,

And gild the casement high.

THE SABELLA.

Oct. 12th.-Peeping into a little crevice of an overhanging ridge at Hele, within the fissure that leads 
up to the curious Perforated Rock, I saw a tube projecting, just beneath the surface of the water, about $1 \frac{1}{2}$ inch long. I could just get my arm into the crevice, and feel the tube with my fingers; it resembled both in consistency and appearance half-boiled macaroni. I thought it was a sponge, and tried to pull it off; unfortunately I could get only one hand in, and so could not work with the hammer and chisel. But by loosening some of the laminæ of the shale with my fingers, I managed to expose the tube for several inches lower down, and at length detached it by pulling. The lower part was membranous, of a clear reddish-brown colour, and angular. Again looking into the obscurity of the hole, for I could only look and work by turns, I saw in the now turbid water what seemed a noble white Actinia, with expanded tentacles. I now felt again with my fingers, and presently pulled away a couple of inches more of the membranous part of the tube; still it did not occur to me to connect it with the actinia-looking creature, which I could still dimly see in the muddy water.

By feeling carefully I got hold of the animal, and having worked my fingers down as close to its point of attachment as possible, I pulled it away, and put my prize into the glass-jar of clear water. $O$ what a magnificent creature! I thought, as I gazed delighted upon it, that it excelled in beauty any of the marine animals I had yet found. It proved to be a Sabella, and, as I believe, the S. vesiculosa of Montagu.

It was a large stout worm, beset along each side with little bundles of satiny bristles, closely packed in pencils, of a golden colour. There was no proper 
head, but the anterior extremity was furnished with two ample fans of many plumes, each fan having one side curled spirally inward, and the pair forming an exquisite funnel-shaped appendage, inclosing two beautiful volutes of the same. The expansion of this elegant organ was fully an inch and a half, and the length of the plumes but little less. The latter were bearded with short vanes of extreme tenuity, and reminded me of those feathers of the bird of Paradise, that are worn in ladies' head dress. Their colour was white and maronne-brown, in broad alternate bands.

This feeble description can afford scarcely any idea of the elegance of this plumous crown, which seemed as if it would have well become the head of some noble cacique, or the lord of one of those isles in the distant east which are the depositories of earth's most precious things. Well, I put my captive into my jar, and was gratified to see the crown expanded, and gracefully waving; notwithstanding that in dislodging the animal I had unfortunately torn off the hinder extremity of the body. This, however, I hoped, might be healed, and reproduced.

But a disappointment was in store. Presently afterward, I came across a pool in which several specimens of Anthea cereus were stretching their snaky tentacles like so many Medusas' heads. Wishing to show the species to a friend, I selected one, and unthinkingly dropped it into the jar which held my Sabella. The long tenacious tentacles could hardly fail to come into contact with its beautiful plumes, and I soon saw with vexation that such was the case; and that several of these organs were entangled around 
the crown and body of the worm. I did not well know what to do, but I thought the best thing was to take both out, and endeavour to pull away the tentacles of the Anthea one by one. While thus engaged, to $\mathrm{my}$ infinite chagrin, the lovely coronet suddenly came off all in a piece from the body, though pulled with the least imaginable force. To use a phrase of the ladies', "I could almost have sat down and cried." I did no such thing, however, but put body and headdress into another bottle, only, alas! to wote the sad contrast between its now shrunken form, and that which it had assumed when the life was pervading it, spreading its graceful curres, opening and closing the spires, and gently waving every delicate filament.

It has often occurred to me,-so often that I have wondered at the coincidence,- - that when I have found any thing very rare or curious that I have long vainly desired to see, I meet with others directly afterwards, though in circumstances which have no connexion with the first. It was so with respect to this Sabella. The very next day a man who keeps a little shop for the sale of shells, corals, and other specimens of natural history, took me to the cove at the back of the quay, to shew me "a sort of barnacles" that he had found there. What should these be but a colony of this very Sabella? When we arrived at the place, there, in a little hollow about as large as a washingbasin, were the tubes of some eight or nine clustered together, and protruding, apparently, from the edges of the laminæ of the shale, for there was no visible crevice.

We emptied the little basin with our hands, and 
set to work with hammer and chisel to cut out the rock around them. The hollow was breast-high in the side of a great mass of rock, so that it was easy to work at it; the shale too was fortunately very soft and friable. In about an hour we had cut away the surrounding parts to the depth of five or six inches, when the laminæ of the shale came away piecemeal, with the tubes adhering by the side to them. The membranous matter, of which the tubes are formed, and which is, I have no doubt, an exudation from the skin of the animal, was spread about upon the surface of the laminæ on each side of the adherent tube. What was particularly interesting was that some of the tubes had a family of young ones attached to them. These were of different ages, and their little slender tubes were creeping in irregular directions along the parent tube, from the thickness of a hog's bristle to that of a goose-quill. The young tubes are not straight, but bent at various angles, adherent to the parent for the greatest part of their length, but free at the anterior extremity, where a tuft of plumes protrudes. The feathery crown does not differ from that in the adult essentially, but consists of fewer plumes in the ratio of age, and these are pure white to their base. The youngest that $I$ can find, inhabiting a tube about as thick as a bristle, and half-an-inch long, has a simple brush of five or six filaments, in the form of a concave fan, the middle plumes being the longest. Another, with a tube about as thick as a stout pin, has thirteen, and one, as thick as a wheatstraw, seventeen plumes, arranged in each case in a simple funnel-like circle. 
At the time of preparing this note for the press, the Sabelle have been in captivity about four months, more than three of which have been spent in London. Some have died, but the others are still apparently in good health. No increase has taken place in the young ones, in the number of filaments in their coronets, nor, so far as I can perceive, in the dimensions of their tubes. The species is probably slow of growth and long-lived. The man who shewed me the group in the rock, had himself known them to be there for several years past, and they were as large when he first discovered them as at last.

An interesting circumstance, however, has occurred, illustrative of the faculty which the creature has of reproducing its organs. When the specimens were transferred to London, I found that the confinement in close jars had been well-nigh fatal to several. Two were disposed to desert their tubes, but I pushed them back by gentle force, and these presently recovered, though their fans were very flaccid at first. Those of two other tubes, which were attached, side by side, to the same fragment of rock, did not protrude the fans at all, and though I watched day by day, it was in vain, for these beautiful organs appeared no more, and I concluded that the animals had died.

I did not, however, remove the tubes from the vase of water, but allowed them to lie week after week upon the bottom; remarking all the time, with curiosity, yet without suspicion of the actual state of the case, that neither the tubes, nor, as far as I could see, the contents, showed any tendency to decomposition, nor did the water become offensive. 
At length, on the 4th of January, about two months after the disappearance of the animals, I was surprised to see issuing from each tube, a new fandisk, the filaments very delicate, of a translucent white, and about a quarter of an inch long, curled at their tips. Each formed a nearly flat disk, about as large as a sixpence, divided into two semi-circles, but without any appearance of the spiral volutes. There were about twenty-two filaments in each moiety: and the bases of all formed a ring apparently as large as the old neck, but this part I could not see distinctly. The disks of the two animals agreed precisely in appearance with each other.

It is manifest that each of the tenants of these tubes,-full-grown animals, - has undergone first the loss, and then the reproduction of the tentacular disk. Perhaps the accident which befel the first specimen that fell under my notice, may be one to which the species is not unexposed naturally; and hence it is a merciful provision that an organ so easily lost, yet so essential, should be replaceable. Dr. Williams, of Swansea, in his able 'Report on the British Annelida' (1852), does not notice this power in Sabella, and seems (p. 217) to doubt its existence in the whole class.

THE CORYNACTIS.

The spring tides of the new moon in the middle of October this year, were lower than I had ever seen at Ilfracombe, a circumstance the more fortunate for me that it was the last opportunity I had of exam- 
ining the shores. Large tracts of the rocks were exposed every day for a week, which I had never before been able to approach, and my searchings were rewarded with several interesting novelties. Among these was the charming little Corynactis Allmanni. (Plate VIII.)

If the visitor, standing at the mouth of either of the Tunnels, or at the margin of the Ladies' Bathing Pool, look out seaward, he will see that the rocks, which are low for some distance from the beach, rise at length into enormous angular masses, the strata of which project towards the sky in a diagonal direction from the shore. One of these masses lying far away to the right, is the Lion Rock, so conspicuous and remarkable an object in the view from Wildersmouth, and from the field-path leading to Hele, when the tide is pretty well in. The next is separated from this by a wide space of clear water; and is seen when you come close to it to be not a single solid rock, but rather a collection of masses, divided by chasms and fissures, with deep but narrow inlets running between them, strewn with boulders and gravel. It was down at the water's edge in one of these inlets, as I was intently examining the beetling sides of the lofty rock, that I looked into a shallow cavity into which the tide was washing. The rock is here more solid than usual, and the surface, bathed by the sea, has none of that ragged friable appearance that so characterises its exposed parts. The cavities and projections, though of various irregular forms, are nearly as smooth as if wrought by the sculptor's chisel. They are almost quite free from sea-weeds, at least where the outline is 
near the perpendicular ; yet they are not naked, being: encrusted with Flustre, Cellularice, Lepralice, Crisia, Sertularice, and Sponges; and the lower parts are studded with the elegant Madrepore, Caryophyllia Smithii.

The over-arching roof of the hollow in question,it cannot be called a cave,-was studded over with scores of what seemed a new Actinia, for as the tide had left them dry, they were all in a contracted state, and I had no opportunity of seeing the beautiful clubbed form of their tentacles that distinguishes the genus Corynactis. They were, however, much more tender and soft than the Actiniæ, so that, though I had no difficulty in detaching them with the point of my pocket-knife, their substance yielded so much that I feared I was destroying them; especially as under the irritation they gave out an enormous quantity of thick, tenacious white mucus, scarcely less consistent than their own substance.

They were of various colours, but all beautiful. I will describe them, however, not as I imperfectly saw them then, hanging from their native roof-tree, but as I see them now before me, some five and twenty of the finest that I selected for preservation, now comfortably established in a saucer of sea-water.

First as to form. When contracted they are com. monly little flattish warts or sub-conical buttons, much like Actiniæ; but sometimes one will greatly elongate its figure, swelling at the extremity, somewhat like a long fig. (Fig. 8.) Sometimes they are very much depressed, the surface corrugated, and the outline irregularly lobed. (Fig. 9.) 
When expanded, the margin of the disk forms a distinct crenated rim, outside the tentacles, always brilliantly coloured. This rim is everted in the most complete expansion, the tentacles spreading over it, and the disk dilated beyond the diameter of the body. But a more common state is that of a short cylinder, the rim upright, and the tentacles crowded in nearly perpendicular rows, and scarcely projecting over the edge. (Fig. 10.) The tentacles have exactly the same form and structure as in Caryophyllia Smithii, consisting of a rather short thick body tapering from the base upward, and studded with transver'sely-oblong warts, and of a large globular head, diverse in colour and surface from the body, and covered with a dense coat of short down. They are arranged in two complete marginal rows, and two incomplete and irregular discal rows. I counted them in one specimen, and found the exterior rows to contain twenty-four each, and the interior about eighteen each; making the total number eighty-four. In another there were more than one hundred, and then there were four compact rows, besides smaller scattered ones on the disk, so that I feel sure the number and arrangement of these organs form but insufficient specific characters, especially since we know that in the Actiniæ they increase with the age of the animal.

The oral disk is usually concave, the mouth, however, rising into an oblong cone. The disk is marked as usual with radiating lines. The mouth forms two projecting lips, which are strongly crenate, like the edges of a cowry-shell. 'The whole appearance of the disk, tentacles, lips, and all, is almost exactly a 
counterpart of these parts in Caryophyllia Smithii, so that we can scarcely avoid considering it a nearer approach than the Actiniæ to this Madrepore.

In taking food, such as a morsel of meat presented to it, the Corynactis does not protrude the lips to embrace it, nor close the tentacles orer it, like the Actiniæ in general; but dilates the oral orifice slowly and uniformly until the lips form a circle strongly crenated, of great width, nearly as wide indeed, as the entire disk, within which the stomach, like a broad shallow saucer, is seen, with the coils of ovarian (?) filaments lying all over its bottom and sides. Into this gaping earity the morsel is drawn, and then the lips gradually contract and embrace it, finally protruding in a pouting cone.

Now for colours. The most common hue is a pale and very delicate rose or flesh-colour, with the rim a brilliant coral-scarlet, or an equally brilliant emeraldgreen; in the latter case, the body is slightly tinged with lilac. The delicate tint of the body is lost torards the base, which is of a whitish-brown. The disk is of the same colour as the body. When the rim is scarlet, the tentacles are pure white; or rather the body is pellucid with white warts, and the globose head is also white. When the rim is green, the tentacle-warts are umber-brown, and the centre of the head is of the same hue. The size of these varieties does not exceed, so far as I have seen, a quarter of an inch in diameter at the base, about one-sixth across the disk, and about the same in height.

A larger variety, half-an-inch in width of base and in height, is of a rich sienna-brown, the rim and the 
lips brownish orange, the tentacle bodies deep umberbrown, and the globose heads pure white. This has a very fine appearance.

The filiferous capsules of this little Corynactis (See Plate XXVIII. figs. 1 to 13) are the largest that I have yet seen, being as long as those of Caryophyllia Smithii, $\left(\frac{1}{300}\right.$ th inch) and twice their diameter. They are ovate or elliptical, compressed in one aspect (fig. 13), with a little nipple at the anterior end. (Figs. 1, 12, 13). Within the cavity and almost filling it, the thread is distinctly seen, coiled round and round in a spiral more or less regular in different individuals. There is no lozenge-shaped body at the anterior end, and in correspondence with this lack, we find the thread when projected to be destitute of a brush of hairs, and to be of uniform structure throughout its length. The length of the thread is rery great; one that I measured reached to about $\frac{1}{8}$ th inch, or about thirty-seven times that of the capsule. Its thickness also is distinctly measurable, and I found it $\frac{1}{7000}$ th of an inch, equal throughout. It is marked for its entire length with diagonal lines, alternating at right angles to each other, which I presume to indicate a similar structure of imbricate plates to that observed in Caryophyllia, but set more widely apart. (See fig. 2). By delicate manipulation a series of transverse or angular striæ were visible throughout the thread, rather close together, about four or five to each alternation of the diagonal imbrications.

Such then is the structure of the larger capsules and their filaments. These are very numerous, both in the ovarian bands and in the tentacles. There was 
much diversity in the manner of the projection of the thread. In many cases, especially in such capsules as were found loose in the enveloping mucus, (liberated probably in the act of detaching the fragment for examination,) the thread was found already shot to its utmost, when presented to the microscope, before pressure was applied with the compressorium. Many under pressure projected it in a moment, and I invariably found that the imbricate structure could be made out only in such threads as were thus perfectly and suddenly expelled.

But it was quite as common for the thread to shoot out partially, and by starts, a coil or two at a time emerging ; and in this case, the projected part appeared thin and shrivelled, with no defined marks, nor even a distinct diameter. I think the cause of this imperfect transmission was always some obstruction lying in the way of the tip of the thread, sometimes overcome, but often presenting an insuperable barrier, when the capsule would remain half empty, the anterior portion of the coil having disappeared, but the posterior part remaining unchanged.

A curious proof of the projectile force employed was by accident presented to me. The tip of a thread in the act of emission came into contact with a capsule already emptied. It was stayed for an instant; but the crystalline wall of the capsule was driven inward in an indentation, and presently it yielded, and the thread forced its way in, shooting all round the interior of the oval cavity.

These capsules, and even their projected threads, are distinctly visible with a common triple pocket-lens. 


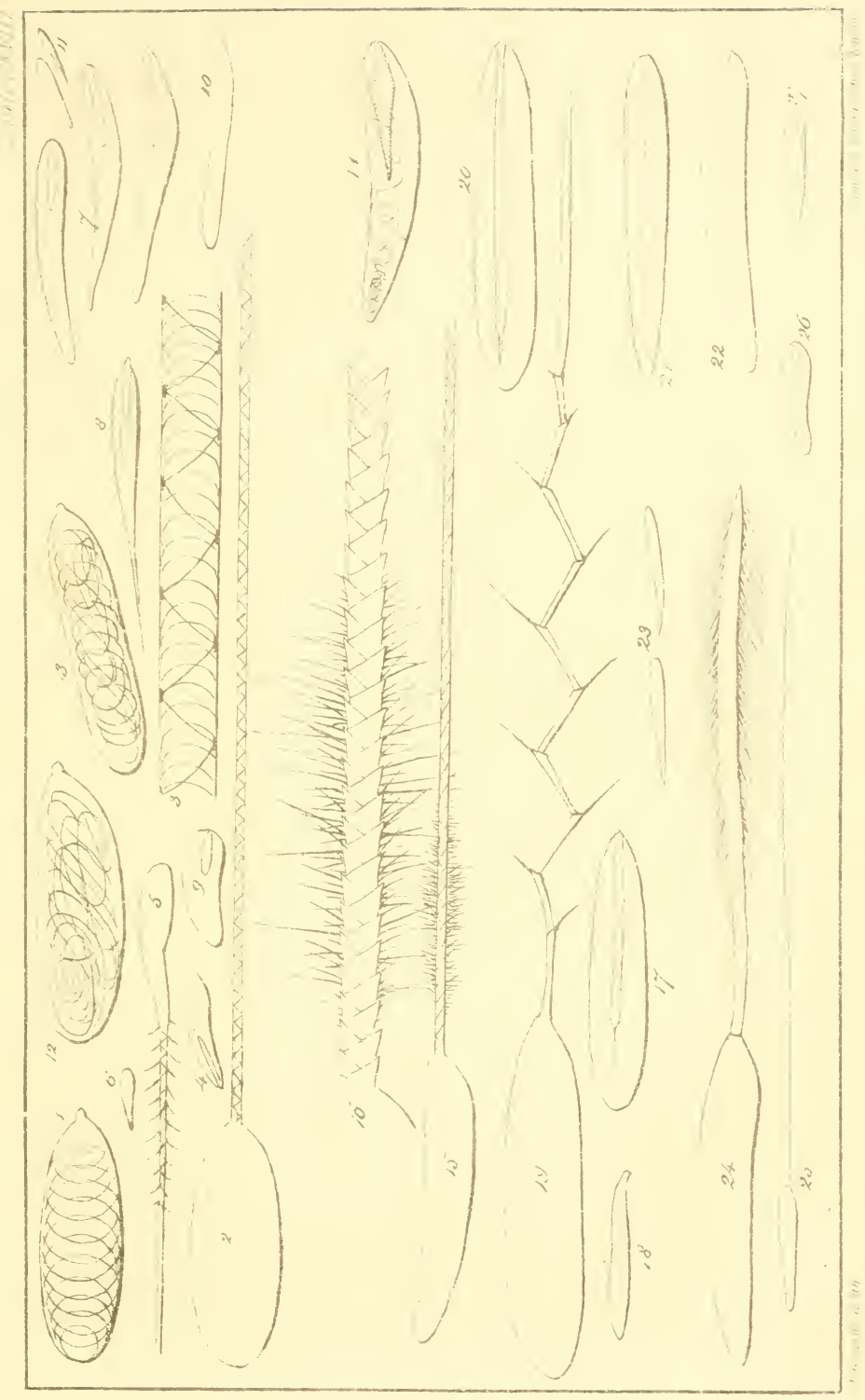



But besides these, there are other smaller capsules differing in their structure. They have the common oblong form of those of the Actinice, but attenuated at one end, which is sometimes drawn out to a needle like point, (fig. 8). Sometimes at the small (4) but more commonly at the large end $(7,9,11)$, there is a cylindrical clear body, about one-third of the length of the capsule, besides the evanescent spiral coils which occupy the remainder of the cavity.

The thread of these is furnished with a brush of divergent bristles at its base, extending up a space about equal to the length of the capsule (5); so that I have no doubt of the connection of this elongated body with the brush. 'These capsules vary much in form (figs. 7 to 11), and also in size; the largest being about $\frac{1}{600}$ inch, the smallest $\frac{1}{800}$ inch in length. Of these latter, however, I could not discover the thread, either coiled or evolved.

The specimens readily expanded their tentacles in captivity, and were not at all sensitive or impatient of irritation. They did not, however, make any attempt to affix themselves by their adliering bases, but remained loose at the bottom of the ressel.

I feel no doubt that they are identical with the Corynactis Allmanni of Mr. Thompson, described and figured in Dr. Johnston's Brit. Zooph. (2nd Edit.) p. 474. His single specimen differed in some minute details of colouring from all mine, but in so variable a species this is of no consequence. None of mine have any adventitious covering, except that the base was surrounded by a dense mucus, in which mud had become entangled. This mucus is thrown off, I 
believe, by all Actiniæ, A. gemmacea in particular, round which it often hangs like a loose annular rest.

Whether, however, there is any specific difference between it and C. viridis of Prof. Allman, I have strong doubts. I should not hesitate to say there is none, but for Prof. Allman's personal opinion on the specimen submitted to him by Mr. Thompson, and for Mr. Peach's figure published by Dr. Johnston (Brit. Zooph. p. 35) in which all the tentacles have bi-globose heads.

THE PURPLE-SPOTTED ANEMONE.

A little Actinia, which though it does not present all the recorded characters of $A$. alba of Mr. Cocks, I was at first disposed to refer to that species, occurred to my explorings during the rery low spring-tide of October 16th, in two localities. Both were on the surface of rocks near the extreme low-water; the one was an overhanging, the other a perpendicular surface. In both cases the animals were social; in the one case I found three individuals associated, in the other many dozens, a large colony thronging the sides of a narrow fissure or chasm, just wide enough to get into, that runs far up the rock at the seaward base of Capstone Hill. Even here many of the specimens were hanging from beneath the little points and projecting ledges.

Its consistency is very soft and yielding, somerrhat resembling, in this respect, another social Anemone, that I had found in similar circumstances the day before, Corynactis Allmanni. It is easily detached, 
as it does not inhabit holes or crerices; nor is its body indued with gravel, or any extraneous substances. When put into a vessel of water it rery readily expands its large conical tentacles, and dilates its disk to the utmost; and though, on being touched, it will partially contract, it unfolds the instant the annoyance ceases, and is presently full-blown again.

None of the specimens that I saw exceeded about half-an-inch in height, and the same in expanse. There is scarcely any variation in their colouring. They are ribbed longitudinally with many opaque white lines and bands, differing in breadth, that traverse the ribs; these lines are separated by interspaces, always narrow, of pale, semi-pellucid brown or drab. The margin is sometimes slightly tinged with reddishbrown. The oral disk is opaque-white, marked with five pellucid radiating lines. The mouth and lips are also pure white. The tentacles are arranged in three or four irregular rows, and are graduated in size, those at the interior row being much the largest, and the exterior ones the smallest. They are all opaque snowy-white, without the least appearance of bars or rings, except that the rery base of each is encircled with a narrow ring of dark purplish-red or brown, which passes off in a line behind the tentacle. Sometimes this ring is obsolete, except around the base of the twelve largest tentacles that form the innermost circle, where I think it is nerer wanting. The lips are capable of being inflated and protruded to an immense extent.

None of my specimens hare any rellow spots on the lips, nor the least trace of the minute tubercles 
which Mr. Cocks speaks of, as surrounding the margin of his $A$. alba in three rows. Hence, considering also the well-marked dark ring embracing the tentaclebases, I am inclined to doubt whether the present may not be an undescribed species. Should it prove such, I would propose for it the name of Actinia candida.

Plate VIII, fig. 11 represents this species of the natural size, contracted; fig. 12, the same, magnified; fig. 13, with the disk expanded.

The (so-called) ovarian filaments are protruded from the pores in various parts of the body with great readiness by this species on the slightest irritation. They are slender, white, and highly ciliated, so as to move freely with apparent spontaneity. On being subjected to pressure, they were found to contain a number of filiferous capsules quite amazing; I should think it by no means a hyperbole to presume that many millions of these offensive weapons are wielded by one Actinia. As usual, they exhibit different models of structure, and different sizes. (See Plate XXVIII., figs. 21 to $2 \pi$.)

The largest are longo-elliptical, or oblong, slightly enlarged towards one end; $\frac{1}{450}$ th inch in length, and $\frac{1}{3600}$ th in width; a linear cylindrical body passes down through the centre, which seems to pervade the whole length, but becomes evanescent towards the posterior end. (Figs. 21, 22.) The thread when propelled is quite unique; it is not more than $1 \frac{1}{2}$ times as long as the capsule; and is armed, except at the basal third, with a dense brush of bristles, pointing in a reverse direction, and thus constituting so many barbs. (Fig. 
24.) I had noticed that the tentacles of this species were more than usually tenacious: whether this quality may be owing to the barbed armature of the filiferous capsules, I will not certainly say, but I think it not unlikely.

The small capsules are of a similar shape (fig. 23), but are not more than $\frac{1}{1200}$ th inch in length; and they propel a thread, which, with the microscopic power that I use, appears simple, to the length of $\frac{1}{200}$ th inch, or six-times that of the capsule. (Fig. 25.)

The tentacles do not, so far as I have seen, contain any large capsules; nor are the small ones present in extraordinary number. The larger, $\frac{1}{1200}$ th in. long, are long-oval, a little curved, and permeated by a clear, cylindrical body throughout their centre. (Fig. 26.) The smaller are more linear, $\frac{1}{1500}$ th jnch in length, with a central evanescent line, that appeared zigzagged, or perhaps spiral (fig. 27); but the minuteness here precluded a satisfactory resolution. The same reason, probably, prevented my seeing the structure of the emitted thread; but the similarity of appearance between the central column of the larger tentacular capsules, and that of the larger ovarian capsules, suggests a similarity of structure also.

I cannot help thinking, from facts already recorded in these pages, that the filaments which are so freely shot forth by most Actinia from pores scattered over their whole surface, are neither seminal nor ovarian ducts, but offensive weapons. In all cases in which I have examined them, they are filied more or less densely with filiferous capsules, and those the most elaborately armed. Why should seminal or 
ovigerous ducts be shot forth by the animal at various points when irritated?

THE following is a List of the Zoophytes that I have found during the present season (from May to October inclusive) in the neighbourhood of Ilfracombe. It may be useful as a guide to other naturalists who may hereafter visit the place.

Clava multicornis.-Near Watermouth.

Coryne ramosa.-Tunnel Rocks, \&c.

sessilis.-Capstone base.

Cerberus.-Capstone.

stauridia.-Ilfracombe.

Sertularia rosacea.-Wildersmouth Beach (dead).

argentea.-Wildersmouth Beach (dead).

abietina.-On Oysters from Lee.

pumila.-Smallmouth. On Corallina offic.

Plumulariasetacea.-Tunnel Rocks; Santon Rocks.

pinnata.-Smallmouth.

cristata.-Capstone.

Antenmularia antennina.-Hele; on a Crab.

Laomedea gelatinosa.--In a rock-pool at Capstone base.

geniculata.-Tunnel Rocks; on Tangle.

obliqua.-Tunnel Rocks, extreme low-water.

Campamularia volubilis.-Santon; Smallmouth.

Alcyonium digitatum.-Tunnel Rocks.

Caryophyllia Smithii.-Tunnel Rocks; Smallmouth ; extreme low-tide.

Balanophyllia regia.-Tunnel Rocks; extreme low-tide. 
Corynactis Allmanni.-Tunnel Rocks; extreme low-tide.

Actinia mesembryanthemum.-Wildersmouth.

candida.-Fissure at Capstone base.

anguicoma.-Smallmouth.

gemmacea.-Wildersmouth; Smallmouth ; Tunnel.

crassicornis.-Wildersmouth; Tunnel; Hele. bellis.-Capstone base; Tunnel.

nivea.-Wildersmouth.

Anthea cereus.-Tunnel; Compass Hill ; Hele. Tubulipora Aabellaris.-Rock-pool at Hele, on Alga.

Crisidia cornuta.-Hele; on Delesseria sang. Crisia denticulata.-Hele; on Alga.

geniculata.-Tunnel Rocks; roots of Tangle.

eburnea.-Tunnel Rocks; Hele.

aculeata.-Capstone; in a rock-pool.

Eucratea chelata.-Capstone base; Hele.

Anguinaria spatulata.-Tunnel; Hele; on Alge. Lepralia spinifera.-Tunnel; on roots of Tangle.

coccinea.-Capstone base.

Membranipora pilosa.-Everywhere; on Alga.

Cellularia avicularia.-Capstone; in a rock-pool.

ciliata.-Tunnel Rocks; Watermouth.

reptans.-Wildersmouth Beach (dead).

Hookeri.-Smallmouth.

Flustra foliacea.-Wildersmouth Beach (dead).

chartacea.-Tunnel Rocks; very low tide.

Alcyonidium hispidum.-Lee; in caverns.

Cycloum papillosum.-Tunnel.

Beania mirabilis.-Capstone; in rock-pool. 
Valkeria cuscuta.-Hele; on small Alga. pustulosa.-Barricane; in a deep pool.

Bowerbankia densa.-Wildersmouth; on a small Alya.

Pedicellina eckinata.-Smallmouth.

Belyica.-Tunnel; Hele; on Alga, and on rocks.

gracilis.--Capstone; on Corallines.

AND here ends the record of a delightful season spent on the Coast of Devon. I suppose it would be quite superfluous to assure my readers that it was delightful, that the whole of the nine months, ill health notwithstanding, was one continuous, unflagging holiday. I wish that the perusal of these pages may awaken in any, even a few, of my readers, a relish for similar pursuits, and induce them to drink of this ever flowing stream of pure water.

It has indeed been delightful to read page after page of God's book of nature ; and though I am conscious that the study has not been, so much as it might, a pathway to Himself, yet the impress on all of His hand, who is our Father and our Saviour, has added a keener edge to the enjoyment. It is sweet (to use the words of a dear friend,) to feel no stranger to the great Architect, to feel the friendship of a blood-redeemed and reconciled sinner with that glorious Being, the Maker and Sustainer of all things; to be able to come into his presence, to speak to Him, to anticipate a yet far deeper acquaintance with Him, 
to know that "this God is our God for ever and ever!" Blessed revelation! that has opened such springs of sweet and lasting joy in the wilderness of a sinner's heart!

"If music, with its mysteries of sound,

Gires to the human heart a hearenward feeling ;

The beauty and the grandeur which are found

Wrapping in lustre this fair earth around,

Creation's wondrous harmonies revealing,

And to the soul in truth's strong tongue appealing,

With all the magic of those secret powers,

Which, mingling with the lovely band of light,

The sun in constant undulation showers

To mould the crystals, and to shape the flowers,

Or give to matter the immortal might

Of an embracing soul-should, from this sod,

Exalt our aspirations all to God."*

"For of HIM, AND THROUGH HIM, AND TO HIM ARE ALL THINGS; TO WhOM BE GLORY FOR EVER. AMEN."

\footnotetext{
*Hunt's "Poetry of Science," 162.
} 



\section{A P P E N D IX.}

Marine Viraria. (See p. 228, et seq.) Since the former note was written in September last, on the keeping of marine animals alive in unchanged Sea-water, I have continued the prosecution of experiments on the same subject, with the most gratifying results. Actiniæ of different species and other interesting animals, brought by me from Deronshire, are now living in the highest health in London, some of which have been in confinement nearly eleren months.

The following facts may be considered as established. Marine animals and plants may be kept in health in glass vases of sea-water for a period of greater or less length according to circumstances, provided they be exposed to the influence of light. The oxygen given off by healthy vegetation under this stimulus, is sufficient for the support of a moderate amount of animal life; and this amount can be readily ascertained by experiment.

But another element in the question soon obtrudes itself. The Actiniæ and other animals habitually throw off a mucous epidermis, and other excretions, which fall to the bottom of the vessel, or accumulate around them. The process of natural decay also continually goes on in the older fronds of the Algæ. Here then there is a continually increasing deposit of organized matter in a state of decomposition; and after a while the presence of this substance becomes too manifest in the offensive odour 
which proceeds from the water, especially when it is disturbed, and in the feebleness, disease, and final death of the animals.

In this difficulty chemistry came to my aid. Professor Schonbein had proved that phosphorus possesses the curious property of causing water and hydrogen to unite so as to form a new compound, the peroxide of oxygen, which he calls ozone; and that ozone then immediately re-acts upon the phosphorus, and oxidates it, producing the peculiar light called phosphorescence. In like manner he had suggested that the luminosity of the sea is dependent on the particles of organic matter being brought into contact with the atmosphere. The phosphorus of this organic matter causes the union of the atmospheric oxygen with the water so as to form ozone, which immediately oxidates and destroys it.

What then is necessary but the presentation of the water, so charged with organic matter, to the atmosphere in a minutely divided state? This I did, and found the objectionable qualities of the water at once removed, and my difficulties vanished. I even took sea-water, containing animal matter in suspension, so putrescent as to be highly offensive, and after passing it through the air in a slender stream a few times successively, the water was restored to purity.

Another advantage is secured by the same process, viz. the aeration of the water. For though the requisite oxygen may be supplied by the agency of the plants alone, the mechanical admixture of the atmospheric air with the water by artificial aeration is highly conducive to the health and comfort of the animals, as is evident from their vigour and increased action under its stimulus.

Should any of my readers wish to see these experiments in operation, or to cultivate a personal acquaintance with many of the individual specimens whose history has been 
recorded in the preceding pages, they may do both by visiting the Zoological Gardens in the Regent's Park. The able and zealous Secretary, D. W. Mitchell, Esq., has already set up one large glass tank, filled with sea-water, (the purity of which is maintained in the manner I have just described,) and stocked with marine plants and animals so as to resemble one of those charming tide-pools, so often mentioned in these pages, with the adrantage of having its sides formed of plate-glass, and its whole contents therefore clearly visible. There the visitor may see the Sabelle, the Actinia of brilliant hues and many kinds, Mollusca both shelled and naked, Crustacea, and Annellida, all pursuing their various avocations and enjoying themselves without restraint, under circumstances scarcely distinguishable from those of nature. All who have seen this aquarium concur in considering it a most attractive exhibition; and it is fairly anticipated that when seven other tanks of equal dimensions are added to the one already stocked, each containing some of the numerous tribes of marine creatures (a result which we hope to accomplish in the course of a few months), the whole will form one of the most unique and interesting features of these beautiful Gardens.

But my attention has been directed to the realization of such a desideratum as I have before mentioned (See p. 234, ante) a Marine Aquarium for the Parlour or Conservatory. An apparatus for this purpose has been for some time in the manufacturer's hands; and though there are some minor difficulties attendant on the mechanical part of the execution, they are not such as to throw any material doubt on my confident expectation, that in a short time an elegant vase stocked with algæ and sea-anemones, and comprising within itself the elements of its constant selfpurification, will be before the world. 



\section{GENERAL INDEX.}

Acorn Shells, $23 ; 206$.

Equorea, (glassy), $340 ; 345$.

(Forbesian), 343; described, 345 ; luminosity of, 346. (Forskal's), 347.

Anemone, (Smooth) ; $9 ; 10$; poetical allusions to, $11 ; 17$.

(Purple-spotted), 430 ; described, 431.

(Daisy), 24; 25; difficulty of procuring, 26 ; change of its form, 27 : description of, 27 ; varieties of, 31 ; habits of, 32 ; 55 ; structure of, 32 .

(Thick-horned), 34 ; probably identical with $A$.coriacea, 36 ; habits of, 38 ; cooked and eaten, 150.

(Rosy), 90.

(Snowy-disked), 93 ; habits of, 95.

(Snake-locked), 96 .

(Gemmaceous), 108 ; described, 168 ; young of, 170.

Animals, On keeping in unchanged sea-water, $228 ; 439$.

Animalcules, luminous, 253 ; parasitic, 260 ; 291 ; 359 ; 367 .

Annelida, $10 ; 94 ; 172 ; 275 ; 391$.

Anstey's Cove, 70 ; animals of, 71.

Anthea described, 15; habits of, 17 ; white variety, 18; table qualities of, 153 ; stinging powers, 267 ; power of retraction, 268 ; thread-capsules, 268.

Antiopa, crested, 325 ; spawn of, 326.

Aquarium, marine, $229 ; 439$.

Ascidia, a transparent ; 241 ; larva of, 322.

Babbicombe, 5 ; 11 ; prospect from, 68 .

Barricane, visit to, 322 ; shell-beach of, 323.

Bathing-pool, 344 ; 397.

Beach, process of its formation, 266.

Beania, $205 ; 225$. 
Birds, songs of, $45 ; 69 ; 107$.

Bloody-field, 327.

Boulders, barren of animals, 9 .

Bowerbankia, 205.

Braunton, fertility of, 281 ; legend of, 281.

Bristle-tail, 389.

Burrows, 283 ; botany of, 285 ; animals of, 286.

Brixham, visit to, 44 ; appearance of, 46 ; its natural history, 47 .

Brittlestars, 56 ; 206.

Campanularia, structure of, 297; egg-vesicles, 298; medusoid, 299.

Caprella ; $82 ; 379$.

Capstone Hill, 102 ; 129 ; description of, 159 ; prospects from, 162 ;

164 ; spout-holes, 320.

Care of God over his creatures, $67 ; 144 ; 201 ; 207 ; 302$.

Carn-top, 279 ; legend of, 279.

Caverns, $293 ; 294 ; 397$.

Cellularia, (ciliated) cells of, 144 ; bird's heads of, 146 . (bird's head), 195; cells of, 198; polype of, $199 ; 204$.

Chondrus, iridescence of, $188 ; 382$.

Chrysaora, 364 ; eye-prisms of, 366 ; parasites of, 367 ; light of, 368 ; beauty of, 368 ; mode of taking prey, 369 ; of ovipositing, 373 ; eggs, 374 ; thread-capsules, 376 .

Circulation, in Alcyonium, 80 ; in Laomedea, 149 ; in Tunicate Mollusca, 240.

Clava, 206.

Compass-hill Bay, 393; legend of, 394.

Coralline, 204 ; white light of, 226.

Corynactis, 423 ; its locality, 423 ; varieties of, 424 ; structure of, 424 ; mode of feeding, 426; colours, 426 ; threadcapsules, 427 ; habits of, 429 .

Coryne (branching), 190 ; generation of, 194.

- (sessile), 208.

(three-headed), 222.

(slender) 257 ; tentacles of, 259.

Crab, habits of, 174 .

Crewkhorne Cave, 397 ; legend of, 397.

Crisia, 205.

Cycloum, 157 .

Dead-man's fingers, 76 ; 94 ; beauty of its polypes, 77 ; structure of, 79 ; circulation in, 80 ; spiculæ, 81 . 
Devonshire, claims of, 2 ; beauty of its scenery, 3; 104; lanes of, $4 ; 305$; rocks of, $107 ; 307 ; 329$; 396 ; wells of, 306 .

Disaster, a fatal, $166 ; 395$.

Doris, $12 ; 62 ; 71$; habits of, $13 ; 59$; spawn of, 14 .

Doto, 83.

Economy in Nature, 202.

Eolis coronata, 12.

- despecta, 82 .

- papillosa, 12; voracity of, 16.

- exigua, 83 .

Epitaph, curious, 282.

Eucratea, its mode of growth, 133; 141 ; structure of, 134 ; analogy with Rotifera, 139 ; ciliary action, 139.

Exploit, a gallant, 309.

Feather-star, 56 ; its habits, 57.

Fishing, Mode of, 106.

Flowers, $104 ; 107 ; 172 ; 263 ; 270 ; 280 ; 284 ; 292 ; 327 ; 339$;

Flustra, fleshy, 276.

Galathea, 71.

Glory of God in Creation, 248 ; 354.

Grantia, 235.

(ciliated) 238.

Hangman Hill, 265; legend of, 272.

Hele, $104 ; 130$; legend of, 130 ; pools of, 141.

Hillsborough, 129; etymology of, 261; described, 262; fall of, 266.

Hockey Lane, 104.

Ilfracombe, beauty of, 101; View of, 128; 129; Tunnels of, 397 ; Zoophytes found at, 434; Farewell tc, 436.

Jackdaws, 8 ; 105.

Johnstonella, 356 .

Kestrel, 8 ; 310 .

Landslips, $266 ; 293$.

Langley Open, 271.

Laomedea, (angled), 82 ; medusoids of, 84 ; mode of growth, 84 ; 89 ; luminosity, 252.

(slimy), 148 ; circulation in, 149 ; polype of, 149.

Lee, beauty of, 176 ; 273 ; in a shower, 304 .

Legends, $46 ; 130 ; 166 ; 272 ; 279 ; 281 ; 308 ; 327 ; 340 ; 394 ; 397$.

Lepralia, 204 ; metamorphosis of, 218. 
Light, influence of upon colour, 42 ; produced by animals, 250 ; 253 ; various effects of, 412 ; ode to, 415.

Lime Light, 226.

Limestone, honey-combed, 23.

Lion Rock, 130 ; 155 ; 423.

Lobster's Horn, 313 ; secondary cells, 314 ; generation of, 315 ; derelopment of stem, 316.

Madrepore (Smith's), locality of, 103; 108; 127 ; 132 ; skeleton of, 110 ; resemblance to Actinia, 112; the fleshy structure, 113 ; beauty of, 113 ; tentacles of, 114 ; 116 ; ciliary action, 115 ; mode of feeding, 117 ; reproduction of parts, 120 ; the frilled bands, 121 ; thread-capsules, 123 ; aggregated specimens, 127.

(Scarlet and gold), 399 ; locality of, $400 ; 404$; beauty of, 400 ; characters, 401 ; 404 ; skeleton, 403 ; threadcapsules, 402.

Marychurch, visited, 3 ; farewell to, 100.

Medusæ, mode of procuring, 332 ; 349 ; luminous, $335 ; 346$.

- structure of, 335 ; 341 ; 364 ; generation of, 353 ; 368 .

Ruby, 348; motions of, 351 ; habits of ; 369 ; 409 ; disease of, 409.

Fairy's cap, 387.

Medusoids of Polypes, 84 ; 299 ; 331.

Microscope, difficulties of, 184; charrns of, 197.

Morte Stone, 308. -village, 309 ; legend of, 309.

Oceania, tiny, 384 .

Oddicombe, $6 ; 21 ; 54$.

Pedicellina, (Belgian), 158; 205; 210 ; structure of, 210 ; generation of, 213.

(spined), 217.

Pelagia, white, 378. (slender), 217.

Petit Tor, prospect from, 5 ; cove of, 7 ; the promontory, $21 ; 33$.

Pholas, habits of, 62 ; respiration of, 63 ; siphonal tubes, 64 ; their tentacular extremities, 65 .

Pipe-fish, described 179; habits of, 180 ; disease of, 183.

Pleurobranchus, described, 71 ; habits of, 73 ; shell, 75 .

Plumularia, (crested), 82.

(bristle) 311 ; generation of, 311. 
Plumularia (feather) 287; generation of 288.

Polycera, 13; 222.

Polynoe, 391 ; weapons of, 392.

Pomeroy family, legends of, 46.

Pools in rocks, $6 ; 10 ; 24 ; 34 ; 39 ; 54 ; 93 ; 141 ; 187 ; 324$; $330 ; 423$.

Prawn, habits of, 39 ; its beauty of colour, 41 ; changes, 42.

Prospects, $5 ; 105 ; 162 ; 264$.

Purpura, 60 ; experiments with its dye, 61.

Rapparee Cove, 338 ; legend of, 340.

Respiration in Mollusca, $63 ; 240$.

Rock of Death, 308.

Rockham Bay, 306.

Sabella, beauty of, 417 ; mode of procuring, 419 ; reproduction of the crown, 421.

Samson's Cave, 293 ; 333.

Sand-worm, 171 ; dye of, 173.

Saxicava. its boring powers, 23 ; its habits, 47 ; 93.

Scallop Painted, beauty of, 47 ; the mantle, 48 ; eyes, 49,52 ; spins a thread, 50 ; the foot, 50 ; manner of leaping, 50 ; structure of the gills, 53 .

Score Valley, 280.

Sea spider, 171 .

Sea-weeds, $24 ; 39 ; 55 ; 71 ; 94 ; 142 ; 188 ; 189 ; 204 ; 230$; $324 ; 330$.

Sea-worm, honeycomb, $275 ; 284$.

Serpula, $11 ; 63$.

Shipwrecks, $131 ; 274 ; 308 ; 340$.

Shrimp (Medusa), 367; metamorphosis of, 368. - (Mantis), 379; its weapons, 379 ; its habits, 380. (Caddis), 382.

Shore, charm of, 154.

Smallmouth, Caves at, 294; animals of, 103, 296.

Snake-head, 142; 205 ; cells of, 142 ; their door and hinge, 143.

Sponges, $9 ; 94 ; 204$; crystals of, $234 ; 238 ; 276$.

Spring, charm of, $68 ; 103$.

Squirrel, 22.

Stone, a populous, 202.

Stone-turning, a productive occupation, 178.

Sunset, glories of, 161; 413.

Syrinx, (Harvey's), 157. 
Thaumantias (hairy), $334 ; 344$. (Busk's), 385.

(Club-bearing), 407.

Thread-capsules, of Act. bellis, 32 ; of A. anguicoma, 99 ; of Caryophyllia, 123 ; of Anthea, 268. -suggestions respecting, 33 ; 124 ; phenomena of, $123 ; 360 ; 407 ; 428$. elaborate structure of, $125 ; 406 ; 427 ; 429$. evolution of, 126, 407 . of Medusæ, 351 ; $360 ; 376 ; 410$. of Balanophyllia, 402 ; of Act. crassicornis, 405. of Corynactis, 427 ; of Act. candida, 432.

Tor Abbey, 62.

Torr Point, 328 ; 399.

Torrs, 327 ; 397.

Tracy, Tomb of, 310 ; legend of, 397 .

Trochus, 47 ; 62 .

Tubulipora, 227.

Tunnel Rocks, 396 ; 423.

Turris, Ruby, 348 ; generation of, 349 ; 353 ; thread-capsules, 351 ; beauty of, 354 .

Vivaria, marine, 228.

Walk, Summer morning, 269.

Watcombe, wild scenery of, 58.

Watermouth, $105 ; 172$.

White-pebble Bay, 329.

Wildersmouth, $129 ; 155 ; 160 ; 162$; described, 165 .

Willsia, 359 ; parasite of, 359.

Woodlouse, 390 .

Woollacombe Sands, in a shower, 310 . 


\section{SYSTEMATIC INDEX.}

VERTEBRATA.

Mugil chelo, 106.

Blennius, 56.

Clupea alba, 369.

Syngnathus lumbriciformis, 178.

\section{MOLLUSCA.}

Doris tuberculata, $13,14,59,71$. bilamellata, $12,13,62,83$, 232.

pilosa, 62 .

Johnstoni, 71.

Polycera ocellata, 12, 13.

Doto coronata, 83.

Eolis papillosa, 12, 16.

- coronata, 12.

- despecta, 82 .

- exigua, 82 .

Antiopa cristata, 325.

Pleurobranchus plumula, 71.

Patella vulgata, 23, 276.

Purpura lapillus, 60.

Trochus cinerarius, 119. ziziphinus, $47,62,71$.

Littorina littorea, 23.

Cypræa Europæa, 71.

Pecten opercularis, 47, 71. distortus, 71.

Anomia, 71.

Mytilus edulis, 10.

Saxicava rugosa, 23, 47, 65, 93.

Pholas dactylus, 62, 63 .

Botryllus, 71 .

$$
\text { parva, 62, } 65 .
$$

Perophora Listeri, 241.
Amaroucium proliferum, 322.

Balanus, 23.

\section{ANNELLIDA.}

Serpula, 11, 63, 71, 233.

Sabella vesiculosa, 416 .

Sabellaria alveolata, 275, 284.

Arenicola branchialis (?) 172 .

Polynoe cirrata, $71,391$. -impar, 391.

Phyllodoce lamelligera, 10, 232.

Hirudo (?) 359.

Johnstonella Catharina, 356.

\section{CRUSTACEA.}

Cancer pagurus, 174.

Maia squinado, 311.

Galathea rugosa, 71 .

$$
\text { strigosa, } 71 \text {. }
$$

Palæmon serratus, 39.

Hyperia medusarum, 367.

Cerapus Whitei, 382.

Caprella, 82, 379.

Ligia oceanica, 390.

Phoxichilus, 171.

\section{INSECTA。}

Machilis maritima, 389 .

Eristalis tenax, 390 .

$$
\text { POLYZOA. }
$$

Tubulipora flabellaris, 227.

Crisidia cornuta, 435 . 
Crisia denticulata, 232.

- geniculata, 435 . eburnea, 435 . aculeata, 205.

Eucratea chelata, 132, 206, 226.

Anguinaria spatulata, 142, 205, 216.

Lepralia spinifera (?) 204. cocinea, 218.

Membranipora pilosa, 222, 232.

Cellularia avicularia, 195, 204, 226.

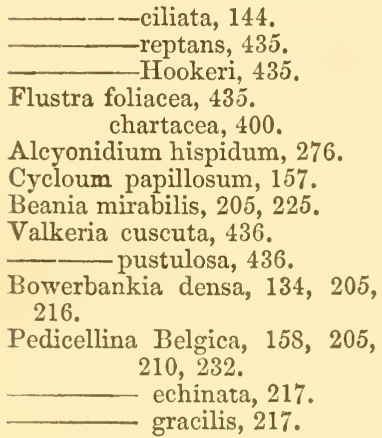

ECHINODERMATA.

Comatula rosacea, 56.

Ophiocoma neglecta, 56. rosula, 71 . minuta, 207.

Asterina gibbosa, 62 .

Echinus esculentus, 71.

Syrinx Harveii, 157.

ACALEPHA。

Chrysaora cyclonota, 364 .

Pelagia — ? 378.

Willsia stellata, 359 .

Turris neglecta, 348,410 .

Saphenia Titania, 387.

Oceania pusilla, 384 .

Equorea vitrina, 340, 345 .

Thaumantias pilosella, 334, 344, 359 .
Thaumantias Buskiana, 385.

- (?) Corynetes, 407 .

Noctiluca miliaris, 253.

\section{ZOOPHYTA.}

Clava multicornis, 206.

Coryne ramosa, 190, 232. - sessilis, 206, 208.

Cerberus, 222, 259. stauridia, 257.

Sertularia rosacea, 226.

—_- argentea, 434. abietina, 434 . pumila, 434 .

Plumularia setacea, 143, 311.

- pinnata, 287.

379.

Antennularia antennina, 311,

313.

Laomedea gelatinosa, 148.

84, 252, 290. geniculata, 39,82 , obliqua, 434.

Campanularia volubilis, 296. Alcyonium digitatum, 76,94 . Caryophyllia Smithii, 103, 108, $132,226,296,400,405,421$, 427.

Balanophyllia regia, 399 .

Corynactis Allmanni, 423, 430.

Actinia mesembryanthemum, 9 , 10, 24, 232 .

candida, 430 .

anguicoma, 96, 120, 232.

168, 284.

- crassicornis, $16,34,59$, $92,150,405$.

232. nivea, 93, 232 .

rosea, 90,232 .

alba, 71 .

Anthea cereus, 15, 62, 120, 153, $232,267,330,418$.

PORIFERA.

Pachymatisma Johnstonia, 9. 
Halichondria panicea, 276. -celata, 204. sanguinea, 204, 276.

Grantia botryoides, 234. ciliata, 238. nivea, 233.

\section{ALGE.}

Halidrys siliquosa, 330 .

Fucus, 10, 55, 230,

Laminaria digitata, 39, 82, 89, $93,230,252,330$.

$$
55,330 \text {. }
$$

Taonia atomaria, 325 .

Cladostephus verticillatus, 324 .

Polysiphonia, 188.

Dasya arbuscula, 132, 188.

Laurencia pinnatifida, 25.

Chylocladia articulata, 25.
Corallina officinalis, $10,54,188$, $204,226$.

Delesseria sanguinea, 39, 71, 94, 188, 230, 232.

hypoglossum, 142.

Plocamium coccineum, 24.

Rhodymenia ciliata, 25.

- ${ }_{\text {jubata, } 232,330 .}$ palmata, $10 ; 55$,

188. palmetta, 24.

Chondrus crispus, $55,188,230$, $232,382$.

Iridæa edulis, 39, 71, 94, 230.

Ptilota sericea, 188, 189, 204. plumosa, 232.

Ceramium, 24, 188.

Bryopsis plumosa, 204.

Ulva, 55, 188, 230, 232.

Enteromorpha, 230.

FINIS. 




SMITHSONIAN INSTITUTION LIBRARIES 